\title{
Hate Crime and the Legal Process \\ Options for Law Reform
}

\author{
Mark A. Walters, \\ Susann Wiedlitzka and \\ Abenaa Owusu-Bempah \\ with Kay Goodall
}

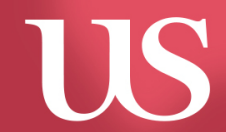




\section{Table of Contents}

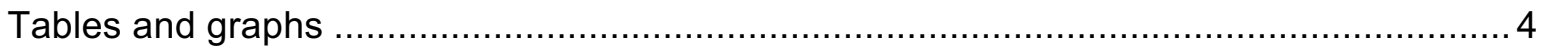

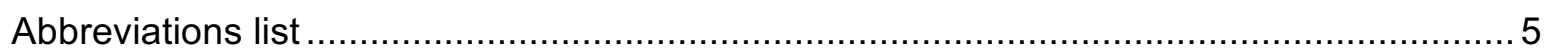

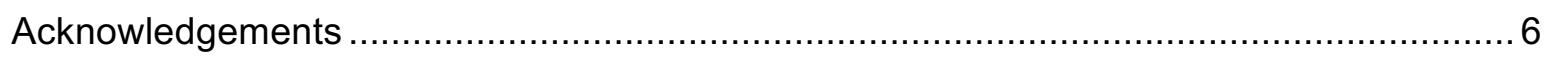

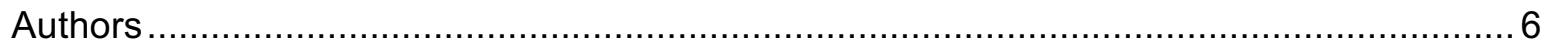

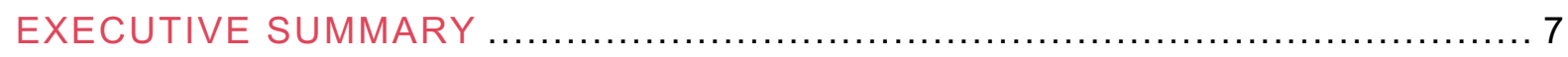

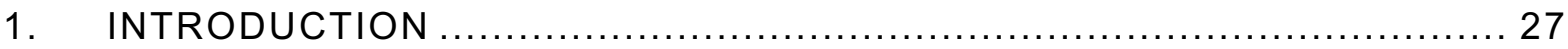

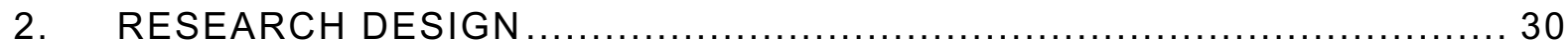

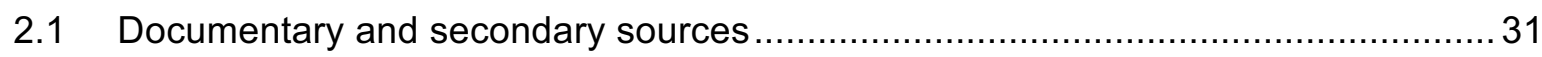

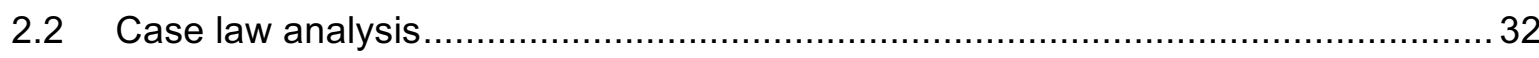

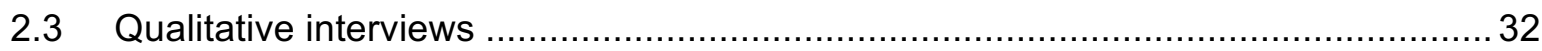

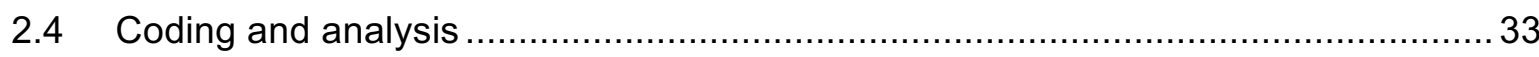

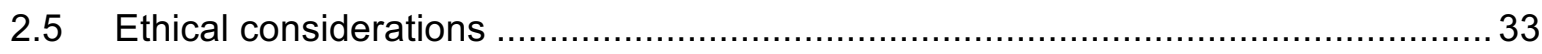

PART A: LAW, POLICY AND STATISTICS: UNDERSTANDING THE "LIFE

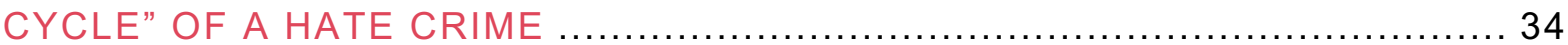

3. THE LEGISLATIVE FRAMEWORK FOR HATE CRIME IN ENGLAND AND

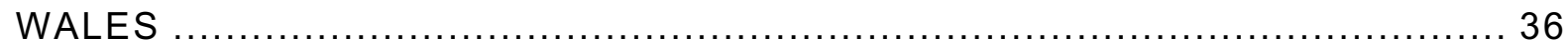

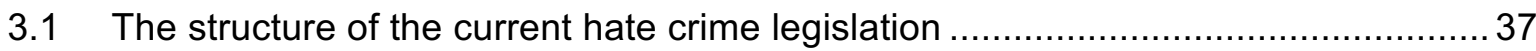

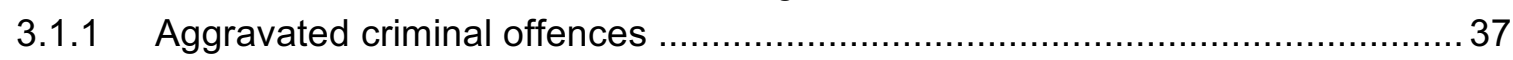

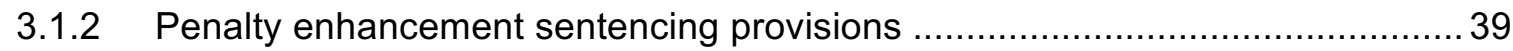

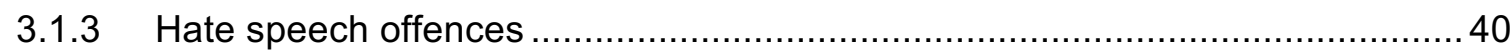

3.1.4 Differences in victim categories and protection under hate crime legislation .... 42

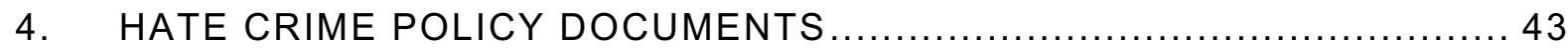

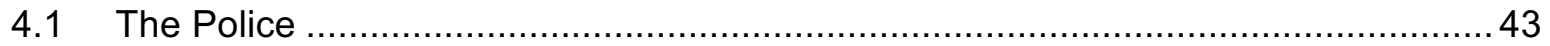

4.2 The Crown Prosecution Service guidance ............................................................. 44

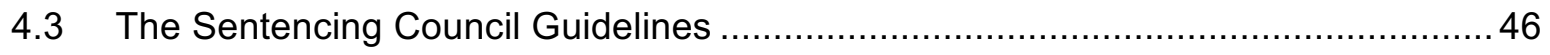

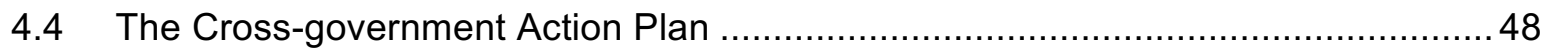

4.5 Code of Practice for Victims of Crime ............................................................. 49

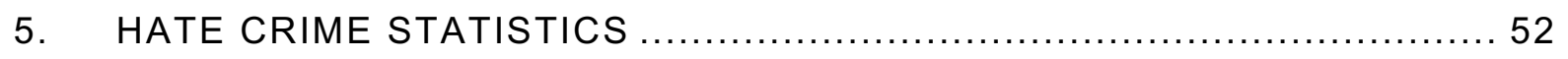

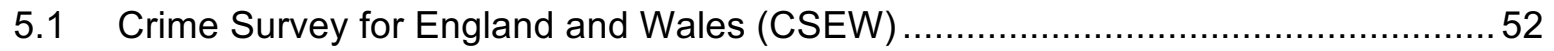

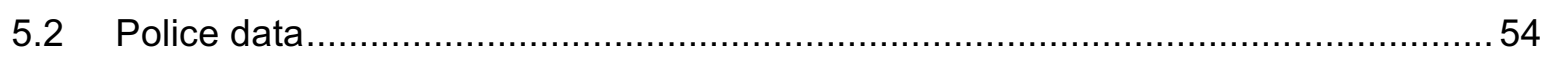

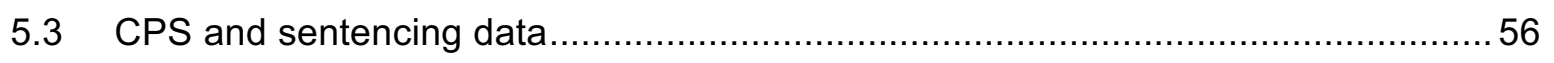

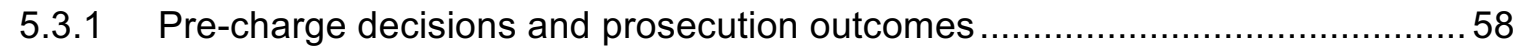

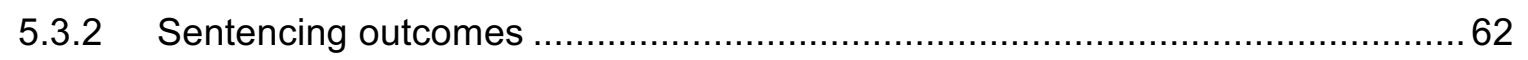

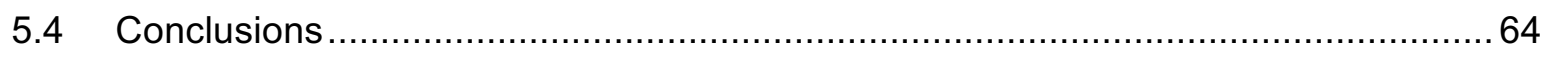


5.5 The lifecycle of a hate crime 65

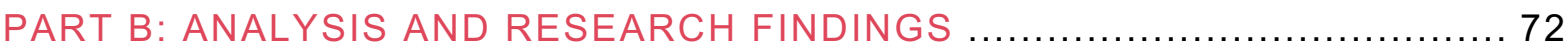

6. PRACTICAL ISSUES IN IMPLEMENTING HATE CRIME LEGISLATION .. 75

6.1 Preparing cases for prosecution: Collating evidence to prove hostility ........................ 75

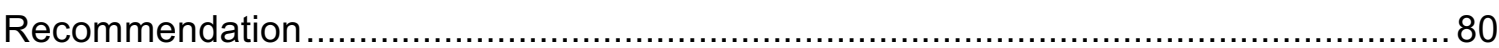

6.2 Gathering evidence: Failure to identify and investigate hostility early enough.............81

6.3 Gathering evidence: The importance of good relationships between police and the CPS

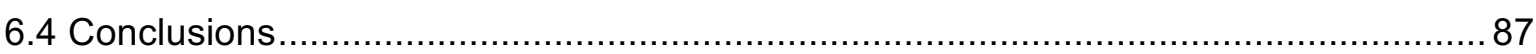

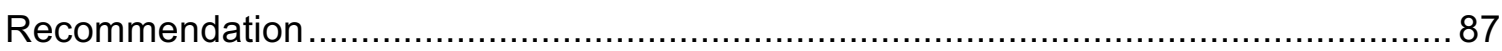

7. CHARGING DECISIONS AND THE TRIAL PROCESS $\ldots \ldots \ldots \ldots \ldots \ldots \ldots \ldots$

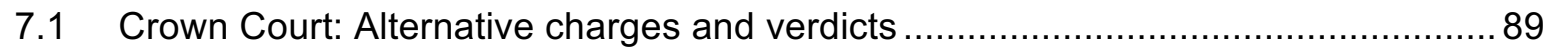

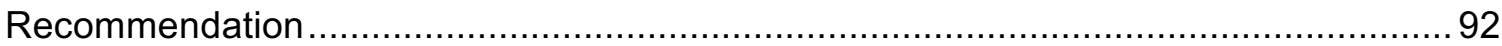

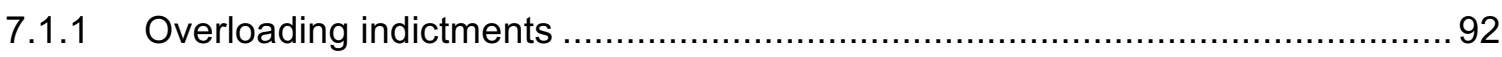

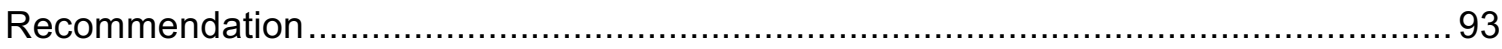

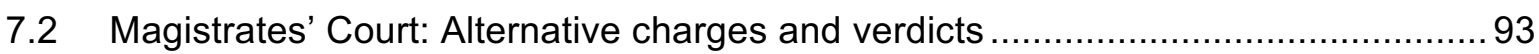

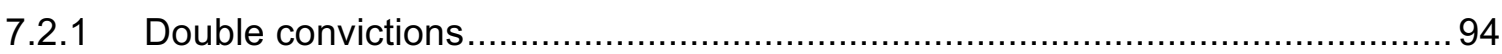

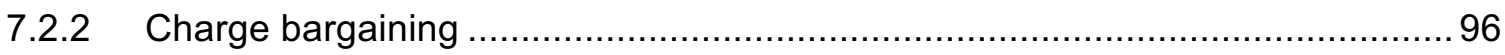

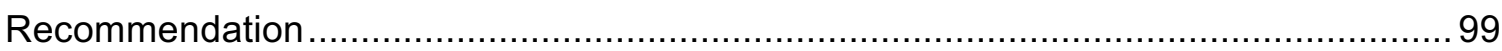

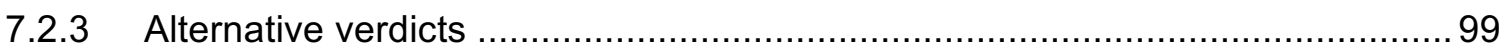

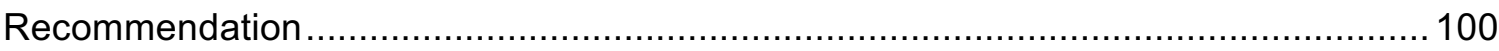

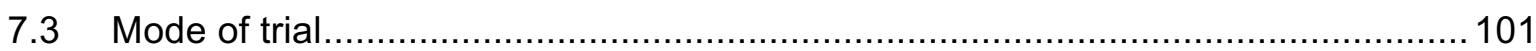

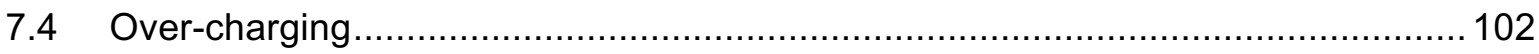

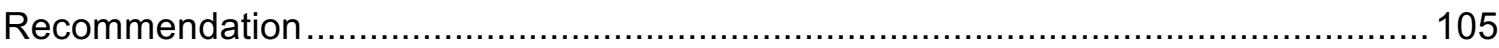

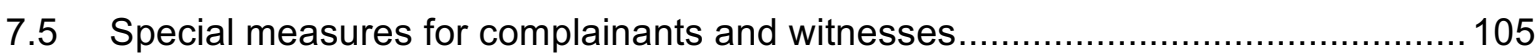

7.5.1 Special measures must be implemented appropriately ................................ 106

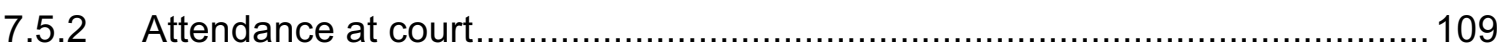

7.6 Alternative responses to prosecution: Restorative justice for hate crime? ............ 110

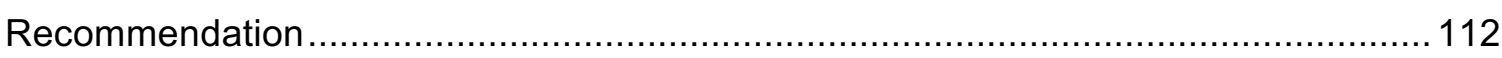

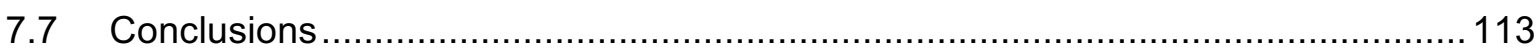

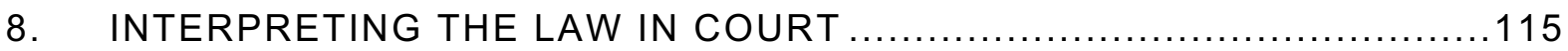

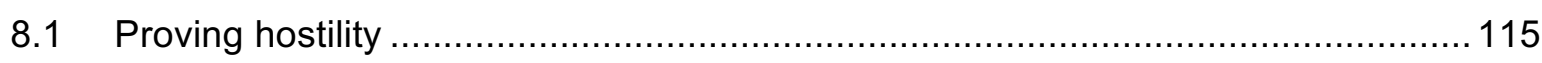

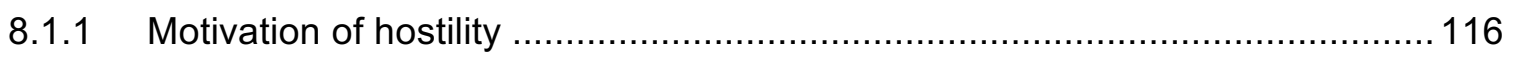

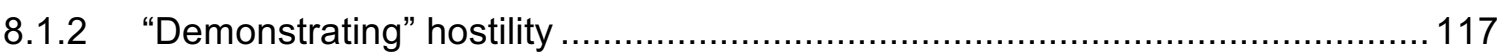

8.2 The reluctance of juries to accept demonstrations of hostility as a form of

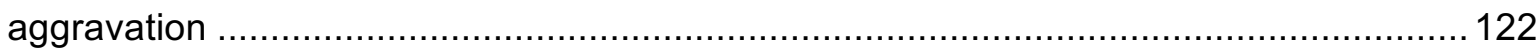

8.3 Judicial resistance to accepting demonstrations of hostility as hate crime ............ 124

8.4 Proving hostility as racism - "God's gift to defence" ..................................... 125

8.5 Is a demonstration of hostility really a "hate crime"? ........................................ 126

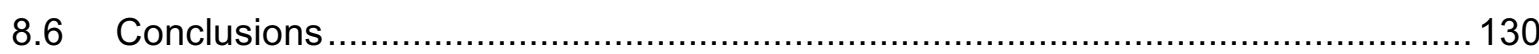

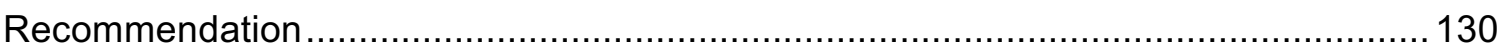

8.7 Minority versus majority hate crimes .......................................................... 131

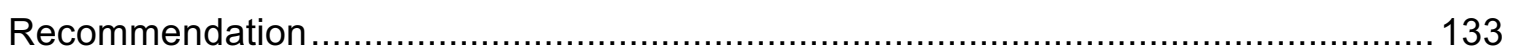


8.8 Reluctance to proceed against "same-race" hate crimes ................................ 134

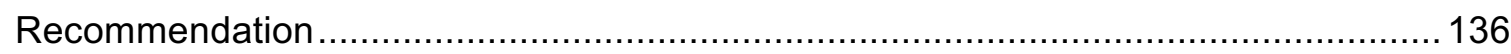

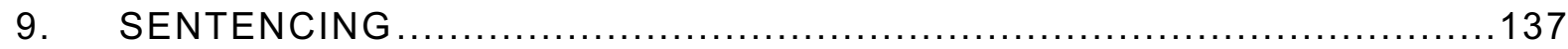

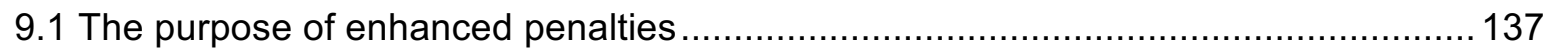

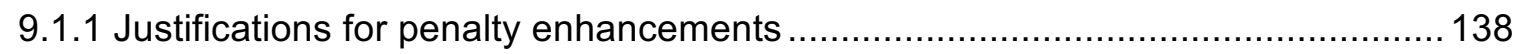

9.1.2 Looking beyond deterrent and retributive uplifts ............................................ 140

9.1.3 Focusing on community and rehabilitation sentences as going towards the uplift 141

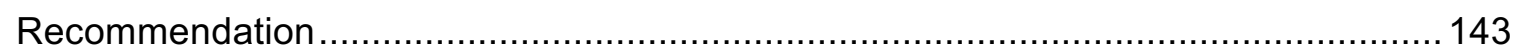

9.2 Are sentences "appropriate"? ......................................................................... 144

9.3 Enhanced penalties: Approaches to calculating sentence uplifts ........................... 145

9.4 Enhanced penalties: Double counting........................................................... 149

9.5 The importance of mens rea in sentencing: Differences between hate crimes

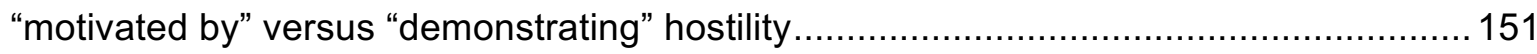

9.5.1 Why is motivation more serious than demonstrating hostility? .......................... 153

9.6 Understanding harm at sentencing: The importance of victim personal statements.. 156

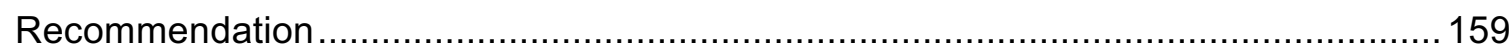

9.7 Applying ss. 145 \& 146 CJA 2003: Lack of awareness and reluctance to engage with

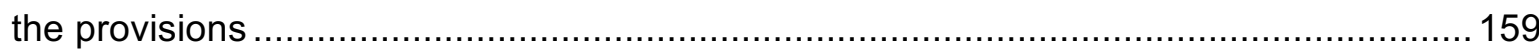

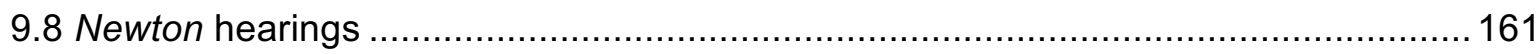

9.9 The relationship between the RRAOs and the CJA .......................................... 166

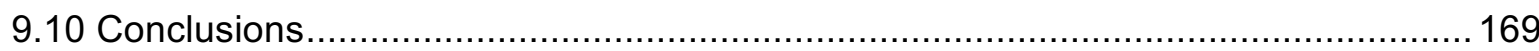

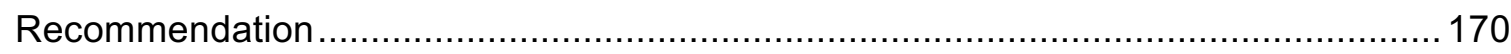

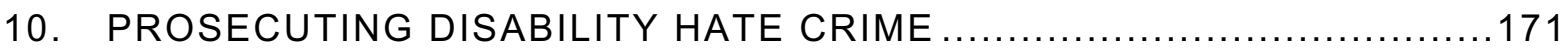

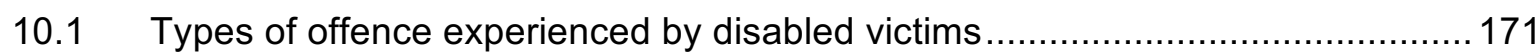

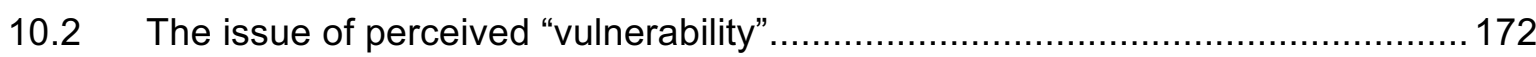

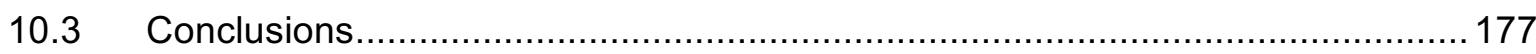

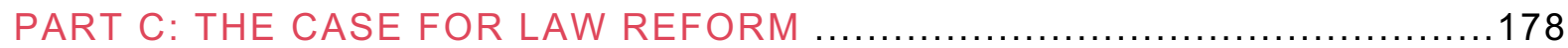

11. SHOULD THE CDA AND CJA BE REPEALED OR AMENDED? ............180

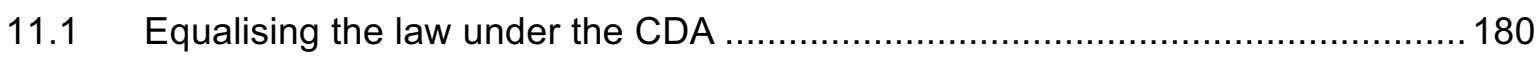

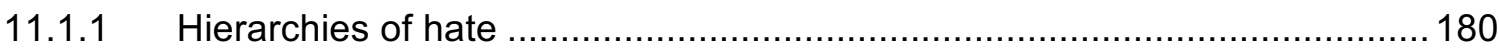

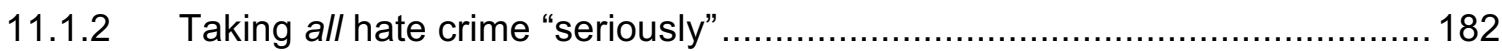

11.1.3 The importance of symbolic denunciation ................................................... 185

11.1.4 The benefits of consistent "flagging" ..................................................... 187

11.1.5 Defendants' rights will be better protected under the CDA .......................... 189

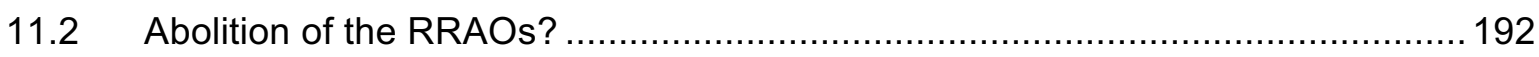

11.2.1 Clogging up the Crown Court with "low-level" hate crimes............................ 193

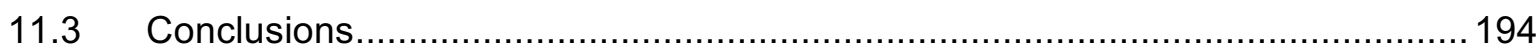

Reform Option 1: Extension of the CDA to include sexual orientation, disability and

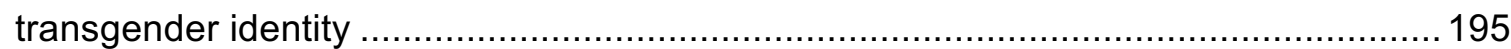

11.4 What categories of offence should be included under the CDA? ........................ 195

Reform Option 2: Extension of offence categories under the CDA.............................. 198

11.5 A new Hate Crime Act? ......................................................................... 198

Reform Option 3: Including all aggravated offences under one Act............................ 200 
11.6 Amendment of s. 28(1)(b): Introducing a "by reason" test 201

Reform Option 4: Amendment of section 28(1)(b) to replace motivation with a "by reason" test 206

11.7 Conclusions

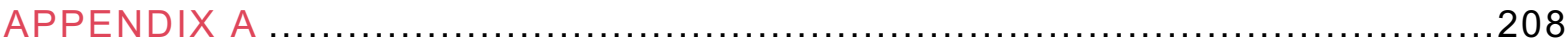

Discussion paper: What other characteristics should be included under hate crime laws?

ches

Choosing characteristics to be protected under the criminal law................................ 208

Including other characteristics under the Sentencing Guidelines .............................. 210

\section{TABLES AND GRAPHS}

Table 1 Basic offences compared with aggravated offences 38

Table 2 CSEW-estimated crime by monitored hate crime strand $(2012 / 13-2014 / 15) \ldots \ldots \ldots . .53$

Table 3 CSEW-estimated hate crime percentage by type of offence $(2012 / 13-2014 / 15) \ldots . .54$

Table 4 Police recorded offence type by monitored hate crime strand $(2015 / 16) \ldots \ldots \ldots \ldots \ldots . . . .55$

Table 5 CPS principal offence categories by monitored hate crime strand $(2015 / 2016) \ldots . .57$

Table 6 Pre-charge decision by monitored hate crime strand $(2015 / 2016)$.......................58

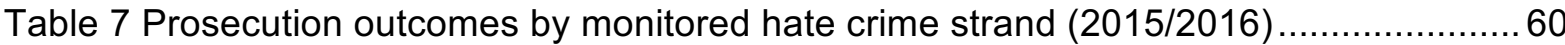

Table 8 Key reasons for unsuccessful prosecution by monitored hate crime strand (2015/2016)

Table 9 Percentage of sentence uplift announced and recorded in court by monitored strand $(2015 / 16)$

Table 10 Average custody sentence length by offence type, comparing RRAOs to nonRRAOs (2012)

Table 11 Numbers of police recorded hate crime by strand compared with numbers estimated by CSEW

Figure 1: Legal remedies for hate crime (England and Wales) 


\section{ABBREVIATIONS LIST}

BAME Black, Asian and minority ethnic

CDA Crime and Disorder Act 1998

CIS Community Impact Statement

CJA Criminal Justice Act 2003

CJS Criminal justice system

CPS Crown Prosecution Service

CSEW Crime Survey for England and Wales

ECRI European Commission against Racism and Intolerance

FRA European Union Agency for Fundamental Rights

GBH Grievous bodily harm

JCAR Joint Committee Against Racialism

ONS Office for National Statistics

OSCE Organisation for Security Corporation in Europe

NOMS National Offenders Management Service

PCC Police and Crime Commissioner

PNC Police National Computer

POA Public Order Act 1986

RAOs Racially aggravated offences

RRAOs Racially or religiously aggravated offences

VPS Victim Personal Statement 


\section{ACKNOWLEDGEMENTS}

There have been many organisations and individuals who have provided valuable support to this project. We would like to lend a special thank you to the Crown Prosecution Service, the Judicial Office, the Criminal Bar Association, a number of Circuit Leads, and Victim Support, all of whom made special efforts to reach out to their members in order to participate in this study. We note also our gratitude to the Office for National Statistics who responded quickly to our ad hoc requests for data analysis of the Crime Survey for England and Wales.

We would also like to thank Kay Goodall and Alex Adamou for their research assistance on this project; we would not have been able to complete this project on time without their efforts. We offer our gratitude to Dr Chara Bakalis who acted as critical reviewer on our final report and whose feedback was greatly appreciated. We also thank the CPS, and the Judicial Office, who reviewed and commented on this report before publication.

Finally, we give special thanks to all those individuals who took part in interviews.

All content and any errors remain the responsibility of the authors.

This project is financially supported by the Rights, Equality and Citizenship Programme of the European Union.

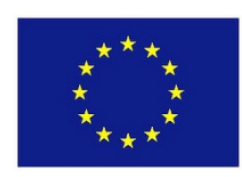

\section{AUTHORS}

Dr Mark A. Walters, University of Sussex (Principal Investigator)

Dr Susann Wiedlitzka, University of Sussex (Research Fellow)

Dr Abenaa Owusu-Bemaph, London School of Economics (Co-investigator)

with Dr Kay Goodall (Researcher)

\section{For further information please contact:}

Dr Mark A. Walters

University of Sussex

School of Law, Politics and Sociology

Freeman Building, BN1 9QE

Email: mark.walters@sussex.ac.uk 
HATE CRIME AND THE LEGAL PROCESS - FINAL REPORT

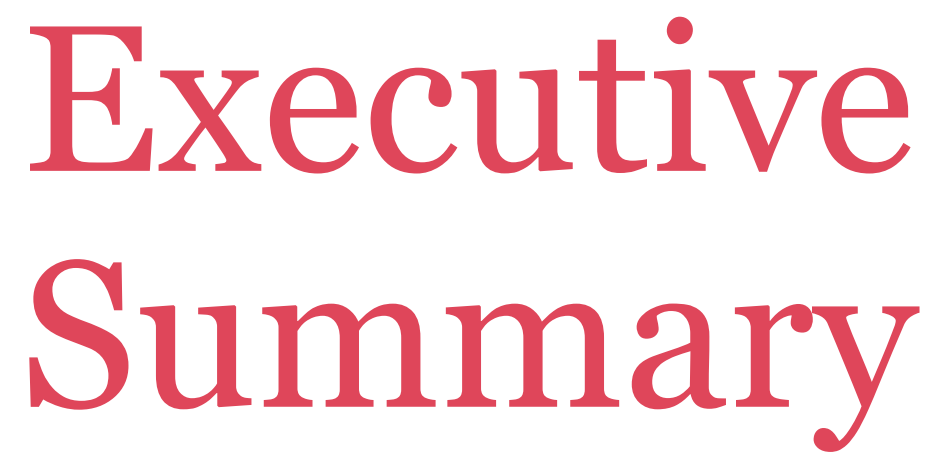




\section{BACKGROUND}

The aim of this study was to assess the application of criminal laws and sentencing provisions for hate crime in England and Wales (Crime and Disorder Act 1998 (CDA), ss. 2832, and the Criminal Justice Act 2003 (CJA), ss. 145 and 146) in order to capture best practices and identify barriers to the implementation of these rules. The study was carried out over a 24-month period and used a multitude of sources, both secondary and primary, to answer a number of key questions that were first set out by the Law Commission's 2014 report on hate crime law reform, as well as other questions set out as part of an EU crossjurisdictional project.

The report is funded by the EU Directorate-General Justice and Consumers department and forms part of a wider European study into the use of hate crime laws across five EU member states (England and Wales; Ireland; Sweden; Latvia; and the Czech Republic).

\section{METHODOLOGY}

A mixed-methods approach was employed for the project which enabled us to compare and contrast the stated aims and purposes of policies and legislation with the experiences of those tasked with enforcing and applying the law. This approach included: (a) an assessment of existing policies and publically available statistics; (b) a review of over 100 reported cases; and (c) 71 in-depth, qualitative semi-structured interviews with "hate crime coordinators" and "hate crime leads" at the Crown Prosecution Service (CPS), District (Magistrates' Court) and Circuit (Crown Court) Judges, independent barristers, victims and staff at charitable organisations that support victims of hate crime, police officers, and local authority minority group liaison staff.

\section{Part A: Law, policy and statistics: Understanding the "life cycle" of a hate crime}

\section{HATE CRIME STATISTICS}

Using publically available statistics on hate crime, we calculate an approximate number of offences that are likely to "drop out" of the criminal justice system. The total number of cases that drop out of the system represent what is known as the "justice gap" for hate crime. Analysis of the Crime Survey for England and Wales (CSEW) suggests that approximately 110,160 hate crimes are reported to police each year. The most recent police statistics recorded $\mathbf{6 2 , 5 1 8}$ hate crimes between $2015 / 16$. This suggests that only $57 \%$ of those incidents reported to the police are recorded as hate crimes. During the same year, the CPS prosecuted 15,442 hate-based offences, of which 12,846 resulted in a conviction. The CPS recorded the announcement of sentencing uplifts in court as $33.8 \%$ of total hate crime convictions, which equates to 4,342 cases. If these data are accurate, it means that out of an approximate 110,160 reported hate crimes, only 4,342 offences (4\%) resulted in a sentence uplift based on identity-based hostility. In other words, approximately $96 \%$ of reported hate 
crimes $(102,658$ cases $)$ may not result in a sentence uplift. We explore the possible reasons for this in the full report, but it is indicative of a significant "justice gap" for hate crime. ${ }^{1}$

\section{Part B: Analysis and research findings}

\section{PREPARING CASES FOR PROSECUTION: COLLATING EVIDENCE TO PROVE HOSTILITY}

- The most cogent form of evidence to prove the hostility element of a hate crime is witness testimony of verbalised prejudice, expressed during the commission of an offence.

- Additional ways in which hate crimes can be proved in court include the use of audio and video recording of the incident. However, interviewees emphasised that, without a sound recording of verbal slurs, proving a demonstration of hostility beyond reasonable doubt via video footage is extraordinarily difficult. This was most apparent in relation to disability hate crime cases.

- The defendant's prior record and bad character can be important factors in proving that a defendant was motivated by hostility. However, accessing this information is problematic, as the hostility element will not be noted on a perpetrator's record where a prior offence was aggravated by sexual orientation, disability or transgender identity hostility (under CJA provisions).

- Other forms of evidence that can be sufficient to prove the hostility element of a hate crime include leaflets, letters and other written documentation which indicate an affiliation with right-wing hate groups. Social media comments, subscription to websites with links to racist organisations, and text messages displaying hate-based content are also useful forms of evidence in hate crime cases.

\section{GATHERING EVIDENCE: FAILURE TO IDENTIFY AND INVESTIGATE HOSTILITY EARLY ENOUGH}

- There was evidence to suggest that the CPS has made recent improvements to the identification of disability hate crimes. However, there remains a significant proportion of incidents that are not flagged correctly by the police. Interviewees noted that even where there is evidence of a disablist slur having been expressed during the commission of an offence (the most common type of evidence for all types of hate crime), the disability hate crime flag is still frequently not applied.

- Conversely, in some cases, the "flags" that are added to case files can become a barrier to looking beyond the wider facts of the case. This may mean that other facts or types of prejudice are lost during the investigation.

\footnotetext{
${ }^{1}$ Note that this number does not represent the conviction rate for hate crime, due to different definitions used for hate crimes across data collectors. Note also that the justice gap is less if convictions that did not result in a declared uplift is included. See further information in the infographics in the full report.
} 
- There was a perception amongst some CPS interviewees that the police need to be more "proactive" in identifying the relevant pieces of evidence that will make for a compelling case, especially in complex cases that do not involve verbalised prejudice. However, even with more carefully crafted evidence files, prosecutors frequently fail to secure uplifts at sentence for disability hate crime, meaning that the effective enforcement of hate crime legislation for victims of disability hate crime remains in doubt.

- CPS prosecutors pointed to issues with some police officers not being aware of hate crime sentencing provisions, which led to investigators not collating the necessary evidence of hostility towards the complainant's sexual orientation, transgender identity or disability.

\section{GATHERING EVIDENCE: THE IMPORTANCE OF GOOD RELATIONSHIPS BETWEEN POLICE AND THE CPS}

- Gathering evidence and presenting it successfully in court depends on a good relationship between the police and the CPS. Breakdowns in this relationship can result in cases "dropping out" of the system.

- Communication problems can occur if charging advice is not sought by the police early on. In some cases, this makes it difficult to gather the necessary evidence for the hostility element later in the process. Although all interviewees were aware that the CPS needed to be contacted for charging advice, CPS prosecutors noted that this did not always happen.

- Open lines of communication are key to ensuring that charging advice is sought and that discussions regarding the quality of evidence are had early on in a case's "life cycle". Police officers indicated that more immediate contact with the CPS is necessary, especially because hate crime legislation can be confusing and the police may need advice before interviewing suspects.

- Communication between the CPS and the police is sometimes strained due to difference in preferred styles of communication - with the CPS frequently preferring e-communication (and reviewing of files), whereas police officers often preferred interpersonal discussions about a case.

- Independent barristers for the prosecution noted that advice is often not sought from them early in the process, and a breakdown of communication between barristers and police via the CPS can lead to evidence not being collated or presented in court.

\section{RECOMMENDATION}

We recommend that investigators use (a non-exhaustive) checklist during the investigation and charging stages of the criminal process (the items on the checklist can be found at 6.1 in the main report). 
We recommend that the CPS provide police (and independent barristers employed for the prosecution) with a direct and open line to CPS area hate crime leads. Independent barristers for the prosecution should also be included in the case review process where possible.

\section{CROWN COURT: ALTERNATIVE CHARGES AND VERDICTS}

- Where a defendant is tried in the Crown Court for a RRAO under the CDA, the judge may allow the jury to return an alternative verdict regarding the basic offence. This can prevent "over-" or "under-" conviction where the aggravated element cannot be proved. Alternatively, separate counts can be put on the indictment, one covering the aggravated offence and one covering the basic offence.

- Despite occasionally appearing unnecessary or detrimental to the prosecution case, the majority of interviewees indicated that it is good practice to put the basic offence to the jury as an alternative to the RRAO. Interviewees expressed a strong preference for alternative counts on the indictment rather than leaving an alternative verdict to the jury at the end of the trial, primarily for the sake of transparency and because it makes it easier for the jury to understand the issues in the case.

- The majority of interviewees took the view that indictments are rarely overloaded, alternatives do not present any significant problems, and juries can cope with multiple charges.

- Notwithstanding the above finding, RRAOs are complicated and can be difficult to present and sum up to juries.

\section{RECOMMENDATION}

For the sake of clarity and consistency, we recommend that the basic offence should ordinarily be left to the jury. The exception is cases where, without the hostility element, there is no basic offence (e.g. certain public order offences). We further recommend that the basic offence ordinarily be included on the indictment from the start of the trial, so that the jury, as well as the judge and parties to the case, have a clear statement of the issues which the jury must determine. This is consistent with CPS guidance on drafting indictments, but should be stated more clearly in prosecution guidance on racist and religious crime.

We recommend that jurors be provided with written directions or "route to verdict" documents, setting out the issues that must be proven or disproven in respect of each count on the indictment.

\section{MAGISTRATES' COURT: ALTERNATIVE CHARGES AND VERDICTS}

- In the Magistrates' Court, there is no power to return alternative verdicts in hate crime cases. To avoid losing liability for the basic offence if the racially or religiously aggravated element cannot be proven, the CPS recommends that both the basic offence and the RRAO should be charged in the alternative. 
- Interviewees indicated that the CPS guidance to charge both offences in the alternative is usually followed, but there may be some variations between local areas, and charging decisions sometimes depend on the nature of the offence.

- Not all District judges were familiar with the correct way to deal with alternative charges. Consequently, defendants are at risk of being convicted twice for a single offence.

- Interviewees who were familiar with the current law on "double convictions" felt that there is a need for further (accessible) clarification on the procedure for dealing with alternative charges in the Magistrates' Courts, and expressed dissatisfaction with the proper course of adjourning the basic offence before conviction for the aggravated offence.

- While attempts at "charge bargaining" are very common, the majority of interviewees stated that charge bargaining no longer occurs in hate crime cases. However, a minority of independent barristers suggested that charge bargaining does occur occasionally.

- There has been a clear shift in attitude towards charge bargaining since the RRAOs first came into force, with less "cultural resistance" to the legislation. However, the possibility and perception that charge bargaining still occurs remains a cause for concern.

- We found strong support among all interviewee cohorts for a power to return alternative verdicts in the Magistrates' Court. If magistrates had the power of finding alternative verdicts on RRAOs, only the RRAO would need to be charged and, if not convinced of the aggravated element, the defendant could instead be convicted of the basic offence.

- Interviewees identified the following benefits of making alternative verdicts available in the Magistrates' Court: fairer outcomes; consistency between courts; prosecutors would avoid the problem of trying to lay an alternative charge after the trial has commenced; magistrates would avoid confusion as to how to deal with the basic offence if the defendant is convicted of the aggravated offence; and there would not be a risk of double convictions.

\section{RECOMMENDATION}

To ensure adherence to the current CPS policy not to accept a plea to the basic offence alone to expedite court processes, we recommend that records be kept. For example, the CPS could keep a comprehensive record of charges proceeded with after the initial hearing, and of the reasons for downgrading charges from the RRAO to the basic offence in individual cases. These data could alleviate concerns about "charge bargaining", or they could indicate a need for better enforcement of CPS policy. 
Given the strong support for a change in the law, and the problems associated with alternative charges, we recommend that magistrates should be allowed to reach alternative verdicts to racially and religiously aggravated charges.

\section{MODE OF TRIAL}

- While the bulk of RRAOs are dealt with in the Magistrates' Court, the perception amongst interviewees was that most defendants opt for the Crown Court, where they are more likely to be acquitted.

- Circuit judges, in particular, expressed frustration at the number of cases reaching the Crown Court. Trials in the Crown Court for relatively minor offences were perceived to be largely a waste of time and money. This perception can result in pressure on the CPS and magistrates to keep cases out of the Crown Court.

\section{OVER-CHARGING}

- Many Crown Court judges and independent barristers expressed concern that a "procharge" policy has resulted in RRAOs being pursued in court where there is insufficient evidence to support the aggravated element of the offence.

- Some independent barristers noted that, where the evidence of hostility is weak, focusing on the aggravated element can lead juries to acquit altogether, even if there is evidence to support a serious underlying offence.

\section{RECOMMENDATION}

We recommend that charging decisions always be made in accordance with the Code for Crown Prosecutors, to ensure that the required threshold for prosecution is met on the aggravated element as well as the basic offence.

\section{SPECIAL MEASURES FOR COMPLAINANTS AND WITNESSES}

- Special measures are often used to assist complainants of hate crime during criminal proceedings. The most common measures employed to enhance a complainant's evidence or minimise emotional trauma in hate crime cases are screens and live-link.

- The application of special measures must be done with due care and attention. Failure to consider the needs of individual witnesses may result in the measures exacerbating, rather than improving, the difficulties that they face. Legal practitioners should also be alert to the risk that, if special measures and trial adjustments are applied arbitrarily, they might affect the defence's ability to effectively challenge the prosecution's case.

- Attention must be paid to the language used when examining hate crime complainants and witnesses, including use of correct pronouns in transgender hate crime cases. Practitioners should also be mindful of making irrelevant, incorrect and offensive assumptions about an individual based on their personal characteristics. 
- Interviewees indicated that one of the biggest challenges faced by prosecutors in hate crime cases is getting complainants to court. Lack of complainant support for the prosecution case was attributed to: the expense of taking time off work; the general inconvenience of going to court; not wanting to relive the incident; the delay between commission of the alleged offence and trial; not regarding the incident as seriously as they initially had; and fear of repercussions.

\section{ALTERNATIVE RESPONSES TO PROSECUTION: RESTORATIVE JUSTICE FOR HATE CRIME?}

- Because it is usually considered to be in the public interest to prosecute hate crime, out-of-court disposals are rarely available. Furthermore, the CPS's policy and guidance on the use of conditional cautioning (which can include restorative and reparative processes) restricts their use for hate crime.

- The growing number of restorative justice practices (that are used as alternatives to conventional justice mechanisms and in addition to retributive penalties) are scarcely applied in hate crime cases. A few pockets of practice are, however, being developed in some parts of the country.

- There is a small body of research that has evidenced the potential benefits of restorative justice for hate crime, in regard to both improving victim emotional wellbeing and preventing repeat victimisation.

\section{RECOMMENDATION}

We recommend that restorative justice be offered to victims and defendants in hate crime cases that involve "low-level" offences, and where the accused is willing to accept the allegations against them and the victim requests restorative justice.

We also recommend that the CPS review its policy in relation to conditional cautions only being used for hate crime in exceptional cases, as such an exception is not grounded in evidence or empirical research.

Finally, we recommend that restorative justice practices should also be used in addition to prosecution in more serious cases, both as an activity that can be used after conviction but before sentence, or as a measure to be implemented alongside other retributive sanctions.

\section{INTERPRETING THE LAW IN COURT}

- Cases involving motivated hostility, as opposed to demonstrated hostility, were extremely rare. One reason cited for the paucity of s. 28(1)(b) CDA cases was lack of adequate evidence collated by the police to prove motivation in court.

- Despite the legislation stating that it is immaterial whether or not the offender's hostility is also based, to any extent, on a factor other than the victim's group membership, the courts (and juries) have been reluctant to label offences as "racially 
or religiously aggravated" where the main motivation for a crime is non-hate based (such as anger or frustration).

- A "demonstration of hostility" has been interpreted by the House of Lords as an "outward manifestation of hostility". However, it remains unclear whether the trier of fact should assess whether the defendant understood their actions to be racially or religiously hostile. A difference of opinion emerged amongst practitioners as to whether a determination of hostility involves only an objective assessment of the actus reus of the conduct (i.e. the act of shouting a slur) or whether it also includes a subjective examination of the mens rea (i.e. what was in the mind of the accused at the time of making the statement).

- There was a perception amongst legal practitioners that, because of the broad definition of "demonstrating hostility" under s. 28(1)(a), many jurors are reluctant to convict defendants of RRAOs. This reluctance was attributed to jurors not wanting defendants to be labelled as a "hater" or "racist", simply because they lost their temper and said something abusive in the heat of the moment.

- Some legal practitioners and judges were also uncomfortable with demonstrations of hostility amounting to an aggravated offence where the defendant had not been motivated by hostility, but had merely used "unpleasant" language during an offence. One judge referred to these as "silly little so-called 'racially aggravated' cases".

- Defence barristers are attuned to juror and judicial reluctance to convict defendants who demonstrate hostility, which they use to their advantage. Trials can become consumed by the question of whether the defendant is a "racist", with counsel calling witnesses to testify that the defendant is not prejudiced. One independent barrister stated that the perceived need to prove that the defendant is a "racist" was "God's gift to defence".

- One way to challenge the general resistance to convict for aggravated offences is to provide careful explanations that set out why a demonstration of hostility should attract the label of "racially or religiously aggravated", and why aggravated offences are deserving of an enhanced penalty.

- The perception amongst some practitioners (and scholars) that demonstrations of hostility committed in the heat of the moment should not amount to an aggravated offence can be refuted by two arguments. The first is that any intentional (or reckless) demonstration of hostility amounts to a conscious attempt to subjugate a victim based on their identity, and that this should attract additional culpability. The second is that whether an offence is motivated or demonstrates hostility, the likely enhanced impact will be the same on the victim and community.

- There is some limited evidence to suggest that some courts are reluctant to convict minority against majority hate crimes, due to a perception that this does not fall within the purpose of the legislation. 
- Conversely, other statistics indicate that there are disproportionality high numbers of BAME people being proceeded against by the police and the CPS as hate crime offenders.

- Practitioners are often reluctant to pursue "same-race" hate crimes (i.e. hate crimes where the accused is perceived to be of the same or similar ethnicity as the complainant) because it is believed that jurors and magistrates are less likely to accept that hate crimes can be, or have been, committed intra-communally.

\section{RECOMMENDATION}

In determining whether hostility has been demonstrated by the defendant, whether applying the CDA or CJA, the court or jury may wish to ask:

"(1) Would the defendant have directed the same insult towards anyone, regardless of their identity characteristics? And,

(a) Is the defendant aware that such an insult demonstrates racial, religious, sexual orientation, disability or transgender based hostility?

Or

(b) Does he understand that his language or conduct is likely to be understood by rightminded people as indicating hostility towards the victim based on the victim's (perceived) identity characteristic?

If the answer is no to the first question and yes to either part of the second it is clear that the demonstration made is one of hostility."

\section{THE PURPOSE OF ENHANCED SENTENCING}

- Retributive (i.e. commensurate and deserved punishment) and deterrent (including examples of individual, general and educative deterrence) principles underpin most judges' justifications for enhancing sentences for hate crime offenders.

- The increased maximum sentences for aggravated offences under the CDA signifies that hate crime offenders should always be punished more severely than those who commit basic offences. However, simply adding more time onto an offender's term of imprisonment, or adding an additional sum of money onto a fine, is unlikely to fulfil the Government's aims of "preventing hate crime by dealing with the beliefs and attitudes that can lead to hate crime" and reducing the number of incidents that occur in our communities.

- Interviewees commented that adding a minor uplift is likely to do little other than to pay lip service to the provisions. Some interviewees doubted whether sending offenders to prison for slightly longer durations helped offenders to challenge their negative beliefs and attitudes.

- The purposes of sentencing, as set out under s. 142 of the CJA, means that the courts can, and should, use their sentencing powers to attach other types of 
sanctions (programmes) to hate crime offenders' sentences that focus on both rehabilitation and restorative measures.

- Depending on the seriousness of the offence, a hate crime intervention programme could be used as a mandatory part of a sentence, and as a specific means of imposing a sentence "uplift". However, as it stands, there are only a small number of locations throughout England and Wales that provide community-based and rehabilitation interventions for hate crime - and those that do exist focus heavily on racially motivated offending.

- The potency of the message that is sent to society by hate crime legislation need not be tied (solely) to punitive sanctions. The criminalisation and conviction of hate crime offenders can also be supported by community and rehabilitation programmes (as well as restorative justice practices) that aim to address the hostile attitudes that give rise to this type of offending. This is not to suggest that the enhanced penalties should be abolished, but rather it is to urge the courts to save the most severe of punitive penalties as a last resort.

\section{RECOMMENDATION}

When dealing with first and second time offenders, the court should consider community or custody-based rehabilitation interventions (where available) as a means of "uplifting" sentence. For example, where the basic version of the offence might ordinarily attract a sixmonth term of imprisonment, this could be uplifted by attaching a rehabilitation programme to this term of imprisonment (as against, for example, adding three months to the term as a percentage uplift for the aggravation). The courts would be better supported in this approach to sentencing where probation services bring specific programmes to the attention of the court.

\section{ENHANCED PENALTIES: APPROACHES TO CALCULATING SENTENCE UPLIFTS}

- There is no single approach taken by judges to "uplifting" sentences for hate crime. Three distinct, but sometimes overlapping, approaches to enhancing sentence were described by judges. These can be summarised as follows:

The intuitive approach - no exact percentage or calculation is applied. Judges gauge the level of sentence, intuitively, based on the facts as presented, as well as their sentencing experience.

The sentencing category climber - sentencers do not apply a percentage uplift but instead simply climb to the next sentencing range using the category levels as set out in Sentencing Guidelines.

The percentage uplift - the judge follows the guidelines for the general seriousness of the offence and then applies a percentage uplift to the final penalty. 


\section{ENHANCED PENALTIES: DOUBLE COUNTING}

- "Double counting" the hostility element of a hate crime at sentencing can happen for several reasons, including: racial or religious hostility influencing the starting point when sentencing a RRAO and then being used to uplift the sentence; judges being asked to apply s. 145 of the CJA to a RRAO which already has a sentence uplift; and judges uplifting a sentence based on aggravating factors set out in Sentencing Guidelines and then applying ss. 145 or 146.

- In an effort to avoid double counting where the hostility element appears in a Sentencing Guideline, ss. 145 and 146 may become side-lined or viewed as redundant. Consequently, the hate crime element of an offence might be applied to the sentence, but not announced in court in the way that is required by ss. 145 and 146. This could undermine the "labelling" function of the legislation.

- There is a need for more, or clearer, guidance on double counting in hate crime cases, particularly for offences that include the hostility element as part of the offence, or are subject to a Sentencing Guideline which includes the hostility element. Judges need to know the stage at which they should take account of the hostility element and how to present it to the court.

\section{DIFFERENCES IN SENTENCE BETWEEN HATE CRIMES "MOTIVATED" VERSUS “DEMONSTRATING” HOSTILITY}

- There was a sense amongst most judges that offenders motivated by hostility should receive a harsher penalty because their conduct carried a higher degree of culpability compared with those who merely demonstrate hostility.

- Three explanations emerged as to why judges felt that hate-motivations gave rise to greater levels of culpability:

11. Motivation was felt to reflect the fact that hatred or hostility was the central cause of the offence, as against a peripheral factor that occurs during the commission of the crime.

Motivation was felt by some judges to indicate premeditation in the offending, which is itself an aggravating factor in sentencing.

A hate-motivated offender was thought to pose an increased level of threat to the victim and to society.

- Three judges felt that there would not necessarily be a difference in their approach to sentencing crimes motivated versus demonstrating hostility, with one judge explaining that the harm to the victim would be the same either way. 


\section{UNDERSTANDING HARM AT SENTENCING: THE IMPORTANCE OF VICTIM} PERSONAL STATEMENTS

- One way in which the courts can become more attuned to the distinct harms of hate crime is through Victim Personal Statements (VPS). However, there were concerns amongst some (non-judicial) interviewees that the VPS scheme is not being used consistently and that some judges see them as "unnecessary".

- While VPS help to articulate the direct harms caused to the victim and their family, the courts can also benefit from understanding the "ripple effect" of hate crimes which affect wider communities. Greater use of Community Impact Statements (CIS) in hate crime cases could ensure that the impacts on entire minority groups are more fully considered by the courts.

\section{RECOMMENDATION:}

All police services should make it a priority to offer all complainants of hate crime the opportunity to participate in the VPS scheme. Officers should explain how information about the direct impacts of hate crime can be an important part of the sentencing process. The police should also consistently liaise with the CPS regarding the timing of such statements, and increased efforts should be put into making VPS and CIS available to courts during sentencing.

\section{LACK OF AWARENESS AND RELUCTANCE TO ENGAGE WITH THE PROVISIONS}

- Despite ss. 145 and 146 of the CJA having been in force since 2005, there remains widespread lack of awareness about the provisions amongst key professionals. This was especially the case amongst defence counsel and Crown Court judges. A key reason for this lack of awareness is that, historically, there has been both a failure to publicise and, in turn, use the provisions.

- CPS hate crime leads consistently stated that they had improved the way they prosecute offences in cases involving a ss. 145 or 146 uplift. This is borne out in the CPS statistics, which show that declared uplifts have increased from $11.8 \%$ in $2014 / 15$ to $33.8 \%$ in $2015 / 16$.

- Prosecutors noted that the Magistrates' Courts had also become more aware of the provisions, since they were regularly applied in these courts. This finding was reinforced by the District Judges that we interviewed, most of whom were well versed in the provisions, to the extent that some felt they had to remind prosecutors of their applicability.

- Even where the courts were aware of the CJA provisions, many Crown Court judges remained reluctant to apply them. 


\section{NEWTON HEARINGS}

- If the hostility element of an offence is not dealt with at trial, or (more likely) the defendant pleaded guilty to an offence and disputes the aggravating factor, a Newton hearing should usually be held to decide whether ss. 145 or 146 applies.

- We found widespread familiarity with the relevant rules and procedures for the conduct of Newton hearings. However, our findings suggest that Newton hearings are perceived to be largely unnecessary in hate crime cases and are rarely held.

- Various reasons were cited for the lack of Newton hearings, including: the hostility element of an offence usually being dealt with at trial; sparing victims from having to give evidence in court; and not wanting to deter guilty pleas. However, the primary reasons were that the aggravating factor would not make a substantial difference to the sentence in the Magistrates' Court, and that defendants wish to avoid Newton hearings. In the experience of many judges, defendants would rather accept the aggravated element of an offence than risk losing credit for a guilty plea following an unsuccessful Newton hearing.

- The perception that Newton hearings are unnecessary may be viewed as a problem in the light of our findings as to lack of awareness or application of ss. 145 and 146 of the CJA. It is also concerning that the fear of losing a sentence reduction prevents defendants from challenging allegations against them.

\section{THE RELATIONSHIP BETWEEN THE RRAOS AND THE CJA}

- In theory, the RRAOs and the penalty enhancing sentencing provisions are "mutually exclusive". Section 145 of the CJA "applies where a court is considering the seriousness of an offence other than one under sections 29 to 32 of the Crime and Disorder Act 1998" (emphasis added). However, the wording of s. 145 has created confusion as to whether the provision can be applied to an offence which could have been, but was not, charged as a RRAO (e.g. a common assault which was not charged as a racially aggravated common assault). This confusion has not been fully resolved by practitioner guidance or case law.

- While some interviewees believed that a sentence uplift can (and should) be applied where a RRAO could have been, but was not, charged, others thought that this was wrong both as a matter of law and principle.

- In practice, if an offence can be charged under the CDA, it usually will be. Nonetheless, the responses from interviewees indicate that the relationship between the RRAOs and s. 145 needs to be simplified, or at least clarified.

\section{RECOMMENDATION}

We recommend that the Sentencing Council provide a new Guideline for hate crime that includes the following information for the courts: 
1. The general approach that should be taken to determining the level of uplift, whether that be a percentage range or a policy of moving the offence to the next category range.

2. Clear and concise information on when and how to take account of the hostility element when it is covered by the CJA as well as a Sentencing Guideline or the offence charged. This should include a statement that sentencers must not enhance penalties twice, by uplifting using the CJA provisions and then Sentencing Guidelines, or vice versa.

3. The factors that should be taken into account when sentencing cases involving motivation and demonstrations of hostility.

4. The relationship between the CDA provisions and the CJA provisions, including when the latter should not be applied in court.

5. That due regard should be taken to the availability of community and rehabilitation programmes as forming part of any uplift given.

6. That VPS and CIS should be read out in court before sentence is determined.

\section{PROSECUTING DISABILITY HATE CRIME}

- The most common types of hate crime across the protected characteristics included assaults and public order offences. However, in terms of disability hate crime, there are two other categories of offences that are commonly perpetrated against victims: property offences and sexual offences. Together, these two categories of offences made up $38 \%$ of all disability hate crimes proceeded against in court.

- Because of the different nature of disability hate crime, and the different context in which offending occurs, police investigators may overlook or fail to gather evidence of identity-based hostility.

- Recent training of all CPS lawyers has helped to improve the prosecution of disability hate crime. As a result of this training, many prosecutors felt that they had reconsidered their understanding of when targeted abuse against disabled people will amount to a demonstration or motivation of hostility.

- Cases where the defendant had demonstrated hostility at the time of committing the offence, such as where the defendant has shouted a disablist slur, were considered the easiest to prove. However, most disability hate crime cases did not involve a verbal demonstration of hostility. In these cases, prosecutors often rely on factors such as additional taunting of the victims, gratuitous violence attached to the incident, or highlighting the fact that there is a lack of evidence suggesting any other reason for the commission of the offence. 
- Offences directed against disabled people are frequently connected with the perceived "vulnerability" of the victim. The complex relationship between perceived vulnerability and hostility continues to confuse practitioners and inhibits the successful prosecution of an offence as a disability hate crime.

- A minority of interviewees argued that the fact that someone had been targeted by reason of their disability should be evidence enough of a demonstration/motivation of hostility.

- Some prosecutors believed that the justice agencies should avoid conflating vulnerability and hostility as this can set up a false expectation amongst victims and communities that reporting a crime as motivated by disability will result in the offence being sentenced as a "hate crime".

- Almost all interviewees who discussed disability hate crime stated that, even where prosecutors present carefully curated evidence of disability hostility, there remains considerable "pushback" from the courts. Judges have generally stayed firm in their belief that selecting a victim because they are considered vulnerable (or an easy target) is insufficient to prove "hostility" for the purposes of hate crime legislation. The result is that most disability hate crimes do not attract the sentencing uplift which is prescribed under s. 146 of the CJA. This is supported by CPS statistics that show just $11 \%$ of convictions for disability hate crime resulted in a declared "uplift".

- Failure to recognise hostility in cases where the victim has been specifically targeted because of their disability does not mean that convicted defendants do not receive any uplift in sentence. In such cases, judges will almost always refer to the victim's "vulnerability" as an aggravating factor, as per Sentencing Guidelines.

- Judges commonly stating that disabled victims are "vulnerable" can serve to perpetuate a false representation of disabled people as innately weak, and as somehow incapable of caring for themselves. Many CPS lawyers were aware of the marginalising effects of labelling victims as innately vulnerable when prosecuting hate crime.

\section{PART C: THE CASE FOR LAW REFORM}

- There was little appetite amongst interviewees for the wholesale repeal of hate crime laws, either the CDA or the CJA provisions. The majority of interviewees believed that hate crime laws were now a necessary part of the State's toolkit in responding to hate-based offending.

- Just over half of the interviewees who spoke about law reform stated that all five characteristics should be protected equally under the CDA. There were five main reasons in support of extension:

1. The current framework of legislation creates a "hierarchy of hate". Failure to ensure that hate crime laws apply equally to all protected characteristics may 
send the message that some types of hate are more serious than others, or that certain groups of people are more deserving of protection under the law than others.

2. Inclusion of all five characteristics under the CDA would help to ensure that all strands of hate crime are taken seriously by the authorities. Interviewees believed that evidence of hostility is more likely to be collated and become a central part of a case file where it makes up part of the substantive offence.

3. The CDA provides for symbolic denunciation of specific types of identity-based hostility. This may help to challenge pervasive prejudices and reduce the social acceptability of public displays of hostility. The CDA also plays an important role in making sure that targeted communities feel protected.

4. Inclusion would assist the consistent "flagging" of hate crimes (both pre- and post-conviction) as criminal justice authorities are more likely to record the hateelement of a crime where it makes up a substantive part of the offence. Accurate flagging can have three important functions. First, it helps to identify repeat offenders when dealing with future incidents of hate. Second, criminal justice agencies that are tasked with addressing offending behaviour post-sentence are also likely to be assisted where offences are labelled to reflect the hate-element of an offence. Third, accurate labelling of hostility-based offences also ensures that victims and targeted communities see that justice has been done and that the crimes committed against them have been treated as "hate crimes".

5. Defendants' rights will be better protected under the CDA. We identified three key reasons that interviewees offered for this proposition:

- First, the CDA provides a safeguard for defendants by ensuring transparency as to the issues in the case, and by enabling jury trials (unless the charge is an aggravated s. 5 public order offence). A number of interviewees suggested that juries are more open to defence evidence and scrutinise the hostility element more thoroughly than judges or magistrates.

- Second, the CDA may provide a tactical advantage, as juries are perceived to be reluctant to convict defendants of RRAOs and defence barristers can use this to secure acquittals.

- Third, it is the role of a jury, and not a judge, to decide questions of fact. Moreover, the nature of hate crime cases are so connected to societal norms and values, that they should be determined by lay people who are representative of the community.

- Just under half of interviewees who spoke about law reform stated that the CDA should not be extended. Two main reasons were given for this:

1. The aggravated offences are overly complex and could lead to defendants being acquitted of both the basic and aggravated version of the offence. 
2. "Low-level" hate crimes are "clogging up" the Crown Court, and adding further characteristics would result in further costs and delays in the criminal justice system.

\section{LAW REFORM OPTION 1:}

On balance, we believe that the arguments in favour of extending the CDA outweigh those put forward by the judges and barristers that preferred the use of sentencing provisions/guidelines only. We recommend, as a minimum, that Parliament amend s. 28 of the CDA to include sexual orientation, disability and transgender identity.

\section{WHAT CATEGORIES OF OFFENCE SHOULD BE INCLUDED UNDER THE CRIME AND DISORDER ACT?}

- The current offence categories included under the CDA do not map precisely onto the most common types of offence committed across the five hate crime strands. If all five characteristics are to be included under the CDA further assessments should be made on which new offence categories should also be added. The basis for this analysis should start with the statistics collated by the police and the CPS, as well as data from the CSEW.

\section{LAW REFORM OPTION 2:}

Based on the statistics and analysis of interviewee data, the following offences should be considered for inclusion under the CDA:

- Affray

- Violent disorder

- All sexual offences

- Theft and handling stolen goods

- Robbery

- Burglary

- Fraud and forgery

- S. 18 Grievous bodily harm

- Homicide offences 


\section{A NEW HATE CRIME ACT?}

- The current framework of hate crime legislation is complex and fragmented. The extension of categories under the CDA would inevitably result in some categories of offence falling outside the scope of the Act.

\section{LAW REFORM OPTION 3:}

We recommend, as a preference, the enactment of a new Hate Crime Act, based on the relevant provisions currently contained in the Crime and Disorder Act 1998, but extending to all categories of crime. (The Hate Crime Act could also be used to consolidate other relevant offences, namely the stirring up offences in the Public Order Act 1986). A single Act could contain all the relevant provisions for hate crime under one code that aggravated any offence where there is sufficient evidence of hostility. Sentencing maxima for the aggravated offences should be the same as for the basic offence, with the legislation mirroring ss. 145 and 146 CJA in so far as the courts "must" take into consideration hostility (or the by reason selection, explained below) and state in open court how the sentence has been affected by the aggravation.

\section{AMENDMENT OF S. 28(1)(B) TO REMOVE MOTIVATION AND REPLACE WITH A "BY REASON" TEST}

- Despite a myriad of criminal justice inquiries, CPS guidance, research reports, and the lobbying efforts by disability groups, it is clear that judges and many enforcement agencies refuse to comprehend discriminatory selection of disabled victims as evidence of hostility. It is likely that this is due to the word "hostility" itself. Parliament should question whether 12 lay jurors should be expected to grasp the complexities of the relationship between concepts such as "hostility" and "perceived vulnerability", when legal practitioners remain divided on the issue.

- Without any specific legislative guidance, the literal (dictionary) meaning of hostility will not fit well with cases that involve some form of pre-existing relationship with the victim; cases that are likely to involve some form of grooming; faux friendships; a carer's role; or those just opportunistically "taking advantage" of someone. 


\section{LAW REFORM OPTION 4:}

We propose that the successful prosecution of all types of hate crime will be enhanced were the legislation to be amended at s. 28(1)(b) (or equivalent in a new Hate Crime Act) so that the provision reads as follows:

(1) An offence is racially or religiously aggravated [or aggravated in relation to disability, sexual orientation or transgender identity] for the purposes of sections 29 to 32 if

(a) at the time of committing the offence, or immediately before or after doing so, the offender demonstrates towards the victim of the offence hostility based on the victim's membership (or presumed membership) of a racial or religious group, or based on the victim's sexual orientation (or presumed sexual orientation), disability (or presumed disability), or transgender identity (or presumed transgender identity); or

(b) the offence is committed by reason of the victim's membership (or presumed membership) of a racial or religious group, or by reason of the victim's sexual orientation (or presumed sexual orientation), disability (or presumed disability), or transgender identity (or presumed transgender identity). 


\section{Introduction}

It is 20 years since the introduction of racially aggravated offences under the Crime and Disorder Act 1998 (henceforth, CDA) in England and Wales. Since then, the legislation has been amended to include religiously aggravated offences. ${ }^{2}$ Sentencing provisions that prescribe sexual orientation, disability and transgender hostilities have also been introduced, and are set out in the Criminal Justice Act 2003 (henceforth, CJA). ${ }^{3}$ The piecemeal way in which hate crime laws have been enacted means that there are now different levels of legislative protection for the current five recognised groups commonly targeted for hate crime. In response to this, in 2012, the Ministry of Justice requested that the Law Commission examine whether the Government should extend the aggravated offences in the CDA to apply equally to all five protected characteristics. ${ }^{4}$ In its final 2014 report, the Commission recommended that a wider review of the law be carried out in order to determine how the law should be amended, abolished or extended. ${ }^{5}$ As part of the Commissions' recommendation for a full-scale review, the report outlined the following questions (summarised here) that should be addressed:

1. What are the purposes of legislation specifically addressing hate-based offending?

2. To what extent do the current systems of aggravated offences and enhanced sentencing serve those purposes?

3. For victims, what is the best way to respond to hate crime?

4. If aggravated offences are needed, what model should be used to criminalise hate or hostility?

5. If enhanced sentencing is needed, what model should be used?

6. What protected characteristics should be included within legislation?

7. What other initiatives or measures could be used alongside or in place of legislation?

This study is partly a response to the Law Commission's call for a wider review into hate crime laws in England and Wales. The report is funded by the EU Directorate-General

\footnotetext{
${ }^{2}$ Amended by the Anti-terrorism, Crime and Security Act 2001, s. 39.

${ }^{3}$ Section 146 of the CJA. Note that offences that fall outside the CDA can also be racially and religiously aggravated under s. 145 of the CJA.

${ }^{4}$ And extend the stirring up of hatred offences under the Public Order Act 1986 to apply equally to all five protected characteristics. Note also that an independent review of hate crime legislation is currently being undertaken in Scotland, chaired by Lord Bracadale, <https://consult.scotland.gov.uk/hate-crime/independent-review-of-hate-crime-legislation/>

${ }^{5}$ In relation to the CDA, the Commission recommended that failing a full scale review the Crime and Disorder Act 1998 be amended to include the three characteristics currently protected under s. 146 of the CJA only. They also recommended that there should be new guidance from the Sentencing Council on the sentencing approach in hate crime cases and that every time enhanced sentencing is applied, this should be recorded on the offender's criminal record in the Police National Computer (PNC). In relation to the stirring up offences, the Commission recommended that these offences should not be extended to include disability or transgender hatred. The Government is yet to fully respond to the Commission's recommendation, despite the general rule they provide an interim response "as soon as possible and in any event within six months" and a final response "as soon as possible after delivery of the interim response and in any event within one year of publication of the response".
} 
Justice and Consumers department and forms part of a wider European study into the use of hate crime laws across five EU member states (England and Wales; Ireland; Sweden; Latvia; and the Czech Republic). The study was carried out over a 24-month period and uses a multitude of sources, both secondary and primary, to answer a number of key questions set out by the Commission's report, as well as other questions set out as part of the crossjurisdictional project (see research design below).

The study starts from the position that hate crime legislation is a crucial mechanism through which hostility-based offences should be addressed. The use of hate crime legislation is not only entrenched within the UK's legal system, but it is also a legal requirement under international law. ${ }^{6}$ The internationalisation of hate crime laws is further supported by bodies such as the European Commission against Racism and Intolerance (ECRI), the European Union Agency for Fundamental Rights (FRA) and the Organisation for Security Corporation in Europe (OSCE) as a norm that all liberal democratic countries should employ to tackle hate crime. ${ }^{7}$ The use of hate crime laws has also been subjected to extensive academic scrutiny since their inception in the US in the early 1980 s. $^{8}$ The Law Commission published a detailed theoretical paper as part of the 2013-14 review of hate crime law which provides a clear and concise outline of the justifications underlying hate crime laws. ${ }^{9}$ We do not attempt to repeat this work here by undertaking an in-depth scholarly examination of the purposes of hate crime laws. ${ }^{10}$ We do, nevertheless, explore judges', legal practitioners' and victim groups' perceptions of hate crime laws, including whether sentencing uplifts are perceived to be "appropriate" for hate crime, and also the reasons why judges enhance penalties of hate crime offenders.

We start this report by detailing the research design for the study, including the various primary and secondary sources that make up the basis for our findings. The report is then divided into three main parts. Part A starts by outlining the legislative framework for hate crime, before summarising the key policy and guidance documents that inform current practice for the prosecution and sentencing of hate crime. This part also analyses publicly available statistics for hate crime in England and Wales and we use these figures to highlight what we call "the life cycle" of a hate crime (illustrated in the infographics below), which indicates the "drop out" rate of offences from the criminal justice system.

Part B then provides a detailed analysis of the interview data as they relate to issues of evidence and procedure, the legal interpretation of hate crime laws, and sentencing of offenders. This part of the report focuses on the following themes:

\footnotetext{
${ }^{6}$ Article 4 of the European Union Framework Decision on Racist and Xenophobic Crime, Council Framework Decision 2008/913/JHA of 28 November 2008.

${ }_{7}^{7}$ See further, Jennifer Schweppe and Mark A Walters (eds) The Globalization of Hate: Internationalizing Hate Crime? (OUP 2016).

${ }^{8}$ See e.g. Frederick M Lawrence, Punishing Hate: Bias Crimes Under American Law (Harvard University Press 2006); James M Jacobs and Kimberly Potter Hate Crimes: Criminal Law and Identity Politics (Oxford University Press 2006); and more recently the 'When Law and Hate Collide: Perspectives On Hate Crime' project, which examined the philosophies underpinning hate crime laws. Publications can be found at: <http://www.uclan.ac.uk/research/explore/projects/when_law_and_hate_collide.php> ${ }^{9}$ John Stanton-Ife, 'Criminalising Conduct with Special Reference to Potential Offences of Stirring Üp Hatre $\bar{d}$ Against Disabled or Transgender Persons' (Law Commission 2013).

${ }^{10}$ See 'When Law and Hate Collide: Perspectives On Hate Crime' project:

$<$ http://www.uclan.ac.uk/research/explore/projects/when_law_and_hate_collide.php>
} 
- The process of evidence collation for hate crime cases;

- The relationship between the police and the Crown Prosecution Service (CPS);

- Prosecution practices, including the use of alternative charges and charge bargaining;

- Procedural matters, including: modes of trial; overloading of indictments; special measures for complainants and witnesses; and the use of victim personal statements;

- The potential use of alternative initiatives (such as restorative justice) that can be used to address the causes and consequences of hate crime.

- Interpretation and application of the law by the courts (including the difficulties in interpreting the meaning of "hostility");

- Sentencing practices and approaches to uplifts in penalties (including the different approaches used to calculate "uplifts").

Part B also includes a separate section on disability hate crime. The reason we deal with this type of hate crime separately is that significant issues with prosecuting and sentencing disability hate crime were pervasive throughout the research study. We discuss the complexities of collating evidence and prosecuting this type of hate crime, and examine the issues that prosecutors face in court when presenting evidence of targeted abuse, which is often perceived by practitioners and the judiciary as relating to "vulnerability".

In the final part of this report (Part C), we review the current legislative framework for hate crime and offer bold options for law reform that are based on both the empirical data obtained as part of this study, as well as drawing on important theoretical approaches to understanding criminal law. These reform options include:

1. Incorporating all five protected characteristics under the CDA;

2. Extending the categories of offence included under the CDA;

3. The creation of a new Hate Crime Act that would cover all aggravated offences in the criminal law;

4. Amending both the CDA and the CJA to abolish the test on motivation and to replace this with a new "by reason" test.

Note that this study does not cover stirring up of hatred offences or cyber offences. This is partly due to the original scope of the wider study being conducted across Europe, which did not allow for hate speech offences to be included. More importantly, the issues pertaining to hate speech and cyber hate are so unique and complex that a separate large study would be required to explore these in full.

We aim for this report to offer important insights into the workability of hate crime laws in England and Wales, including both their benefits and limitations, and how law enforcement agencies may be able to improve further their practices in this area. We hope too that the judiciary find this report helpful, and that recommendations, if taken up, will aid in their consistent application of legislation. Finally, this report offers evidence-based options for law reform which the Government should carefully consider when assessing how to improve the current legal responses to hate crime. 


\section{Research design}

The aim of this study was to assess the application of criminal laws and sentencing provisions for hate crime in England and Wales (CDA 1998, ss. 28-32, and the CJA 2003, ss. 145 and 146) in order to capture best practices in the tools used to combat hate crime, as it relates to strategies of legal intervention and the implementation of these rules.

The objectives of the research project were as follows:

1. To detail the operational realities of hate crime legislation by gathering experiential accounts of the legislation "in action" from legal professionals;

2. To document differences in both practitioners' and users' experiences of the criminal justice system according to the legislative and policy context;

3. To identify best practice models of hate crime legislation and supporting policy;

4. To disseminate information across the UK to benchmark, learn, and develop strategies to help combat hate crime;

5. To inform future policy and legislative responses to hate crime by offering options for law reform.

In the light of these objectives, we planned to explore the manner in which legislation operates in practice from the perspective of those who directly engage in the criminal justice system (including police personnel, prosecutors, defence lawyers, judges and magistrates, victims, victim support workers and offenders). ${ }^{11}$

A mixed-methods approach was employed for the project which enabled us to compare and contrast the stated aims and purposes of policies and legislation with the experiences of those tasked with enforcing and applying the law. This approach included:

a. An assessment of existing policies and publicly available statistics;

b. A review of over 100 case law reports, and

c. 71 in-depth, qualitative semi-structured interviews with "hate crime coordinators" and "hate crime leads" at the Crown Prosecution Service (CPS), District (Magistrates' Court) and Circuit (Crown Court) Judges, independent barristers, victims and staff at

\footnotetext{
${ }^{11}$ All but one of these cohorts of interviewees were accessed as part of this study. During the study it became clear that accessing offenders who had been convicted of a hate crime would not be possible. This was due to a long delay in the assessment of the project's research application to the National Offenders Management Service (NOMS). We were also unable to contact lay magistrates due to the Magistrates Association requesting financial payments to both contact and interview magistrates that were far beyond the means of the project's budget.
} 
charitable organisations that support victims of hate crime, police officers, and local authority minority group liaison staff. ${ }^{12}$

\subsection{DOCUMENTARY AND SECONDARY SOURCES}

We first sourced official documents, including legislation, policy and procedures relevant to the enforcement of hate crime legislation to establish the ways in which hate crime is conceptualised and operationalised by authorities in England and Wales. Additionally, public statistics relating to the number of police recorded hate crimes, related prosecutions and successful convictions were sourced, collated and compared. These data are readily available on public websites, such as the Home Office and Crown Prosecution Service websites. We then obtained the most recent estimates of hate crime occurrences, as calculated by the Crime Survey for England and Wales (CSEW), via an "ad hoc" data request to the Office for National Statistics. The estimates were provided via email and also published on the ONS website. ${ }^{13}$ The CSEW monitors the extent and nature of crime by asking members of the public about their experiences of crime in the previous year. ${ }^{14}$ The survey is an important tool to uncover the true level of crime in England and Wales, as it also captures crimes that are not reported to and not recorded by the police. ${ }^{15}$

We used the sources above to illustrate the "drop out" rate ${ }^{16}$ of hate crime cases throughout the criminal justice system, starting with estimates of hate crimes per year, through to police recorded hate crime cases, the number of prosecuted cases and successful convictions, as well as the number of cases where hate crime legislation was successfully used and sentence uplifts applied (see section 5.5 on the lifecycle of a hate crime). It is important to note that the rates at which cases drop out of the system, as displayed in our infographics, are used for illustrative purposes only and do not necessarily represent a "conviction rate" for hate crime. This is because the CSEW, the police and the courts use slightly different definitions of "hate crime". For instance, what the CSEW might record as a hate crime ${ }^{17}$ will not necessarily reach the evidential threshold required for a prosecution or conviction of an

\footnotetext{
${ }^{12} \mathrm{NB}$, when referring to interviewees in the singular we use the pronouns "they" and "their". This is to protect anonymity and to ensure gender neutrality. Other pronouns are used throughout this report where these have already been identified by interviewees or within legal judgments.

${ }^{13}$ Office for National Statistics, 'Number of incidents of hate crime, by strand of hate crime and percentage of those incidents reported to the police, Crime Survey for England and Wales, years ending March 2014 to March 2016, combined (12-month averages)'

<https://www.ons.gov.uk/peoplepopulationandcommunity/crimeandjustice/adhocs/007533numberofincidentsofhatecrimebystran dofhatecrimeandpercentageofthoseincidentsreportedtothepolicecrimesurveyforenglandandwalesyearsendingmarch2014tomarch 2016combined12monthaverages>

${ }^{14}$ Kantar Public and Office for National Statistics, 'Crime Survey for England \& Wales'

$<$ http://www.crimesurvey.co.uk/index.html>

${ }^{15}$ Kantar Public and Office for National Statistics, 'About the Crime Survey for England and Wales' (n.d.)

$<$ http://www.crimesurvey.co.uk/AboutTheSurvey.html>

${ }^{16}$ Known also as the "justice gap". This refers to the "difference between the number of offences recorded and the number of offences for which an offender receives either a caution, a conviction or has the offence taken into consideration by the court." Crown Prosecution Service, 'Narrowing the Justice Gap' (n.d.)

$<$ https://www.cps.gov.uk/publications/prosecution/justicegap.html>

${ }^{17}$ I.e. whether the respondent believed the incident was motivated by their identity characteristic. This may over-represent numbers, such as where someone is targeted because of their identity but not because of hostility or prejudice towards that identity. However, the survey may also under-estimate numbers of hate crime, such as where it fails to question hard-to reach groups (LGBT who are not "out"; or disabled people unable to communicate their experiences of victimization).
} 
"aggravated offence". ${ }^{18}$ For this reason we cannot estimate a conviction rate for hate crime based on estimated levels of hate crime compared with conviction numbers for aggravated offences. Nevertheless, as one of the largest victimization surveys carried out globally, the CSEW is generally considered to provide reliable estimates on crimes levels, including those offences which are perceived to be motivated by a group identity characteristic. We are therefore able to provide an approximation of the number of cases believed to be "hate crimes" that do not make it to court. Such approximations are helpful in examining the extent to which hate crime offences are being addressed by the CJS, and provide a starting point for the exploration of reasons behind why so few cases reach court.

\subsection{CASE LAW ANALYSIS}

Using the case law databases, Lexis Library and Westlaw, we searched for all reported cases that had applied or interpreted hate crime legislation up until $2017 .{ }^{19}$ CDA and CJA cases were summarised and listed in a matrix, displaying case and offence details, a brief summary of the case circumstances and the evidence of the hostility element, an indication of the type of hostility, any legal/ evidential problems, an indication of how the court responded to these problems/questions, and a brief note on the court's decision in each case. Thematic analysis was then used to highlight common points of confusion or problems emerging from the facts and decisions in hate crime cases, such as definitional issues, the interpretation of different provisions, confusion between subsections in the relevant statutes, and the relationship between the CDA and the CJA.

\subsection{QUALITATIVE INTERVIEWS}

Finally, in-depth qualitative semi-structured interviews were conducted with key actors in the criminal justice system for the purpose of gathering tacit information on, and informed insights into, the day to day operation of the criminal justice system in relation to hate crimes. In particular, these interviews were essential to revealing any disjuncture between stated policy and day to day practice, and any consequences for the prosecution, conviction and sentencing of hate crime. We conducted face-to-face and phone/skype interviews with 21 CPS Hate Crime Leads/ Hate Crime Coordinators, 17 independent barristers, nine Crown Court (Circuit) judges and 11 Magistrates' Court (District) judges, ${ }^{20}$ to explore questions on the prosecution of hate crime at key stages of the criminal process; proof requirements and making the decision to prosecute; court procedure and rules of evidence; and sentencing approaches. We also conducted interviews with six practitioners working for a charitable organisation (or civil society organisation) that supported victims of hate crime workers, and one hate crime victim, as well as six police officers (and linked personnel) involved in hate crime cases. We explored their experiences of their roles in the prosecution of hate crime, reflecting the key stages above, as well as their encounters with justice agencies.

\footnotetext{
${ }^{18}$ I.e. evidence that proves beyond reasonable doubt that the defendant was (partly) motivated by, or demonstrated, hostility during the commission of an offence.

${ }^{19}$ We are grateful to Chara Bakalis for giving us access to a list of cases on hate crime that had previously been collated up to March 2014.

${ }^{20}$ The 11 Magistrates' Court judges we interviewed were all District judges, as we were unable to reach any lay magistrate participants: see footnote 11 .
} 


\subsection{CODING AND ANALYSIS}

The 71 interviews were transcribed and uploaded onto a new software programme called Quirkos for the coding. ${ }^{21}$ Quirkos allowed us to easily highlight interview text and compare responses to specific interview questions and topics from the different participant sources. We employed two separate coding stages: at stage one, the interview transcripts were read in full and coded thoroughly, while stage two included a check of the first coding by a second coder, as well as any necessary additional coding.

Throughout this process, we used thematic analysis, which allowed us to organise the data into a number of different "thematic reports", from which we drew out evolving topics from the interview transcripts. The idea of this approach is to construct central themes in the study and then sub-themes that emerge from the main issues/points which interviewees discussed. The themes that emerged from the data were then used to structure the report and its attendant recommendations.

\subsection{ETHICAL CONSIDERATIONS}

We received institutional ethical approval through the University of Sussex (reference number ER/SW474/1), as well as approval from the Judicial Office, allowing judicial participation in our research project (05/12/2016). The participant recruitment of 71 interviewees was possible via the help and assistance of a number of key organisations. First, a call for participants was sent to barristers via the Criminal Bar Association newsletter, as well as through emails to barristers and chambers by circuit leaders. We also had the support of the Crown Prosecution Service, who identified 23 prosecutors/Hate Crime Leads/Hate Crime Coordinators in different CPS Areas to be interviewed. All but two hate crime leads accepted our offer to participate. The identification of judges who had presided over hate crime cases was facilitated through the Judicial Office and further judges were identified through recent cases and recruited by contacting Crown and Magistrates' Courts. Further participant recruitment, especially of victim advocates and law enforcement staff, was possible through personal/professional contacts and snowball sampling. ${ }^{22}$ All interviewees were offered anonymity. ${ }^{23}$

\footnotetext{
${ }^{21}$ More information about Quirkos can be found here: <https://www.quirkos.com/index.html>

${ }^{22}$ Snowball sampling is a non-random method to sample participants upon availability. After interviewing one participant, we then inquired about the possibility to recruit their contacts.

${ }^{23}$ Two professionals indicated that they wished their contribution to be attributed. However, in order to keep the presentation of all data consistent, we have anonymised all participants.
} 


\section{Part A}

\section{Law, policy and statistics: Understanding the "life cycle" of a hate crime}




\section{Part A: Law, policy and statistics: Understanding the "life cycle" of a hate crime}

In this first part of the report, we outline the current legislative framework for hate crime in England and Wales. We then summarise the policy documents that guide criminal justice system agencies tasked with addressing hate crime. We then analyse publicly available hate crime statistics that have been collected by the Crime Survey for England and Wales (CSEW) or recorded by the police or the CPS. We use these data to highlight a number of significant issues, including: the stark difference between the numbers of hate crime across CSEW data compared with recorded hate crime; the low rates of declared sentencing "uplifts" for hate crime, and especially for disability hate crime; and finally the approximate "drop out" rate for hate crime from the criminal justice system. 


\section{The legislative framework for hate crime in England and Wales}

England and Wales has an extensive and complex framework of legislation for hate crime. The piecemeal approach to legislating against hate-based offending taken by governments over the past 20 years has resulted in the enactment of various statutory provisions covering different "protected characteristics" in slightly different ways.

Despite a long history of racial violence throughout the UK, ${ }^{24}$ it was not until as late as the 1970 s and 1980s that the number of violent offences targeted against black and minority ethnic (BME) ${ }^{25}$ communities became a visible public issue. In 1980, the Joint Committee Against Racialism (JCAR) was set up to investigate the extent to which racial violence was a widespread phenomenon. Directly afterwards, the Government commissioned its first study into racial violence and harassment. ${ }^{26}$ The report highlighted the pervasiveness of racial attacks (known more commonly now as "hate crimes") in the UK. It finally gave validity to the concern, consistently expressed by lobby groups, that racially motivated violence was a major social problem that was in need of government attention. ${ }^{27}$ However, it was not until after the brutal murder of the teenager Stephen Lawrence in $1993^{28}$ by a group of racially motivated offenders, and the prolonged media attention that this single case garnered, that the Government gave its support to the introduction of new racially aggravated offences. ${ }^{29}$

In 1997, the "New" Labour Party stated in their election manifesto that if elected they would introduce new "racially aggravated" criminal offences. ${ }^{30}$ One year later, the newly elected Labour government enacted the Crime and Disorder Act 1998, creating racially aggravated offences covering assaults, criminal damage, harassment and various public order offences (ss. 28-32). During the second reading speech of the Crime and Disorder Bill, Lord Williams of Mostyn set out why the UK needed new racially aggravated offences, stating:

"These [racist] crimes are particularly odious, damaging, as they do, not just the victim but the very fabric of the multi-racial society in which we live" (16.12.97, HL Deb. c. 534).

\footnotetext{
${ }^{24}$ Ben Bowling, Violent Racism, Victimization, Policing and Social Context (OUP 1998).

${ }^{25}$ Now more commonly referred to as Black, Asian and minority ethnic communities (BAME).

${ }^{26}$ Home Office, Racial attacks: Report of a Home Office Study (Home Office 1981).

${ }^{27}$ Ben Bowling, Violent Racism, Victimization, Policing and Social Context (OUP 1998).

${ }^{28}$ Sir William Macpherson of Cluny, The Stephen Lawrence Inquiry: Report of an Inquiry by Sir William Macpherson of Cluny (Cm 4262-I, 1999)

<https://www.gov.uk/government/uploads/system/uploads/attachment_data/file/277111/4262.pdf>

${ }^{29}$ Maleiha Malik, '"Racist Crime”: Racially Aggravated Offences in the Crime and Disorder Act 1998 Part II' 62(3) MLR 409.

${ }^{30}$ New Labour Party 'Manifesto: New Labour because Britain deserves better' (1997)

$<$ http://www.politicsresources.net/area/uk/man/lab97.htm>
} 
Three years later, in 2001, the CDA was amended by the Anti-terrorism, Crime and Security Act 2001 to incorporate religiously aggravated offences mirroring the racially-aggravated offences. ${ }^{31}$ It would take a further four years for other characteristics to be specifically protected in law. In 2005, the Criminal Justice Act 2003 finally came into force, enacting sentencing provisions prescribing that the court "must" treat as an aggravating factor at sentencing any offence that is motivated by, or that demonstrates hostility, based on the victim's (presumed) sexual orientation or disability (s. 146). ${ }^{32}$ In 2012, the CJA was amended to add transgender hostility as a protected category under section $146 .{ }^{33}$ The CJA is therefore more far-reaching, covering all five hate crime strands - race, religion, sexual orientation, disability and transgender identity - for all types of offence, while the CDA covers only race and religion in relation to specific categories of crime.

Although hate speech offences are outside the scope of this report, it is worth highlighting that the Government first introduced legislation to deal with "incitement to commit racial hatred"' under the Race Relation Act 1965, which was amended by the Public Order Act 1986 (henceforth, POA) ${ }^{34}$ In 2006, the Racial and Religious Hatred Act 2006 amended the POA, introducing new offences of stirring up religious hatred. In 2008, the POA was amended again by the Criminal Justice and Immigration Act 2008 to add offences of stirring up hatred based on sexual orientation.

\subsection{THE STRUCTURE OF THE CURRENT HATE CRIME LEGISLATION}

\subsubsection{Aggravated criminal offences}

The offences prescribed under ss. 28 to 32 of the Crime and Disorder Act 1998 create specific criminal offences aggravated by racial or religious hostility. These are more serious versions of pre-existing, or "basic", offences. Throughout this report, we refer to the aggravated offences as RRAOs (racially or religiously aggravated offences) to distinguish them from other offences where hostility based on a personal characteristic is treated as an aggravating factor at sentencing.

Section 28 of the CDA states:

(1) An offence is racially or religiously aggravated for the purposes of sections 29 to 32 below if-

(a) at the time of committing the offence, or immediately before or after doing so, the offender demonstrates towards the victim of the offence hostility based on the victim's membership (or presumed membership) of a racial or religious group; or

(b) the offence is motivated (wholly or partly) by hostility towards members of a racial or religious group based on their membership of that group.

\footnotetext{
${ }^{31}$ Note that the Protection of Freedoms Act 2012 further amended the CDA to include racially and religiously aggravated versions of new stalking offences.

${ }^{32}$ Section 145 makes the same basis for aggravation for any crime motivated or demonstrating racial or religious hostility.

33 Sentencing and Punishment of Offenders Act 2012, s. 65.

${ }^{34}$ Maleiha Malik, '“Racist Crime”: Racially Aggravated Offences in the Crime and Disorder Act 1998 Part II' 62(3) MLR 409.
} 
Offences that can be aggravated under this provision encompass the following:

- racially or religiously aggravated assaults (malicious wounding or grievous bodily harm, actual bodily harm, and common assault); ${ }^{35}$

- racially or religiously aggravated criminal damage (destroying or damaging property belonging to another); ${ }^{36}$

- racially or religiously aggravated public order offences (fear or provocation of violence, intentional harassment, alarm or distress, or recklessly causing harassment, alarm or distress); ${ }^{37}$ and

- racially or religiously aggravated harassment and stalking (including putting people in fear of violence). ${ }^{38}$

Each of these offences attracts a higher penalty (see Table 1 below).

Table 1 Basic offences compared with aggravated offences ${ }^{39}$

Maximum Penalty

\begin{tabular}{|c|c|c|}
\hline Criminal Offence & Basic Offence & Aggravated Offence \\
\hline Malicious wounding & 5 years & 7 years \\
\hline Actual bodily harm & 5 years & 7 years \\
\hline Common assault & 6 months & 2 years \\
\hline Criminal damage & 10 years & 14 years \\
\hline Fear or provocation of violence & 6 months & 2 years \\
\hline Harassment, alarm or distress & Fine of up to $£ 1,000$ & Fine of up to $£ 2,500$ \\
\hline Causing intentional harassment, alarm or distress & 6 months & 2 years \\
\hline Offence of harassment or stalking & 51 weeks & 2 years \\
\hline $\begin{array}{l}\text { Putting people in fear of violence and stalking } \\
\text { involving fear of violence or serious alarm or } \\
\text { distress }\end{array}$ & 10 years & 14 years \\
\hline
\end{tabular}

\footnotetext{
${ }^{35}$ Crime and Disorder Act 1998, s. 29.

${ }^{36}$ Crime and Disorder Act 1998, s. 30.

${ }^{37}$ Crime and Disorder Act 1998, s. 31.

${ }^{38}$ Crime and Disorder Act 1998, s. 32.

${ }^{39}$ Table adapted (and amended to include new sentencing maxima for stalking offences) from Law Commission, Hate Crime: Should the Current Offences be Extended? (Law Com No 348, 2014)

<https://www.gov.uk/government/uploads/system/uploads/attachment_data/file/316103/9781474104852_Print.pdf>
} 


\subsubsection{Penalty enhancement sentencing provisions}

Sections 145 and 146 of the Criminal Justice Act 2003 set out provisions for when a judge must enhance the penalty of a defendant convicted of a crime aggravated by racial, religious, sexual orientation, disability or transgender hostility. Section 146 states:

(1) This section applies where the court is considering the seriousness of an offence committed in any of the circumstances mentioned in subsection (2).

(2) Those circumstances are-

(a) that, at the time of committing the offence, or immediately before or after doing so, the offender demonstrated towards the victim of the offence hostility based on-

(i) the sexual orientation (or presumed sexual orientation) of the victim, or

(ii) a disability (or presumed disability) of the victim, or

(iii) the victim being (or being presumed to be) transgender, or

(b) that the offence is motivated (wholly or partly)-

(i) by hostility towards persons who are of a particular sexual orientation, or

(ii) by hostility towards persons who have a disability or a particular disability, or

(iii) by hostility towards persons who are transgender.

(3) The court-

(a) must treat the fact that the offence was committed in any of those circumstances as an aggravating factor, and

(b) must state in open court that the offence was committed in such circumstances.

(4) It is immaterial for the purposes of paragraph (a) or (b) of subsection (2) whether or not the offender's hostility is also based, to any extent, on any other factor not mentioned in that paragraph.

Section 145 of the Act uses identical language to 146 and covers all criminal offences aggravated by racial or religious hostility that are not specified under ss. 28-32 of the CDA. ${ }^{40}$ Both ss. 145 and 146 apply to any criminal offence and are applicable at sentencing only. This means that only those offences covered by the CDA can be classified in criminal law as "aggravated offences" (e.g. "racially aggravated assault"), while those covered by the sentencing provision will be recorded in law as the basic offence (e.g. an assault).

\footnotetext{
${ }^{40}$ Though, as we will see later in this report, decisions as to when s. 145 or ss. 28-32 will apply can become highly complex (see Abenaa Owusu-Bempah and Mark Walters, 'Racially aggravated offences: When does section 145 of the Criminal Justice Act 2003 apply?' [2016] 2 Crim LR 116).
} 


\subsubsection{Hate speech offences}

The third set of provisions, not covered in detail by this report, includes stirring up hatred provisions, ${ }^{41}$ which incorporates acts that are intended or are likely to stir up hatred by: using words or behaviour or displaying written material; ${ }^{42}$ publishing or distributing written material; ${ }^{43}$ publicly performing a play; ${ }^{44}$ distributing, showing or playing a recording; ${ }^{45}$ broadcasting or including programme in cable programme service ${ }^{46}$ or possessing racially inflammatory material. ${ }^{47}$

The Football (Offences) Act 1991 also proscribes indecent and racialist chanting during football games. Section 3 of the Act states:

(1) It is an offence to [engage or take part in chanting of an indecent or racialist nature at a designated football match].

(2) For this purpose-

(a) "chanting" means the repeated uttering of any words or sounds [(whether alone or in concert with one or more others)]; and

(b) "of a racialist nature" means consisting of or including matter which is threatening, abusive or insulting to a person by reason of his colour, race, nationality (including citizenship) or ethnic or national origins.

Other statutes that may be of particular relevance to addressing hate crime-related offences, but which are not specifically prescribed in terms of identity-based hostility, include the Communications Act 2003, s. 127, which makes the improper use of a public electronic communications network an offence, and the Malicious Communications Act 1988, s. 1, which makes it an offence to send letters etc. with intent to cause distress or anxiety. ${ }^{48}$

The following figure shows how different types of crime, aggravated by different forms of hostility, are likely to proceed through the criminal process, from arrest through to sentencing.

\footnotetext{
${ }^{41}$ Public Order Act 1986, ss. 18-23 and ss. 29B-29G.

42 Public Order Act 1986, s. 18 (for racial hatred) and s. 29B (for hatred based on religion or sexual orientation).

${ }^{43}$ Public Order Act 1986, s. 19 (for racial hatred) and s. $29 \mathrm{C}$ (for hatred based on religion or sexual orientation).

${ }^{44}$ Public Order Act 1986, s. 20 (for racial hatred) and s. 29D (for hatred based on religion or sexual orientation).

${ }^{45}$ Public Order Act 1986, s. 21 (for racial hatred) and s. 29 E (for hatred based on religion or sexual orientation).

${ }^{46}$ Public Order Act 1986, s. 22 (for racial hatred) and s. 29F (for hatred based on religion or sexual orientation).

${ }^{47}$ Public Order Act 1986, s. 23 (for racial hatred) and s. 29G (for hatred based on religion or sexual orientation).

${ }^{48}$ See further Law Commission, Hate Crime: Should the Current Offences be Extended? (Law Com No 348, 2014)

<https://www.gov.uk/government/uploads/system/uploads/attachment_data/file/316103/9781474104852_Print.pdf>
} 
Figure 1: Legal remedies for hate crime (England and Wales) ${ }^{49}$

An incident is reported or identified as a hate crime.

Investigators must now confirm that the incident constitutes an offence and that

it constitutes a hate crime.

Did the incident involve:

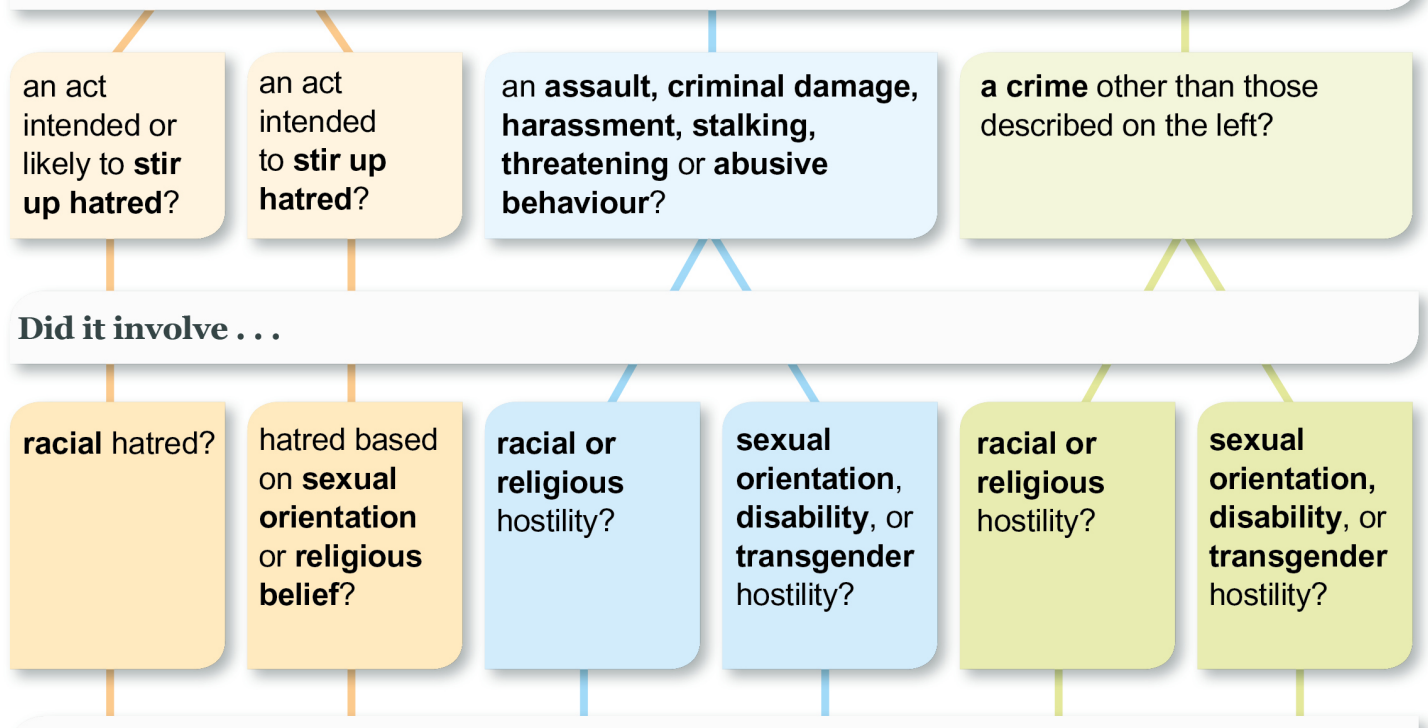

If so, there may be recourse to the...

\begin{tabular}{|c|c|c|c|c|c|}
\hline $\begin{array}{l}\text { Public Order } \\
\text { Act } 1986, \\
\text { Part } 3\end{array}$ & $\begin{array}{l}\text { Public Order } \\
\text { Act 1986, } \\
\text { Part 3A }\end{array}$ & $\begin{array}{l}\text { Crime and } \\
\text { Disorder Act } \\
\text { 1998, } \\
\text { ss. 28-32. }\end{array}$ & $\begin{array}{l}\text { Criminal } \\
\text { Justice Act } \\
2003 \text {, s. } 146 .\end{array}$ & $\begin{array}{l}\text { Criminal } \\
\text { Justice Act } \\
2003 \text {, s. } 145 .\end{array}$ & $\begin{array}{l}\text { Criminal } \\
\text { Justice Act } \\
2003, \text { s. } 146 .\end{array}$ \\
\hline \multicolumn{6}{|c|}{ The offence is prosecuted as ... } \\
\hline $\begin{array}{l}\text { a stirring up of } \\
\text { hatred offence }\end{array}$ & $\begin{array}{l}\text { a stirring up of } \\
\text { hatred offence }\end{array}$ & "aggravated" & $\begin{array}{l}\text { a basic offence } \\
\text { with a penalty } \\
\text { uplift imposed } \\
\text { at sentencing. }\end{array}$ & $\begin{array}{l}\text { a basic offence } \\
\text { with a penalty } \\
\text { uplift imposed } \\
\text { at sentencing. }\end{array}$ & $\begin{array}{l}\text { a basic offence } \\
\text { with a penalty } \\
\text { uplift imposed } \\
\text { at sentencing. }\end{array}$ \\
\hline
\end{tabular}

\footnotetext{
${ }^{49}$ Figure previously used in Mark A Walters and Rupert Brown with Susann Wiedlitzka, Causes and Motivations of Hate Crime (Research Report 102, EHRC 2016), co-designed with the Equality and Human Rights Commission

<https://www.equalityhumanrights.com/sites/default/files/research-report-102-causes-and-motivations-of-hate-crime.pdf>
} 


\subsubsection{Differences in victim categories and protection under hate crime legislation}

Within England and Wales, official data are collected by a number of criminal justice agencies on hate crimes based on race, religion, disability, sexual orientation and transgender identity. ${ }^{50}$ However, as we have observed, these five monitored categories are not equally protected under the three main legislative frameworks addressing hate crime (discussed above). The CDA, for example, only proscribes racial and religious aggravation, while the POA covers hatred based on race, religion and sexual orientation. The Law Commission for England and Wales has recently investigated whether the CDA should be extended to include the remaining monitored categories, as well as also examining whether the POA should be extended to cover the categories of disability and transgender identity. ${ }^{51}$ The Commission's final report uncovered a number of practical problems associated with the legislative framework that require further investigation. The Commission recommended that in the absence of a full-scale review of the legislative framework for hate crime, those groups currently not protected under the CDA (i.e., sexual orientation, disability and transgender identity) should be included under ss. 28-32 of the Act (i.e. offences relating to assault, criminal damage, harassment and public order offences). However, in terms of the stirring up of hatred offences (i.e., hate speech offences) as set out under Part 3 and $3 A$ of the POA, the Commission recommended that those characteristics currently not covered under the legislation (i.e. disability and transgender identity) should not be incorporated, due to the fact that the law is rarely enforced successfully for these types of offence. Furthermore, the Commission asserts that the problem of disablist and transphobic hate speech offences can be adequately dealt with under other legal provisions (primarily ss. 4-5, POA). ${ }^{52}$

The Commission has additionally recommended that the Sentencing Council provide formal sentencing guidance for hostility-based offending under the CDA and for enhanced sentencing under the CJA (ss. 145-146). ${ }^{53}$ Furthermore, the Commission recommended that all types of hate crime should be recorded on the Police National Computer and noted on the offender's criminal record. ${ }^{54}$ At the time of publishing this report, the Sentencing Council is yet to provide the recommended new guidance, while formal changes are yet to be made to the data collection process for offences covered by ss. 145 and 146 of the CJA (for further discussion on the criteria for including characteristics in law and in the sentencing guidelines see Appendix A).

\footnotetext{
${ }^{50}$ Law Commission, Hate Crime: Should the Current Offences be Extended? (Law Com No 348, 2014)

<https://www.gov.uk/government/uploads/system/uploads/attachment_data/file/316103/9781474104852_Print.pdf> Some institutions also monitor other characteristics such as subcultures by Greater Manchester Police: see e.g. 'Hate Crime: Policy and Procedure' (2014)

<http://www.gmp.police.uk/content/WebAttachments/A902DDDD4CD8149180257CED0050D768/\$File/GMP\%20Hate\%20Crim e\%20Policy\%20January\%202014\%20updated\%20May\%202014.pdf> and misogyny hate crimes in Nottingham Police Service.

${ }^{51}$ Law Commission, Hate Crime: Should the Current Offences be Extended? (Law Com No 348, 2014)

<https://www.gov.uk/government/uploads/system/uploads/attachment_data/file/316103/9781474104852_Print.pdf>

${ }^{52}$ Law Commission, Hate Crime: Should the Current Offences be Extended? (Law Com No 348, 2014)

<https://www.gov.uk/government/uploads/system/uploads/attachment_data/file/316103/9781474104852_Print.pdf>

${ }^{53}$ Bakalis asserts that this guidance should not be provided until a review of the aggravated offences and the CJA is carried out: Chara Bakalis, 'Legislating against hatred: the Law Commission's report on hate crime' [2015] 3 Crim LR 192. We aim for this report to provide the required information that the Sentencing Council needs to amend their guidelines.

54 Law Commission, Hate Crime: Should the Current Offences be Extended? (Law Com No 348, 2014)

<https://www.gov.uk/government/uploads/system/uploads/attachment_data/file/316103/9781474104852_Print.pdf>
} 


\section{Hate crime policy documents}

Since the introduction of hate crime legislation in England and Wales, a number of policy documents have been created that give practical guidance to police, prosecutors, judges and other justice practitioners tasked with addressing hate crime. We summarise this CJS guidance below, as this information informs our study and is the background to how different actors in the CJS deal with hate crimes.

\subsection{THE POLICE}

In 2014, the College of Policing compiled a National Policing Hate Crime Strategy, as well as the Hate Crime Operational Guidance for police staff. ${ }^{55}$ The Operational Guidance document sets out the agreed "operational" definition of hate crime that is used across the criminal justice system:

"A hate crime is any criminal offence which is perceived, by the victim or any other person, to be motivated by a hostility or prejudice based on a person's race or perceived race, religion or perceived religion, sexual orientation or perceived sexual orientation, disability or perceived disability, [or] against a person who is transgender or perceived to be transgender."

The guidance also identifies "hate incidents" which must also be recorded by the police. These include:

"Any non-crime incident which is perceived, by the victim or any other person, to be motivated by a hostility or prejudice based on a person's race or perceived race, religion or perceived religion, sexual orientation or perceived sexual orientation, disability or perceived disability, [or] against a person who is transgender or perceived to be transgender."

The National Policing Hate Crime Strategy lays out a statement of commitment by the police service to prevent, positively respond to and reduce the underreporting of hate crime, as defined above. ${ }^{56}$ The aim of the strategy is to reduce the harm that hate crime causes to victims, and to increase the trust and confidence in the police, especially by communities targeted by hate crime. Strategic improvements for police include: improving investigation

\footnotetext{
${ }^{55}$ Updating the previous Association of Chief Police Officers' guidance (see Association of Chief Police Officers (ACPO), 'Hate crime: delivering a quality service, good practice and tactical guidance'(2005) $<$ http://www.bedfordshire.police.uk/pdf/tacticalguidance.pdf>

${ }^{56}$ College of Policing, 'National Policing Hate Crime Strategy' (2005)

<http://www.college.police.uk/What-we-do/Support/Equality/Documents/National-Policing-Hate-Crimestrategy.pdf\#search=hate $\% 20$ crime>
} 
and prosecution of hate crime (assessed, for example, through a hate crime diagnostic tool); creating a better understanding of the nature and extent of hate crime (through common definitions, better data collection and community intelligence and engagement); and the reduction of underreporting (by developing True Vision ${ }^{57}$ to improve communication with victims). ${ }^{58}$

The 2014 Hate Crime Operational Guidance document also reflects current developments in the policing of hate crime and the needs of diverse communities. ${ }^{59}$ This guidance incorporates the improvements set out in the National Policing Hate Crime Strategy, including detailed definitions and examples of hate crime, the legislative and sentencing frameworks and specific offences, information and case studies on the five monitored strands, dealing with the underreporting of hate crime, and data sharing and guidance on police responses to and recording of hate crime. ${ }^{60}$ The Hate Crime Operational Guidance also incorporates information on working with other partners, the minimum standards for responding, investigating and supervising offences, engaging the community, as well as intelligence and performance measures. ${ }^{61}$ It also contains a section on sports-related hate crime, inciting hatred and internet hate crime, as well as "internal hate crime". ${ }^{62}$

\subsection{THE CROWN PROSECUTION SERVICE GUIDANCE}

The CPS recently published new legal guidance to prosecutors on charging decisions and the prosecution of racist and religious hate crime ${ }^{63}$ disability hate crime and other crimes against disabled people, ${ }^{64}$ and homophobic, biphobic and transphobic hate crime ${ }^{65}$ Hate crime guidance statements were revised to account for the growing trend in online hate crime, to acknowledge the different experiences and unique needs that biphobic hate crime victims have, compared with homophobic and transphobic hate crime victims, and to address the barriers to access justice that disability hate crime victims and witnesses experience. ${ }^{66}$ The prosecution guidance for racist and religious hate crime, for example, contains

\footnotetext{
${ }^{57}$ True Vision is owned by the Association of Chief Police Officers and provides information on hate crime and how to report hate crimes. It also offers an online reporting form and victims support information.

${ }^{58}$ College of Policing, 'National Policing Hate Crime Strategy' (2005)

$<$ http://www.college.police.uk/What-we-do/Support/Equality/Documents/National-Policing-Hate-Crimestrategy.pdf\#search=hate $\% 20$ crime>

${ }^{59}$ College of Policing, 'Hate Crime Operational Guidance' (2014)

<http://www.college.police.uk/What-we-do/Support/Equality/Documents/Hate-Crime-Operational-

Guidance.pdf\#search=hate\%20crime>

${ }^{60}$ College of Policing, 'Hate Crime Operational Guidance' (2014)

$<$ http://www.college.police.uk/What-we-do/Support/Equality/Documents/Hate-Crime-Operational-

Guidance.pdf\#search=hate\%20crime>

${ }^{61}$ College of Policing, 'Hate Crime Operational Guidance' (2014)

<http://www.college.police.uk/What-we-do/Support/Equality/Documents/Hate-Crime-Operational-

Guidance.pdf\#search=hate\%20crime>

${ }^{62}$ The College of Policing guidance refers to internal hate crime as hate crimes or incidents which occur while police staff are on duty, perpetrated either by colleagues or the public. College of Policing, 'Hate Crime Operational Guidance' (2014)

<http://www.college.police.uk/What-we-do/Support/Equality/Documents/Hate-Crime-Operational-

Guidance.pdf\#search=hate\%20crime>

${ }^{63}$ Crown Prosecution Service, 'Racist and Religious Hate Crime - Prosecution Guidance' (2017)

$<$ http://www.cps.gov.uk/legal/p to $\mathrm{r} / \mathrm{racist}$ and religious crime/>

${ }^{64}$ Crown Prosecution Service, 'Disability Hate Crime and other Crimes against Disabled People - Prosecution Guidance' (2017) $<$ http://www.cps.gov.uk/legal/d_to_g/disability_hate_crime/>

${ }^{65}$ Crown Prosecution Service, 'Homophobic, Biphobic and Transphobic Hate Crime - Prosecution Guidance' (2017)

$<$ http://www.cps.gov.uk/legal/h_to_k/homophobic_and_transphobic_hate_crime/>

${ }^{66}$ Crown Prosecution Service, 'CPS publishes new public statements on hate crime' (21 August 2017)

<http://www.cps.gov.uk/news/latest_news/cps-publishes-new-public-statements/>
} 
information on the importance of flagging cases as hate crimes, being proactive in seeking information and evidence from the police, steps reviewing prosecutors should go through when reviewing hate crime cases, the relevant legislation (e.g., CDA, CJA, POA and other Acts relevant to the offences and protected hate crime strand) and definitions (e.g., motivation vs. demonstration of hostility, and definitions of racial and religious group), while also including relevant case law and the elements that need to be satisfied to prove the case. ${ }^{67}$ In addition, the guidance document provides important information on alternative charges and verdicts, CPS policy on not accepting pleas in hate crime cases, enhanced sentencing powers and sentencing duty, and it sets out maximum penalties for different offences. $^{68}$

The CPS guidance on prosecuting cases of disability hate crime mostly mirrors the information to the guidance for racist and religious hate crimes, but makes prosecutors aware of aspects that are unique to disability hate crime. ${ }^{69}$ The guidance covers common factors in disability hate crime, such as incidents escalating in severity and frequency, opportunistic offending, and victims often knowing the perpetrators (i.e., family or carers). ${ }^{70}$ The guidance also provides examples of "[a]ctions that may amount to evidence of hostility" and provides examples of common types of offences where it is necessary to distinguish between disability hate crime from crimes against disabled people, including acquisitive crime, sexual offences and offences against the person. ${ }^{71}$ The guidance also provides a section on accounting for the vulnerability of a victim at sentencing stage and an explanation of what "vulnerable" means in the context of a criminal offence:

"This guidance does not suggest that a disabled person is vulnerable per se. Where the guidance refers to a "vulnerable" victim, witness or person, it does so in the context of the person being vulnerable to a particular criminal offence in particular circumstances, or in the context of a relevant Sentencing Guideline or an application for special measures for a "vulnerable witness" under s16 of the Youth Justice and Criminal Evidence Act 1999."72

The guidance includes vocabulary that may be seen as offensive to disabled people, such as "bullying", "has a mental age of" or "mate crime". ${ }^{73}$ The CPS also provides information and guidance on how to access support available for disabled victims and witnesses. This document lays out help available for victims when reporting a crime, during the police

\footnotetext{
${ }^{67}$ Crown Prosecution Service, 'Racist and Religious Hate Crime - Prosecution Guidance' (2017)

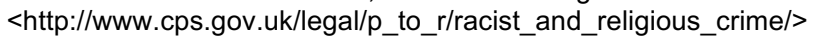

Crown Prosecution Service, 'Racist and Religious Hate Crime - Prosecution Guidance' (2017)

$<$ http://www.cps.gov.uk/legal/p_to_r/racist_and_religious_crime/>

${ }^{69}$ Crown Prosecution Service, 'Disability Hate Crime and other Crimes against Disabled People - Prosecution Guidance' (2017) $<$ http://www.cps.gov.uk/legal/d_to_g/disability_hate_crime/>

${ }^{70}$ Crown Prosecution Service, 'Disability Hate Crime and other Crimes against Disabled People - Prosecution Guidance' (2017) <http://www.cps.gov.uk/legal/d_to_g/disability_hate_crime/>

${ }^{71}$ Crown Prosecution Service, 'Disability Hate Crime and other Crimes against Disabled People - Prosecution Guidance' (2017) <http://www.cps.gov.uk/legal/d_to_g/disability_hate_crime/>

${ }^{2}$ Crown Prosecution Service, 'Disability Hate Crime and other Crimes against Disabled People - Prosecution Guidance' (2017) $<$ http://www.cps.gov.uk/legal/d_to_g/disability_hate_crime/>

${ }^{73}$ As they are likely to minimize disabled people's experiences of crime. Crown Prosecution Service, 'Disability Hate Crime and other Crimes against Disabled People - Prosecution Guidance' (2017)

<http://www.cps.gov.uk/legal/d_to_g/disability_hate_crime/>
} 
investigation, after the perpetrator is charged, while going to court, as well as after trial, and special measures available while giving evidence in court. ${ }^{74}$

In addition to the information provided in other CPS hate crime guidance, the guidance for the prosecution of homophobic, biphobic and transphobic crime also consists of information on the appropriate language used when dealing with cases, as well as acknowledging that victims or witnesses of homophobic, biphobic and transphobic hate crimes may be reluctant to come forward and engage with the criminal justice system, if they "believe that they will become the subject of a police investigation and then a CPS prosecution because of where they were when the incident occurred; because of whom they were with; or because of what they were doing at the time". ${ }^{75}$

In 2008, the CPS published a good practice and lessons learnt toolkit for homophobic and transphobic hate crime, which assists CPS staff in improving performance outcomes related to such crimes. ${ }^{76}$ This toolkit contains good practice and lessons learned in prosecuting homophobic and transphobic hate crime cases, exemplified by case studies. It also identifies the different steps in the prosecution process, such as pre-charge/charge, before court, at court and after court. ${ }^{77}$

\subsection{THE SENTENCING COUNCIL GUIDELINES}

The Sentencing Council provides sentencing guidelines for the judiciary and other criminal justice professionals to ensure consistency in sentencing. The Council provides a guide on hate crime that sets out information on the statutory provisions of racial and religious aggravation, as well as aggravation related to disability, sexual orientation and transgender identity. It also sets out the approach that should be taken to sentencing. ${ }^{78}$ The first part of the hate crime sentencing guide discusses the statutory provisions for racial and religious aggravation under the CDA (the RRAOs). ${ }^{79}$ The guide then refers to s. 145 of the CJA for all other offences that are aggravated by racial or religious hostility. ${ }^{80}$ The guide notes that where a charge for a RRAO has resulted in an acquittal, s. 145 should not be used. ${ }^{81}$ The sentencing guide also indicates that "[t]he court should not normally treat an offence as racially or religiously aggravated if a racially or religiously aggravated form of the offence was

\footnotetext{
${ }^{74}$ Crown Prosecution Service, 'Support for disabled victims and witnesses of crime' (n.d.)

$<$ http://www.cps.gov.uk/publications/docs/hate_crime_leaflet_support.pdf>

${ }^{75}$ Crown Prosecution Service, 'Homophobic, Biphobic and Transphobic Hate Crime - Prosecution Guidance' (2017)

<http://www.cps.gov.uk/legal/h_to_k/homophobic_and_transphobic_hate_crime/>

${ }^{76}$ Crown Prosecution Service Equality and Diversity Unit, 'Homophobic and Transphobic Crime Toolkit: Good Practice and Lessons Learnt' (October 2008) <https://www.cps.gov.uk/publications/docs/htc_toolkit.pdf>

${ }^{77}$ Crown Prosecution Service Equality and Diversity Unit, 'Homophobic and Transphobic Crime Toolkit: Good Practice and Lessons Learnt' (October 2008) <https://www.cps.gov.uk/publications/docs/htc_toolkit.pdf>

${ }^{78}$ Sentencing Council, 'Hate Crime' (n.d.) <https://www.sentencingcouncil.org.ük/explanatory-material/item/hate-crime/>

${ }^{79}$ Sentencing Council, '1. Racial or religious aggravation - statutory provisions' (n.d.)

$<$ https://www.sentencingcouncil.org.uk/explanatory-material/item/hate-crime/1-racial-or-religious-aggravation-statutoryprovisions/>

${ }^{80}$ Sentencing Council, '1. Racial or religious aggravation - statutory provisions' (n.d.)

<https://www.sentencingcouncil.org.uk/explanatory-material/item/hate-crime/1-racial-or-religious-aggravation-statutoryprovisions/>

${ }^{81}$ Sentencing Council, '1. Racial or religious aggravation - statutory provisions' (n.d.)

$<$ https://www.sentencingcouncil.org.uk/explanatory-material/item/hate-crime/1-racial-or-religious-aggravation-statutoryprovisions/>
} 
available but was not charged". ${ }^{82}$ We discuss the complicated inter-relationship between the RRAOs and s. 145 below (see 9.9). The second part of the hate crime sentencing guide provides information on the statutory provisions of aggravation related to disability, sexual orientation and transgender identity, again including demonstrated hostility or the offence being motivated by hostility as an aggravating factor under s. 146 of the CJA. ${ }^{83}$

The final part of the sentencing guide sets out the approach to sentencing hate crimes more generally. Courts are advised to give the defence notice, to allow for challenge of allegations of hostility. It also provides a step-by-step approach for the sentencing of aggravation under both CDA and CJA. ${ }^{84}$ The steps are as follows:

1) Sentencers should first determine the appropriate sentence, leaving aside the element of aggravation related to race, religion, disability, sexual orientation or transgender identity but taking into account all other aggravating or mitigating factors;

2) The sentence should then be increased to take account of the aggravation related to race, religion, disability, sexual orientation or transgender identity;

3) The increase may mean that a more onerous penalty of the same type is appropriate, or that the threshold for a more severe type of sentence is passed;

4) The sentencer must state in open court that the offence was aggravated by reason of race, religion, disability, sexual orientation or transgender identity;

5) The sentencer should state what the sentence would have been without that element of aggravation.

A number of factors may be taken into consideration by the courts when establishing the level of aggravation. The guide states that these include the offender's intention and/or the impact on the victim or others. Other factors that might reduce the sentence to the lower end of the scale when considering the aggravation as a less serious offence are provided. ${ }^{85}$

The Sentencing Council also includes information on hostility aggravation within specific offence guidelines. For example, the Council's Assault Definitive Guideline (Crown Court) ${ }^{86}$ includes the following identity-related aggravating factors under "Factors indicating higher culpability":

\footnotetext{
${ }^{82}$ Sentencing Council, '1. Racial or religious aggravation - statutory provisions' (n.d.)

$<$ https://www.sentencingcouncil.org.uk/explanatory-material/item/hate-crime/1-racial-or-religious-aggravation-statutoryprovisions/>

${ }^{3}$ Sentencing Council, '2. Aggravation related to disability, sexual orientation or transgender identity - statutory provisions' (n.d.)

<https://www.sentencingcouncil.org.uk/explanatory-material/item/hate-crime/2-aggravation-related-to-disability-sexualorientation-or-transgender-identity-statutory-provisions/>

${ }^{84}$ Sentencing Council, '3. Approach to sentencing' (n.d.)

<https://www.sentencingcouncil.org.uk/explanatory-material/item/hate-crime/3-approach-to-sentencing/>

${ }^{85}$ Examples of mitigating factors include the limited scope or duration of the aggravation or if "the offence was not motivated by hostility on the basis of race, religion, disability, sexual orientation or transgender identity, and the element of hostility or abuse was minor or incidental”. See Sentencing Council, '3. Approach to sentencing' (n.d.)

<https://www.sentencingcouncil.org.uk/explanatory-material/item/hate-crime/3-approach-to-sentencing/>. We discuss the

different approaches to sentencing crimes motivated by hostility versus demonstrating hostility in section 9.5 .

${ }^{86}$ Sentencing Council, <Assault: Definitive Guideline> (2011) <http://www.sentencingcouncil.org.uk/wp-

content/uploads/Assault_definitive_guideline_-_Crown_Court.pdf>
} 
Statutory aggravating factors:

- Offence racially or religiously aggravated

- Offence motivated by, or demonstrating, hostility to the victim based on his or her sexual orientation (or presumed sexual orientation)

- Offence motivated by, or demonstrating, hostility to the victim based on the victim's disability (or presumed disability) ${ }^{87}$

Other aggravating factors:

- Deliberate targeting of vulnerable victim

- Offence motivated by, or demonstrating, hostility based on the victim's age, sex, gender identity (or presumed gender identity)

This list gives the courts the discretion to go beyond the five characteristics included under the CJA, to consider age, sex, and gender identity hostility as factors that might aggravate an offence. It is not clear why these specific identity characteristics have been included in the guidelines while others (such as subcultural affiliation, social class, homelessness) are omitted. $^{88}$

\subsection{THE CROSS-GOVERNMENT ACTION PLAN}

In 2012, the UK Government set out an Action Plan on hate crime, allowing local areas to develop their own strategies reflecting local needs, rather than a top-down approach. ${ }^{89}$ The three core principles of the Action Plan were:

1) Preventing hate crime - by challenging the attitudes that underpin it, and early intervention to prevent it escalating;

2) Increasing reporting and access to support - by building victim confidence and supporting local partnerships; and

3) Improving the operational response to hate crimes - by better identifying and managing cases, and dealing effectively with offenders.

A 2014 progress review on the delivery of the actions laid out by the Action Plan indicated that many actions have been delivered. However, this is an ongoing process. ${ }^{90}$ Many Police and Crime Commissioners (PCCs) ${ }^{91}$ have focused their attention on tackling hate crime and have been responsible for commissioning the majority of victim support services since

\footnotetext{
${ }^{87}$ Note that "transgender identity" is missing from the statutory aggravating factors.

${ }^{88}$ See Appendix A where we discuss criteria for inclusion of "protected characteristics".

${ }^{89} \mathrm{HM}$ Government, Challenge it, Report it, Stop it: Delivering the Government's hate crime action plan (Home Office 2014)

$<$ https://www.gov.uk/government/uploads/system/uploads/attachment_data/file/307624/HateCrimeActionPlanProgressReport.pd $\mathrm{f>}$

${ }_{90} \mathrm{HM}$ Government, Challenge it, Report it, Stop it: Delivering the Government's hate crime action plan (Home Office 2014) <https://www.gov.uk/government/uploads/system/uploads/attachment_data/file/307624/HateCrimeActionPlanProgressReport.pd $\mathrm{f}>$

91 The Government's Hate Crime Action Plan also introduced PCCs to make the police more accountable for the communities they serve. Since 2014, PCCs have been responsible for the commissioning of the majority of victim support services depending on local needs and priorities.
} 
October $2014 .^{92}$ The review also outlined some of the new challenges that emerged since the Action Plan was published in 2012, such as increasing the awareness of disability hate crime, the growing significance of online hate crime, and the importance of tackling extremism and anti-Muslim hatred. ${ }^{93}$

In 2016, a new "Action Against Hate" plan laid out actions to tackle hate crime until May 2020 , with an expected review of deliverables in $2018 .{ }^{94}$ This new action plan focuses on the following five key areas:

1) Preventing hate crime by dealing with the beliefs and attitudes that can lead to hate crime.

2) Responding to hate crime in our communities with the aim of reducing the number of hate crime incidents.

3) Increasing the reporting of hate crime.

4) Improving support for the victims of hate crime.

5) Building our understanding of hate crime.

The action plan concentrates on: educational projects that challenge hatred and prejudice; security measures around faith institutions, public transport, night-time economy and cyberhate; third party reporting mechanisms; community impact statements and improved court experiences for victims and witnesses; and learning from improved data and academic insights into hate crime.

\subsection{CODE OF PRACTICE FOR VICTIMS OF CRIME}

In 2012, the EU adopted a new victims' rights directive introducing minimum standards on the rights, support and protection of victims. ${ }^{95}$ Article 22 is of significance in the context of hate crime.

Article 22(1) states that, in assessing the needs of victims, an assessment must be carried out to determine if the victim has any particular "protection needs" and the extent to which they would benefit from "special measures" in the course of criminal proceedings "due to their particular vulnerability to secondary and repeat victimisation, to intimidation and to retaliation."

Article 22(2) states that the assessment should take the personal characteristics of the victim, the nature of the crime and the circumstances of the crime into account.

\footnotetext{
${ }^{92}$ HM Government, Challenge it, Report it, Stop it: Delivering the Government's hate crime action plan (Home Office 2014) <https://www.gov.uk/government/uploads/system/uploads/attachment_data/file/307624/HateCrimeActionPlanProgressReport.pd f>

${ }^{93}$ HM Government, Challenge it, Report it, Stop it: Delivering the Government's hate crime action plan (Home Office 2014) <https://www.gov.uk/government/uploads/system/uploads/attachment_data/file/307624/HateCrimeActionPlanProgressReport.pd f>

${ }^{94}$ Home Office, Action Against Hate: The UK Government's plan for tackling hate crime (2016) <https://www.gov.uk/government/uploads/system/uploads/attachment_data/file/543679/Action_Against_Hate_UK_Government_s_Plan_to_Tackle_Hate_Crime_2016.pdf>

${ }^{95}$ The Directive 2012/29/EU of the European Parliament and of the Council replaced the previous Council Framework Decision 2001/220/JHA.
} 
Article 22(3) goes on to state that particular attention should be paid to victims who "have suffered a crime committed with a bias or discriminatory motive, which could notably be related to their personal characteristics." It goes on to note that, in this regard, victims of hate crime "shall be duly considered."

In the context of criminal investigations, the "particular attention" to be paid to victims includes the following measures which the Directive states in Article 23(2) should be made available to victims:

(a) interviews with the victim should be carried out in premises designed or adapted for that purpose;

(b) interviews with the victim should be carried out by or through professionals trained for that purpose;

(c) all interviews with the victim should be conducted by the same persons unless this is contrary to the good administration of justice;

(d) all interviews with victims of sexual violence, gender-based violence or violence in close relationships, unless conducted by a prosecutor or a judge, being conducted by a person of the same sex as the victim, if the victim so wishes, provided that the course of the criminal proceedings will not be prejudiced.

In the context of court proceedings, the Directive goes on to provide in Article 23(3) that the following measures should be made available to victims:

(a) measures to avoid visual contact between victims and offenders including during the giving of evidence, by appropriate means including the use of communication technology;

(b) measures to ensure that the victim may be heard in the courtroom without being present, in particular through the use of appropriate communication technology;

(c) measures to avoid unnecessary questioning concerning the victim's private life not related to the criminal offence; and

(d) measures allowing a hearing to take place without the presence of the public.

In response to these new rules under the EU Victims' Rights Directive, the UK amended its Code of Practice for Victims of Crime (2015) to fulfil its EU obligations. The Code of Practice sets out enhanced entitlements for "victims of the most serious crime, persistently targeted victims and vulnerable or intimidated victims". ${ }^{96}$ Under this Code of Practice, a hate crime is considered a serious crime, and enhanced entitlements are available for victims who are deliberately targeted, or victims whose quality of evidence is likely to be diminished by

\footnotetext{
${ }^{96}$ Ministry of Justice, Code of Practice for Victims of Crime (Ministry of Justice 2015)

<https://www.gov.uk/government/uploads/system/uploads/attachment_data/file/476900/code-of-practice-for-victims-ofcrime.PDF>
} 
intimidation or their vulnerability due to a physical or mental disability. ${ }^{97}$ Vulnerable and intimidated witnesses giving evidence in court are entitled to ask the police or the Witness Care Unit for special measures. The CPS will make the decision to go ahead with any application for such measures, or the court of its own motion may raise the issue. The court will ultimately decide on the necessity of an order for special measures. ${ }^{98}$ Special measures can involve screens or curtains to shield a witness from the defendant while giving evidence; examination via a live-link; giving evidence in private; the removal of wigs and gowns by legal professionals; and video-recorded evidence-in-chief. ${ }^{99}$ In addition, special communication aids, such as alphabet boards, and Registered Intermediaries are also available to witnesses who are eligible for special measures on the basis of age or incapacity. ${ }^{100}$

\footnotetext{
${ }^{97}$ Ministry of Justice, Code of Practice for Victims of Crime (Ministry of Justice 2015)

<https://www.gov.uk/government/uploads/system/uploads/attachment_data/file/476900/code-of-practice-for-victims-ofcrime.PDF>

${ }_{98}$ The criteria for eligibility and granting a special measures direction are set out in ss. 16-22A of the Youth Justice and Criminal Evidence Act 1999. The use of special measures for hate crime are examined further in section 7.5.

${ }^{99}$ Youth Justice and Criminal Evidence Act 1999, ss. 23-28.

${ }^{100}$ Youth Justice and Criminal Evidence Act 1999, ss. 29-30.
} 


\section{Hate crime statistics}

In this section of the report, we will highlight some of the official and public hate crime statistics that further inform our study. The tables in this section include estimates for hate crime occurrences calculated by the Crime Survey for England and Wales (CSEW), policerecorded statistics and CPS-recorded data on hate crime cases. Comparisons across the datasets help us to illuminate a number of issues which should be of concern to the CJS. These issues include: the vast differences in percentages of strands of hate crime estimated by the CSEW compared with the numbers/percentages recorded by the police; and the number of hate crimes prosecuted compared with the number that result in conviction and a declared "uplift", thereby illustrating the percentage of cases where hate crime legislation is applied in practice.

We also include infographics which summarise some of these statistics and visualise what we term "the lifecycle of a hate crime". The lifecycle of a hate crime illustrates how many hate crimes are estimated to "drop out" of the criminal justice system. The number of cases that drop out of the system represent what is known as the "justice gap" for hate crime. The larger the justice gap, the greater the concern should be for criminal justice agencies tasked with enforcing hate crime laws.

\subsection{CRIME SURVEY FOR ENGLAND AND WALES (CSEW)}

The Crime Survey for England and Wales (CSEW) monitors the extent and nature of crime and is an important tool to uncover the "true" level of crime in England and Wales, as it captures crimes that are not reported to and not recorded by the police. ${ }^{101}$ The two tables below are based on 12-month averages of combined CSEW data for March 2014 to March 2016. There is an average estimated total of 204,000 hate crimes committed each year, of which $54 \%(110,160)$ were estimated to have come to the attention of the police. Table 2 displays the estimated numbers for hate crimes by monitored strand, showing that 104,000 hate crimes per year were based on the victim's race, 31,000 hate crimes per year were based on the victim's religion, 27,000 hate crimes per year were based on the victim's sexual orientation, and 67,000 hate crimes per year were based on the victim's disability. Due to low numbers, a yearly estimate for gender identity hate crime and the estimates for reporting gender identity and sexual orientation hate crime to police are not available at this point.

\footnotetext{
${ }^{101}$ Please refer to section 2.1 which addresses some of the limitations of the CSEW data. Kantar Public and Office for National Statistics, 'About the Crime Survey for England and Wales' (n.d.) <http://www.crimesurvey.co.uk/AboutTheSurvey.html>
} 
Table 2 CSEW-estimated 12-month averages of hate crime incidents monitored by strand (March 2014 to March 2016) ${ }^{102}$

\begin{tabular}{lll}
$\begin{array}{l}\text { Monitored hate } \\
\text { crime strand }\end{array}$ & $\begin{array}{l}\text { Estimated number of } \\
\text { incidents }\end{array}$ & $\begin{array}{l}\text { Percentage of incidents } \\
\text { reported to police }\end{array}$ \\
\hline Race & 104,000 & $58 \%$ \\
Religion & 31,000 & $43 \%$ \\
Sexual orientation & 27,000 & ${ }^{*}$ no estimates available \\
Disability & 67,000 & $52 \%$ \\
Gender identity & $*$ no estimates available & *no estimates available \\
All hate crime & 204,000 & $54 \%$
\end{tabular}

\footnotetext{
${ }^{102}$ Table adapted from Office for National Statistics, Number of incidents of hate crime, by strand of hate crime and percentage of those incidents reported to the police, Crime Survey for England and Wales, years ending March 2014 to March 2016, combined (12-month averages)

<https://www.ons.gov.uk/peoplepopulationandcommunity/crimeandjustice/adhocs/007533numberofincidentsofhatecrimebystran dofhatecrimeandpercentageofthoseincidentsreportedtothepolicecrimesurveyforenglandandwalesyearsendingmarch2014tomarch 2016combined12monthaverages>
} 
Table 3 below displays the percentages of incidents that respondents identified as hate crimes by type of offence. The CSEW data estimate that the majority of hate crime incidents were violence without injury $(29 \%)$ or with injury $(20 \%)$, followed by criminal damage $(17 \%)$.

Table 3 CSEW-estimated yearly hate crime incident percentage by type of offence (March 2014 - March 2016) $)^{103}$

Offence type

All personal crime

Violence without injury

Violence with injury

Robbery

Theft from person

Other theft of personal property

\section{All hate crime incidents}

$67 \%$

$29 \%$

$20 \%$

$5 \%$

$7 \%$

$5 \%$

\section{All household crime}

Criminal damage

Burglary

Vehicle-related theft

Bicycle theft

Other household theft

\subsection{POLICE DATA}

In $2015 / 16$, the police recorded 62,518 hate crimes, compared with 52,465 hate crimes the previous year (an increase of 19\%). ${ }^{104}$ The police use the "operational definition" (based on perception of hostility or prejudice, as explained at section 4.1 ) to record hate crimes, meaning that not all recorded "hate crimes" will necessarily meet the criteria for prosecution or conviction under specific hate crime legislation. Of the police recorded hate crimes in

\footnotetext{
${ }^{103}$ Table adapted from Office for National Statistics, Percentage of hate crime incidents, by type of offence, Crime Survey for England and Wales, year ending March 2014 to March 2016 combined. (The figures for each type of crime are rounded up or down, which is why the individual household crime figures appear to reach a total of $34 \%$ rather than $33 \%$ ).

<https://www.ons.gov.uk/peoplepopulationandcommunity/crimeandjustice/adhocs/007557percentageofhatecrimeincidentsbytyp eofoffencecrimesurveyforenglandandwalesyearendingmarch2014tomarch2016combined>

${ }^{104}$ Hannah Corcoran and Kevin Smith, Hate Crime, England and Wales, 2015/16 (Statistical Bulletin 11/16, Home Office 2016)

<https://www.gov.uk/government/uploads/system/uploads/attachment_data/file/559319/hate-crime-1516-hosb1116.pdf>
} 
$2015 / 16,79 \%$ were hate crimes based on race $(N=49,419), 12 \%$ were based on sexual orientation $(\mathrm{N}=7,194), 7 \%$ were based on religion $(\mathrm{N}=4,400), 6 \%$ were based on disability $(\mathrm{N}=3,629)$ and $1 \%$ were based on transgender identity $(\mathrm{N}=858) .{ }^{105}$ Although we are unable to draw exact comparisons between the CSEW data and the police recorded data, it is notable that there is a large dark figure of hate crimes that do not come to the attention of police. In addition, certain types of hate crime are disproportionately recorded by police, with many of the hate crimes that come to the attention of police being based on race $(79 \%)$, compared to the other hate crime strands $(21 \%)$. This disproportion either suggests a heightened awareness or easier identification by police of race-based hate crime compared with the other monitored hate crime strands. As we will go onto discuss, this significant disparity may also relate to the unequal protection of different strands under the current legislation, with police taking some hate crimes more seriously than others (see section 6.2 for a discussion on police failing to identify hostility early enough and section 11.1.2 for further discussion on "taking all hate crime seriously").

The table below displays a breakdown of selected hate crime offences by monitored strand recorded by police in England and Wales in 2015/16.

Table 4 Police recorded offence type by monitored hate crime strand $(2015 / 16)^{106}$

Monitored hate crime strand

\begin{tabular}{|c|c|c|c|c|c|c|}
\hline Offence type & Race & Religion & $\begin{array}{c}\text { Sexual } \\
\text { Orientation }\end{array}$ & Disability & $\begin{array}{l}\text { Transgender } \\
\text { Identity }\end{array}$ & $\begin{array}{l}\text { Total } \\
\text { hate } \\
\text { crime }\end{array}$ \\
\hline Public order offences & $59 \%$ & $50 \%$ & $46 \%$ & $31 \%$ & $47 \%$ & $55 \%$ \\
\hline $\begin{array}{l}\text { Violence against the } \\
\text { person with injury }\end{array}$ & $8 \%$ & $6 \%$ & $13 \%$ & $11 \%$ & $11 \%$ & $9 \%$ \\
\hline $\begin{array}{l}\text { Violence against the } \\
\text { person without injury }\end{array}$ & $23 \%$ & $27 \%$ & $30 \%$ & $32 \%$ & $31 \%$ & $25 \%$ \\
\hline $\begin{array}{l}\text { Criminal damage } \\
\text { and arson }\end{array}$ & $7 \%$ & $14 \%$ & $6 \%$ & $9 \%$ & $4 \%$ & $7 \%$ \\
\hline $\begin{array}{l}\text { Other notifiable } \\
\text { offences }\end{array}$ & $3 \%$ & $3 \%$ & $5 \%$ & $17 \%$ & $7 \%$ & $4 \%$ \\
\hline Total & $100 \%$ & $100 \%$ & $100 \%$ & $100 \%$ & $100 \%$ & $100 \%$ \\
\hline
\end{tabular}

\footnotetext{
${ }^{105}$ Hannah Corcoran and Kevin Smith, Hate Crime, England and Wales, 2015/16 (Statistical Bulletin 11/16, Home Office 2016) <https://www.gov.uk/government/uploads/system/uploads/attachment_data/file/559319/hate-crime-1516-hosb1116.pdf>

106 Table adapted from the underlying data tables of Hannah Corcoran and Kevin Smith, Hate Crime, England and Wales, 2015/16 (Statistical Bulletin 11/16, Home Office 2016)

<http://www.cps.gov.uk/data/hate_crime/hate_crime_2014_16_report.html>
} 
Table 4 shows that the most commonly recorded hate crimes are public order offences $(55 \%)$, followed by violence against the person without injury offences $(25 \%)$. The police record more violence against the person with injury offences for hate crimes based on sexual orientation (13\%) and transgender identity and disability (11\%), than for race $(8 \%)$ and religion $(6 \%)$. Recorded hate crimes involving criminal damage and arson offences are most often based on religion (14\%), followed by disability ( $9 \%$ ). The police recorded $17 \%$ of disability-related other notifiable offences, which include crimes, such as theft, burglary and sexual offences.

The data on the types of hate crime offence that are recorded across the five monitored strands of hate crime show that there are slightly different categories of offence being recorded at different rates. For example, there are lower rates of public order offences and higher rates of theft, burglary and sexual offences for disability hate crime cases compared with the other strands of hate crime. Similarly, criminal damage and arson is much higher for religion-based hate crime (14\%) compared with transgender hate crime $(4 \%)$. These data hint at a diverging picture of the types of hate crime that are likely to be experienced by different groups. It also shows that the CDA may not currently be codified in a way that would capture, sufficiently, most forms of hate crime were the Act to be extended to cover the other three strands of hate crime (i.e. sexual orientation, disability and transgender identity). We use these data to explore more fully the types of hate crimes experienced by certain groups (see 10.1 for further discussion of types of offences experienced by victims of disability hate crime) and outline what categories should be considered for inclusion under the CDA were the law to be extended (see 11.3 and 11.4 for Reform Options 1 and 2).

\subsection{CPS AND SENTENCING DATA}

The CPS provides information on its performance in prosecuting hate crime cases, again applying the broad "operational definition" of hate crime. In 2015/16 the CPS carried out 15,442 prosecutions of hate crime cases. Once prosecuted, cases receive a principal offence category, indicating the seriousness of the charge. Table 5 below displays the principal offence categories for hate crimes by race and religion, "homophobic" ${ }^{107}$ and "transphobic" hate crimes and disability hate crimes in 2015/16.

\footnotetext{
${ }^{107}$ We replicate CPS wording here. Note that homophobic hate crime refers to sexual orientation hate crime, which may include biphobic, and anti-lesbian crimes.
} 
Table 5 CPS principal offence categories by monitored hate crime strand $(2015 / 2016)^{108}$

\begin{tabular}{lccc} 
& \multicolumn{2}{c}{ Monitored hate crime strand } \\
\cline { 2 - 4 } & & $\begin{array}{c}\text { Homophobic } \\
\text { and }\end{array}$ & Disability \\
\hline Principal offence categories & Race and religion & Transphobic & $0.55 \%$ \\
\hline Homicide & $0.06 \%$ & $0.00 \%$ & $48.01 \%$ \\
Offences Against The Person & $76.45 \%$ & $59.23 \%$ & $3.64 \%$ \\
Sexual Offences & $0.25 \%$ & $1.34 \%$ & $8.72 \%$ \\
\hline Burglary & $0.34 \%$ & $0.28 \%$ & $6.73 \%$ \\
\hline Robbery & $0.58 \%$ & $1.13 \%$ & $12.14 \%$ \\
\hline Theft And Handling & $1.69 \%$ & $1.69 \%$ & $6.40 \%$ \\
\hline Fraud And Forgery & $0.08 \%$ & $0.07 \%$ & $2.87 \%$ \\
\hline Criminal Damage & $3.27 \%$ & $3.94 \%$ & $0.44 \%$ \\
\hline Drugs Offences & $0.60 \%$ & $1.20 \%$ & $9.27 \%$ \\
\hline Public Order Offences & $15.11 \%$ & $29.79 \%$ & \\
\hline
\end{tabular}

As table 5 shows, the majority of prosecuted hate crime offences across all strands included offences against the person (76.45\% race and religion, 59.23\% homophobic and transphobic, and $48.01 \%$ disability hate crimes). ${ }^{109}$ Homophobic and transphobic hate crimes $(29.79 \%)$ displayed higher percentages of public order offences, ${ }^{110}$ compared with race and religion $(15.11 \%)$ and disability hate crimes $(9.27 \%)$. Disability hate crime, however, contained a noticeably larger percentage of theft and handling $(12.14 \%)$, robbery $(6.73 \%)$, burglary $(8.72 \%)$, fraud and forgery $(6.40 \%)$, and sexual offences $(3.64 \%)$ compared to the other strands. Criminal damage percentages differed only slightly between the strands (3.27\% for race and religion, $3.94 \%$ for homophobic and transphobic and $2.87 \%$ for disability hate crime).

\footnotetext{
${ }^{108}$ Table adapted from the underlying data table 'Hate Crime by Principal Offence Category 2014-16' of the Crown Prosecution Service, 'Hate Crime Report 2014/2015 and 2015/16' (CPS 2016) <http://www.cps.gov.uk/data/hate_crime/hate_crime_2014_16_report.html>

${ }^{109}$ These include offences such as common assault, assault occasioning actual bodily harm, wounding and grievous bodily harm.

${ }^{110}$ Such as where someone has been threatened or abused in a public place which causes (or is likely to cause) harassment, alarm or distress.
} 
Comparing the police data with the CPS data ${ }^{111}$, it is notable that public order offences make up a lower percentage of prosecutions compared with the percentage of crimes of this type that are recorded by the police (e.g. $59 \%$ of race hate crimes recorded by the police are public order offences, while only $15.1 \%$ of prosecutions for race hate crime are of this type). There are a number of possible reasons for this, ranging from the broader victim-centred definition used by the police to record hate crimes, to the fact that "low-level" offences may be less likely to reach prosecution and are dealt with instead by way of out-of-court disposals. It is most likely, though, that public order offences do not provide the necessary evidence for prosecution (section 5.2), as in many such cases the accused is not apprehended due to the transient nature of such offences.

\subsubsection{Pre-charge decisions and prosecution outcomes}

The following account includes detailed information collected by the CPS on pre-charge decisions, prosecution outcomes, key reasons for unsuccessful prosecutions and key victims' issues of hate crimes based on race, religion, homophobic and transphobic, and disability hate crime in $2015 / 16 .{ }^{112}$ As above, the information is based on the "operational definition" of hate crime, and not the application of specific hate crime legislation. Crown Prosecutors decide whether or not to charge a person with a criminal offence (see table 6 on pre-charge decisions in 2015/16).

Table 6 Pre-charge decision by monitored hate crime strand (2015/2016) $)^{113}$

\section{Monitored hate crime strand}

\begin{tabular}{|c|c|c|c|c|c|c|c|c|}
\hline \multirow{2}{*}{$\begin{array}{l}\text { Pre-charge decisions } \\
\text { Charged }\end{array}$} & \multicolumn{2}{|c|}{ Race } & \multicolumn{2}{|c|}{ Religion } & \multicolumn{2}{|c|}{$\begin{array}{l}\text { Homophobic and } \\
\text { transphobic }\end{array}$} & \multicolumn{2}{|c|}{ Disability } \\
\hline & 8017 & $78.95 \%$ & 448 & $78.18 \%$ & 979 & $73.11 \%$ & 709 & $76.24 \%$ \\
\hline No Prosecution & 1261 & $12.42 \%$ & 80 & $13.96 \%$ & 232 & $17.33 \%$ & 152 & $16.34 \%$ \\
\hline Out of Court Disposal & 104 & $1.02 \%$ & 7 & $1.22 \%$ & 16 & $1.19 \%$ & 6 & $0.65 \%$ \\
\hline $\begin{array}{l}\text { Administratively } \\
\text { Finalised }\end{array}$ & 770 & $7.58 \%$ & 37 & $6.46 \%$ & 109 & $8.14 \%$ & 63 & $6.77 \%$ \\
\hline Other & 3 & $0.03 \%$ & 1 & $0.17 \%$ & 3 & $0.22 \%$ & 0 & $0 \%$ \\
\hline Total & 10155 & $100 \%$ & 573 & $100 \%$ & 1339 & $100 \%$ & 930 & $100 \%$ \\
\hline
\end{tabular}

\footnotetext{
${ }^{111}$ Note that these comparisons must be viewed in the context that the police use a broader definition of hate crime, than that which is contained in the CDA and CJA.

112 Information collated from the underlying data and tables of the following report: Crown Prosecution Service, 'Hate Crime Report 2014/2015 and 2015/16' (CPS 2016) <http://www.cps.gov.uk/data/hate_crime/hate_crime_2014_16_report.html> 113 Information collated from the underlying data and tables of the following report: Crown Prosecution Service, 'Hate Crime Report 2014/2015 and 2015/16' (CPS 2016) <http://www.cps.gov.uk/data/hate_crime/hate_crime_2014_16_report.html>
} 
Table 6 above displays the CPS pre-charge decisions of 2015/16 by monitored hate crime strand. ${ }^{114}$ In 2015/16, the CPS decided to bring proceedings against suspects in $73.11 \%$ of homophobic and transphobic hate crime cases, compared with $76.24 \%$ of disability hate crime, $78.18 \%$ of religious hate crime and $78.95 \%$ of race hate crime. $17.33 \%$ of homophobic and transphobic hate crime cases resulted in no prosecution, while the CPS decided not to prosecute for evidential or public interest reasons in $16.34 \%$ of disability, $13.96 \%$ of religious and $12.42 \%$ of race-based hate crime cases. These data suggest that fewer homophobic and transphobic hate crime cases are charged compared with the other monitored hate crime strands. It may be possible that victims of homophobic or transphobic hate crime withdraw support for the prosecution of hate crime out of fear for being "outed" in the process. This issue is further discussed in section 7.5.1 on special measures and the importance of implementing these appropriately. However, as we will go onto to discuss, such outcomes may also be the result of police investigators failing to collate adequate evidence of "hostility" (see section 6) due to the fact that these types of hate crimes do not require the CPS to prove hostility as part of the substantive offence (see 11.1.2).

${ }^{114}$ Data separating homophobic from transphobic hate crime were not publicly available at this point in time. 
Table 7 Prosecution outcomes by monitored hate crime strand $(2015 / 2016)^{115}$

Monitored hate crime strand

\begin{tabular}{|c|c|c|c|c|c|c|c|c|}
\hline \multirow{2}{*}{$\begin{array}{l}\text { Prosecution Outcomes } \\
\text { Unsuccessful Outcomes }\end{array}$} & \multicolumn{2}{|c|}{ Race } & \multicolumn{4}{|c|}{$\begin{array}{l}\text { Homophobic } \\
\text { and } \\
\text { transphobic }\end{array}$} & \multicolumn{2}{|c|}{ Disability } \\
\hline & 1958 & $15.93 \%$ & 154 & $20.90 \%$ & 250 & $17.02 \%$ & 234 & $24.87 \%$ \\
\hline Prosecutions Dropped ${ }^{116}$ & 1147 & $9.33 \%$ & 79 & $10.72 \%$ & 141 & $9.60 \%$ & 142 & $15.09 \%$ \\
\hline $\begin{array}{l}\text { Of which - no evidence } \\
\text { offered }\end{array}$ & 759 & $6.17 \%$ & 37 & $5.02 \%$ & 92 & $6.26 \%$ & 104 & $11.05 \%$ \\
\hline Dismissed after full trial & 406 & $3.30 \%$ & 31 & $4.21 \%$ & 66 & $4.49 \%$ & 43 & $4.57 \%$ \\
\hline Judge directed acquittal & 16 & $0.13 \%$ & 3 & $0.41 \%$ & 1 & $0.07 \%$ & 4 & $0.43 \%$ \\
\hline Jury acquittal & 132 & $1.07 \%$ & 22 & $2.99 \%$ & 19 & $1.29 \%$ & 30 & $3.19 \%$ \\
\hline $\begin{array}{l}\text { All other unsuccessful } \\
\text { outcomes }\end{array}$ & 257 & $2.09 \%$ & 19 & $2.58 \%$ & 23 & $1.57 \%$ & 15 & $1.59 \%$ \\
\hline Convictions & 10337 & $84.07 \%$ & 583 & $79.10 \%$ & 1219 & $82.98 \%$ & 707 & $75.13 \%$ \\
\hline Guilty plea & 9131 & $74.27 \%$ & 508 & $68.93 \%$ & 1085 & $73.86 \%$ & 597 & $63.44 \%$ \\
\hline Conviction after trial & 1155 & $9.39 \%$ & 73 & $9.91 \%$ & 130 & $8.85 \%$ & 109 & $11.58 \%$ \\
\hline Proved in absence & 51 & $0.41 \%$ & 2 & $0.27 \%$ & 4 & $0.27 \%$ & 1 & $0.11 \%$ \\
\hline Total Prosecutions & 12295 & $100 \%$ & 737 & $100 \%$ & 1469 & $100 \%$ & 941 & $100 \%$ \\
\hline
\end{tabular}

Table 7 above displays the prosecution outcomes for 2015/16 by monitored hate crime strand, showing details for unsuccessful outcomes and prosecutions that resulted in a conviction. Both disability hate crime $(75.13 \%)$ and religious hate crime $(79.10 \%)$ had fewer successful convictions, compared with homophobic and transphobic $(82.98 \%)$ and race hate crime (84.07\%). Compared with the other hate crime strands $(5.02 \%$ to $6.26 \%)$, disability hate crime had a larger proportion of prosecutions dropped for no evidence offered $(11.05 \%)$. Although disability hate crime cases had fewer convictions than the other strands and fewer guilty pleas overall, the percentage of cases where the defendant pleaded not guilty, but was convicted after trial, is slightly larger $(11.58 \%)$ than the percentages of other strands $(8.85 \%$ to $9.91 \%)$.

\footnotetext{
${ }^{115}$ Information collated from the underlying data and tables of the following report: Crown Prosecution Service, 'Hate Crime Report 2014/2015 and 2015/16' (CPS 2016) <http://www.cps.gov.uk/data/hate_crime/hate_crime_2014_16_report.html> ${ }_{116}$ Including discontinued, no evidence offered and withdrawn.

117 Includes administrative finalisation, discharged committals and no case to answer.
} 
The data suggest that many unsuccessful outcomes include prosecutions being dropped and that most of those (especially in disability hate crime cases) are dropped because of lack of evidence. Our study also addresses the practical issues involved with proving hostility in hate crime cases in section 6.1 and addresses issues with the prosecution of disability hate crime cases in detail in section 10.

Table 8 Key reasons for unsuccessful prosecution by monitored hate crime strand $(2015 / 2016)^{118}$

\section{Monitored hate crime strand}

\begin{tabular}{|c|c|c|c|c|c|c|c|c|}
\hline \multirow{3}{*}{$\begin{array}{l}\text { Key reasons for } \\
\text { unsuccessful prosecution }\end{array}$} & & & & & & & & \\
\hline & & ace & \multicolumn{4}{|c|}{$\begin{array}{c}\text { Homophobic } \\
\text { and } \\
\text { transphobic }\end{array}$} & \multicolumn{2}{|c|}{ Disability } \\
\hline & 638 & $32.58 \%$ & 36 & $23.38 \%$ & 71 & $28.40 \%$ & 59 & $25.21 \%$ \\
\hline Victim Retraction & 157 & $8.02 \%$ & 11 & $7.14 \%$ & 29 & $11.60 \%$ & 25 & $10.68 \%$ \\
\hline Victim Non-Attendance & 450 & $22.98 \%$ & 23 & $14.94 \%$ & 39 & $15.60 \%$ & 21 & $8.97 \%$ \\
\hline $\begin{array}{l}\text { Evidence of Victim does not } \\
\text { support case }\end{array}$ & 31 & $1.58 \%$ & 2 & $1.30 \%$ & 3 & $1.20 \%$ & 13 & $5.56 \%$ \\
\hline Conflict of Evidence & 112 & $5.72 \%$ & 11 & $7.14 \%$ & 13 & $5.20 \%$ & 33 & $14.10 \%$ \\
\hline $\begin{array}{l}\text { Essential Legal Element } \\
\text { Missing }\end{array}$ & 43 & $2.20 \%$ & 8 & $5.19 \%$ & 5 & $2.00 \%$ & 7 & $2.99 \%$ \\
\hline Other Indictment/ Sentence & 46 & $2.35 \%$ & 3 & $1.95 \%$ & 18 & $7.20 \%$ & 12 & $5.13 \%$ \\
\hline Acquittal after trial & 538 & $27.48 \%$ & 53 & $34.42 \%$ & 85 & $34.00 \%$ & 73 & $31.20 \%$ \\
\hline Total Key Reasons & 1,377 & $70.33 \%$ & 111 & $72.08 \%$ & 192 & $76.80 \%$ & 184 & $78.63 \%$ \\
\hline All Other Reasons & 364 & $18.59 \%$ & 29 & $18.83 \%$ & 39 & $15.60 \%$ & 44 & $18.80 \%$ \\
\hline Administrative finalisations & 217 & $11.08 \%$ & 14 & $9.09 \%$ & 19 & $7.60 \%$ & 6 & $2.56 \%$ \\
\hline Total & 1,958 & $100 \%$ & 154 & $100 \%$ & 250 & $100 \%$ & 234 & $100 \%$ \\
\hline
\end{tabular}

Table 8 above displays the main reasons for unsuccessful prosecutions by monitored strand in 2015/16. Key reasons included: victim issues (for instance, the victim refuses to be called as a witness, retracts or withdraws a complaint, or the evidence does not support the prosecution case); conflict of evidence issues; lacking an essential legal element; the

\footnotetext{
118 Information collated from the underlying data and tables of the following report: Crown Prosecution Service, 'Hate Crime Report 2014/2015 and 2015/16' (CPS 2016) <http://www.cps.gov.uk/data/hate_crime/hate_crime_2014_16_report.html>
} 
defendant being subject to other indictments or sentences; and an acquittal after trial. The key reason for an unsuccessful prosecution of race hate crime cases were victim issues (32.58\%), followed by an acquittal after trial $(27.48 \%)$ and a conflict of evidence $(5.72 \%)$. Key reasons for hate crime cases based on religion included acquittal after trial (34.42\%), followed by victim issues (23.38\%), conflict of evidence $(7.14 \%)$, and missing an essential legal element (5.19\%). An acquittal after trial was the key reason for unsuccessful prosecutions of homophobic and transphobic hate crime cases $(34.00 \%)$ as well as of disability hate crime cases $(31.20 \%)$, followed by victim issues $(28.40 \%$ in homophobic/transphobic and $25.21 \%$ in disability hate crimes) and contradictions in prosecution evidence $(5.20 \%$ in homophobic/transphobic and $14.10 \%$ in disability hate crimes). Conflict of evidence issues were especially high in disability hate crime cases, compared to the other monitored hate crimes strands.

The data above suggest that many cases "drop out" of the system because of victim issues, which we explore further in section 7.5 in relation to the importance of special measures and support for victims and witnesses. We further address the evidential issues that may lead to cases dropping out in section 6 where we focus especially on issues in disability hate crime cases (see also section 10).

\subsubsection{Sentencing outcomes}

Table 9 provides an overview of the proportions of successfully completed prosecutions, where a sentence uplift pursuant to ss. 145 or 146 was both announced and recorded, compared with the proportion of cases where the CJA was not successfully applied.

Table 9 Percentage of sentence uplift announced and recorded in court by monitored strand $(2015 / 16)^{119}$

\section{Monitored hate crime strand}

\begin{tabular}{lcccccc}
$\begin{array}{l}\text { Announced } \\
\text { and recorded } \\
\text { sentence uplift }\end{array}$ & Race & Religion & $\begin{array}{c}\text { Sexual } \\
\text { orientation }\end{array}$ & $\begin{array}{c}\text { Transgender } \\
\text { Identity }\end{array}$ & Disability & $\begin{array}{c}\text { All } \\
\text { strands }\end{array}$ \\
\hline Yes & $35.0 \%$ & $31.9 \%$ & $38.0 \%$ & $35.3 \%$ & $11.9 \%$ & $33.8 \%$ \\
No & $65.0 \%$ & $68.1 \%$ & $62.0 \%$ & $64.7 \%$ & $88.1 \%$ & $66.2 \%$ \\
Total & $100 \%$ & $100 \%$ & $100 \%$ & $100 \%$ & $100 \%$ & $100 \%$ \\
\hline
\end{tabular}

Although these percentages have improved from 2014/15 to 2015/16 for all strands, uplifts seem to be applied for $31.9 \%$ to $38.0 \%$ of successful convictions for race, religion, sexual orientation and transgender identity, compared with only $11.9 \%$ of hate crime cases involving

\footnotetext{
${ }^{119}$ Data collated from Crown Prosecution Service, 'Hate Crime Report 2014/2015 and 2015/16' (CPS 2016) <http://www.cps.gov.uk/publications/docs/cps_hate_crime_report_2016.pdf>
} 
the disability of a victim. As the announcement and application of sentence uplift is "a clear indicator of the law being applied to best effect", ${ }^{120}$ there is reason to believe that there is an additional limitation to applying the legislation in disability hate crime cases. In our study, we also address the issue of lack of awareness and reluctance to apply sentencing provisions in hate crime cases (see section 9.7).

Table 10 below displays the average custodial sentencing length (in months) for RRAOs, compared with non-aggravated corresponding offences in all courts in 2012, which are the most recent publicly available data. Racially and religiously aggravated assault with injury offences, for example, received on average custody sentence lengths of 16.7 months, compared with 15.5 months for the non-aggravated corresponding offence. The average custodial sentencing length for criminal damage was 5.2 months for the RRAO, while the non-aggravated corresponding offence received average sentences of 3.9 months.

Table 10 Average custody sentence length by offence type, comparing RRAOs to nonRRAOs (2012) ${ }^{121}$

\section{Average custodial sentence length (months)}

\begin{tabular}{lcc}
\hline Offence type & Racially or religiously aggravated & Non-aggravated \\
\hline Assault with injury & 16.7 & 15.5 \\
Assault without injury & 4.9 & 3.1 \\
Harassment & 4.9 & 4.8 \\
Criminal damage & 5.2 & 3.9 \\
$\begin{array}{l}\text { Causing public fear, alarm or } \\
\text { distress }\end{array}$ & 3.6 & 2.4 \\
\hline
\end{tabular}

The data in table 10 suggest that RRAOs received higher average custodial sentence lengths compared with non-RRAOs in 2012; however, no official data are available on sentencing provision outcomes by offence type. According to the CPS, there has been an increase in hate crime prosecutions in 2015/16, with the largest number of completed prosecutions to date $(\mathrm{N}=15,442)$, a slight increase in conviction rates from the previous year (82.9\% in $2014 / 15$ to $83.2 \%$ in $2015 / 16$ ), and an increase in the application of sentencing uplifts from $11.8 \%$ the previous year to $33.8 \%$ in $2015 / 16 .{ }^{122}$ Nevertheless, many hate crime cases reported to the police will drop out of the CJS at various stages of the criminal

\footnotetext{
${ }^{120}$ Crown Prosecution Service, 'Hate Crime Report 2014/2015 and 2015/16' (CPS 2016) 14 $<$ http://www.cps.gov.uk/publications/docs/cps_hate_crime_report_2016.pdf>

${ }^{121}$ Data collated from Table 3.13 of the following source: Home Office, Ministry of Justice and Office for National Statistics, 'An overview of hate crime in England and Wales' (2013) <https://www.gov.uk/government/statistics/an-overview-of-hate-crime-inengland-and-wales>

122 Crown Prosecution Service 'Hate Crime Report 2014/2015 and 2015/16' (CPS 2016)

<http://www.cps.gov.uk/publications/docs/cps_hate_crime_report_2016.pdf>
} 
process. The infographics in the next section display the "lifecycle of a hate crime" - overall as well as per strand of hate crime - throughout the CJS in 2015/16. ${ }^{123}$

\subsection{CONCLUSIONS}

England and Wales now has one of the most comprehensive data collection and monitoring systems for hate crime in the world. ${ }^{124}$ While there will be a number of limitations in the collection of each dataset, much can be gleaned from the statistics, both in terms of identifying patterns of hate crime and how the law is being applied in practice. A number of themes and issues have emerged throughout our exploration of the hate crime statistics above. Whilst keeping in mind that the different datasets are not directly comparable, we are still able to see a general picture of how many hate crimes are committed each year, through to how many offences result in conviction and uplift in sentence. The issues can be summarised as follows:

- The disparity between the numbers of CSEW-estimated hate crimes and police recorded hate crimes suggests that a high percentage of incidents go unreported.

- The disparity between CSEW-estimated reporting of hate crime and the police recording of hate crime points to a possible under-recording of hate crimes by the police.

- Certain types of hate crime are disproportionately recorded by police, with more police records for race hate crimes.

- Different strands of hate crime experience different types (categories) of offence.

- More violence against the person with injury offences were recorded by police for hate crimes based on sexual orientation, followed by transgender identity and disability.

- The percentages of public order offences in the police data are much higher than the percentages of these types of offence prosecuted by the CPS.

- Fewer homophobic and transphobic hate crimes reported to the police result in a charge compared with the other monitored hate crime strands.

- Many unsuccessful outcomes in hate crime cases are due to prosecutions being dropped (e.g., discontinued, no evidence offered or withdrawn) and most of those (especially in disability hate crime cases) are dropped because of lack of evidence.

- The key reasons for an unsuccessful prosecution outcome include victim issues (e.g., the victim refuses to be called as a witness, retracts or withdraws a complaint, or the evidence does not support the prosecution case), and conflict of evidence issues

\footnotetext{
123 Data collated from the following sources and underlying data tables: The numbers displaying hate crime offences per year $\left.{ }^{*}\right)$ are the most recent yearly hate crime incident estimates by the Crime Survey for England and Wales, which were included in Corcoran, Lader and Smith's 2015 report: Hannah Corcoran, Deborah Lader and Kevin Smith, Hate Crime, England and Wales, 2014/15 (Statistical Bulletin 05/15, Home Office 2015)

< https://www.gov.uk/government/statistics/hate-crime-england-and-wales-2014-to-2015>

<https://www.gov.uk/government/uploads/system/uploads/attachment_data/file/467366/hosb0515.pdf>; other data included information and statistics Hannah Corcoran and Kevin Smith, Hate Crime, England and Wales, $2015 / 16$ (Statistical Bulletin 11/16, Home Office 2016) <https://www.gov.uk/government/uploads/system/uploads/attachment_data/file/559319/hate-crime1516-hosb1116.pdf>; and Crown Prosecution Service 'Hate Crime Report 2014/2015 and 2015/16' (CPS 2016) <http://www.cps.gov.uk/publications/docs/cps hate crime report 2016.pdf>

124 See for comparisons via the OSCE website: <http://hatecrime.osce.org/>
} 
were especially high in disability hate crime cases, compared to the other monitored hate crimes strands.

- Although percentages have improved in recording and announcing uplifts in court, sentence uplifts were only applied in $33.8 \%$ of successful hate crime convictions, while there seems to be a further limitation to applying the legislation in disability hate crime cases (where just $11.9 \%$ of convictions included a declared uplift).

These issues, and various others, form the basis for our analysis in the following two parts. Before this, we illustrate the hate crime statistics outlined in the infographics below.

\subsection{THE LIFECYCLE OF A HATE CRIME}

Attrition in hate crime cases refers to the gradual reduction of hate crime cases as these are dealt with by different actors throughout the criminal justice system. This process starts with the number of hate crimes committed and reported to the authorities, and ends with the number of the successful applications of hate crime legislation. According to Burney and Rose, '[a]ttrition' is a common feature within the criminal justice process, as potential offences, charges and convictions make their way through the system's many 'gateways'”. ${ }^{125}$

Analysis of the most recent CSEW data showed that there were approximately 204,000 hate crimes per year (estimated by combined years March 2014 to year ending March 2016). ${ }^{126}$ Further analysis of data also found that $54 \%$ of respondents stated that the incident was reported to (or came to the attention of) the police. ${ }^{127}$ This suggests that approximately 110,160 hate crimes are reported to the police each year. The most recent police statistics recorded 62,518 hate crimes between $2015 / 16$. If approximately 110,160 hate crimes are reported each year (based on this general time period), then comparing CSEW data with the police data suggests that only $57 \%$ of reported incidents are recorded as hate crimes.

Out of the number of hate crimes recorded by the police, the CPS went on to prosecute 15,442 cases, of which 12,846 resulted in a conviction. ${ }^{128}$ These numbers suggest that the CPS was unsuccessful in obtaining a conviction in $17 \%$ of the cases brought to court. Finally, the CPS recorded the announcement of sentencing uplifts in court as $33.8 \%$ of total hate crime convictions, which equates to 4,342 cases. Taking the data altogether, we can see that out of an approximate 110,160 reported hate crimes each year, just 4,342 offences (4\%) resulted in conviction and a declared sentence uplift based on identity-based hostility. It is this number that represents the "justice gap" for hate crime.

\footnotetext{
${ }^{125}$ Elizabeth Burney and Gerry Rose, Racist Offences: How is the Law Working? (Home Office Research Study 244, 2002 ) 25.

${ }^{126}$ This represents an $8 \%$ decrease on previous figures, Hannah Corcoran and Kevin Smith, Hate Crime, England and Wales, 2015/16 (Statistical Bulletin 11/16, Home Office 2016)

<https://www.gov.uk/government/uploads/system/uploads/attachment_data/file/559319/hate-crime-1516-hosb1116.pdf>

${ }^{127}$ This represents a $6 \%$ increase in the number of respondents that stated they reported the incident to the police, Hannah Corcoran and Kevin Smith, Hate Crime, England and Wales, 2015/16 (Statistical Bulletin 11/16, Home Office 2016)

<https://www.gov.uk/government/uploads/system/uploads/attachment_data/file/559319/hate-crime-1516-hosb1116.pdf>

${ }^{128}$ Note that CPS data may not match precisely with police data time periods as some recorded hate crimes may take many

months before the case comes to court.
} 


\section{The Lifecycle of a Hate Crime}

\section{$2015-2016$}

\section{4,000 total hate crimes}

110,160

reported

62.518

recorded by police

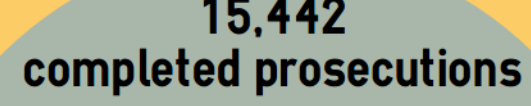

\subsection{6}

convictions

4,342 cases

with uplifts

We reiterate that this percentage does not represent the "conviction rate" for hate crime, but rather it is an estimate of how many hate crimes may be "dropping out" out the system. This number does not tell us the reasons why cases drop out. There are likely to be a myriad of explanations for the justice gap, including: issues relating to the way in which incidents are reported to the police; the quality of evidence available to officers; recording practices and investigation procedures; the systems used to determine charge and decision to prosecute; factors affecting jury decision making; sentencing practices; and finally, the recording 
mechanisms used post-sentence. ${ }^{129}$ These are issues which we go on to explore in the next two parts of this report.

The following infographics display a visual of the lifecycle of a hate crime based on race or ethnicity, religion or beliefs, sexual orientation, transgender identity, and disability.

The CSEW data estimate 104,000 hate crimes are committed each year targeting the race or ethnicity of a victim. The police recorded 49,419 hate crimes based on a victim's race or ethnicity in 2015/16. The CPS prosecuted 12,295 hate crime cases related to race or ethnicity in the same year. This resulted in 10,337 (84\%) successful convictions. The prosecution of $16 \%$ of hate crime cases based on race was therefore unsuccessful.

\title{
The Lifecycle of a Race/Ethnicity Hate Crime

\author{
$2015-2016$
}

\author{
104.000 \\ race/ethnicity hate crimes \\ 60.320 \\ reported \\ 49.419 \\ recorded by police
}

12,295

completed prosecutions

\section{0,337 convictions}

\section{3,618 cases}

with uplifts

\footnotetext{
${ }^{129}$ One reason noted in Burney and Rose's study was explained by a police sergeant who stated that the drop out between the number of hate crimes that are recorded by police and the subsequent prosecutions are a result of police applying a lower standard of evidence to justify arrests, compared with the evidence necessary for a charge. Elizabeth Burney and Gerry Rose, Racist Offences: How is the Law Working? (Home Office Research Study 244, 2002) 53.
} 
According to CPS data, in $35 \%$ of race-related hate crime cases sentencing uplifts were announced and recorded in court, an estimated 3,618.

In 2015/16, the police recorded 4,400 hate crimes that targeted victims for their religion or beliefs, The CSEW data estimate 31,000 religion-related hate crimes per year. The CPS indicated having prosecuted 737 cases in the same year, of which $583(79 \%)$ resulted in a conviction. The prosecution of around $21 \%$ of hate crime cases based on religion or beliefs was unsuccessful. The CPS recorded $31.9 \%$, an estimated 186 cases, where a sentencing uplift was announced and recorded in court.

\section{The Lifecycle of a Religion/Beliefs Hate Crime \\ $2015-2016$}

\section{1,000 \\ religion/beliefs hate crimes}

13.330

reported

\section{4,400}

recorded by police

737

completed prosecutions

583

convictions

186 cases

with uplifts 
The CSEW estimates around 27,000 sexual orientation hate crimes per year. The police recorded a total of 7,194 hate crimes based on sexual orientation in 2015/16. CPS statistics indicate that 1,384 cases were prosecuted and 1,151 convictions obtained. $17 \%$ of prosecuted cases were unsuccessful. The CPS recorded that sentencing uplifts were announced in $38 \%$ of cases, estimating to about 437 cases.

\section{The Lifecycle of a Sexual Orientation Hate Crime \\ $2015-2016$}

\section{7,000 \\ sexual orientation hate crimes}

*no estimates available*

\subsection{4}

recorded by police

\section{1,384}

completed prosecutions

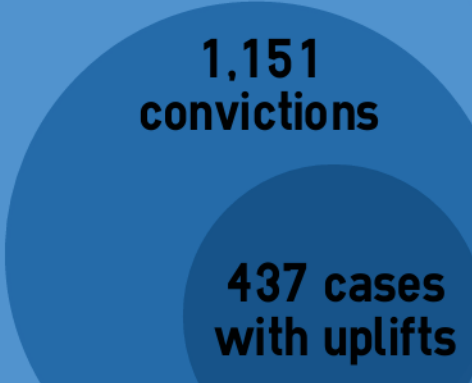


The CSEW estimates an average of 67,000 cases of disability hate crime per year, which is a larger than the estimates for religion- and sexual orientation-based hate crime. In 2015/16, the police recorded 3,629 disability hate crimes. The CPS prosecuted 941 cases, of which $707(75 \%)$ resulted in a successful conviction. Sentencing uplifts were announced and recorded in $11.9 \%$ of disability hate crime cases, estimated at approximately 84 cases, which suggests an additional limitation to the application of hate crime legislation in disability hate crime cases (further addressed in section 10).

\section{The Lifecycle of a Disability Hate Crime $2015-2016$}

\section{7,000 \\ disability hate crimes}

34,840

reported

3,629

recorded by police

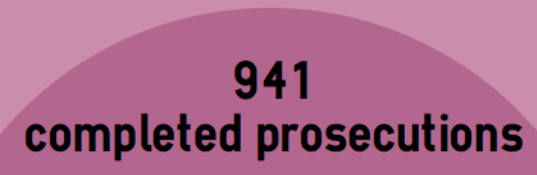

707 convictions

84 cases

with uplifts 


\section{The Lifecycle of a Transgender Identity Hate Crime \\ $2015-2016$}

\section{*no estimates available* \\ transgender identity hate crimes}

*no estimates available*

858

recorded by police
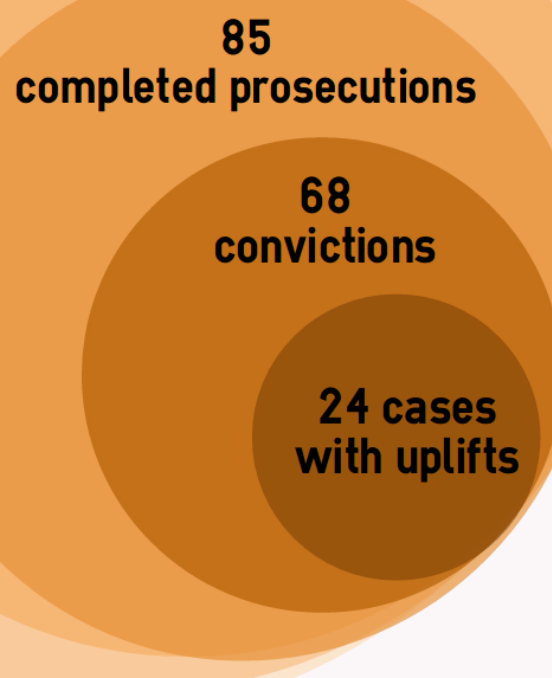

No yearly CSEW-estimates are available for transgender identity hate crimes at this point; however, in 2015/16, 858 hate crimes targeting transgender people were recorded by police. ${ }^{130}$ The CPS prosecuted 85 cases in the same year, with $68(80 \%)$ successful convictions. CPS data indicate that sentencing uplifts were announced and recorded in $35.3 \%$ of transgender identity hate crime cases, estimated at 24 cases that received a sentence uplift.

\footnotetext{
${ }^{130}$ A recent study found that found that 29 per cent of Trans respondents had experienced a physical assault motivated by antiLGBT hostility over the previous 3 years; this was more than twice the rate reported by LGB respondents (12 per cent). Mark A Walters, Jennifer Paterson, Rupert Brown and Liz McDonnell, 'Hate crimes against trans people: assessing emotions, behaviors and attitudes towards criminal justice agencies' (2017) Journal of Interpersonal Violence DOI: <https://doi.org/10.1177/0886260517715026>
} 
HATE CRIME AND THE LEGAL PROCESS - FINAL REPORT

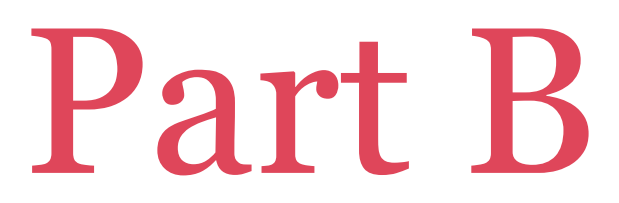

Analysis and research findings 


\section{Part B: Analysis and research findings}

There is now a comprehensive legislative and policy framework for hate crime in England and Wales. The impressive body of documentation for hate crime is unlikely to be rivalled anywhere else in the world. ${ }^{131}$ However, the extensive policy and legislative domain for hate crime does not automatically equate to an effective application of these policies and laws. This study seeks to provide new information on how the law on the books is being applied in practice. It follows on from two other important reports on hate crime law. The first, a Home Office study published in 2002 by Burney and Rose, found that racially aggravated offences charged under the CDA (RAOs) only rarely appeared in courts, and that the majority of cases included public order and minor violence offences. ${ }^{132}$ Further, the study found that RAO charges were frequently contested (with offenders fearing the racist label and enhanced penalty), and were twice as likely to be committed to trial at the Crown Court compared to triable either-way basic offences. Magistrates and judges pointed to particular problems with the legislation, which included:

- The often marginal nature of the racist element in many cases;

- The inability to take racist evidence into account when potential RAOs were prosecuted in the basic form; and

- The reduction of charges to the basic form just before a trial. ${ }^{133}$

Over a decade later, a detailed 2014 Law Commission report points to continuing concerns relating to the application of law (including a lack of application of the sentencing provisions under s. 146 of the CJA), confusion in interpreting the CDA (e.g. conflation between motivation and demonstration of hostility), ${ }^{134}$ and a failure to properly record and flag offences aggravated by sexual orientation, disability or transgender hostility.

Building upon these previous reports, this study examines the central (thematic) issues that were identified as being key to the successful application of hate crime laws in England and Wales by those individuals who use them most. We start this endeavour by examining the main processes involved in investigating and collating evidence for presentation in court, highlighting the need for good police-CPS relations and the importance of police identifying evidence of hostility early in the CJS process (section 6). In section 7, we move on to explore a number of problems with procedure that can arise during the prosecution of RRAOs, including the use of alternative charges and verdicts, and the potential for double convictions and charge bargaining. Section 7 also details the issues that occur during different modes of trial; whether some hate crimes are "over-charged"; and the use of special measures for complainants and witnesses. Section 8 then explores how the legislation is interpreted in the

\footnotetext{
${ }^{131}$ See e.g. Organization for Security and Co-operation in Europe, Hate Crimes in the OSCE Region - Incidents and Responses: Annual Report for 2012 (OSCE 2013)

<http://tandis.odihr.pl/hcr2012/pdf/Hate_Crime_Report_full_version.pdf>

${ }^{132}$ Elizabeth Burney and Gerry Rose, Racist Offences: How is the Law Working? (Home Office Research Study 244, 2002).

${ }^{133}$ Elizabeth Burney and Gerry Rose, Racist Offences: How is the Law Working? (Home Office Research Study 244, 2002).

134 See for example, SH [2010] EWCA Crim 1931, [2011] 1 Cr App R 14. See also Mark A Walters, 'Conceptualizing "hostility" for hate crime law: minding “the minutiae” when interpreting section 28(1)(a) of the Crime and Disorder Act 1998' (2014) 34(1) OJLS 47.
} 
courtroom, focusing in particular on the interpretation of "hostility" and the confusion that this can sometimes give rise to. In section 9, we address sentencing approaches in hate crime cases, including the methods used by judges to calculate "uplift" for hostility. Finally, in section 10 , we explore (separately) the barriers to successfully prosecuting disability hate crime cases, noting in particular the persistent "push back" amongst some judges to accept targeted abuse against disabled people as evidence of hostility. Where appropriate, recommendations are provided to improve current practice. More substantial options for law reform are set out in Part C. 


\section{Practical issues in implementing hate crime legislation}

After a hate crime offence is reported to police, an officer should apply a hate crime flag to the online case file, which should then trigger a hate crime investigation. The police have specific guidance (described in section 4.1), which details the definition of a hate crime and when incidents should be recorded by the police. College of Policing guidance provides further strategies on improving the investigation and prosecution of hate crimes and creating a better understanding of the nature and extent of these offences. Police officers are key actors in collating evidence and preparing cases for prosecution. We summarise the main types of evidence used to prove identity-based hostility and also point to a number of implications with the practical implementation of hate crime legislation below.

\subsection{PREPARING CASES FOR PROSECUTION: COLLATING EVIDENCE TO PROVE HOSTILITY}

We asked all interviewees what were the most common types of evidence they had come across to prove hostility in court, as well as asking them what common evidential factors they felt had increased or decreased the likelihood of a successful prosecution. We also examined over 100 reported cases to explore the types of evidence that are most commonly used to prove hate crimes. This analysis revealed that, in almost every case, hostility (whether motivated or demonstrated), was evidenced at trial by prejudiced language. This was nearly always as part of an aggressive verbal statement expressed by the defendant. Participants across interviewee cohorts concurred with this finding, often stating that the most cogent form of evidence to prove their case was witness testimony of verbalised hostility expressed during the commission of an offence:

"Well it's invariably what they say ... I've never done a case where it's been based on anything else. I've never done a case, for instance, where there's been an attack and somebody's gone back to the person's house and found hate material and therefore made the assumption or made the association that the attack was as a result of that. It's always inevitably as a result of the words used at or about the time of the incident. So it's witness evidence either in the form of what the complainant says ... Or ... in the form of what the complainant says or what the witnesses hear or what somebody videos. That being by far, as we all know, the most common thing now ..." (Interview Crown Court Judge 04) 
Another CPS lawyer explained:

"For most of the offences, certainly with race and religion, homophobia, transphobia and disability, the first level of evidence you often get is the defendant will normally say something. When he commits either the offence it's the words itself, or he'll say something on top of what he's doing ..." (Interview CPS 03)

This does not mean that verbal hostility is the only evidence that can prove the hostility element of a hate crime, whether prosecuted as a RRAO or considered at sentencing. As Baroness Hale stated in Rogers, "[t]he [aggravated] offences do not require particular words to be used: the necessary hostility could be demonstrated in other ways, such as wearing swastikas or singing certain songs." ${ }^{135}$ Indeed, actions can often speak louder than words. In the case of Graham, the appellants had ripped out the victim's (a Rastafarian) dreadlock and brandished this as a trophy. The trial judge stated:

"The [additional] racial element ... is what you did with his dreadlocks afterwards. It was like tearing the turban from a Sikh or a crucifix from a Christian. That is the severe element in this case and something that I take on board very strongly." 136

Whether by words or actions, evidence of hostility is most often presented at court through the testimony of witnesses. A complaint supported by independent eyewitnesses was described as making a case "pretty straightforward" (Interview Independent Barrister 15). Other legal practitioners noted:

"Well, it varies. If it's a guilty plea for example, then the evidence would be effectively what the prosecution outline on the basis of the witness's statements to the police. If it's a trial, then it would be what the witness themselves says in the witness box." (Interview District Judge 07)

"Well, the common element is obviously witness statements taken from those [who] were present at the alleged racially aggravated matters, so commonly it's the complainant or the arresting officers who are dealing with a defendant ... either as part of the main incident or during the arrest process. And it's during that process that something may be said which may come under the relevant legislation." (Interview Independent Barrister 03)

Four police officers indicated that convictions are more difficult to secure in "one-on-one" cases, where one word stands against the other. Four CPS prosecutors, eight barristers, three Crown Court judges and two District Judges noted that multiple eyewitness testimony and especially independent witnesses are an important factor in securing a conviction in hate crime cases:

\footnotetext{
${ }^{135}$ [2007] UKHL 8 [13].

${ }^{136}$ [2004] EWCA Crim 2762 [11]. Note the two assailants appealed, arguing that the attack was not racially motivated. Fulford J for the appeal panel seems to have relied on verbal abuse as evidence, rather than this behaviour. He did not disagree with the trial judge, but stated: "the proper basis of sentence was that, whilst Mr Senior was being dragged along the floor and one of his dreadlocks was being pulled out, one of the group said, 'Get the fucking nigger' and, 'Get the wog'."
} 
"The stronger the evidence is, the more likely there'll be a conviction ... So if the incident is witnessed by a number of people, none of whom know the complainant, and they all hear what the defendant said, then it is more likely they'll secure a conviction. And that's true of any crime." (Interview Independent Barrister 15)

"Obviously the more independent witnesses you have the better. And generally speaking the longer the incident in which the alleged language or actions have taken place, the higher your chances of getting a conviction. Perfectly sensibly, because the more you say something, the longer your aggression lasts, the less likely it is that you're acting merely in temper rather than some rather more powerful and rather less explicable motivation." (Interview Crown Court Judge 03)

There are, however, some problems associated with gathering witness statements necessary in hate crime cases. Several interviewees identified the need for improved questioning during the interview, especially when gathering evidence of motivation of hostility, which was only very rarely presented to the CPS. One CPS lawyer noted that, "if you haven't had a demonstration of hostility at the time of the commission of the offence, then the interview can be the critical point in trying to delve into the motivation a person might have" (Interview CPS 21). This was especially important for disability hate crime cases, where verbal slurs used against victims are less common (see further section 10.1). Although the failure to gather evidence of motivation was seen as a frustration for some CPS interviewees, others acknowledged that while "'motivation' is a bit more difficult to find ... the police are being really encouraged in interviews to deal with motivation, to get as much information from the defendant or the suspect so that we can use that to put together [the case]" (Interview CPS 02). (We return to the issue of demonstrations and motivations of hostility in section 8.1 ).

Next to witness statements, there are a number of additional ways in which hate crimes can be proved in court, including securing audio and video recording of the incident, with multiple interviewee cohorts explaining that such recordings are helpful to secure a conviction. This may include CCTV, body-worn cameras, mobile phone footage, or 999 calls:

"Well any re-playable evidence is always effective. So body-worn video footage or CCTV, or as in my recent case, the 999 call. If there wasn't that 999 call, I'm pretty confident that we would have been acquitted." (Interview Independent Barrister 02)

"Usually if it's a public order or a violence case, if you can catch it on CCTV, you can secure your conviction. Because there's no way out." (Interview Independent Barrister 15)

Five District Judges and one Crown Court judge, however, pointed out that CCTV footage has its limitations, as it often only provides video footage and rarely picks up audio:

"CCTV isn't necessarily very helpful because on many occasions the CCTV doesn't have any audio - it's simply visual. So you can't hear what's being said at the time of an incident. And so it's very dependent on what the witness actually says." (Interview District Judge 07) 
In addition, getting the footage to court can sometimes prove problematic, with one District Judge pointing out:

"[We] still have problems with the fact that the evidence is out there on CCTV or body worn video and we still can't get it into the court room because the administration between the police and the prosecution just sometimes cannot do what seems to be very simple, which is to get piece of evidence from point A to point B. That's not rocket science and we still fail." (Interview District Judge 03)

While these forms of evidence were capable of proving identity-based hostilities, it was emphasised that, without a sound recording of verbal slurs, proving a demonstration of hostility beyond reasonable doubt could via video footage was extraordinarily difficult. This was most apparent in relation to disability hate crime cases.

Five CPS prosecutors, one barrister and three District Judges also noted that the defendant's prior record and bad character can be an important factor in cases where the offender was motivated by hostility:

"[W]hen you look at a record, you know if that person is prone to behaving in a certain way, so you can field this as someone that targets people who are vulnerable, people with disabilities for example; or this is a person who's got issues with transgender people or gay people ... Just like you can see on a record that this is someone who's racist. And it's very helpful for the Crown when we have things like bail applications where we want to apply for a criminal behaviour order, it's helpful to pick up a record of previous convictions and know exactly what kind of an offender you're dealing with." (Interview CPS 12)

"Bad character - that can be helpful if they've got previous convictions. Then it shows a propensity towards this type of thinking and behaviour, particularly if we're looking for motivation; how we can see that they are a person who has used that type of language before, has demonstrated hostility with that group before, then yes ... we're looking at previous convictions of bad character - that arises quite often as well." (Interview CPS 16)

Accessing this information is, however, problematic, as the hostility element will not be noted on a perpetrator's record where the offence is aggravated by sexual orientation, disability or transgender identity hostility (under CJA provisions) (further discussed in section 11.1.4):

"And it would also make it easier to recognise ... At the moment you wouldn't, for example, necessarily see an uplift on sentence recorded on somebody's PNC record ... so when they come before the court for further offences you wouldn't necessarily know that the burglary, the theft, the assault that's on their record was an offence that was dealt with by the court that received an aggravated or an increased and uplifted sentence. If they had committed an offence under the Crime and Disorder Act, then very clearly it's on the record that that's what it is. So from a practical point of view, things like that make a difference to how they're dealt with in the future ... If they commit further offences then it's clear ... that they've got a previous history of it”. (Interview CPS 15) 
Other ways of collating sufficient evidence to prove the hostility element of hate crimes included the identification of painted signs, leaflets, letters, and other written documentation, some of which can be helpful in proving an affiliation with right-wing hate groups:

"But also then the documents that were sent were adorned with pictures of the intended explosive devices - the incendiary devices - and also with symbols such as White Power ... And there was another right wing organisation, which I'm afraid I can't remember the name of it, but they'd effectively drawn that logo, and there were some swastikas and that sort of thing. So the racial motive was very clear." (Interview Independent Barrister 07)

CPS prosecutors and independent barristers also mentioned social media and websites with links to racist organisations as powerful evidence to prove the hostility element of the offence and the motivation of the defendant:

"[B]ut he'd made the mistake and the police had got screen shots of him posting, you know, about the EDL on Facebook ... so we knew that was obviously ... He'd taken a photograph of it and posted it with those comments, so he couldn't argue ostensibly that he didn't know about it." (Interview CPS 14)

"And we also in that case used evidence from websites that were run by the one of the defendants, which included the Combat 18 website, and also various Death or Glory, various white supremacist websites, that he was responsible for in the UK." (Interview Independent Barrister 07)

Another three barristers referred to text messages as important pieces of evidence in hate crime cases, either showing conversations about an intended target (Interview Independent Barrister 07) or containing slurs that prove the hostility element of the case:

"The subject of the text messages ... the racial aggravation was references to the complainant's new partner, who was black. And making various racial slurs about him, references to him being a 'monkey' and things like that. So there was clear evidence of racial hostility within the text messages. It was unambiguous in that case." (Interview Independent Barrister 08)

One prosecuting barrister also mentioned proving hostility through making the connection to either "trigger events" ${ }^{137}$ or drawing inferences from culturally, ethnically or linguistically differences between defendants and complainants, which historically are known to have hostile relationships. The interviewee noted that:

"[W]e were able to prove that I suppose you would say it was almost a matter of really history, but contemporaneous events, the trigger for what happened is that there'd been a Turkish air strike that had killed a number of Kurdish women and children, that's what had

\footnotetext{
${ }^{137}$ Possible "trigger events" include domestic or international terrorism attacks or political events, such as Brexit, which often contribute to a spike in the recording of both online and offline hate crime. See for example Emma Hanes and Stephen Machin, 'Hate crime in the wake of terror attacks: evidence from 7/7 and 9/11' (2014) 30(3) Journal of Contemporary Criminal Justice 247 and Bryan D Byers and James A Jones, 'The impact of the terrorist attacks of 9/11 on anti-Islamic hate crime' (2007) 5(1) Journal of Ethnicity in Criminal Justice 43.
} 
motivated the defendants to ... commit the firebombing ..." (Interview Independent Barrister 07)

Our analyses showed that there are many ways in which evidence of hostility can be presented to the court, but that in the main these methods are all used to show that the defendant uttered a slur during the commission of the offence. Nonetheless, there are numerous other ways in which hostility can be evidenced in court. Both the police and the CPS must think beyond the common verbalised epithets which are commonly used to prove hate crime if the CJS is to successfully address those incidents where no verbalised demonstration of hostility is committed. It is particularly important for the CPS to communicate back to the police the types of evidence that can help to prove hostility successfully in more complex cases. Loretta Trickett's recent research study on hate crime training for police officers similarly concludes that there need to be more examples provided by the CPS about cases where hostility has been proven and the factors involved. ${ }^{138}$

Below we provide a non-exhaustive list of types of evidence that the police and CPS identified as helping them to successfully prosecute hate crimes. As we will see further below, the successful collation of these forms of evidence often rests on the formation of a strong relationship between the police and CPS.

\section{RECOMMENDATION}

The following list highlights the most common forms of evidence that practitioners either used or considered to be important to prove hate crime cases. We recommend that investigators use this as a (non-exhaustive) checklist during the investigation and charging stages of the criminal process: ${ }^{139}$

1. Complainant and witness testimony of verbal slurs and prejudiced epithets;

2. Police-worn cameras and mobile phone footage of verbal slurs;

3. 999 recordings of incidents that include words spoken in the background;

4. Background information of the accused, including: past convictions, membership of hate-based groups, websites, and blogs;

5. Previous conversations with associates evidencing identity-based prejudices; and police questioning which may elicit hostilities;

6. Previous convictions for hate-based offences;

7. Possession of hate-based signs and symbols;

8. Social media posts displaying hate speech;

9. Text messages expressing identity-based hostility;

10. Possession of leaflets, letters or other written documents with hate-content;

11. Conduct that specifically targets the identity/perceived vulnerability of the victim (e.g. tipping someone out of a wheel chair or purposefully pulling off a religious headscarf);

12. Contemporaneity with trigger events or in the context of historically hostile relationships.

\footnotetext{
${ }^{138}$ Loretta Trickett with Paul Hamilton, Hate Crime Training of Police Officers in Nottingham: A Critical Review (Nottingham Law School, Nottingham Trent University 2016) 198 <http://irep.ntu.ac.uk/id/eprint/28089/7/5642Trickett.pdf>

${ }^{139}$ Note that some of these forms of evidence may constitute bad character evidence and/or hearsay evidence, and would not necessarily be admissible in court. See Part 11 of the Criminal Justice Act 2003.
} 
Further types of evidence should be added to the list which have been shown by investigators to be useful in prosecuting hate crimes.

\subsection{GATHERING EVIDENCE: FAILURE TO IDENTIFY AND INVESTIGATE HOSTILITY EARLY ENOUGH}

In order to identify when an offence is a "hate crime" offence, officers typically "flag" cases on their crime information reporting systems. This flag can be maintained or removed based on subsequent investigations into the offence. Complainant, (and where possible) witness and suspect statements will be taken by responding officers and other police personnel who subsequently take up any formal investigation. As we have seen above, it is these statements, and sometimes audio or video footage, that become crucial in proving that the offence was aggravated by hostility.

There was a perception amongst CPS interviewees that the police have become much better at identifying and correctly flagging racist and certain other types of hate crimes:

"I think [the police are] very, very good at identifying racist language; sometimes they conflate anti-Muslim language as racist language or behaviour towards Muslim dress as being racist, when it's obviously anti-religion. But apart from that mistake between race and religion, I think, you know, they're pretty good at identifying racist cases. They're pretty good with homophobic language as well, it's pretty clear isn't it?" (Interview CPS 05)

Yet, despite the improved flagging of hate crimes on reporting systems, there remains a significant proportion of incidents that are not flagged correctly, if at all. Based on a comparison of recorded hate crimes by the police $(62,518)$ and CSEW figures relating to the estimated number of victims who said they reported a hate crime to the police over the same period $(110,160)$, it is estimated that 57 per cent of reported hate crimes are not recorded as such (see section 5.1 ). In particular, there is still a systemic failure to correctly identify and flag disability hate crimes. This theme emerged throughout the interviews:

"I think the police often ... well ... occasionally fail to identify hate crimes - particularly the disability strand. They regularly supply files to us where they've made their own charging decision. As you'll be aware, they can't make a charging decision in a hate crime case. They often miss the fact that it's a disability hate crime." (Interview CPS 05)

Some interviewees noted that even where there is evidence of a disablist slur having been expressed during the commission of an offence (the most common type of evidence for all types of hate crime), the disability hate crime flag is still not being applied:

"I prosecuted a nurse who threw a cup of water in a [mentally impaired] lady's face, saying 'You're demented', when the lady wouldn't take her medication. And again, the police didn't think that might be a disability hate crime, even though you've got a clear demonstration of hostility and the words 'You're demented'; which, you know, you could never get a clearer case, but the police didn't spot that it was a disability hate crime." (Interview CPS 05) 
Conversely, in some cases the "flags" that are added to case files can become a barrier to looking beyond the wider facts of the case. This may mean that other facts or types of prejudice are lost during this stage of the investigation, but can still be picked up during the prosecution preparation stage. One CPS manager commented:

"[T] here is a tendency that once a flag's been put up, to stop looking wider. And part of the hate crime checks we do, we actually look at the crimes against older persons, because sometimes you'll find other hate crime strands within that. So is there a hidden disability offence? Is this based on dementia or some other aspect that you've actually got a disability crime linked in there? And we've had cases involving abuse of elderly patients in care homes where the investigation by the police hadn't identified that aspect. We had. We then flagged that up as a hate crime case and got significant sentences as a result; but again, that information was shared with the police and used in training exercises. But that shows the complexity." (Interview CPS 07)

It is these checks that the CPS do which have resulted in many more disability hate crime cases being identified and prosecuted in court. In some cases it required the CPS going back to the police and asking them to go back to the investigation and ask further questions such as "[was the] man local, why was he taking this route home? ... Was it off the obvious route? Could we draw an inference from the fact that this has taken place in an area which clearly housed disabled people? That he's gone off his route looking for a particular type of victim? ... what's the demographics of the housing? Were we able to secure evidence that it was indeed for disabled people?" (Interview CPS 08)

In other words, there was a perception amongst some interviewees that the police need to be more "proactive" in identifying the relevant pieces of evidence that will make for a more compelling case. This included:

"[l]dentifying disabilities and vulnerabilities when dealing with members of the public or people making complaints. And particularly ... [i]f you've got the situation where somebody with learning disabilities has made a complaint, then really there needs to be identification at an early stage as to what's the best way to achieve the best evidence for that individual, what support will that person need when they're giving evidence in court. Do we need an intermediary? Should there be a video interview? Should this person be given a statement with the help of an intermediary? So that the quality of the evidence extracted really reflects what happened, and cases which might have been dismissed as not being hate crime, but on closer inspection, had the victim been treated differently at the outset in terms of the support that was made available, might have let the evidence come across in a completely different way." (Interview CPS 09)

It is by crafting a fuller picture of why a hate crime has occurred that the CPS can be more confident in presenting a case that could prove the existence of a hostile motivation. Yet, as we will see below, even with these more carefully crafted cases, prosecutors frequently fail to secure uplifts at sentence for disability hate crime, meaning that the effective enforcement of hate crime legislation for victims of disability hate crime remains in doubt (see section 10). 
Law Commission consultees emphasised a lack of awareness by police, CPS and probation staff in regards to enhanced sentencing provisions, which in turn hinders the successful application of such provisions at sentencing. ${ }^{140}$ There have also been concerns that the police do not always properly understand or apply specific hate crime offences. ${ }^{141}$ Although police officers generally seem to be aware of hate crime legislation, Burney and Rose found that the CPS and court staff had criticised the police for their lack of knowledge on the law, which led to mistakes in charges, including incorrectly charging RAOs and choosing the incorrect basic offence. ${ }^{142}$ Interviewees indicated that evidence of hostility is often/should be presented at trial, even if it cannot be determined/taken account of until sentencing. Consequently, police may not actively search for evidence of hostility during their investigations.

At least six CPS prosecutors pointed to issues with police often not being aware of the sentencing provisions, which lead to investigators not collating the necessary evidence of the hostility element in hate crime cases based on hostility towards the complainant's sexual orientation, transgender identity or disability (see further section 11.1.2). CPS prosecutors noted:

"Well obviously there's a ... disconnect ... between the race and religion and the other strands, because they're not enshrined in the same legislation. So that causes a lot of problems frankly .... The race and religious hate is well established now from the Crime and Disorder Act, and the police are very familiar with those offences, and they know the points to prove when they set about an investigation ... And it's part of their interview strategy. And you see that in the way they approach it. So we have more success in those areas ... But with 145 and 146 particularly, it's almost treated as a bit like an ancillary application, you know, when the police go out and investigate that common assault, they're not thinking ..., 'Hang on ... Is this a 146 case? What do I need to prove?' They're just thinking, 'This is common assault. What do I need to prove?'” (Interview CPS 08)

"But at least as the section 28 offences, it's the element of the offence, it's the point to prove in the interview, so they know to ask the questions in the interview. For 146 cases in particular though, they don't ... So they wouldn't necessarily think about this - again back to disability - they wouldn't necessarily think about how to interview and establish, you know, sort of a more offender-centric interview ... So for instance, if you have someone who was robbed shortly after getting off a bus, that person was the only person getting off the bus who'd been on the bus who was disabled ... Why did they target that individual? ... But with disability the availability of that evidence is just not going to be there ... So we do need the police to ask the correct interview questions. Homophobic as well, you know ... It's the ones where we don't have the specific offences, where we need a good interview and we need to point them in the direction". (Interview CPS 14)

\footnotetext{
${ }^{140}$ Law Commission, Hate Crime: Should the Current Offences be Extended? (Law Com No 348, 2014)

<https://www.gov.uk/government/uploads/system/uploads/attachment_data/file/316103/9781474104852_Print.pdf>

${ }^{141}$ Loretta Trickett with Paul Hamilton, Hate Crime Training of Police Officers in Nottingham: A Critical Review (Nottingham Law School, Nottingham Trent University 2016) <http://irep.ntu.ac.uk/id/eprint/28089/7/5642Trickett.pdf>

The report also discusses the deficiencies in current online training and the need for improving methods of gathering evidence in more complex cases.

${ }^{142}$ Elizabeth Burney and Gerry Rose, Racist Offences: How is the Law Working? (Home Office Research Study 244, 2002).
} 
The College of Policing Hate Crime Operational Guidance 2014 provides information on the importance of police officers understanding "what can demonstrate such hostility as they plan their investigation and interview" and directly refers to the need for evidence for ss. 145 and 146 of the CJA 2003. One police officer noted, however, that this is quite a lengthy document and that shorter briefs, newsletters or five-minute briefings before a shift would be more beneficial (Interview Police Staff 02). However, the interviews with police officers revealed that, generally, officers are aware of sentencing uplifts, with one interviewee explaining:

"Yeah, we've got ... almost like a little preamble, whether it's 146 or 145, you've basically got like a little statement that you put on your charging decision. So at the top of, when you start to give your view of the circumstances, you're basically copying, you'll copy and paste, but you've basically got a preamble which basically says this is 146 and the circumstances are racially aggravated and this should be given the highest degree of enhancement and so on and so forth. So that's put on so the CPS can see it, so they know straight away that it's hate crime." (Interview Police Staff 03)

Identifying a hostility element early in a case will allow police to gather the appropriate evidence in hate crime cases. Knowledge of the sentencing provisions is a key factor in police effectively gathering evidence of hostility and building a strong case for the CPS in hate crime prosecutions. An important part of enhancing the general knowledge base amongst the police on evidence of hostility is the relationship and communication that occurs between them and other agencies. ${ }^{143}$ In particular, it is the work that occurs between the police and the CPS that becomes crucial to ensuring that hate crime laws are applied in practice. It is to this relationship that we now turn. Recommendations follow this next section.

\subsection{GATHERING EVIDENCE: THE IMPORTANCE OF GOOD RELATIONSHIPS BETWEEN POLICE AND THE CPS}

As Burney and Rose previously commented, "the translation of a police investigation of a racist incident into a live court case, and the subsequent progress of that case, is an area fraught with potential tension between the police and the [CPS]". Indeed, a number of issues were exposed during interviews that continue to challenge the efficacy of this process. As we have already noted above, the way in which evidence of hostility is collated for presentation in court is key to the successful prosecution of hate crimes. However, before an alleged offence can be prosecuted, the CPS must be satisfied that it is in the "public interest" to charge the offence as racially or religiously aggravated, and that there is sufficient evidence to provide a realistic prospect of conviction. ${ }^{144}$ However, gathering the evidence, as highlighted above, and presenting this successfully in court depends heavily on a good relationship between the police and the CPS. Before the CPS put forward their case in court, every case passes through a continuous review process. ${ }^{145}$ During this review process,

\footnotetext{
${ }^{143}$ See further Loretta Trickett with Paul Hamilton, Hate Crime Training of Police Officers in Nottingham: A Critical Review (Nottingham Law School, Nottingham Trent University 2016)

<http://irep.ntu.ac.uk/id/eprint/28089/7/5642Trickett.pdf>

${ }^{144}$ Crown Prosecution Service, 'The Code for Crown Prosecutors' (2013)

<https://www.cps.gov.uk/publications/docs/code_2013_accessible_english.pdf>

${ }^{145}$ Crown Prosecution Service, 'The Code for Crown Prosecutors' (2013)

<https://www.cps.gov.uk/publications/docs/code_2013_accessible_english.pdf>
} 
prosecutors take into account any changes in circumstances as the case develops and work closely with police, advising on "possible lines of inquiry and evidential requirements, and assist[ing] with pre-charge procedures". ${ }^{146}$

It is during this review process that close relations with police investigators become crucial. However, before then, the police need to be aware of the types of evidence that the CPS can use to prove hostility in court. One CPS interviewee noted "[the police] need to know how to identify these kind of offences, how to then prioritise these offences, what supporting evidence they can look at obtaining to help strengthen the case" (Interview CPS 21). However, this knowledge exchange works both ways. Indeed, the CPS can also benefit from what the police know about the case and the evidence (Interview CPS 03):

"Well, you know, they send us the file, so we rely a hundred per cent on them. You know, the CPS doesn't initiate any prosecutions, so, obviously we rely entirely upon their skills in investigating the offence and the accuracy of the documents that they supply to us." (Interview CPS 05)

Problems, however, can exist if charging advice is not sought by the police early on. In some cases, this makes it difficult to gather the necessary evidence for the hostility element later in the process:

"[O]ur policy is that CPS will provide charging advice in all hate crime cases; and in the instances where the police don't correctly identify the hate crime, then we sometimes find that we ... are coming to that case late, we've got less ability to assist with the rest of the investigation ensuring that the necessary evidence is there at the outset." (Interview CPS 09)

Ultimately, the responsibility to charge cases as a hate crime falls to the CPS, ${ }^{147}$ and prosecutors are advised to be proactive in seeking necessary information from the police to consequently put forward hate crime charges. ${ }^{148}$ Although all interviewees were aware that the CPS needed to be contacted for charging advice, eight CPS prosecutors noted that this is sometimes missed:

"Well there's always scope for improvement, yes, because not every police officer will bring every case of hate crime to the CPS, but they should do. I mean, the majority do, certainly, but there's still the odd case whereby the police authorise the charge without CPS authority. But they are few and far between." (Interview CPS 06)

Open lines of communication are key to ensuring that charging advice is sought and that discussions regarding the quality of evidence are had early on in a case's "life cycle". In their 2002 study, Burney and Rose found that a key issue facing hate crime cases was the

\footnotetext{
${ }^{146}$ Crown Prosecution Service, 'The Code for Crown Prosecutors' (2013)

<https://www.cps.gov.uk/publications/docs/code_2013_accessible_english.pdf>

${ }^{147}$ Crown Prosecution Service, 'The Director's Guidance On Charging 2013 - fifth edition, May 2013 (revised arrangements)'

(2013). <https://www.cps.gov.uk/publications/directors_guidance/dpp_guidance_5.html>

${ }^{148}$ Crown Prosecution Service, 'Racist and Religious Hate Crime - Prosecution Guidance' (2017)

$<$ http://www.cps.gov.uk/legal/p_to_r/racist_and_religious_crime/>
} 
communication between the police and the CPS, with police officers preferring person to person contact over communicating via files. ${ }^{149}$ Our interviews also revealed similar communication problems between the CPS, independent prosecutors, and the police. For example, one issue that emerged was that the CPS and police officers may prefer different styles of communication, with the CPS sometimes wanting e-communication (and reviewing of files), whereas some police officers preferred interpersonal discussions about a case. One police officer noted that, in improving this relationship, there should be more face-to-face contact with the CPS in hate crime cases:

"So I think the only thing that could improve the relationship is if it was face to face, more so than electronic. Because that's how it used to be years ago. The CPS were next door and you just went and spoke to them about a job. And then decide together and you could speak face to face with somebody." (Interview Police Staff 03)

Other police officers indicated that more immediate contact with the CPS is necessary in hate crime cases, especially because the existing hate crime legislation can be confusing for the police and so they may need further advice before interviewing suspects:

"I think that there is a need for a much closer case by case contact advice type 'telephone immediate now' type conversational relationship with the CPS so that ... Even actually a pre-interview advice ... So, you know ... 'l've got this case here ... This is what the victim says ... I'm just going to go and interview the suspect...' You know, to have it that early on ... Now I rather suspect that we won't be in a position to do that ... I suspect for financial reasons and logistical reasons ... But yes, I think it is absolutely key." (Interview Police Staff 04)

"If I have a question on the case, it's not that easy to get access to them ... officers struggle to try and get contact from CPS because there's no contact telephone number, and when there is nobody answers it ... or you know, they just won't give you a response ... [W]e have a very good relationship with the County Council and also the District Councils ... you know, we have a direct person that we go [to] ... But with CPS they are based in different parts of the country and we don't have one just for the area, or if there is one I'm not aware of it, because I'm still trying to find out somebody who I can call directly ... I still cannot do that." (Interview Police Staff 05)

Independent barristers for the prosecution also highlighted shortfalls in communication. One barrister explained that independent counsel is normally not involved in the preparation of the case at all:

"I was briefed for the prosecution on behalf of the CPS ... I wasn't involved in the preparation, so I didn't advise on the evidence, which is normal. Normally the CPS will do most of that before it is instructed out to barristers; so effectively my involvement is the prosecution of the case at trial." (Interview Independent Barrister 08)

\footnotetext{
${ }^{149}$ Elizabeth Burney and Gerry Rose, Racist Offences: How is the Law Working? (Home Office Research Study 244, 2002).
} 
Two independent barristers pointed out that there is a lack of seeking advice from independent barristers earlier in the process, and a breakdown of communication between barristers and police via the CPS can lead to evidence not being collated:

"[W]hat's of importance is that advices from the prosecution counsel that go to the CPS have to get to the police to be actioned; and where there is a breakdown in that communication, then evidence which could have been obtained and should have been obtained is not obtained. And not through the fault of the police officer ... They just haven't been told." (Interview Independent Barrister 15)

Such breakdowns in communication clearly inhibit the successful preparation and prosecution of hate crime cases. A strong and consistent relationship between criminal justice system authorities is based on open lines of communication between these actors throughout the criminal process. Without this, some cases are likely to "drop out" of the system altogether.

\subsection{CONCLUSIONS}

The analysis of the interviews revealed that a number of problems arise with the practical implementation of hate crime legislation. Although interviewees identified a number of different ways in which the hostility element in hate crime cases can be proved, problems exist when communication channels between the CPS, the police and independent barristers break down. The existence of good relationships between the CPS and the police is key in getting the necessary evidence to court. When charging advice is not sought or CPS prosecutors fail to seek information from the police, police officers may fail to collect sufficient evidence in hate crime cases. Further problems arise when police fail to identify hate crime cases early enough and consequently do not gather the necessary evidence for a successful prosecution in hate crime cases.

\section{RECOMMENDATION}

We recommend that the CPS provide police (and independent barristers employed for the prosecution) with a direct and open line to CPS area hate crime leads in order to ensure that credible evidence of hostility is collated early on in the investigation process. Independent barristers for the prosecution should be included in these discussions as early on in the case review process as possible. 


\section{Charging decisions and the trial process}

Once a hate crime is recorded by the police, investigated, and evidence is presented to the CPS, a decision is made regarding the charges that will be laid against the defendant. Where an offence can be charged as a RRAO under the CDA, it is CPS policy not to accept a plea to the underlying basic offence for the sake of expediency. ${ }^{150}$ RRAOs should be proceeded against in either the Crown or Magistrates' Court, depending on the seriousness of the offence and whether the defendant opts for trial by jury. ${ }^{151}$ Once in court, there are various procedural matters that can affect the successful prosecution of hate crimes. Burney and Rose have previously described the aggravated offences under the CDA as being "the cause of many a procedural headache". ${ }^{152}$ The main issues have concerned alternative charges in the Magistrates' Court and alternative verdicts in the Crown Court, which are explained in sections 7.1 and 7.2. Burney and Rose found a great variety of opinion and practice as to when, whether and why it is desirable to charge defendants with both the aggravated and basic versions of an offence, indicating confusion and inconsistency in the prosecution of hate crimes. ${ }^{153} \mathrm{~A}$ detailed doctrinal examination of the issues surrounding charging decisions and verdicts in hate crime cases is provided by Owusu-Bempah, ${ }^{154}$ who argues that procedural problems associated with the RRAOs can cause significant unfairness to defendants, complainants, and the wider community, including wrongful convictions and acquittals. In its final report, the Law Commission also highlighted procedural problems as an area of concern, particularly "charge bargaining". 155

Our findings indicate that procedural problems related to charging decisions and the trial process are less of a concern now than in the early days of the RRAOs, with some interviewees expressing the view that there are no problems:

“There's no procedural issues at all." (Interview Crown Court Judge 05)

"I think it’s perfectly workable." (Interview Crown Court Judge 08)

150 See e.g. Crown Prosecution Service, 'Racist and Religious Hate Crime - Prosecution Guidance' (2017) <http://www.cps.gov.uk/legal/p to $\mathrm{r} / \mathrm{racist}$ and religious crime/>

151 All RRAOs are triable-either-way, except for the aggravated version of section 5 of the Public Order Act 1986.

152 Elizabeth Burney and Gerry Rose, Racist Offences: How is the Law Working? (Home Office Research Study 244,2002 ) 17. 153 Elizabeth Burney and Gerry Rose, Racist Offences: How is the Law Working? (Home Office Research Study 244,2002 ) 17. 154 See Abenaa Owusu-Bempah, 'Prosecuting Hate Crime: Procedural Issues and the Future of the Aggravated Offences' (2015) 35(3) LS 443

155 Law Commission, Hate Crime: Should the Current Offences be Extended? (Law Com No 348, 2014) paras 5.19-5.28. 
However, responses to specific questions about the trial process revealed inconsistency, uncertainty and dissatisfaction as to certain procedures and policies.

This section begins with an exploration of current practices and attitudes towards alternative charges and verdicts in the Crown Court, and whether there is any danger of "overloading" the indictment in trials for RRAOs. We then turn our attention to the Magistrates' Court, where different procedural rules apply. Beyond the procedures for alternative charges and verdicts, we found dissatisfaction with the number of RRAOs tried in the Crown Court, as well as a perceived "pro-charge" policy in respect of RRAOs. These concerns are explored before we move on to examine the application of special measures at trial for complainants of hate crime. Finally, we put forward suggestions for alternative responses to prosecution and highlight the need for further, and clearer, guidance on the prosecution process.

\subsection{CROWN COURT: ALTERNATIVE CHARGES AND VERDICTS}

Where a defendant is tried for a RRAO in the Crown Court and there is insufficient proof of racial or religious hostility, the judge may allow the jury to return an alternative verdict regarding the basic offence. ${ }^{156}$ This means that, if the jury is not satisfied of the aggravated element of the offence, the defendant can be found guilty of the basic offence.

Allowing the jury to return an alternative verdict, rather than considering only the aggravated offence, can prevent the jury from facing a stark choice in circumstances where the aggravated element cannot be proven but there is clear evidence of the basic offence. The choice is between: 1) convicting of the aggravated offence so that the defendant does not escape liability for the basic offence (i.e. over-conviction), or; 2) acquitting of the aggravated offence despite clear evidence of the basic offence (i.e. under-conviction). To avoid juries being faced with this kind of difficult choice, in the case of Coutts, the House of Lords held that the public interest in the administration of justice would be best served "if in any trial on indictment the trial judge leaves to the jury, subject to any appropriate caution or warning, but irrespective of the wishes of trial counsel, any obvious alternative offence which there is evidence to support." ${ }^{157}$ Applying this to the hate crime offences, an alternative verdict of the basic offence should ordinarily be available when a RRAO is tried.

Another option is to put separate counts on the indictment, one covering the aggravated offence and one covering the basic offence, rather than waiting until the end of the case to leave an alternative verdict to the jury. The vast majority of CPS interviewees, who are responsible for charging decisions, expressed a preference for alternative counts on the indictment rather than alternative verdicts, with one CPS interviewee describing this as "good practice" (Interview CPS 09). The experience of Crown Court judges was mixed, with many, but not all, stating that they typically encountered both counts on the indictment. All of the judges who expressed a preference, preferred both counts to be on the indictment, primarily for the sake of transparency and because they felt that it made it easier for the jury to understand the issues in the case:

\footnotetext{
${ }^{156}$ Criminal Law Act 1967, ss. 6(3) and 6(3A); Criminal Justice Act 1988, s. 40; Crime and Disorder Act 1998, ss. 31(6), 32(5) and 32(6)

${ }^{157}$ Coutts [2006] UKHL 39 [23]. See also Foster [2007] EWCA Crim 2869; Barre [2016] EWCA Crim 216.
} 
"[T]he modern practice is not just to be telling the jury at the end of the day that there's a secret hidden lesser alternative, but to set it out right at the very beginning that there are not two counts, there are four counts, and you'll only have to consider count two and count four if you're unsure about count one and count three." (Interview Crown Court Judge 07)

If the basic offence is not on the indictment at the start of the trial, some judges said that they would direct the prosecution to add it during the trial.

This preference for alternative counts on the indictment was echoed by the majority of independent barristers. There was concern amongst some barristers that the failure to add an alternative to the indictment could result in defendants being acquitted, despite there being cogent evidence of the basic offence having been committed. For instance, in one case described to us, the defendant had left a severed pig's head outside a Muslim-owned building which was planned to become a place of worship:

“... he essentially admitted the basic offence ... But, because it wasn't on the indictment, and for whatever reason the jury weren't directed that they could find him guilty of the basic offence, so he was acquitted ... of the entire thing." (Interview Independent Barrister 17)

However, most Crown Court judges stated that, when only the aggravated offence is on the indictment, juries are usually directed that they can return an alternative verdict.

A small minority of interviewees were not in favour of alternatives. Two CPS lawyers did not see the value in leaving an alternative in any form (irrespective of whether it would be on the indictment or left to the jury at the end of the case), preferring to "nail [their] colours to the mast" (Interview CPS 03). Another two CPS lawyers said that the desirability of an alternative depends on the nature of the offence. If, for example, the defendant is accused of a racially aggravated public order offence, where the demonstration of racial hostility constitutes both the basic and aggravated offending behaviour, it can be seen as detrimental to put forward both offences:

"Now there are some occasions ... where, if you haven't got the aggravated offence, in fact you haven't got anything. And in those cases l'm a little bit wary of charging the basic one, because it's almost that you're suggesting that you've got some doubts about your own case, and it needs to be handled quite carefully." (Interview CPS 01)

For a further two CPS interviewees, whether an alternative should be available depends on how central the aggravated element is to the case, regardless of the type of offence. One CPS lawyer provided the following example:

"[W]here all the evidence you have effectively is that this is an offence that meets the criteria to be a hate crime, then we should really just nail our colours to the mast and proceed on that offence. Because that is what the complainant has made a complaint about ... they haven't said that 'I've been assaulted'; what they've said to you is 'I've been assaulted and it's a hate crime'". (Interview CPS 15) 
This perspective can also be observed in case law. In Mihocic, ${ }^{158}$ the appellant argued that the trial judge had been wrong not to leave an alternative verdict in relation to a count of racially aggravated harassment, and that the jury's finding of guilt might have been a means of ensuring liability for the basic offence, rather than an acceptance of racial aggravation. The Court of Appeal upheld the conviction, finding that the real gravamen of the count was whether racial abuse had been used, and, so, it was understandable that only the aggravated count had been left to the jury. This was held even though, on the facts, it was possible for the defendant to have committed a basic harassment offence in the absence of racial aggravation.

As well as occasionally appearing unnecessary or detrimental to the prosecution case, including the basic offence on the indictment or leaving an alternative verdict to the jury might overly complicate the jury's task. However, as we explain below in section 7.1.1, judges and lawyers do not perceive this to be a problem in practice. It is also possible that, if the basic offence is available, the jury might prefer to convict of the basic offence when they otherwise would have convicted of the aggravated offence. Several responses to the Law

Commission's consultation on the aggravated offences indicate that juries can be reluctant to convict defendants of aggravated offences, resulting in apparently "unjust acquittals". ${ }^{159}$ This is consistent with a widespread perception amongst our interviewees that juries are reluctant to convict of aggravated offences. As one Crown Court judge put it:

"[I]n a lot of these cases the jury do compromise, and they won't convict of the racially aggravated part. And I suspect that's why: that it's difficult for the jury to come to a conclusion that this really is a racist incident, when they perceive what happened - if they're sure it did - as merely an insult said in the heat of the moment. And I think that might be a reason why a lot of juries compromise and will only convict of the lesser offence." (Interview Crown Court Judge 09)

While conviction rates in the Crown Court are lower than in the Magistrates' Court, ${ }^{160}$ we cannot, with any degree of confidence, attribute this to alternative charges or verdicts. Even without the alternative, there are a number of reasons why jurors might acquit defendants of RRAOs, including their reluctance to label defendants as "haters" or "racists" (this is discussed further in section 8.4), and shortcomings in the way in which evidence of hostility is collected or presented (see section 6).

Overall, the responses from interviewees indicate that it is good practice to ensure that an alternative is available, and there was a strong preference for putting the alternative count on the indictment, rather than leaving an alternative verdict to the jury at the end of the trial. However, there is scope for a more consistent practice, particularly since some cases may

\footnotetext{
158 [2012] EWCA Crim 195.

159 Law Commission, Hate Crime: Should the Current Offences be Extended? (Law Com No 348, 2014) para 4.175 $<$ https://www.gov.uk/government/uploads/system/uploads/attachment_data/file/316103/9781474104852_Print.pdf>

${ }^{160}$ In 2012, the conviction rate for all RRAOs in the Crown Court was $63.7 \%$. In the Magistrates' Court, in 2012 , the conviction rate for RRAOs was $74 \%$. Note, however, that only 481, of a total 8,898 defendants, were found not guilty - with most other cases being dropped early on. See Home Office, Ministry of Justice and Office for National Statistics, 'An overview of hate crime in England and Wales' (2013), Appendix Tables 3.07 and 3.08.

<https://www.gov.uk/government/statistics/an-overview-of-hate-crime-in-england-and-wales>
} 
be inconsistent with the principle set out by the House of Lords in Coutts that it in the public interest for any obvious alternative charge to be left to the jury.

\section{RECOMMENDATION}

We recommend that the basic offence should ordinarily be left to the jury. The exception is cases where, without the hostility element, there is no basic offence. For example, public order offences where the demonstration of hostility constitutes both the basic offence and the aggravation. In other cases, the basic offence will usually be an obvious alternative, as it forms part of the aggravated offence. As such, the elements of the basic offence will be in issue, and both the prosecution and the defence should be prepared to address them. We further recommend that the basic offence ordinarily be included on the indictment from the start of the trial, so that the jury, as well as the judge and parties to the case, have a clear statement of the issues which the jury must determine. Including the basic offence on the indictment is consistent with CPS guidance on drafting indictments, ${ }^{161}$ but should be stated more clearly in prosecution guidance on racist and religious crime, which currently states that "[w]here the Criminal Law Act 1967 does not apply ... or where there are no statutory provisions for alternative verdicts, consideration has to be given to including alternative counts on the indictment". ${ }^{162}$ Concerns that leaving an alternative may weaken the prosecution's case cannot override the public interest in avoiding under- or over-conviction in hate crime cases. ${ }^{163}$

Before reaching this recommendation, we took account of the possibility of overloading indictments, as explained below.

\subsubsection{Overloading indictments}

We asked interviewees whether alternative counts or leaving alternative verdicts to the jury could raise the possibility of overloading the indictment or confusing jurors, particularly where more than one offence is being tried. In the case of O'Leary, the Court of Appeal took the view that, where there is a risk of overloading the indictment, in some situations it may be preferable to charge only the basic offence(s), so as not to over-complicate the jury's task. ${ }^{164}$ The question of whether jurors may be confused by multiple offences and alternatives was met with mixed responses. However, most interviewees took the view that indictments are rarely overloaded, alternatives do not present any significant problems, and juries can cope with multiple charges. There was also a view amongst interviewees that, if there is confusion in complex hate crimes cases, it is no greater than in other areas of criminal law. As one CPS interviewee put it, "in the scheme of things, I don't think it's a complexity which is overly difficult compared with other branches of criminal practice in that arena" (Interview CPS 13).

\footnotetext{
${ }^{161}$ Crown Prosecution Service, 'Drafting the Indictment' (n.d.) <http://www.cps.gov.uk/legal/d_to_g/drafting_the_indictment/>

${ }^{162}$ Crown Prosecution Service, 'Racist and Religious Hate Crime - Prosecution Guidance' (2017)

$<$ http://www.cps.gov.uk/legal/p_to_r/racist_and_religious_crime/>. There are statutory provisions for alternative verdicts for RRAOS. See footnote 156

${ }^{163}$ The case law on alternative verdicts makes it clear that the tactical wishes of trial counsel on either side are immaterial. See Barre [2016] EWCA Crim 216 [22].

${ }^{164}$ See O'Leary [2015] EWCA Crim 1306 [18]
} 
These views are interesting in the light of the views of some Crown Court judges and independent barristers that the aggravated offences themselves are complicated and difficult to present to jurors:

“... the wording of the provisions is complex ... It's easy to understand if you're a highly educated person, but I think, for a jury it's really quite difficult. It's a simple idea - that's the annoying thing!" (Interview Crown Court Judge 06)

Several interviewees noted the benefits of providing juries with written directions or a "route to verdict" document as a way of clarifying the issues that the jury must consider and aiding their understanding of the offences. One judge also noted the benefit of directing juries as to the meaning of racial or religious aggravation, and the elements of the legislation, early on in a trial:

"... if you can get in quite early with the jury to identify where the issues are, then it seems to me that saves a lot of the problems that otherwise we might have if the jury have to wait until the very end, and they get directions all thrown at them all at once." (Interview Crown Court Judge 07)

\section{RECOMMENDATION}

To ease the jury's task, we recommend that jurors be provided with written directions or "route to verdict" documents, setting out the issues that must be proven or disproven in respect of each count on the indictment.

\subsection{MAGISTRATES' COURT: ALTERNATIVE CHARGES AND VERDICTS}

In the Magistrates' Court, there is no power to return alternative verdicts in hate crime cases. This means that, if only the RRAO is charged, and the prosecution can prove that the defendant committed the basic offence, but not that it was racially or religiously aggravated, then the defendant must be acquitted. To avoid this, the CPS recommends that, where there is evidence that a racially or religiously aggravated offence has been committed, both the basic and aggravated version of the offence should be charged in the alternative. ${ }^{165}$

The responses from interviewees indicate that the CPS guidance is usually followed. One CPS lawyer described alternative charges as "part of standard CPS policy" (Interview CPS 21). Another explained, "[y]es we do tend to double up, and the practice is well engrained now" (Interview CPS 13).

However, as with alternatives in the Crown Court, decisions sometimes depend on the nature of the offence:

"[l]f it's Magistrates' Court you would tend to put the non-racial in there anyway as well, unless [it] so obviously rests and falls on the racial element, then you wouldn't necessarily put the alternative". (Interview CPS 18)

\footnotetext{
${ }^{165}$ Crown Prosecution Service, 'Racist and Religious Hate Crime - Prosecution Guidance' (2017) <http://www.cps.gov.uk/legal/p_to_r/racist_and_religious_crime/>
} 
Only one CPS lawyer (Interview CPS 07) suggested that there is a tendency to charge the aggravated offence alone, and was conscious that this can result in losing liability for the basic offence.

District Judges had a slightly more varied experience. While the majority confirmed that the CPS normally charge both offences, one explained that "the CPS in [named location] ${ }^{166}$ proceeds with the racial offence and very rarely puts the simple offence" (Interview District Judge 02). Another identified a more recent trend of prosecutors "nailing their colours to the mast" ${ }^{167}$, which was attributed to the decision in Henderson, ${ }^{168}$ discussed below (Interview District Judge 07).

Our findings indicate that, while there may be some variations between local areas, charging practices in the Magistrates' Court are more consistent than in the Crown Court. This is likely to be because alternative verdicts cannot be returned in the Magistrates' Court, but it is also a result of the preference being expressly set out in CPS guidance on prosecuting hate crime.

\subsubsection{Double convictions}

One significant consequence of the CPS charging both offences is that it has resulted in double convictions in the Magistrates' Court. ${ }^{169}$ This means that the defendant is convicted of the basic offence and the aggravated version, both of which are then recorded on the defendant's criminal record - despite the fact only a single offence has been committed. The main reason for this duplication is that, if there is a successful appeal against the aggravated element, the conviction for the underlying basic offence will still stand. However, an unfortunate consequence is that the defendant will have two separate convictions on their record for the same crime, even if they receive only one sentence. In 2013, in the case of $R$ (on the application of Dyer) v Watford Magistrates' Court, the Divisional Court was critical of this practice, finding that it was unfair and disproportionate for a defendant to be convicted twice for a single wrong. ${ }^{170}$ Yet, the practice continues. In 2016, in Henderson v CPS, the Divisional Court again held that, where a defendant faces two charges which are properly characterised as alternatives, there should not be findings of guilt on both charges. ${ }^{171}$ The proper course is to adjourn the lesser charge before conviction under s. 10 of the Magistrates' Courts Act 1980, so that if an appeal against the aggravated offences was successful, the lesser charge could subsequently be dealt with.

Four CPS interviewees mentioned the outcome of Henderson, with two expressing concern about the implications of the decision. One described the process of dealing with the basic offence as "clumsy" (Interview CPS 13). The other explained that adjourning the basic offence:

\footnotetext{
${ }^{166}$ Exact location removed to protect participant anonymity.

${ }^{167}$ This phrase, and similar iterations, were repeated by numerous interviewees.

${ }^{168}$ Henderson v CPS [2016] EWHC 464 (Admin).

${ }^{169}$ See Rupert Wheeler, 'The Danger of the Double Conviction' (2013) 177(12) Criminal Law and Justice 191.

${ }^{170} \mathrm{R}$ (on the application of Dyer) v Watford Magistrates' Court [2013] EWHC 547 (Admin).

${ }^{171}$ Henderson v CPS [2016] EWHC 464 (Admin).
} 
"causes problems for the courts' recording system and our recording system. And, as a result of Henderson, because I think in Henderson what happened was the judge purported to convict of both, which is clearly wrong - you shouldn't do that, because that's duplicitous ... But the issue that we're currently wrestling with is what do we do then with the less serious one. And at the moment we haven't got a conclusive answer to that." (Interview CPS 01)

Several District Judges also expressed frustration at the lack of clarity in the law and the prospect of the basic offence "hanging around":

“... it's one of those things that you have to run to the law books to remind yourself of the principles ... And again, ideally the law should be simple enough to not require such complications." (Interview District Judge 05)

"We need a neater way of dealing with the alternative charges ... if you find them guilty of the racially aggravated offence but then don't return a decision on the lower charge because you want to preserve the position pending appeal, that lower charge then just hangs around ... So that's a tedious little bit of red tape, but it does cause some heartache for the ... not for us as tribunals ... but for the administration underneath." (Interview District Judge 03)

One District Judge expressed dissatisfaction with the decision in Henderson:

"So I'm not quite sure that I agree with the reasoning of the court in Henderson because their thinking - and I suppose they're right about it - is that you shouldn't be at risk of conviction of two offences on the same facts: it's one or the other. But for years the Magistrates' Courts have been quite happily dealing with people for the more serious offence and then imposing no separate penalty for the basic offence, and no one's ever really raised their eyebrows at it. So it is a bit of a frustration, but, as ever, when you get these problems thrown your way you just work around them." (Interview District Judge 07)

Not all District Judges were familiar with the correct way to deal with alternative charges. One explained that they would convict of both charges, but only sentence for the aggravated offence, and that the two convictions on the defendant's criminal record would not "cause a particular problem":

"I don't think somebody would be thought of as having double the offending as a result; it's something that everybody would recognise that that's what's happened there, and it would be marked, the sentence would be marked as no separate penalty." (Interview District Judge 08)

Another District Judge thought that:

"the court has an obligation there to convict [of the basic offence] as well ... it's a little unfortunate because [defendants] then end up with an additional conviction on their record; although they almost certainly won't end up with an additional punishment." (Interview District Judge 09) 
The recent decision in Henderson has had some limited impact on how alternative charges are dealt with on conviction, but it is clear that defendants continue to be convicted twice for a single offence. Even in those cases where the CPS or judge was familiar with the correct approach under Henderson, most felt that there is a need for further (accessible) clarification on the procedure for dealing with alternative charges in the Magistrates' Courts. ${ }^{172}$ Alternatively, and in the light of the dissatisfaction with adjourning the basic offence, magistrates could be given the power to return alternative verdicts, as recommended below.

\subsubsection{Charge bargaining}

Since the enactment of the RRAOs, there has been concern that alternative charges can result in "charge bargaining". ${ }^{173}$ This concern is most prevalent in respect of the Magistrates' Court, where both offences must be charged in order to avoid losing liability for the basic offence. Charge bargaining occurs where the defendant either offers or accepts a plea of guilty to the basic offence on the condition that the charge for the aggravated offence is dropped. In response to criticism over this practice (as identified by Burney and Rose), the CPS policy is not to accept a plea to the basic offence alone to expedite court processes. ${ }^{174}$

The CPS lawyers that we interviewed were adamant that charge bargaining does not happen, and that a plea to the basic offence will only be accepted if there is insufficient evidence to proceed with the aggravated offence, which is consistent with CPS policy:

"I'd be very surprised if there are any prosecutors, if they're satisfied they've got sufficient evidence of hostility, that they would accept a basic offence. I just don't think ... I think they'd have quite a lot of difficulty justifying that to their superiors afterwards." (Interview CPS 03)

One defence barrister noted the rigidity of some prosecutors to stick to this policy:

"My experience has kind of been ... that where a complainant makes an allegation of a racial or religiously offensive term, however weak the case is otherwise, they definitely prosecute. And they don't review ... they take an approach that's very similar to domestic violence, which is to say we will prosecute come hell or high water because this is this kind of case, and we take these kind of cases seriously. And for them, taking them seriously means prosecuting all of them." (Interview Independent Barrister 02)

While it was clear that the policy on charge bargaining had changed since the initial enactment of the offences, some interviewees indicated that attempts at charge bargaining are still common:

\footnotetext{
172 The latest version of the CPS guidance on prosecuting racist and religious hate crime, published in August 2017, refers to the decision in Henderson, and the "sensible course" being to "adjourn the trial of the underlying offence sine die." $<$ http://www.cps.gov.uk/legal/p_to_r/racist_and_religious_crime/>

${ }^{173}$ Elizabeth Burney and Gerry Rose, Racist Offences: How is the Law Working? (Home Office Research Study 244, 2002) 8083. See also Gus John, Race for Justice: A Review of CPS Decision Making for Possible Racial Bias at Each Stage of the Prosecution Process (Gus John Partnership 2003) para 95.

${ }^{174}$ Crown Prosecution Service, 'Racist and Religious Crime - CPS Prosecution Policy' (n.d.)

<http://www.cps.gov.uk/publications/prosecution/rrpbcrbook.html>
} 
"Almost all defendants ... will deny racially aggravated offending. Virtually all. They'll say 'I'll plead to the substantive offence, but I won't accept the racially aggravated part."' (Interview Independent Barrister 04)

The reluctance to accept the aggravated element of the offence is likely to stem from the severe stigma that is perceivably attached to the aggravated offences. One barrister summed up the position as follows:

"When you're defending, defendants never want to plead to anything that's got 'racially aggravated' on it because they think it means racially motivated - 'you're a racist' ... that's what they think. They'll never plead to anything that's got 'racial' on it." (Interview Independent Barrister 14)

Likewise, a District Judge explained that:

"The reason they fight it is that they don't want to be branded a racist. ... Out of all the things that you could have on your record, having a racial offence on your record is pretty bad." (Interview District Judge 02)

Charge bargaining can be detrimental to victims and the wider community, who may be given the impression that hate crime is not taken seriously. It can also be detrimental to defendants who wish to maintain their innocence, and who may feel coerced to plead guilty to the basic offence in order to avoid the risk of a harsher sentence if convicted of the aggravated offence. ${ }^{175}$

However, one CPS lawyer spoke of the pressure to keep hate crime cases out of the Crown Courts $^{176}$, which could result in charge bargaining in some situations:

"'Prosecuting that as a racially aggravated case means the difference between it being a summary-only offence that can be tried in the Magistrates' Court and it being an eitherway offence that can be tried in the Crown Court. So it would not be uncommon for us to ... charge a racially aggravated offence ... and the defendant to say, 'I punched the victim in the face. I called him a bastard. I did not call him a black bastard. I will plead guilty to common assault. I will not plead guilty, and will seek a trial on racially aggravated common assault; and if you don't accept my plea, I will elect - as is my right - to be tried in the Crown Court.' ... We will then be faced with the dilemma of do we accept his plea which would mean dropping the racial element. Or do we stand our ground and say 'Well if you wish to be tried in the Crown Court at the cost of $£ 10,000$ per day, that's what we will do'. And then we will go to the Crown Court where you can bet your bottom dollar we will be faced with a judge who is going to say, 'Really are we going to have a trial in the Crown Court at the cost of $£ 10,000$ per day, the only issue being one word' ... And

\footnotetext{
${ }^{175}$ See Abenaa Owusu-Bempah, 'Prosecuting Hate Crime: Procedural Issues and the Future of the Aggravated Offences' (2015) 35(3) LS 443, 451-453.

${ }^{176}$ Note that responses to the Law Commission's consultation also indicate that charge bargaining continues to take place: Law Commission, Hate Crime: Should the Current Offences be Extended? (Law Com No 348, 2014) paras 4.177-4.180. See also paras 5.21-5.26, on the relatively low conviction ratios for aggravated offences and the fall in the number of defendants sentenced for aggravated offences

<https://www.gov.uk/government/uploads/system/uploads/attachment_data/file/316103/9781474104852_Print.pdf>
} 
sometimes Crown Court judges will say, 'I can tell you that I don't think it's in the public interest for you to have that trial ... And I will give the defendant the same sentence regardless of whether or not you will prove the use of the word "black"'... And it puts enormous pressure on prosecutors. ... And pressure is put on us to avoid having trials in the Crown Court on what the Crown Court judges consider ... to be minor matters." (Interview CPS 20)

Another defence barrister stated that charge bargaining was most likely to be successful in cases involving "same-race" hate crimes due to the general perception that the jury and/or judge are less likely to accept the racial hostility element of the offence (see section 8.8):

"... you often get sensible prosecutors doing the case in the Crown Court, who take a different view; and sometimes they say, of course we'll accept the lesser charge. Because they know it's not very ... you know, the racial aggravation it's either not very strong in points, or it was never very serious ... or they're going to have problems making it stick. I mean, it's just one person's word against another's. Especially when you get a black person saying it against a black person ... and the jury look at each other with complete surprise." (Interview Independent Barrister 01)

The perceptions regarding charge bargaining amongst other interviewee cohorts were mixed. For example, one Crown Court judge thought that the "prosecution usually accept the plea to the lesser offence" (Interview Crown Court Judge 06). Four independent barristers spoke of their experiences of charge bargaining. One prosecution barrister explained that charge bargaining "does happen occasionally" (Interview Independent Barrister 05). Another gave the following scenario:

"say if the defence, you know, come and talk to me and they say, 'If he pleads to this one, are you willing to drop that one' and I don't have instructions, I'll call up a reviewing lawyer or an advocacy manager and ask them for their opinion. And sometimes they'll say, 'Yeah, if they plead guilty to that, then you can drop the other charges'." (Interview Independent Barrister 09)

While we found evidence to suggest that charge bargaining still occurs, the majority of Crown Court and District Judges, as well as the majority of independent barristers, expressed the view that it is very rare. In the experience of one barrister, "The CPS ... will never accept a plea where there is a racially aggravated offence" (Interview Independent Barrister 08). Similarly, a Crown Court judge described charge bargaining as "practically impossible" (Interview Crown Court Judge 01).

According to interviewees, where a plea to the basic offence is accepted by the prosecution, it is usually contingent on the views of the complainant and accepted because the evidence of hostility is weak. In fact, some judges and barristers took the view that the CPS too readily pursue weak hate crime cases, as explained in section 7.4.

What we found in respect of charge bargaining represents a shift in attitude since the RRAOs first came into force, with less "cultural resistance" to the legislation. One prosecutor put it in the following terms: 
"When the racially aggravated stuff first came out, we used to get that all time, the defence saying, 'We'll plead to the basic offence ...' And we went through quite a few years of difficult times saying no, and getting criticised by courts and judges and all sorts ... But I think that has improved. And if they ask, they're usually expecting us to say no. They may just be doing it so they can say to their client 'Well I asked, and they said no.'" (Interview CPS 11)

Despite the apparent rarity of charge bargaining, the possibility and perception that it happens remains a cause for concern, particularly since official statistics have shown a low conviction ratio for individual aggravated offences when compared to the corresponding basic versions. ${ }^{177}$ Moreover, in a report published by the Home Office, Office for National Statistics and Ministry of Justice in 2013, it is noted that, between the initial hearing at the Magistrates' Court and the first hearing at the Crown Court, the CPS can decide to downgrade the aggravated charge to the basic offence, to "increase the chances of a conviction". ${ }^{178}$

\section{RECOMMENDATION}

To ensure adherence to the current CPS policy not to accept a plea to the basic offence alone to expedite court processes, we recommend that records be kept. For example, the CPS could keep a comprehensive record of charges proceeded with after the initial hearing, and of the reasons for downgrading charges from the RRAO to the basic offence in individual cases. These data could alleviate concerns about "charge bargaining", or they could indicate a need for better enforcement of CPS policy.

\subsubsection{Alternative verdicts}

The problems and confusion that have arisen as a result of alternative charges in the Magistrates' Court could be resolved, or at least alleviated, by giving magistrates the power of finding alternative verdicts on RRAOs. In each case, only the RRAO would be charged and, if not convinced of the aggravated element, the defendant could instead be convicted of the basic offence. In 2002, Burney and Rose found that there was a strong body of opinion among stipendiary magistrates and justices' clerks that magistrates should have the power of finding alternative verdicts on aggravated offences, and went on to recommend that they be given this power. ${ }^{179}$

We also found strong support for a power to return alternative verdicts in the Magistrates' Court. Of the District Judges who took a view on the issue, only one was hesitant because the present situation, although "clumsy", does not present any "great problem" (Interview

\footnotetext{
${ }^{177}$ For example, in 2012, the conviction ratio for racially or religiously aggravated "assault with injury" was $51 \%$, compared to $85 \%$ for the basic offence: Home Office, Ministry of Justice and Office for National Statistics, 'An overview of hate crime in England and Wales' (2013), Appendix Table 3.12

<https://www.gov.uk/government/statistics/an-overview-of-hate-crime-in-england-and-wales>

${ }^{178}$ Home Office, Ministry of Justice and Office for National Statistics, 'An overview of hate crime in England and Wales' (2013) 37

<https://www.gov.uk/government/statistics/an-overview-of-hate-crime-in-england-and-wales>

${ }^{179}$ Elizabeth Burney and Gerry Rose, Racist Offences: How is the Law Working? (Home Office Research Study 244, 2002) 80 and 113.
} 
District Judge 10). Conversely, another District Judge described the present situation as a cause of "unnecessary complication", explaining that it "creates lots of different combinations of offences, which can be confusing" (Interview District Judge 05). Another District Judge explained how the power to return alternative verdicts could result in fairer outcomes:

"I think one has to sort of remember that the court system is about justice, isn't it? So if someone has committed an offence but not the specific offence charged - so a less serious version of specific events - then I think it would make life much easier and be much fairer and more just to be able to do that." (Interview District Judge 09)

Interviewees cited a number of other reasons why alternative verdicts should be available in the Magistrates' Courts, including: consistency between courts; prosecutors would avoid the problem of trying to lay an alternative charge after the trial has commenced; magistrates would avoid confusion as to how to deal with the basic offence if the defendant is convicted of the aggravated offence; and there would not be a risk of double convictions.

From a CPS perspective, "[i]t would make life ... a lot easier and simpler if they could return the non-racially aggravated version without the need for us to lay the actual separate offence as well" (Interview CPS 18).

Only one CPS interviewee was opposed to the idea, because it would require the CPS to relinquish control:

"I think also, because we do charge the basic offence as alternatives in most cases, we're presenting them with the alternative when it's appropriate to present them with an alternative ... so in other words, we're in control of that. And therefore I don't think that they need the option to return alternative verdicts generally, but specifically with hate crime." (Interview CPS 04)

The views amongst independent barristers were slightly more mixed. Of those who directly addressed the issue, 10 independent barristers were in favour of magistrates having the power to return alternative verdicts in hate crime cases. Three independent barristers opposed the proposition, from a defence perspective. They did not want magistrates to have the opportunity to convict of the basic offence when they otherwise would have acquitted altogether because the aggravated element could not be proven. However, their responses were based on the assumption that the power to return an alternative verdict would be used where the prosecution failed to, or deliberately chose not to, charge a basic offence. In practice, the prosecution usually charges both offences, and so, giving magistrates the power to return alternative verdicts (instead of considering alternative charges) would usually represent a change in approach, rather than according them more opportunities to convict.

\section{RECOMMENDATION}

Given the strong support for a change in the law, and the problems associated with alternative charges, we recommend that magistrates should be allowed to reach alternative verdicts to racially and religiously aggravated charges. 


\subsection{MODE OF TRIAL}

The basic offences capable of being aggravated under the CDA consist of both summaryonly offences (e.g. common assault) and either-way offences (e.g. assault occasioning actual bodily harm), whereas all but one of the RRAOs are triable-either-way. The exception is the aggravated version of s. 5 of the Public Order Act 1986 (harassment, alarm or distress), ${ }^{180}$ which remains a summary-only offence, and so can only be tried in the Magistrates' Court. Offences that are triable-either-way can be tried in the Magistrates' Court or by a jury in the Crown Court. If the magistrates consider the alleged offence to be particularly serious or complex, it will be sent for trial in the Crown Court. ${ }^{181}$ Otherwise, it is for the defendant to decide where to be tried.

The bulk of RRAOs are dealt with in the Magistrates' Courts. ${ }^{182}$ However, the perception amongst interviewees was that, when given a choice, most defendants opt for the Crown Court, where they are more likely to be acquitted. Some Crown Court judges expressed frustration at the number of cases reaching the Crown Court:

"... an awful lot of, for want of a better word, crap, that should be being dealt with in the Magistrates' Court is tried here, because what might be a summary-only public order offence becomes either-way, as racially aggravated". (Interview Crown Court Judge 01)

Crown Court trials for relatively minor offences were perceived by judges to be largely a waste of time and money (explored further in section 11.2.1). One CPS lawyer spoke of encountering "traditional resistance" to "not the most serious" conduct being tried in the Crown Court. They took the following approach to public order offences:

"So one of the things that we're having to do now is look at these cases and decide whether to prosecute them as a section 5 rather than as a section $4 \mathrm{~A}$, in order to make sure that they stay in the Magistrates' Court, where we've got a better chance of conviction." (Interview CPS 01)

Another CPS lawyer spoke of "enormous" pressure to keep cases out of the Crown Court (Interview CPS 20). It was noted above that this pressure may lead prosecutors to accept a charge bargain. District Judges were also alert to the pressure to keep cases out of the Crown Court, with one explaining that "we're being encouraged to hear more cases in the Magistrates' Court anyway, and not send so many up to the Crown Court. But reserving that for the sentencing stage". (Interview District Judge 01)

Not all interviewees felt that RRAOs should be kept in the Magistrates' Court:

\footnotetext{
${ }^{180}$ Crime and Disorder Act 1998, s. 31(1)(c).

${ }^{181}$ Magistrates also have the power to send cases to the Crown Court for sentencing after trial if the appropriate sentence exceeds the magistrates' powers. See Powers of Criminal Courts (Sentencing) Act 2000, s. 3; Sentencing Council, Allocation Guideline (2015)

<https://www.sentencingcouncil.org.uk/wp-content/uploads/Allocation_Guideline_2015.pdf>

182 Data from 2002 to 2012 shows that approximately $90 \%$ of all racially and religiously aggravated offences are tried in the

Magistrates' Court. See Home Office, Ministry of Justice and Office for National Statistics, 'An overview of hate crime in England and Wales' (2013), Appendix Tables 3.04 and 3.08

<https://www.gov.uk/government/statistics/an-overview-of-hate-crime-in-england-and-wales>
} 
"[I]t is important that if we are going to criminalise this type of behaviour over and above other types of public order behaviour, and other low level violence, we have to give people the right to a jury trial, because that's one of the most important safeguards for anybody charged with a serious criminal offence, and these are a lot more serious than other types of criminal offences." (Interview Independent Barrister 08)

From a defence barrister's perspective, because juries are less likely to convict of aggravated offences, it is preferable for cases to be tried in the Crown Court:

"If you're contesting a trial and you have the opportunity to take it to a jury rather than a bench of magistrates or a DJ, apart from in very limited circumstances the normal recommendation would be to go in front of a jury trial. And especially in the examples of criticising police officers, or what was said about a police officer. ... Juries I think are a little bit more cynical about police evidence than magistrates or District Judges." (Interview Independent Barrister 10)

Another independent barrister explained that "juries ... don't come to the case with the prejudices which can inevitably arise from practice" (Interview Independent Barrister 13).

The perception among many interviewees, particularly Crown Court judges, that too many RRAOs are being tried in the Crown Court represents another shift in attitude since the offences first came into force. In their 2002 report, Burney and Rose found that the Crown Court was often seen as the appropriate venue for racially aggravated offences, particularly by CPS branches and particularly in London. ${ }^{183}$ A possible explanation for the shift in attitude is the general change in the climate and culture of criminal procedure over the past 15 years. In addition to dwindling resources, there is now much greater emphasis on case management and efficiency. ${ }^{184}$ This is reflected in the responses from interviewees who cited time and cost as a primary reason why less serious RRAOs should be kept in the Magistrates' Courts. The solutions posed by interviewees included higher sentencing powers for magistrates (although it is not clear how that would affect the defendant's decision as to mode of trial), and relying on sentencing legislation rather than criminal offences to deal with aggravated offending (Interview Crown Court Judge 08). Opinions on how best to use legislation to respond to hate crime are explored in the final Part of this report.

\subsection{OVER-CHARGING}

In addition to concerns that too many cases end up in the Crown Court, we also found concerns about "over-charging". Prosecutors should only charge someone for a criminal offence if satisfied that there is sufficient evidence to provide a realistic prospect of conviction (the evidential test) and if prosecution is in the public interest (the public interest test). ${ }^{185}$ There was a perception amongst many Crown Court judges and independent barristers that

\footnotetext{
${ }^{183}$ Elizabeth Burney and Gerry Rose, Racist Offences: How is the Law Working? (Home Office Research Study 244, 2002) 8384, 96-98

${ }_{184}$ See, for example, Sir Brian Leveson, Review of Efficiency in Criminal Proceedings (Judiciary of England and Wales 2015) $<$ https://www.judiciary.gov.uk/wp-content/uploads/2015/01/review-of-efficiency-in-criminal-proceedings-20151.pdf $>$; Abenaa Owusu-Bempah, Defendant Participation in the Criminal Process (Routledge 2017) ch 3.

${ }^{185}$ CPS, 'The Code for Crown Prosecutors' (2013)

<https://www.cps.gov.uk/publications/docs/code_2013_accessible_english.pdf>
} 
a "pro-charge" policy has been adopted in respect of RRAOs, whereby RRAOs are pursued even if there is insufficient evidence to support the aggravated element of the offence. One independent barrister said that "it strikes me that the CPS policy is prosecute on crimes where there's any racial or religious aggravation claimed" (Interview Independent Barrister 02). Another explained that, in their experience, "the CPS will always prosecute the racially aggravated offence if there is some evidence. Even if the evidence is weak, they will prosecute" (Interview Independent Barrister 08).

The perceived "pro-charge" policy was attributed to "political pressure" (Interview Crown Court Judge 09) on the CPS, as well as fear of criticism from government, the public and complainants who can request that a decision not to prosecute be reviewed. ${ }^{186}$ According to one independent barrister:

"[T]hey're worried about complaints. It's similar with sex cases ... they charge virtually every single sex offence. Anyone alleged with it, you just get charged, even though the evidence is not there or is questionable, they'll charge it. And then when they don't, it's now the subject of appeals ... A victim can appeal it." (Interview Independent Barrister 04)

While hate crime is a priority area for the CPS, we did not find evidence in its stated policy of the kind of "pro-charge" policy referred to by some interviewees. The CPS policy on racist and religious crimes states that "the public interest in racist and religious hate crime cases that are referred to us will almost always be in favour of a prosecution." ${ }^{187}$ However, cases should pass the evidential test for prosecution in the usual manner. The Code for Crown Prosecutors states that "[a] case which does not pass the evidential stage must not proceed, no matter how serious or sensitive it may be". ${ }^{188}$ Nonetheless, the perception amongst many interviewees was that cases which do not have a realistic prospect of conviction, and so do not pass the evidential test, still end up in court, including the Crown Court. For many who took this view, the apparent tendency to "over-charge" was linked to the CPS policy not to accept a plea to the basic offence alone. Some interviewees were very critical of CPS decision making in this regard:

"I'm not sure that they always properly consider whether that extra element is made out and meets the prosecution test in the same way that the basic, the assault or whatever, they would do. I think that if they've got an assault that they think is an assault, and the victim says ... 'And they said this ...', they just charge it without thinking; and that does cause problems down the line." (Interview Independent Barrister 14)

"You know, there are some cases they should never charge as racially aggravated, and ends up as a long Crown Court trial that could have been avoided if they'd just been a bit more sensible. That's my personal view." (Interview Independent Barrister 04)

\footnotetext{
${ }^{186}$ Information about the Victims' Right to Review scheme is available at: <http://www.cps.gov.uk/victims_witnesses/victims_right_to_review/>

${ }^{187}$ Crown Prosecution Service, 'Racist and Religious crime-CPS Prosecution Policy’ (n.d.)

<http://www.cps.gov.uk/publications/prosecution/rrpbcrbook.html> See also the CPS guidance on prosecuting racist and religious crime: <http://www.cps.gov.uk/legal/p_to_r/racist_and_religious_crime/>

${ }^{188}$ Crown Prosecution Service, 'The Code for Crown Prosecutors' (2013) para 4.4. Emphasis added

<https://www.cps.gov.uk/publications/docs/code_2013_accessible_english.pdf>
} 
Several District Judges also expressed frustration at the "inflexibility" of the CPS:

"[B]ecause the prosecution can be so inflexible there is the odd case where ... having a trial on an issue with someone who would be a vulnerable witness might not be in their best interest, simply because the prosecution are determined that they cannot let any one of these accusations go." (Interview District Judge 03)

"[T]here seems to be a policy decision that they will come to court as soon as race or homophobia or something like that is mentioned. It seems to be that nobody bothers with any thought process - it just comes to court. I have no problem bringing people who deserve it into the criminal justice system, but I think the more people you can keep out of the criminal justice system the better. I'm talking about these ones where it's just not necessary - a telling off or caution, you know, is probably enough." (Interview District Judge 10)

The following case example was provided by one District Judge who thought that the offence should have been dealt with by a caution rather than a full criminal trial:

"[l]t was a man ... in his sixties ... of good character, never been in any sort of trouble before, at a train station, lost his temper with somebody in a shop and called him something rude ... I don't know whether it was 'bloody black' or even just 'go back to your own country' or one of those offensive comments - I'm not suggesting it isn't offensive. To my recollection, having stormed off after about ten minutes, he actually went back and apologised to the person he'd abused. The police came. They arrested him. Bearing in mind we see people being cautioned for quite serious offences, the police did not caution him because it was racially aggravated. And I'm not sure what the point of bringing a sixty year old of good character into the court process when he has said something that is very offensive but could easily be dealt with by a caution. ... I'm not saying that it doesn't matter that it's racially aggravated. And you have to differentiate. I mean, there are people who are - especially on trains - shouting abuse when there are children by. And that's different. So I think you get this very different range." (Interview District Judge 10)

Conversely, another District Judge noted that they have had two or three cases where they queried why it had not been charged as racially aggravated "when you've clearly got different-coloured skins and there's some hostility". However, the interviewee also explained that the hostility was not evidenced in the language, and that may have been the limitation (Interview District Judge 01).

While there are clearly good reasons for rigorously pursuing allegations of hate crime, the rigid pursuance of "weak cases" may be counter-productive. Some independent barristers noted that, where the evidence of hostility is weak, focusing on the aggravated element can lead juries to acquit altogether, even if there is evidence to support a serious underlying offence. One barrister suggested that the CPS "could do with prioritising those cases where there's an element of motivation" rather than a demonstration of hostility (Interview Independent Barrister 02). Another stressed that CPS decision making must be objective and not "victim-led", emphasising that "[t]he moment you make it victim-led, you remove the 
impartiality of the Crown Prosecution Service ... That's not right" (Interview Independent Barrister 12).

In highlighting the possibility of "over-charging" by bringing "weak" cases to court, this report is not suggesting that the CPS should not rigorously pursue the prosecution of hate crime cases. It is, however, important to emphasise that by bringing insufficiently evidenced cases to court, prosecutors can risk undermining the credibility of hate crime legislation. If the presentation of weak evidence results in complete acquittals, as some interviewees have suggested, this too risks undermining confidence in the justice system amongst those who have experienced hate crime.

\section{RECOMMENDATION}

We recommend that charging decisions always be made in accordance with the Code for Crown Prosecutors, to ensure that the required threshold for prosecution is met on the aggravated element as well as the basic offence.

\subsection{SPECIAL MEASURES FOR COMPLAINANTS AND WITNESSES}

The obligation under EU law to make special measures available to complainants of hate crime is explained at section 4.5 of this report. Under domestic legislation, complainants of hate crime are not automatically eligible for assistance during criminal proceedings by virtue of the nature of the offence. However, they will usually be eligible for a special measures direction on the grounds of fear or distress about testifying, ${ }^{189}$ or because of age (those under 18 are automatically eligible) or incapacity. ${ }^{190}$ Special measures, such as giving evidence from behind a screen, pre-recorded evidence and examination through live-link ${ }^{191}$ can assist vulnerable and intimidated people to participate effectively in criminal proceedings. As well as enhancing the quality of a witness's evidence at a trial, special measures can minimise the negative emotional impact of giving evidence in court proceedings. ${ }^{192}$

Responses from interviewees indicate that special measures are often used to assist complainants of hate crime during criminal proceedings, thus fulfilling EU obligations. One Crown Court judge identified screens as the typical measure which is put in place, and "for particularly unhappy adults the live link, and generally for children always the live link" (Interview Crown Court Judge 06). This was echoed by a District Judge who explained that "everybody's really alert to special measures now" (Interview District Judge 08).

However, this does not mean that special measures are always being applied appropriately, or with the best interests of complainants, witnesses or defendants in mind.

\footnotetext{
${ }^{189}$ Youth Justice and Criminal Evidence Act 1999, s. 17.

${ }^{190}$ Youth Justice and Criminal Evidence Act 1999, s. 16.

191 The available measures are set out in ss. 23-30 of the Youth Justice and Criminal Evidence Act 1999. See also Criminal Practice Directions 2015 [2015] EWCA Crim 1567 (CPD), General Matters 3D-3G.

192 See generally, Penny Cooper and Heather Norton (eds), Vulnerable People and the Criminal Justice System: A Guide to Law and Practice (OUP 2017).
} 


\subsubsection{Special measures must be implemented appropriately}

The legislative scheme for special measures provides an important protection for complainants, witnesses, and eligible defendants ${ }^{193}$ during the prosecution of hate crimes. However, application of special measures must be done carefully and with due care and attention. Failure to consider the needs of individual witnesses may result in the measures exacerbating, rather than improving, the difficulties that they face. One interviewee from the CPS provided examples of where inappropriate use of, or lack of suitable, special measures for hate crime complainants could result in additional distress (Interview CPS 02). These included, for instance, where elderly people with visual and memory impairments are asked to give evidence via video link, without checking first that they are able to see and understand what is going on. There is also a risk of disabled witnesses being asked to attend court without prosecutors checking first that they are able to access the building and/or the relevant court where the case is being tried. While access to court buildings and rooms is not specifically covered by the legislation on special measures, it is something that needs to be carefully considered in cases involving disabled witnesses and complainants. One victim support worker noted that "access to courts could be improved from the sort of aspect of maybe wheelchair access, or maybe for people that are blind, for example, it could be quite difficult for them to access some courts" (Interview Victim Charity Practitioner 04).

One CPS interviewee noted that there is a need for more time to consider individual cases and greater communication between police and CPS on what is required for individual witnesses (Interview CPS 02). They also emphasised the need to "[get] the correct information from the correct specialist to be able to put somebody forward as a reliable witness". Where the complainant has a particular condition or disability, for example, looking into their medical history and seeking the opinion of a body or organisation that specialises in that condition or disability, can help:

"We had an email not so long ago from an organisation, where we had asked the police because the victim had got dementia; and we had a bland statement back from her GP basically saying that she was unreliable. And we had to discontinue the case. And the circumstances are that we then received an email from an organisation that deals with Alzheimer's and dementia, which said well that isn't actually the case ... And if you would have gone further into her case history, we would have been able to assist you in showing that she was a reliable witness." (Interview CPS 02)

While the aim of the special measures is to support complainants and witnesses during the trial process, some interviewees were concerned that the application of such measures arbitrarily could risk the defendants' rights to a fair trial. ${ }^{194}$ This was especially the case where measures were seemingly applied without specific thought for the impacts that they might have on the defence's ability to effectively challenge the prosecution's case. Alongside the legislative provisions for special measures, courts have inherent powers to make trial

\footnotetext{
${ }^{193}$ The criteria for defendant eligibility for special measures are much more restrictive than for non-defendant witnesses. See ss. 33A-33C of the Youth Justice and Criminal Evidence Act 1999.

${ }^{194}$ The right to a fair trial is guaranteed by Article 6 of the European Convention on Human Rights.
} 
adjustments in order to assist vulnerable witnesses. ${ }^{195}$ These include adjustments to crossexamination, such as, for example, a prohibition on leading questions or putting the case to the witness. ${ }^{196}$ One independent barrister raised the following concerns about the crossexamination of witnesses in hate crime cases:

"... we've got to a stage now where simplicity is key in cross-examining a vulnerable witness ... And that is all well and good ... [but it] might erode a defendant's protections in hate crime if those who make allegations of hate crime are automatically treated as vulnerable. So a man who is gay, a woman who is gay, who is otherwise fit, healthy, holds down a job, under no disability - they are not vulnerable, and should not be treated as a vulnerable witness. They need to be cross-examined in exactly the same way as they would be if they were making an allegation other than one to do with their sexuality or gender. Because that erodes the defendant's right properly to challenge the evidence, 'cause it means that you hamstring the advocate where there's no need to do so ... it needs a judge to ensure that the tag of vulnerability is only attached to those who properly deserve it, and not to assume that the person is vulnerable because the allegation is true ... Because that's the question at issue." (Interview Independent Barrister 15)

While many complainants of hate crime are rightly accorded special measures under the current law, a rigorous approach to granting special measures is necessary to ensure that the measures are both appropriate and properly applied. The appropriateness of particular special measures and trial adjustments depend very much on the circumstances of the individual. At the same time, however, one should not underestimate the way in which crime involving hostility towards a personal characteristic, such as sexual orientation, can affect an individual, or make them more susceptible to intimidation or retaliation.

It is also important for the court to consider the implications that involvement in court proceedings could have on an individual. For example, several interviewees noted the possibility of a complainant or witness being "outed" during court proceedings. One police interviewee noted that, "particularly with trans people, they worry about being outed ... but I mean that would be true of LGBT people across the spectrum anyway" (Interview Civilian Police Staff 06). A CPS interviewee explained that fear of being "outed" could prevent complainants from cooperating with the prosecution (Interview CPS 01). It is possible for witness anonymity orders to be granted under very limited circumstances (including where necessary to protect the safety of a witness), ${ }^{197}$ or for reporting restrictions to be put in place. ${ }^{198}$ However, given the importance of the principle of open justice, these are subject to rigorous conditions.

The excerpt above suggests that rigorous cross-examination should not be prevented solely because of a witness's sexual orientation. The same could be said of other personal characteristics if they do not have an impact on a witness's communication abilities.

\footnotetext{
195 See Criminal Practice Directions 2015 [2015] EWCA Crim 1567 (CPD), General Matters 3D-3G.

${ }^{196}$ On developments in cross-examination, see generally Emily Henderson, 'All the Proper Protections: The Court of Appeal rewrites the rules for the cross-examination of vulnerable witnesses' [2014] 2 Crim LR 93.

${ }^{197}$ See Coroners and Justice Act 2009, ss. 74-90.

${ }^{198}$ Youth Justice and Criminal Evidence Act 1999, ch 4. Automatic reporting restrictions apply in the youth court under the Children and Young Persons Act 1933, s. 49.
} 
However, at the same time, attention must be paid to the language used when crossexamining hate crime complainants and witnesses. One police interviewee explained that:

"I've seen it too many times whereby transphobic slurs have happened in the courtroom and the bench haven't done anything about it because they haven't noticed it. And that is the problem. If there's that complete ignorance when it's even going on in their own courtroom, how can you expect them to effectively have justice that's fair when you hear defence ... barristers ... making transphobic slurs to the trans victim who is giving evidence, implying that it would be fair game to call them a male. And by doing it by quite underhand tactics such as referring to a female as 'Mister' ... So saying 'Mister' and their surname in the court! How is that right? How is that fair? And that obviously makes them ... they're being re-victimised, re-traumatised, when they're meant to be giving evidence about one crime and effectively they're being attacked again, and yet that's somehow permissible." (Interview Police Staff 06)

Practitioners should also be mindful of making irrelevant, incorrect and offensive assumptions about an individual based on their personal characteristics. One victim support worker explained how gay complainants can be made to feel at trial:

"in terms of clients' experiences having given evidence, they feel ... that they're on trial for being gay. In the same way, the victims of sexual violence are often on trial for being in the wrong place at the wrong time, dressed a certain way, very similarly, gay clients feel that the sexuality side of it is focused on far too heavily, and that assumptions are made about their lifestyle borne out of their sexuality. For example, in this case, because my client was at a park which is known as a PSE [public sex environment], and he's a gay man, it was assumed by not just the defence, but also the judge, that he was there to have sex. Now whether he was there to have sex was immaterial ... Because like the police were there say 'this is not unlawful, we know it goes on'. But they couldn't get past these things in court, even though the police were saying we're not interested in that." (Interview Victim Charity Practitioner 06)

The CPS guidance on prosecuting homophobic, biphobic and transphobic hate crime includes a section on "appropriate language", which states that "it is essential that prosecutors adopt a style of address or reference that demonstrates respect for the sexual orientation, gender identity and lifestyle of the individuals concerned.." ${ }^{199}$ However, the responses from interviewees suggest that the main culprits for using (or allowing) disrespectful language are barristers and judges.

\footnotetext{
${ }^{199}$ Crown Prosecution Service, 'Homophobic, Biphobic and Transphobic Hate Crime - Prosecution Guidance' (2017) $<$ http://www.cps.gov.uk/legal/h_to_k/homophobic_and_transphobic_hate_crime/>
} 


\subsubsection{Attendance at court}

One of the biggest challenges faced by prosecutors was not the implementation of special measures for complainants, but getting complainants to court in the first place. This was perceived to be a bigger problem in hate crime cases than other types of crime. As one CPS interviewee explained, "I suppose the practical problem we hit most often is that we need the victim to give evidence in court. And very often they don't want to" (Interview CPS 11). The reasons that were cited for lack of complainant support for the prosecution case included: not being able to afford to take time off work; the general inconvenience of going to court; not wanting to relive the incident; the delay between commission of the alleged offence and trial; not regarding the incident as seriously as they initially had; and fear of repercussions.

If the complainant will not give evidence in court, often the prosecution will have insufficient evidence to proceed. The views of the interviewees are supported by statistics which show that "victim issues", including retraction and non-attendance, is a key reason for the unsuccessful prosecution of hate crime cases. In 2015/16, for example, "victim issues" was cited as the reason for over 30 per cent of unsuccessful race hate crime cases, as explained in section 5 of this report. ${ }^{200}$ Complainants being unwilling to proceed was also identified by Burney and Rose as a key reason why racially aggravated cases were terminated. ${ }^{201}$

While attendance at court may seem like a separate issue from special measures, there was a perception amongst interviewees that the more supported the complainant is, the more likely they will support the prosecution. At the time of Burney and Rose's research, the special measures provisions of the Youth Justice and Criminal Evidence Act 1999 had not been implemented. ${ }^{202}$ There have since been significant developments in the provision of support for complainants and witnesses (some of which are outlined above in section 4.5). One Crown Court judge identified these developments as having "encouraged complainants to come to court" (Interview Crown Court Judge 06).

However, more could be done to support complainants in hate crime cases. One independent barrister stressed the importance of the police keeping:

"the prosecution updated in terms of whether the witnesses will be coming to court, keeping in contact with them the days before the trial, and actually being at court as well. ... it is important that you do have the police at court; so if the witness isn't there at court, they're able to then make enquiries, to go round and perhaps knock on the witness's door and try and persuade them to come to court." (Interview Independent Barrister 09)

In its latest Hate Crime Report, the CPS states that "local action plans have been agreed with police forces seeking to identify, early in the proceedings, victims who may find it difficult to support a prosecution to conclusion, with a view to putting in place requisite support

\footnotetext{
${ }^{200}$ See Crown Prosecution Service, 'Hate Crime Report 2014/15 and 2016/17' (CPS 2016) 13 <https://www.cps.gov.uk/publications/docs/cps_hate_crime_report_2016.pdf> and Elizabeth Burney and Gerry Rose, Racist Offences: How is the Law Working? (Home Office Research Study 244, 2002) 64 and 77 .

${ }^{202}$ The special measures provisions in the Youth Justice and Criminal Evidence Act 1999 first came into force in 2002.
} 
measures." ${ }^{203}$ The CPS has also confirmed its commitment to supporting complainants and witnesses to come to court in recently published public statements on hate crime, and has also published a Support Guide for disabled victims and witnesses of crime which includes information about the types of support available and where to access them. ${ }^{204}$ However, finding ways to get more complainants to court will not be easy. In some cases, much will depend on the individual circumstances of the complainant. But it is also worth noting that many of the factors that result in non-attendance, such as delays in getting the case to court, are not restricted to hate crime cases, and, so, more general solutions may also be required.

\subsection{ALTERNATIVE RESPONSES TO PROSECUTION: RESTORATIVE JUSTICE FOR HATE CRIME?}

The CPS guidance for racially and religiously aggravated crimes states that "[i]f the case passes the evidential stage and it is a case of racial or religious hate crime, or it is motivated by discrimination against the victim's ethnic or national origin, or religion or belief, it is more likely that a prosecution is required in the public interest". ${ }^{205}$ This has meant that the use of out-of-court disposals for hate crime offenders is rarely an option. Furthermore, the CPS' policy and guidance on the use of conditional cautioning ${ }^{206}$ states that "[g]enerally, offences involving ... hate crime will not be suitable for Conditional Caution. However, there are rare cases when, because of the nature of the crime or the circumstances of the offender, exceptionally a Conditional Caution could be considered". ${ }^{207}$ This policy remains despite the fact that Burney and Rose recommended that "the unacceptability of [hate-based] behaviour can be signalled by a range of responses which may fall short of prosecution". ${ }^{208}$

Conditional cautions are but one means through which "low-level" offences can be addressed by the CJS. This type of cautioning requires an offender to comply with certain conditions, as an alternative to prosecution. The Code of Practice for Adult Conditional Cautions states that the aim and purpose of the disposal is to provide an opportunity: "to offer a proportionate response to low level offending; for offenders to make swift reparation to victims and communities; for offenders to be diverted at an early opportunity into rehabilitative services thereby reducing the likelihood of re-offending; and to punish an offender by means of a financial penalty". ${ }^{209}$ The code also states that in considering the appropriate conditions to achieve one or more of the objectives of the caution, a decision maker should also consider the "use of restorative and reparative processes to have a positive impact on the community or individuals affected by the offending behaviour." 210

\footnotetext{
${ }^{203}$ Crown Prosecution Service, 'Hate Crime Report 2014/15 and 2016/17' (CPS 2016) 13

<https://www.cps.gov.uk/publications/docs/cps_hate_crime_report_2016.pdf>

$204<$ http://www.cps.gov.uk/publications/docs/guide-to-support-for-disabled-victims-and-witnesses-of-crime.pdf>

${ }^{205}$ Crown Prosecution Service, 'Racist and Religious Hate Crime - Prosecution Guidance' (2017)

$<$ http://www.cps.gov.uk/legal/p_to_r/racist_and_religious_crime/>

${ }^{206}$ Criminal Justice Act 2003, s. 22.

${ }^{207}$ Crown Prosecution Service, Conditional Cautioning (n.d.) <https://www.cps.gov.uk/about/cautioning.html>

208 Elizabeth Burney and Gerry Rose, Racist Offences: How is the Law Working? (Home Office Research Study 244, 2002) 115.

${ }^{209}$ Ministry of Justice, Code of Practice for Adult Conditional Cautions, Part 3 of the Criminal Justice Act 2003 (TSO 2013 ) para 1.4 .

${ }^{210}$ Ministry of Justice, Code of Practice for Adult Conditional Cautions, Part 3 of the Criminal Justice Act 2003 (TSO 2013 ) para 2.26 .
} 
Burney and Rose stated that the use of restorative justice approaches should receive more consideration, especially for lower-level RAOs. ${ }^{211}$ The restorative justice approach allows for victims, perpetrators, and their supporters to engage in dialogue about how the incident/s has affected each party, how conflict can be resolved and harms repaired. ${ }^{212}$ Commonly used restorative practices include family group conferencing and victim-offender mediation. One of the central aspects of these restorative justice practices is empathy, which is most likely achieved by victims directly confronting offenders with their experiences of hurt and suffering, rather than a prosecutor or judge explaining such harms. ${ }^{213}$

There is a growing number of restorative justice practices that are being used as alternatives to conventional justice mechanisms (including as part of a conditional caution), and which are also used in addition to retributive penalties. ${ }^{214}$ However, these are scarcely applied in hate crime cases due to current policy focuses being on prosecution and enhanced sentencing. ${ }^{215}$ Nevertheless, a few pockets of practice are being developed in some parts of the country. One police hate crime coordinator in the South of England explained:

"So if it doesn't make it to court or if they don't want it to go to court ... we can talk about community resolutions and restorative practices ... And that, increasingly, is becoming almost a choice thing for people to decide that they don't want to go through the court system, but they do want to educate the perpetrator ... So we have this scheme we've created [a new RJ scheme] ... and it's all about hate crime and a restorative intervention ... We've mostly been doing it as a community resolution, so not going through the court system - usually at the behest of the victim rather than a lack of evidence ... So what ordinarily happens is that we'll have an intervention with the perpetrator of an incident, and the victim quite often won't be there, but I will be there in lieu of the victim, and I'll be speaking on their behalf ... Obviously there's a lot of planning that goes into it, and we have a bit of a script that's based on restorative justice, and we usually get statements from the victims in their own words - not a police statement - but in their own words about what happened, what were their thoughts and feelings, how it's affected them, that sort of restorative stuff. And we have that as a sort of very structured conversation then with the perpetrator and have that sort of restorative magic happen. And when we can feed that back to the victims, they've always been really pleased with what we've fed back, and sometimes really surprised. They weren't expecting the offender to have come out with some of the things we feed back to them, or the way they've changed their mind about what happened ... and just that sort of transformative aspect of restorative justice. Which I

\footnotetext{
${ }^{211}$ Elizabeth Burney and Gerry Rose, Racist Offences: How is the Law Working? (Home Office Research Study 244, 2002).

${ }^{212}$ Mark A Walters and Rupert Brown with Susann Wiedlitzka, Preventing Hate Crime: Emerging Practices and

Recommendations for the Improved Management of Criminal Justice Interventions - Final Report (Sussex Crime Research Centre and the International Network for Hate Studies 2016)

<https://www.sussex.ac.uk/webteam/gateway/file.php?name=preventing-hate-crime-final-report.pdf\&site=539>

${ }^{213}$ See also Mark Walters and Carolyn Hoyle, 'Healing Harms and Engendering Tolerance: The Promise of Restorative Justice

for Hate Crime' in Neil Chakraborti (ed.), Hate Crime: Concepts, Policy, Future Directions (Willan 2010). SSRN $<$ https://ssrn.com/abstract=2470079>

${ }^{214}$ Criminal Justice Joint Inspection, Facing Up to Offending: Use of Restorative Justice in the Criminal Justice System (2012)

<https://www.justiceinspectorates.gov.uk/hmicfrs/media/facing-up-to-offending-20120918.pdf>

${ }^{215}$ Mark A Walters and Rupert Brown with Susann Wiedlitzka, Preventing Hate Crime: Emerging Practices and

Recommendations for the Improved Management of Criminal Justice Interventions - Final Report (Sussex Crime Research

Centre and the International Network for Hate Studies 2016)

<https://www.sussex.ac.uk/webteam/gateway/file.php?name=preventing-hate-crime-final-report.pdf\&site=539>
} 
don't think they would have got if they'd gone to court. So I think it's preferable for a lot of people, bearing in mind as well, a lot of LGBT people in particular that I speak to, but I should imagine that this is true for all the strands, is that most victims say that they just want the perpetrator to be educated about what it's like to be part of a minority, rather than them to be punished. And I'm hearing that really increasingly. I mean there are some people who want their day in court, and they want to see justice done in a punitive way. But more and more people, just they want that education ..." (Interview Police Staff 06)

There is a growing body of research which has evidenced the potential benefits of restorative justice, both in terms of improving victim satisfaction with the justice process and improving victim emotional wellbeing. ${ }^{216}$ Although the evidence on re-offending is less conclusive, there is some evidence to suggest it reduces recidivism rates (mostly for violent crime), ${ }^{217}$ while also reducing the costs of administering justice. ${ }^{218}$

In relation to the use of restorative justice for hate crime, there is some empirical evidence to suggest that it is likely to help repair the harms caused by prejudice and hostility, while also reducing repeat victimisation. ${ }^{219}$ Such an approach may be particularly effective in hate crime cases, as it attempts to "promote empathy, provide harm reparation and potentially promote acceptance of cultural difference". ${ }^{220}$ Walters' study on the use of restorative justice for hate crime in England Wales found that, if used properly, restorative practices could alleviate many of the harms caused by hate crime victimisation (including fear and anxiety). The study also found that in 17 out of 19 cases researched in central London, involving ongoing targeted victimisation, the behaviour ceased after a restorative process had been completed. ${ }^{221}$

\section{RECOMMENDATION}

A recent report by the House of Commons Justice Committee on restorative justice states that:

"[w]e agree in principle that restorative justice should be available for all types of offence ... We recommend a rigorous system be introduced to improve compliance with the police's requirement to inform victims about restorative justice ... [and] [w] recommend that the Ministry of Justice, when publishing its Action Plan progress report, provide an explanation of how they envisage restorative justice taking place across the criminal justice system."222

\footnotetext{
${ }^{216}$ Lawrence W Sherman and Heather Strang, Restorative Justice: The Evidence (The Smith Institute 2007).

${ }^{217}$ Lawrence W Sherman and Heather Strang, Restorative Justice: The Evidence (The Smith Institute 2007).

218 Joanna Shapland, Anne Atkinson, Helen Atkinson, James Dignan, Lucy Edwards, Jeremy Hibbert, Marie Howes, Jennifer Johnstone, Gwen Robinson and Angela Sorsby, Does Restorative Justice affect Reconviction? The Fourth Report from the Evaluation of Three Schemes (Ministry of Justice Research Series 10/08, 2008).

${ }^{219}$ Mark A Walters, Hate Crime and Restorative Justice: Exploring Causes, Repairing Harms (OUP 2014).

${ }^{220}$ See also Mark Walters and Carolyn Hoyle, 'Healing Harms and Engendering Tolerance: The Promise of Restorative Justice for Hate Crime' in Neil Chakraborti (ed.), Hate Crime: Concepts, Policy, Future Directions (Willan 2010) 245. SSRN $<$ https://ssrn.com/abstract=2470079>; see also Mark A Walters, Hate Crime and Restorative Justice: Exploring Causes, Repairing Harms (OUP 2014).

${ }_{221}^{22}$ Mark A Walters, Hate Crime and Restorative Justice: Exploring Causes, Repairing Harms (OUP 2014).

222 House of Commons Justice Committee, Restorative Justice: Fourth Report of Session $2016-17$ (House of Commons HC 164, 2016) 30-31.
} 
In line with the Committee's recommendation, we recommend that restorative justice be offered to victims and defendants in hate crime cases that involve "low-level" offences, and where the accused is willing to accept the allegations against them and the victim requests restorative justice.

We also recommend that the CPS review its policy in relation to conditional cautions only being used for hate crime in exceptional cases, as such an exception is not grounded in evidence or empirical research.

Finally, restorative justice practices should also be used in addition to prosecution in more serious cases, both as an activity that can be used after conviction but before sentence, ${ }^{223}$ or as a measure to be implemented alongside other retributive sanctions.

\subsection{CONCLUSIONS}

It was noted above that, in general terms, there is less concern about procedural problems now than when the CDA was first enacted. Overall, we found widespread familiarity with relevant policies and guidelines for prosecuting hate crime, particularly RRAOs. Yet, the complexity of hate crime legislation and the accompanying policies continues to cause some confusion and uncertainty, with the potential for inconsistent practices and unfair outcomes. We see this not only in relation to charging decisions and the trial process, but also in relation to the interpretation of hate crime laws, as detailed in the following section. One District Judge summed up the situation as follows:

"The legislation is certainly complicated. You've got lots of different permutations or combinations available to you by virtue of the legislation ... In any particular case you might have a religiously aggravated offence, you might have a racially aggravated offence, you might have a s. 145 or s. 146 ... aggravation. And there are knock-on legal consequences as a result of that. You might be looking at alternative charges in some cases and not alternative charges in other cases. Within the cases that are charged you might be looking at what I call the first limb of racial or religious aggravation, or the second limb which is the displaying of hostility or the motivation. Or both. So there are lots of bits and bobs you've to think about ... It's certainly a complicated picture to consider. I wouldn't say it would give me necessarily problems, but complexity tends to create error or misunderstanding as a general principle, and therefore there's always a possibility in a complex environment of somebody in the process making a mistake that is not made in a more straightforward environment." (Interview District Judge 05)

Since criminal prosecution remains the primary response to allegations of hate crime, it seems to us that there is a need to simplify the prosecution process, and provide judges and lawyers with clear and consolidated guidance, to ensure fair and consistent outcomes. In the above discussion, we have noted various ways of reducing the complexity or confusion of prosecuting RRAOs, including a more consistent approach to charging decisions in the Crown Court. Although charging practices in the Magistrates' Court are more consistent than in the Crown Court, the incidence of double convictions and possibility of charge bargaining

\footnotetext{
${ }^{223}$ The courts can now defer sentence for restorative justice activities under the Powers of Criminal Courts (Sentencing) Act 2000 , s. $1 Z A$.
} 
could be alleviated through our recommendation that magistrates be provided with the power to return alternative verdicts. In addition to the specific recommendations made within this section, those involved in the prosecution of hate crime could benefit from a guidance document, or "handbook", as suggested by some interviewees. The guidance could take the form of a single point of reference on the procedure for prosecuting hate crime, from charging decisions to verdicts. It could set out, for example, the key legislation, case law, CPS policy and guidance, and general best practice for each stage of the prosecution process. 


\section{Interpreting the law in court}

Sections 6 and 7 have highlighted a number of evidential and procedural issues that can affect the effective application of hate crime laws in practice. In this section, we move to the next stage of the legal process by examining some of the key problems that the courts have faced when interpreting and applying the legislation in court. The Law Commission's final report has already outlined a number of complexities and disagreements that the courts have tussled with over the past 15 to 20 years. We do not cover each and every point of the law that has been highlighted by the Commission and others. Instead, we identify those issues which were highlighted thematically during the empirical stage of this research, drawing both on interview data with judges and lawyers as well as a detailed review of over 100 case reports involving hate crime offences. We start by examining how the courts have interpreted the meaning of "hostility", central to both the CDA and CJA provisions. From here, we examine how hate crime laws are applied in cases involving minority ethnic defendants against majority ethnic complainants, and finally offences that involve individuals from the same or similar ethnic group.

\subsection{PROVING HOSTILITY}

Throughout each stage of this project, a central and recurring theme has been how the courts interpret the word "hostility" (in relation to evidence of hostility see section 6.1 ). Both the CDA and the CJA state that hostility can be either "demonstrated" or form part of the offender's motivation for targeting the victim. Hostility must be directed towards the victim based on the victim's presumed membership of a racial or religious group (CDA), or based on the victim's presumed sexual orientation, disability, or transgender identity (CJA). The defendant can also be convicted of having demonstrated hostility towards someone they mistook to be a member of a certain racial or religious group. ${ }^{224}$ In addition, demonstrating hostility towards victims because they associate with (e.g. are married to) someone from a racial or religious group will also satisfy the provisions in the CDA. ${ }^{225}$

Neither the CDA nor the CJA define the key terms "demonstrate", "motivation" or "hostility". As such, what amounts to a demonstration or motivation of hostility is a matter to be determined by the fact-finder (the jury or magistrate in the case of a RRAO, or the magistrate or judge at sentencing). The CPS has provided some guidance on this, stating that, in respect of "hostility", "[c]onsideration should be given to ordinary dictionary definitions, which include ill-will, ill-feeling, spite, prejudice, unfriendliness, antagonism, resentment, and

\footnotetext{
${ }^{224}$ Rogers [2007] UKHL 8, [2007] 2 AC 62; D [2005] EWCA Crim 889, [2005] 1 WLR 2810.

${ }^{225}$ Section 28(2). Note that there is uncertainty as to whether this applies to sexual orientation, disability and transgender identity as the provision is not replicated in S. 146 of the CJA.
} 
dislike." ${ }^{226}$ Yet it is not always clear what types of conduct and language will amount to "hostility" for the purpose of the CDA or the CJA. This has caused various problems when attempting to apply the legislation.

\subsubsection{Motivation of hostility}

Section 28(1)(b) of the $\mathrm{CDA}^{227}$ states that a racially or religiously aggravated offence is committed where the offender is (partly) motivated by hostility towards a victim based on the victim's (presumed) membership of a racial or religious group. This same concept of "motivation" applies in ss. 145 or 146 of the CJA. The legislation is clear that the motivation of hostility need not be the sole motivating factor, s. 28(3) states that:

It is immaterial for the purposes of paragraph (a) or (b) of subsection (1) above whether or not the offender's hostility is also based, to any extent, on any other factor not mentioned in that paragraph.

Hence, a hostile motivation may also be accompanied by other reasons for committing an offence (e.g. the victim's other characteristics, or the victim's perceived vulnerability, ${ }^{228}$ or a parking dispute, ${ }^{229}$ or a payment dispute $\left.{ }^{230}\right)$. A complete lack of evidence to prove motivation by hostility will mean that an offence cannot be aggravated under s. 28(1)(b). ${ }^{231}$ However, where multiple causes of an offence are identified it can sometimes mask the hate-element of an offence. ${ }^{232}$ As we will see below, the courts (and juries) have also been reluctant to label offences as "racially or religiously aggravated" where the main motivation for a crime is nonhate based (such as anger or frustration).

As it stands, there is no prescribed list of the types of evidence that can be adduced to prove an offence that is motivated by hostility. ${ }^{233}$ There is limited common law jurisprudence that provides examples of hostility-based motivation. In the case of Kennedy $v D P P,{ }^{234}$ the court held that the ownership and use of a poster with pictures of black men along with the words "Illegal Immigrant Murder Scum" was evidence of racial motive. The CPS' guidance on prosecuting racially and religiously aggravated offences also notes that in the absence of an admission whilst under caution, prosecutors may seek to adduce "evidence of membership of, or association with, a racist group, or evidence of expressed racist views in the past ..."235

\footnotetext{
${ }^{226}$ Crown Prosecution Service, 'Disability Hate Crime and other Crimes against Disabled People - Prosecution Guidance' (2017) <http://www.cps.gov.uk/legal/d_to_g/disability_hate_crime/>

227 This and the following section refer primarily to the CDA, but the concepts of "motivation of hostility" and "demonstrations of hostility" apply equally to ss. 145 and 146 , CJA.

${ }_{228}$ Mark A Walters, 'Why the Rochdale Gang should have been sentenced as "hate crime" offenders' [2013] 2 Crim LR 131.

${ }^{229}$ McFarlane [2002] EWHC 485 (Admin), [2002] All ER (D) 78 (Mar).

${ }^{230} M$ [2004] EWHC 1453, [2004] 1 WLR 2758.

${ }^{231}$ Howard [2008] EWHC 608 (Admin), [2008] All ER (D) 88 (Feb)

${ }^{232}$ See e.g. Mark A Walters, 'Why the Rochdale Gang should have been sentenced as "hate crime" offenders' 2 [2013] Crim LR 131.

${ }^{233}$ We provide a non-exhaustive list of useful forms of evidence at section 6.1.

${ }^{234}$ [2008] EWHC 1848 (Admin).

${ }^{235}$ Crown Prosecution Service, 'Racist and Religious Crime - Prosecution Guidance' (2017)

$<$ http://www.cps.gov.uk/legal/p_to_r/racist_and_religious_crime/>
} 
Proof of "racist views" (as evidence of motivation) can also be established where there is evidence of past "demonstrations" of hostility. This was emphasised by May LJ in G $v D P P$ who explained:

"The prosecution has to establish the state of mind, and no doubt the evidence required to establish such a motive will often, perhaps usually involve the kind of demonstration of such racial hostility l've referred to in relation to subsection 28(1)(a). The difference however is that section 28(1)(a) essentially requires proof of what the defendant did, or what he or she did at the time of committing the offence, or at a time closely related to it. The motive, in my judgment, is at least capable of being established by evidence relating to what the defendant may have said or done on another or other occasions." 236

The Law Commission's final report on hate crime emphasised that proving motivation of hostility can be extremely difficult and it is for this reason that the CPS predominantly rely on s. 28(1)(a) of the CDA. ${ }^{237}$ Proof of motive is difficult because it requires the prosecution to adduce evidence of the reasons why the offender committed an offence. As Kay LJ stated in $D P P \vee$ Green, "[t]he search for a specific motive can be elusive and complex. That is why the establishment of criminal liability does not generally require it." 238

Our interviewees agreed that cases involving motivated hostility were extremely rare. In fact, many prosecutors and judges stated that they had never even come across a case where the CPS had pursed s. 28(1)(b) as part of the case. This was a significant finding considering that some of these interviewees were CPS hate crime coordinators who were tasked with reviewing hate crime cases that were prosecuted within their area. Some interviewees asserted that the key reason for the paucity of s. 28(1)(b) cases was the lack of adequate evidence collated by the police. One CPS hate crime lead expressed his frustration in the following terms:

"The problem it seems to me is in a lot of cases is a lack of proper investigation, lack of proper interview strategies, particularly in the area of 145,146 , because the police are just not getting it. And therefore, you know, there needs to be a lot more work done there to actually think strategically about what sort of evidence can I actually secure to prove motivation - particularly motivation - at least in part, some hostility." (Interview CPS 08)

Such a finding concurs with our earlier data on evidence collation and highlights again the need for further guidance in relation to investigating hate crimes and collating sufficient evidence to prove hostility-motivation (see section 6).

\subsection{2 "Demonstrating" hostility}

Under s. 28(1)(a) of the CDA, a defendant will be guilty of an aggravated offence where it is proved that they demonstrated hostility towards the victim based on the victim's presumed membership of a racial or religious group. Likewise, the sentence for an offence can be

\footnotetext{
${ }^{236}$ [2004] EWHC 183 (Admin) [14].

${ }^{237}$ Law Commission, Hate Crime: Should the Current Offences be Extended? (Law Com No 348, 2014 ) para 2.33.

<https://www.gov.uk/government/uploads/system/uploads/attachment_data/file/316103/9781474104852_Print.pdf)>

${ }^{238}$ [2004] EWHC 1225 (Admin) [24].
} 
increased under ss. 145 or 146 where hostility was demonstrated on the basis of the victim's (presumed) race, religion, disability, sexual orientation or transgender identity. As highlighted above, a demonstration of hostility is often easier to identify than motivation, as it usually takes the form of the utterance of words or gestures during the commission of a basic offence (section 6). ${ }^{239}$ The reasons for committing the offence, or the fact that the offender mistakenly identifies the victim as belonging to a racial or religious group, are not relevant. In $D P P \vee$ Green, Rafferty J stated: "[s]ection 28(1)(a), as distinct from (b), creates a racially aggravated offence without the requirement to prove racist motive. Disposition at the time is irrelevant". 240

Simply put, a demonstration of hostility is the expression of race or religious-based hostility (or, for the purpose of s. 146, sexual orientation, transgender, or disablist hostility) that is connected, temporally, to the commission of an offence. ${ }^{241}$ It is what Baroness Hale described in Rogers as the "outward manifestation" of racial or religious hostility. ${ }^{242}$ But what does it mean for someone to outwardly manifest hostility? Does this require an assessment of whether things said and done are objectively racially or religiously hostile? Or must defendants actually understand their actions to be racially or religiously hostile? Confusion has arisen in cases where defendants have admitted to expressing racist or anti-religious slurs, but later claim that they did this in the heat of the moment and did not directly intend to demonstrate racial or religious hostility. Burney and Rose highlighted this common occurrence in 2002 , documenting one stipendiary magistrate who commented:

"One thing that has tended to shock me quite substantially is how many people in their mitigation say 'I'm really sorry, I'm not really racist at all, it's just that I drank so much at the time and this is what came out'."243

Such a situation occurred in the case of Woods, ${ }^{244}$ where the defendant had become angry at the fact that his friend had been refused entry to a nightclub. This led to an altercation with the nightclub's doorman which resulted in an assault by Woods, during which he called the victim a "black bastard". At trial, the Justices held:

"We found the Respondent's hostility to be borne out of his frustration and annoyance as a result of his companion being denied entry to the premises, and whilst he may have intended to cause offence by the words, this was not 'hostility based on the victim's membership (or presumed membership) of a racial group'. We believed that the

\footnotetext{
${ }^{239} \mathrm{Pal}$ [2000] Crim LR 756 [16].

${ }^{240}$ [2004] EWHC 1225 (QB) [16].

${ }^{241}$ Note that most demonstrations of hostility will be within the sight or hearing of the victims. However, in some cases involving public order offences, such as using threatening or abusive language, there has been some confusion as to whether the recipient of racist or anti-religious abuse needs to personally experience it, or whether it is sufficient that someone is likely to have heard or seen the defendant's conduct. This is most likely to occur in cases involving a s. 5 POA offence (harassment, alarm or distress) which must occur "within the hearing or sight of a person likely to be caused harassment, alarm or distress". In the case of Taylor v DPP [2006] EWHC 1202 (Admin), the court found that "there must be evidence that there was someone able to hear or see the defendant's conduct, and that the prosecution does not have to call evidence that he or she did actually hear the words spoken or see the behaviour" ([9]). This means that a racially or religiously aggravated public order offence may be committed where someone is "able" to hear or see it even if a person that the slurs is directed at does not actually experience the abuse.

${ }^{242}$ [2007] UKHL 8 [6].

${ }^{243}$ Elizabeth Burney and Gerry Rose, Racist Offences: How is the Law Working? (Home Office Research Study 244, 2002$) 20$.

${ }^{244}$ [2002] EWHC 85 (Admin).
} 
Respondent's frame of mind was such that he would have abused any person standing in [D's] shoes by reference to an obvious physical characteristic had that individual happened to possess one."245

The issue here is that racist and other prejudiced remarks are often said unthinkingly and without premeditated motivation. Should such expressions of hate, which are borne mostly out of frustration and anger, rather than deep-seated prejudice, fall within the meaning of hate crime in law? On appeal, the High Court in Woods made it clear that they should, stating that the trial judge had made an erroneous interpretation of section 28(1)(a), Maurice Kay J explained that:

"Section 28(1)(a) ... is designed to extend to cases which may have a racially neutral gravamen but in the course of which there is demonstrated towards the victim hostility based on the victim's membership of a racial group. Any contrary construction would emasculate section 28(1)(a)."246

The court in DPP $v$ Green provide further reasoning for the approach taken in Woods. Rafferty $\mathrm{J}$ states that "[a]n offender might be minded to offer abuse consequent upon a range of factors, but that cannot diminish or undermine what is contemplated and expressed as 'the additional wrong' of demonstrated racial hostility." 247

Kay LJ agreed with this reasoning, noting further that:

"If [the defendant] were correct, two undesirable consequences would follow: the section would be deprived of much of its impact because a defendant would be able to deflect the emphasis from what he said to some underlying grievance or perceived grievance which caused him to say it; secondly, it would encourage an investigation of motive which, on the face of it, the provision does not require. An investigation of motive is unavoidable under section 28(1)(b), the statute so provides. However, it would be unusual to import a similar requirement where the statute does not expressly call for it. The search for a specific motive can be elusive and complex. That is why the establishment of criminal liability does not generally require it." 248

In effect, the courts are saying that where an act or words objectively demonstrate hostility, then the defendant's intention or reasoning for expressing the hostility is not relevant to a finding of guilt under s. 28(1)(a) of the Act.

Yet, this reasoning assumes that the courts (and juries) are able to determine whether a verbal statement does in fact objectively amount to hostility without enquiring into the intention or purpose of the statement made. In many cases, the meaning of the statement will be clear, based on the context and language that is used. However, there are numerous other situations where the prejudiced meaning of a word is more ambiguous. In other cases, the term used may clearly be prejudiced but the purpose for using it may not be to

\footnotetext{
${ }^{245}$ [2002] EWHC 85 (Admin) [6].

246 [2002] EWHC 85 (Admin) [12].

247 [2004] EWHC 1225 (Admin) [16]

248 [2004] EWHC 1225 (Admin) [27].
} 
demonstrate hostility. Without understanding what the defendant intended and why they said a particular word or term (or at least asking whether they were aware of its inferred meaning) can we legitimately label and punish a defendant as a "hate crime" offender?

A number of examples of ambiguous situations were given during interviews which illustrate this predicament:

"[T]here was a bit of a dispute going on between two men, and the black man said to the white man, 'You're just a fucking pikey!' You know, a pikey is an Irishman? And this fella took exception, and they started to have a bit of an exchange ... And then another black man approached within a couple of seconds, and it sort of calmed down, and he turned round to the second black man and said, 'How would you like it if I called you a fucking nigger?' And so the Irishman was charged with racially aggravated abuse. Now, he was having a discussion about whether or not I would have convicted him. There were three of us in the room. He, in fact, did convict him because he felt that the word 'nigger' crossed the line. I wouldn't have." (Interview District Judge 04)

The difference of opinion amongst the two magistrates relates to whether the determination of culpability is based on an objective assessment of the actus reus of the conduct (i.e. the act of shouting a slur) or a subjective examination of the mens rea (i.e. what was in the mind of the accused at the time of making the statement). The presiding judge determined that the mere utterance of the racist term used at some point during the commission of the offence amounted to a demonstration of hostility for the purposes of the CDA. However, the judge interviewed stated that they would have decided otherwise. Their reasoning was based on an exploration as to what the defendant had truly intended. The defendant's intention was not to express hatred but to question the victim's own expressed hostility.

David Brax explains that a defendant's intention is to be distinguished from his motive, which is the answer to the question of why the agent committed the crime. ${ }^{249}$ Instead, in exploring the intention of the defendant, the court should ask what the defendant's purpose was:

"[w]as the intention to create fear in the targeted group, causing its members to withdraw from public life ... Was it aimed to cause particularly extensive harm, or remind members of the group of their status as potential victims?"250

In practice, questions about why the defendant acted as they did, and what they truly intended by their expressions, appear to be frequent. The excerpt below illustrates the problems caused by the use of the words "black bastards" which have been directed towards police officers:

" $[\mathrm{H}] \mathrm{e}$ [the defendant] referred to [the police officers] as 'black bastards'. One of the officers was Asian origin officer. The rest of them were white British officers. The police interpreted this 'black bastard' as directed to their Asian colleague, and therefore charged

\footnotetext{
${ }^{249}$ David Brax, 'Hate Crime Concepts and their Moral Foundations: A Universal Framework?' in Jennifer Schweppe and Mark A Walters (eds) The Globalization of Hate: Internationalizing Hate Crime? (OUP 2016) 54-55.

${ }^{250}$ David Brax, 'Hate Crime Concepts and their Moral Foundations: A Universal Framework?' in Jennifer Schweppe and Mark A Walters (eds) The Globalization of Hate: Internationalizing Hate Crime? (OUP 2016) 54.
} 
him at the outset with a racially aggravated offence [however] when he said 'black bastards' he was referring to the colour of the uniforms not the colour of the skin of the officer ... When the defence solicitor got involved, it became clear, and it was accepted by the prosecution, that this guy was actually an ex-miner ... And it's common practice ... because of the fact that they wore black uniforms, were referred to by the miners at the time as 'black bastards'." (Interview District Judge 06)

It was only when there was additional exploration of the true intention of the defendant (i.e., what the defendant was trying to do with their expression), that the defendant's conduct was exposed as not intending to be a demonstration of identity-based hostility. There is, as such, good reason to include an assessment of the defendant's mens rea in determining any demonstration of hostility, as one CPS manager noted:

"I would foresee ... cases where [defendants] with a learning disability could have potentially have offended or demonstrated hostility towards someone's nationality or religion without knowing about it." (Interview CPS 14)

This perceived need amongst many interviewees to understand the true intention of the defendant is what has also led a number of judges in the past to conflate the requirements for demonstration of hostility with that of motivation. This occurred in the case of Woods, cited above, but it has also been a recurring theme in several case reports. ${ }^{251}$ In SH, ${ }^{252}$ the defendant had called a job centre employee a "monkey". The trial judge found that "[i]n the absence of any other evidence as to his state of mind I cannot see how you, the jury, could safely exclude the possibility that temper and/or personal dislike were the motivation for the use of such words if, indeed, they were uttered." ${ }^{253}$ Leveson LJ on appeal stated that the trial judge had been in error in exploring the motivation of the defendant, concluding that:

"In our judgment, in this case, it was plain that there was material on which the jury could properly conclude that these circumstances went beyond vulgar abuse into an outward manifestation of racial hostility. Neither do we accept Mr Reid's argument that 'based on membership' is synonymous to 'motivated by membership' which, following the language of Baroness Hale, is to confuse outward manifestation and inward motivation."254

In many cases, judges will make assessments as to whether evidence of hostility can be left to a jury, or, in cases involving ss. 145 and 146, will make determinations as to whether an offence is aggravated by hostility during sentencing. Ultimately, though, in respect of RRAOs, whether the words by a defendant amount to "mere vulgar abuse" or whether they are demonstrations of racial or religious hostility will be a matter for the jury to determine at trial. The next section will explore how juries respond to such a task.

\footnotetext{
${ }^{251}$ See Mark A Walters, 'Conceptualizing "hostility" for hate crime law: minding "the minutiae" when interpreting section 28(1)(a) of the Crime and Disorder Act 1998' (2014) 34(1) OJLS 47.

252 [2010] EWCA Crim 1931.

253 [2010] EWCA Crim 1931 [22].

254 [2010] EWCA Crim 1931 [28]
} 


\subsection{THE RELUCTANCE OF JURIES TO ACCEPT DEMONSTRATIONS OF HOSTILITY AS A FORM OF AGGRAVATION}

The perception amongst the legal practitioners we interviewed was that, because of the broad definition of "demonstrating hostility" under s. 28(1)(a), many jurors (and some judges, see 8.3) are reluctant to convict defendants of RRAOs. ${ }^{255}$ This reluctance has also emerged in some of the research literature with some commentators suggesting that "demonstrations", as against motivations, of hostility should not be conceived as "hate crime" at all. Rather, they argue that these types of offence are better understood as acts of frustration, which are more directly correlated with other emotions, such as anger or rage, those which are often expressed in the "heat of the moment". ${ }^{256}$ Many incidents involving a demonstration of hostility occur as a reaction to a trigger situation, and frequently alcohol is a causal factor:

"They [defendants] say 'I accept I said that, but please don't think I'm a racist. I'm not a racist. I was drunk. I was angry. This person did $x, y$ and $z$ to me. I lashed out and that's the characteristic I picked on. But I'm not a racist."' (Interview District Judge 02)

These situational factors clearly result in some juries and legal practitioners questioning whether hate speech used during the commission of a basic offence should result in the crime being prosecuted/convicted as a RRAO in the Crown Court - with the attendant label and enhanced penalty that goes with it. One Crown Court judge noted:

"I think the thing that juries do find difficult ... is that they assume - as indeed often defendants do - that what's being said is they're racist. And of course that's nothing ... to do with the legislation. We can't get inside people's heads. And indeed holding views that are abhorrent are part of a free society. It's expressing those views, whether you are or are not intrinsically racist isn't the offence; and people struggle with that [and] that's a problem in the jury room." (Interview Crown Court Judge 04)

The issue here is one of labelling. In essence, many people do not like the fact that a defendant will be labelled as a "hater" or as a "racist" simply because they have lost their temper and said something abusive in the heat of the moment. Indeed, most interviewees also noted that defendants rarely, if ever, admit to the racial or religious element of an offence: "I mean once in a blue moon the defendant will actually admit the racially aggravated offence, but just offhand I can't really think of that ever happening" (Interview Crown Court Judge 06).

The denial of hostility by almost all defendants, and the general resistance amongst jurors to label defendants as "haters" or "racists", means that the CPS have an uphill battle to prove most aggravated offences beyond reasonable doubt in the Crown Court. One Crown Court judge explained what they saw as the most frequent outcome in such cases:

\footnotetext{
${ }^{255}$ In practice, the majority of Crown Court trials end in conviction. In 2012, for example, the conviction rate for all RRAOs in the Crown Court was $63.7 \%$. See Home Office, Ministry of Justice and Office for National Statistics, 'An overview of hate crime in England and Wales' (2013) Appendix Table 3.08

$<$ https://www.gov.uk/government/statistics/an-overview-of-hate-crime-in-england-and-wales>

${ }^{256}$ See e.g. Larry Ray, David Smith, and Liz Wastell, 'Shame, rage and racist violence' (2004) 44(3) British Journal of Criminology 350; David Gadd, 'Aggravating Racism and Elusive Motivation' (2009) 49(6) British Journal of Criminology 755.
} 
“... juries don't like, I think, branding somebody as a racist; or they feel, in my view, or they may feel that by convicting somebody they brand them as a racist, which I think often leads - as in my last case - to the jury ... in the face of pretty clear evidence that, you know, hostility was demonstrated ... acquitting of the racially aggravated offence and convicting of the simple one.

I: So, you feel that there's sometimes a reluctance from the jury ...?

P: A huge reluctance ... A huge reluctance. I mean, pretty much every case l've thought very clearly the offence was racially aggravated, but ... they come back and say, "not guilty', or generally, 'not guilty'”. (Interview Crown Court Judge 01)

An independent barrister similarly reflected:

“... juries look at them and they think, 'well that person's not racist. I'm going to find them not guilty.' The legislation doesn't require the prosecution to prove that people are racist; they just have to prove that they've demonstrated a hostility. But there is a disconnection, I think, within the minds of juries and what the legislation says ... they look at defendants and they think, 'they're not racist. They just said something in the heat of the moment'." (Interview Independent Barrister 08)

The reluctance to label defendants as "racist" is likely to reflect the fact that to do so is to attach one of the worst forms of social stigma to someone. In some respects, this reflects a positive social change, meaning that it is no longer socially acceptable to be outwardly racist in the UK. However, it also means that people are generally reluctant to impose such a label on someone unless they are confident that it is morally justified. One judge commented on this phenomena in the following terms:

"I think juries will, generally speaking, reflect social trends; and I think a very positive social trend is that it's not acceptable to call yourself a racist and it's regarded as a big deal to accuse somebody of racism. And, you know, jurors are very reluctant to take the step of labelling somebody as a racist ... I mean there was a time when people where quite happy to admit they were racist, but nowadays nobody would want to accept that ... racist and paedophile are basically the two worst labels you can now attach to anyone". (Interview Crown Court Judge 01)

This general reluctance amongst juries to attach the label of "racist" to those who unthinkingly demonstrate hostility in the heat of the moment is a clear barrier to the successful operationalisation of s. 28 and ss. 145 and 146 of the CJA.

One way to challenge this resistance amongst jurors is for judges to provide careful explanations that set out why a demonstration of hostility should attract the label of "racially or religiously aggravated", and why aggravated offences are deserving of an enhanced penalty.

The problem with such a recommendation is that many judges themselves remain unconvinced that the label should apply in such cases. 


\subsection{JUDICIAL RESISTANCE TO ACCEPTING DEMONSTRATIONS OF HOSTILITY AS HATE CRIME}

The interviews revealed how some legal practitioners felt that the aggravated offences equated to a finding of racism, and they were not always comfortable making such a finding. One Crown Court judge remarked in relation to the definition of aggravated offence:

"I think it's too wide and it includes too much that's trivial and not genuinely motivated by hatred. I mean that's the point - hate crime: if I get cross with you and say, 'Go away you foreign bitch!", that doesn't mean I hate foreigners does it?" (Interview Crown Court Judge 03)

During a discussion relating to the types of cases that should come before the court, the same judge stated:

“... the CPS cannot tell the difference between something unpleasant, insulting, said in temper, and something said, which actually indicates that somebody is motivated by racial dislike. For example, two police officers who are black arrest a white defendant. It takes them twenty minutes to put him in handcuffs and get him back to the police station. During that time, he does nothing but try to physically assault them and call them, 'niggers', tells them to 'get back in the trees', and any other kind of racial insults you can think of. In those circumstances you've got a strong case that he's not just a man who has lost his temper, but he's genuinely motivated by racial dislike. That is a completely different set of circumstances from the one that l've just postulated; but you try explaining that to a CPS lawyer - and you will get nowhere." (Interview Crown Court Judge 03)

The judge continued:

"I think that it is sensible if we reform the system because ... I am sure that [the conviction rate] is very, very low; and the real damage it does is that it brings the system into disrepute in the eyes of the public. Because jurors are members of the public; and if you keep them hanging around for forty-eight hours; and then they go into court and they spend a day doing one of these silly little so-called 'racially aggravated' cases; they acquit; they go home and then they tell their friends and family that the Crown Court's a waste of time and a waste of public money. And if that is the basis of their experience, who can blame them?" (Interview Crown Court Judge 03)

Another Crown Court judge commented critically on what they perceived to be an oldfashioned attitude about hate crime in parts of the judiciary:

"... the older judges still have the attitude 'well, anybody says unpleasant things in the middle of a heated argument and it doesn't make the offence more serious'. I think some might still have that rather old-fashioned attitude ... And I think some people, I think even some judges, still find it difficult to grasp that racially aggravating an offence is out of all proportion to calling someone fat or ginger or another insult ... Some, I think, can't differentiate between an insult which is just an insult, and an insult which goes to the very being of another individual." (Interview Crown Court Judge 05) 
The fact that there is still pervasive judicial resistance to s. 28(1)(a), despite the offences being in operation for 20 years, is of concern. Without general acceptance as to the validity of the section, the CPS will continue to struggle to successfully prosecute some cases under this section in court.

\subsection{PROVING HOSTILITY AS RACISM - "GOD'S GIFT TO DEFENCE"}

A combination of the following factors means that proving hostility beyond reasonable doubt in the Crown Court is extraordinarily difficult: defendant denials; the severe stigma of labelling someone racist; juror resistance to convicting for the RRAOs; and judicial resistance to accepting loss of temper as proving hostility. Our interviews revealed further that defence barristers are attuned to what they perceived as a weakness in the legislative armour which they use to their advantage. One interviewee commented:

"When you're defending, you'll point it out [that the defendant was not motivated by hostility] to them [the jury], because people will grab for the first insulting thing, you know? Whether that's calling someone 'skinny', 'ginger', 'black'... it's just an epithet - the first thing they're going for ... very often it's not racially motivated, it's not derived from hostility. It's they've lost their temper and they're just lashing out." (Interview Independent Barrister 11)

Another independent barrister had also clocked this tactic:

"... what you'll often find is that the defence will argue that, 'Well he may have said that, but he doesn't really hate Asian people.' But obviously ... technically that's not a defence under the Act, but it's still an argument which you sometimes encounter. So that's the ... classic scenario." (Interview Independent Barrister 07)

As a consequence of this tactic, some trials can become consumed with proving whether the defendant is a racist or not. Several judges and independent barristers spoke about cases descending into a trial about character, with counsel calling numerous witnesses to testify that the defendant has "black" or "Asian" friends:

"The irony is, of course, when it comes to trial, the whole case is taken up as to whether your client is racist. So what you do is you call his black dentist, his Chinese doctor, his best friend - and l've done this - his best who is a black shop steward, who specialises in race relations. And as a result, of course, the jury are absolutely convinced you're the least racist person in the country and they acquit you of everything - including the crime you were charged with. So actually, it's God's gift to defence I would say." (Interview Independent Barrister 01)

Clearly, there is a need for some modification in this area if the law is to be applied effectively. However, before we provide our recommendations for improving the application of s. 28(1)(a) of the CDA, it is important to explore further whether the "demonstration of hostility", as proving racial or religious aggravation, can be justified in principle. 


\subsection{IS A DEMONSTRATION OF HOSTILITY REALLY A "HATE CRIME"?}

Is it fair for barristers and judges to argue that the wide reach of s. 28(1)(a) is unfairly labelling and punishing "frustrated" and "angry" offenders as "hate crime" perpetrators? One Crown Court judge thought so. They remarked:

"... you devalue it if you prosecute it in circumstances where a jury will sit back and say, 'I'm sorry, whatever my ethnic background, I have in moments of anger - particular in a moment of anger in drink - said things I regret'." (Interview Crown Court Judge 04)

Some commentators have also argued that the test for hostility is indeed too broad, casting the net of social control too widely over individuals who are not the real purveyors of hate and hostility in society. Kay Goodall, though an advocate of hate crime legislation, nonetheless reflects that there are serious implications for offenders if the public think that their conviction means that they are "racists" when this is not the true purpose of the legislation. Goodall comments (in relation to stirring up of hatred offences) that:

"[society] will attach a tag of pre-meditated bigotry to convictions for something else. If the offenders are characterised as purveyors of extreme forms of racism, the message is lost. Those convicted should be stigmatised for their express acts of abuse, not for imagined acts of hatred." 257

The breadth of s. 28(1)(a) led one Crown Court judge to recommend that the law be reformed to remove aggravated offences that could be proved by a demonstration of hostility caused by a sudden loss of temper:

"... that's why I suggested the re-drafting of s. 28 so that those words 'racially aggravated' have their ordinary English meaning. That is to say something made worse by an element of racism, not mere loss of temper. Now I suppose if you were unlucky and my reforms were agreed to, and you found yourself in front of a politically correct magistrate, that they might take the view that the use of the word 'black' or 'nigger', even in temper ... is of itself racist ... whether the person uttering the word is by character and inclination like that most other times or not." (Interview Crown Court Judge 03)

This line of thinking is prominent amongst some commentators and practitioners involved in addressing hate crime. However, there are two significant arguments in response to concerns about over-labelling of hate crime perpetrators. The first concerns the level of culpability that can be attached to even the most sudden loss of temper that results in a demonstration of hostility. Walters argues that most expressions of identity-based hostility, even when committed in the heat of the moment, are nonetheless still either intended or recklessly expressed in order to subjugate the victim's identity. As such, most demonstrations of hostility are still conscious attempts to subordinate victims based on their

\footnotetext{
${ }^{257}$ Kay Goodall, 'Incitement to Religious Hatred: All Talk and No Substance?' (2007) 70(1) MLR 89, 102. Note though that the Goodall also states that "[s]o long as an offender flung out his racial insult intending it at that moment to diminish his victim on that ground - or utterly disregarded the possibility that it would have that effect - then it is an integral part of his conduct, not any mere ulterior intent nor unintended by-product. His act is thus a constitutive element of the crime." Kay Goodall, 'Conceptualising 'racism' in criminal law' (2013) 33(2) LS 214, 237.
} 
characteristics. ${ }^{258}$ Intentional or reckless attempts to subordinate identity should attract both the label of hate crime and the additional blame that is attached to it. This position appears to be supported by Chalmers and Leverick, whose report sets out the evidence base for the Scottish Government's current consultation on revising hate crime law. In their view, the argument for including "spontaneous insults" in the circumstances outlined here is "entirely justified". ${ }^{259}$ In determining whether the demonstration is meant to subjugate the victim's identity, Walters asserts that the court need only ask one further question:

"would the offender have used similar language if directing the insult towards someone of the same or similar ethnic identity to himself? ... If the answer is no then we can draw inferences from the fact that he decided to use the victim's ethnic background as part of his insult. One might also infer from the offender's use of the [slur] that his intentions went beyond mere description, especially when we consider that the purpose of an insult is to hurt or belittle someone. The insult goes beyond mere description to that of conveying a symbolic message about the victim's identity, which in turn becomes intrinsically linked to the crime committed due to the fact it is expressed during the commission of the offence."260

It is difficult to comprehend situations where an offender could, during the commission of an offence, fail to be aware that their vocalisation of hostility would send a symbolic message to the victim and others like them which devalues them based on their identity. ${ }^{261}$ It may well be true that most such offenders are not hardened bigots who make it their mission in life to eradicate "difference". ${ }^{262}$ However, the fact they have expressed prejudice provides more than an inference that the offender holds some form of internalised bias. One District Judge expounded:

“... a lot of defendants say, 'I'm not racist', or 'I have friends from that ethnic group' ... I don't automatically accept that ... or realistically accept that on many occasions, because if they say something that is blatantly racist, in my view it is because ... or it appears on many occasions that that is a feeling they have internally, which they either suppress or ... express it in some way. But under a situation of stress or a situation of powerlessness i.e. if they've being detained by the police, or a situation where they suddenly come into confrontation with somebody, then they're undergoing the process of whatever they're doing - like a car accident. But then out it comes and they say something racist in that way." (Interview District Judge 03)

Another District Judge commented, "not everyone when they've had too much to drink refers to people in racially abusive terms, so is it really an excuse ...?" (Interview District Judge 07)

\footnotetext{
${ }^{258}$ The subordination of "difference" is what Perry argues is the key to understanding hate crime: Barbara Perry, In the Name of Hate: Understanding Hate Crimes (Routledge 2001).

${ }^{259}$ James Chalmers and Fiona Leverick, A Comparative Analysis of Hate Crime Legislation: A Report to the Hate Crime Legislation Review (University of Glasgow 2017) 50-51.

${ }_{260}$ Mark A Walters, "Conceptualizing "hostility" for hate crime law: minding "the minutiae" when interpreting section 28(1)(a) of the Crime and Disorder Act 1998' (2014) 34(1) OJLS 47, 68.

${ }^{261}$ Mark A Walters, 'Conceptualizing "hostility" for hate crime law: minding "the minutiae" when interpreting section 28(1)(a) of the Crime and Disorder Act 1998' (2014) 34(1) OJLS 47.

${ }^{262}$ Paul Iganski, Hate Crime and the City (Policy Press 2008).
} 
Regardless of whether a perpetrator's prejudices are latent forms of bias that simmer under the surface, boiling over in times of social stress, or whether they have no conscious feelings of animosity towards the victim's presumed characteristic at all, the fact remains that they have chosen (although fleetingly) to hurt their victim through expressing prejudice towards them. It is the intention (or recklessness) to express prejudice in order to hurt someone that carries an enhanced level of culpability (see further section 9.1.1).

The vast majority of people become aware at an early age that public displays of prejudice are deemed as offensive, which, as we have seen above, is why so many defendants actively resist the label of "hate crime offender." One independent barrister referenced this in relation to offences aggravated by homophobia:

"[Y]ou might get clients turning round and saying, 'Oh, you know, I admit I said that ... but I'm not homophobic. I've got friends who are gay', and you know, trying to disassociate themselves with being homophobic ..." (Interview Independent Barrister 09)

Few offenders will be completely ignorant of either the moral reprehensibility or the harmfulness that their demonstration of hostility will embody. Some offenders may not care whether they cause harm to the victim - they may even turn a blind eye to it - but this is a different matter. In terms of criminal culpability, it should matter only that the offender has a subjective awareness of (or intends or is reckless to) the fact that their actions will be perceived by rightminded individuals as an expression of identity-based hostility. Culpability must rest on whether the defendant is a disseminator of hatred (or hostility) within society, and not on whether we believe him or her to be ideologically committed to racism, islamophobia, homophobia or whatever the prejudice might be.

Where the offender's demonstration of hostility is temporally connected with the commission of an offence, it cannot thereafter be separated from the basic offence as a "moment of madness". That is because the demonstration of hostility becomes an intrinsic element of the offence, which underlies part of the offender's intention (recklessness) to harm the victim. Indeed, demonstrations of hostility change the quality of the basic offence. Stanton-Ife explains in the Law Commission's theoretical paper how the addition of hate speech, when committed alongside an act of violence, combines to form something greater than the sum of its parts. ${ }^{263}$ One cannot simply say that the hate speech (or a demonstration of hostility) was unfortunate abuse and not important to the culpability of the basic offence, as it is the hatebased abuse that shapes the victim's and the broader community's experience of the conduct. In fact, for some offences (such as s. 5 of the POA) the demonstration of hostility itself makes up the offence.

The second argument in response to concerns about over-labelling of hate crime perpetrators is that offences which include demonstrations of hostility are likely to cause greater levels (and distinct forms) of harm than basic offences, both to the victim and the

\footnotetext{
263 John Stanton-Ife, Criminalising Conduct with Special Reference to Potential Offences of Stirring up Hatred against Disabled or Transgender Persons (Law Commission 2013) 45-46.
} 
communities to which they are attached. ${ }^{264}$ As we will see below, part of the justification for hate crime laws (and the penalty enhancements that they attract) is that they cause enhanced levels of emotional distress. For example, an attack on identity often results in individuals viewing the world around them differently (as more malevolent and less safe) and, in turn, this can have damaging impacts on an individual's behaviour; such as affecting the way they dress, how they speak, where they are prepared to travel to. ${ }^{265}$ These behavioural changes help victims to avoid repeat targeted violence, but, in doing so, individuals suppress their true identity, which creates internalised suffering. It is these very distinct harms caused by hate crime which differentiate these offences from other types of crime.

The distinct harms caused by hate incidents also frequently have a ripple effect, causing fear, anxiety and anger amongst other minority group members. ${ }^{266} \mathrm{~A}$ recent study by the Sussex Hate Crime Project found that hate crimes have similar impacts on other group members who, as a result of hearing about incidents, also feel vulnerable and anxious about being targeted. ${ }^{267}$ These emotional responses to hate crime are linked again to group members changing their behaviours in order to avoid victimisation.

Beyond the direct and indirect harms of hate crime are the cultural harms caused by public expressions of prejudice. A demonstration of identity-based hostility not only attacks groups of people, but it undermines society's political commitments to equality, respect and dignity. ${ }^{268}$ Duff and Marshall frame these types of harm as civic wrongs. They explain that expressions of hatred aimed at groups of people are a means of denying these individuals "civic fellowship". ${ }^{269}$ By this, they mean that the hostilities demonstrated by offenders send a communicative message of "civic hatred" to entire groups of people that denies them equal participation in public discourse and of their rightful place as equal citizens in society. It is these civic harms, they argue, that makes expressions of hate "distinctively wrong". ${ }^{270}$

It is important to consider the multitude of harms caused by hate-based offending when determining the appropriate offence label and appended penalty, as one independent barrister noted the risk of abolishing demonstrations of hostility would be that defendants could turn up in court and say:

\footnotetext{
${ }^{264}$ Bakalis argues that hate crime harms are increased but that they are not of a different type of harm to the basic offence. Chara Bakalis, 'The victims of hate crime and the principles of the criminal law' (2017) LS, doi: 10.1111/lest.12171 11. We argue differently, noting that the types of harms caused by hate and prejudice are very different in nature, giving hate crime its unique status. See also John Stanton-Ife, Criminalising Conduct with Special Reference to Potential Offences of Stirring up Hatred against Disabled or Transgender Persons (Law Commission 2013), who argues that the hate-element of an offence changes the quality of the conduct.

${ }^{265}$ Paul Iganski, Hate Crime and the City (Policy Press: 2008).

${ }^{266}$ Barbara Perry and Shahid Alvi, "We are all vulnerable": The in terrorem effects of hate crimes' (2012) 18(1) International Review of Victimology 57; Jenny Paterson, Rupert Brown, Mark A Walters and Diego Carrasco, 'Feeling others' pain: Indirect effects of hate crime on two victimised communities' (forthcoming).

${ }^{267}$ Jenny Paterson, Rupert Brown, Mark A Walters and Diego Carrasco, 'Feeling others' pain: Indirect effects of hate crime on two victimised communities' (forthcoming). See also Kathryn Benier, 'The harms of hate: Comparing the neighbouring practices and interactions of hate crime victims, non-hate crime victims and non-victims' (2017) 23(2) International Review of Victimology 179.

${ }^{268} \mathrm{See}$, in relation to sexual offences, Clare McGlynn and Erika Rackley, 'Criminalising Extreme Pornography: A Lost Opportunity' [2009] 4 Crim LR 245.

${ }^{269}$ Antony Duff and Sandra E Marshall, 'Criminalizing Hate?' in Thomas Brudholm and Birgitte Johansen (eds), Hate, Politics, Law (OUP, forthcoming).

${ }^{270}$ Antony Duff and Sandra E Marshall, 'Criminalizing Hate?' in Thomas Brudholm and Birgitte Johansen (eds), Hate, Politics, Law (OUP, forthcoming).
} 
"'Well I know I said that, but l'm not really a racist.' And that would be to see the offence only from their point of view. But if you're the taxi driver who is being called racist names, it's not going to matter to you that in fact he's a lovely young man when he's not had a drink, is it?" (Interview Independent Barrister 07)

Were we to simply strike out demonstrations of hostility as mere drunken mistakes, or as uncharacteristic moments of madness, we would be likely to undermine the concept of hate crime altogether. As one District Judge lamented:

"Can I just say that I'm very concerned about not watering down hate crime. I think if one sort of adopts the approach that somehow that things that are said in the heat of the moment are less significant, then I think that that's creating the opportunity for the unscrupulous to try to avoid the consequences of their behaviour, and at the same time, that ignores the impact upon the community at large and the individual who has suffered it." (Interview District Judge 09)

It is for these reasons that demonstrations of hostility must remain on the statute book. ${ }^{271}$

\subsection{CONCLUSIONS}

The current case law interpreting "hostility" remains in a somewhat unsatisfactory state. This has not changed since 2002, when Burney and Rose suggested that "[s]omething more than the dictionary is required to clarify the question of mens rea in racial aggravation". ${ }^{272}$ While the upper courts have emphasised that demonstrating hostility is an objective "outward manifestation" of hostility, which does not require an appraisal of the inner thinking of the defendant, the reality is that, in practice, prosecutors, barristers, judges, and perhaps most importantly, juries, are rejecting evidence of what might be considered an "objective" demonstration of hostility, having inquired into the defendant's true intentions. There is, then, clearly a need for further guidance as to when, or if at all, an objective demonstration of hostility is, in actuality, an expression of identity-based prejudice that is deserving of the label "hate crime".

\section{RECOMMENDATION}

In an attempt to resolve the issues posed by interpreting and applying s. 28(1)(a) and the concept of "demonstrating hostility", we adopt a refined test put forward by Walters. ${ }^{273}$ This test would ensure that only those who are "aware" of the identity-based "hostility" element of their actions are culpable and sentenced as "hate crime" offenders. In determining whether hostility has been demonstrated by the defendant, whether applying the CDA or CJA, the court or jury may wish to ask:

\footnotetext{
${ }^{271}$ Whether this should mean continued inclusion in both specific criminal offences and sentencing provisions is considered below, at section 11.5 .

${ }^{272}$ Elizabeth Burney and Gerry Rose, Racist Offences: How is the Law Working? (Home Office Research Study 244, 2002$) 114$.

${ }^{273}$ Mark A Walters, 'Conceptualizing "hostility" for hate crime law: minding "the minutiae" when interpreting section 28(1)(a) of the Crime and Disorder Act 1998' (2014) 34(1) OJLS 47.
} 
“(1) Would the defendant have directed the same insult towards anyone, regardless of their identity characteristics? And,

(a) Is the defendant aware that such an insult demonstrates racial, religious, sexual orientation, disability or transgender based hostility?

Or

(b) Does he understand that his language or conduct is likely to be understood by right-minded people as indicating hostility towards the victim based on the victim's (perceived) identity characteristic?

If the answer is no to the first question and yes to either part of the second it is clear that the demonstration made is one of hostility." 274

This type of test would ensure that utterances of words that are not intended, or at least understood as identity-based slurs, will not fall within the meaning of "demonstrating hostility" under the CDA or CJA. ${ }^{275}$ This should serve to aid juries' (and judges') understanding of why a demonstration of hostility in the heat of the moment is still a "hate crime" (i.e. where it is done knowingly), while safeguarding against unfair labelling and disproportionate sentencing for those who objectively, but unknowingly, demonstrate hostility.

As part of the process of determining whether a defendant is aware that they have demonstrated hostility, it may also be important for prosecutors and judges to explain to juries (or magistrates) why demonstrations of hostility are categorised as aggravated offences. For example, the court could explain to the jury (without suggesting that the defendant is guilty) that expressions of prejudice are likely to be more impactful, both in terms of the level of harm experienced by victims and the indirect impacts experienced by minority groups. Moreover, regardless of whether a perpetrator lashes out in the heat of the moment, or whether they have persistent racist or homophobic beliefs, any hostile expressions of prejudice undermine democratic commitments to the principles of equality, respect and individual dignity. ${ }^{276}$

\subsection{MINORITY VERSUS MAJORITY HATE CRIMES}

The main purpose of hate crime laws is to protect groups who are particularly susceptible to targeted abuse and who, as a result, are likely to experience heightened levels of harm. The archetypical hate crime is carried out by an angry white male who brutally attacks his black or Asian victim. ${ }^{277}$ We know from extensive empirical research that this image does not reflect the majority of hate crimes that occur in the UK, with many incidents being committed

\footnotetext{
${ }^{274}$ Mark A Walters, 'Conceptualizing "hostility" for hate crime law: minding "the minutiae" when interpreting section 28(1)(a) of the Crime and Disorder Act 1998' (2014) 34(1) OJLS 47, 72.

${ }^{275}$ Goodall offers a similar model which she terms "constitutive animus". She argues that the prosecution must prove either that the defendant intended the act to have a racist effect or that they have utter disregard for whether it will. Kay Goodall, 'Conceptualising 'racism' in criminal law' (2013) 33(2) LS 214.

${ }^{276}$ As to whether demonstrations of hostility committed in the heat of the moment should attract a different level of uplift in sentence compared with hate-motivated perpetrators, see section 8.5 .

${ }^{277}$ See Gail Mason, 'Hate crime and the image of the stranger' (2005) 45(6) British Journal of Criminology 837.
} 
by individuals from different (including minority) ethnic backgrounds, and often involving lowlevel crimes that are committed by people known to the victim. ${ }^{278}$

How have the courts dealt with cases that fail to resemble the archetypical "hate crime", as depicted in the media and elsewhere? In Johnson $v$ DPP, the appellant told a parking attendant to "leave the black community alone, to get out of the black area where they were and to go to white areas, and he was telling all this as a black person addressing two white people." 279 His statements included, "get up Eccleshall Road and do your white aunties and uncles" and "this is our patch not yours". ${ }^{280}$ At trial for a racially aggravated offence, the court found that the words were not capable of amounting to a demonstration of racial hostility. However, on appeal the court found that the defendant's words were capable of demonstrating racial hostility and that it mattered not that the hostility was only partly based on the victim's presumed racial group.

Other courts have not been as liberal with their interpretations in such situations. In Johnson, ${ }^{281}$ a heavily pregnant woman beeped her car horn in a street where several cars were double-parked and she could not manoeuvre around them. J, a black male, came over to the woman's car, where he shouted, "What the fuck do you want? What the fuck are you doing you stupid white girl?" and "Who do you think you are? What do you think you are doing you fucking stupid white bitch?", causing the woman harassment, alarm and distress. On appeal, Williams $\mathrm{J}$ held that:

"We are satisfied that the appellant lost his temper and that while the racial insult was upsetting, the victim was more concerned about the risk to her of violence and so the racial abuse was incidental to the assault and there are none of the seriously aggravating factors identified in the guideline." 282

It is difficult to comprehend how an exclamation regarding geographical space (as racial space) could amount to a demonstration of racial hostility, but abuse including "stupid white bitch" could not for the purposes of s. 28(1)(a) of the CDA. One potential reason for this disparity is that some judges are inclined to disregard demonstrations of hostility against white people as less serious. Indeed, there was some limited evidence amongst interviewees to suggest that anti-White hate should not amount to an aggravated offence. A hate crime co-ordinator for the police argued:

“... if you're dealing with a black person who has racially abused, and I'll say 'racially' in inverted commas, a white person, we would determine that that's racist, when actually it's

\footnotetext{
${ }^{278}$ See Colin Roberts, Martin Innes, Matthew Williams, Jasmin Tregidga and David Gadd, Understanding Who Commits Hate Crime and Why They Do It (Welsh Government Social Research 38, 2013) <http://gov.wales/docs/caecd/research/130711understanding-who-commits-hate-crime-and-why-they-do-it-en.pdf>; Mark A Walters and Rupert Brown with Susann Wiedlitzka, Causes and Motivations of Hate Crime (Research Report 102, EHRC 2016); Neil Chakraborti, Jon Garland and Stevie-Jade Hardy, The Leicester Hate Crime Project: Findings and Conclusions (University of Leicester 2014)

<https://www2.le.ac.uk/departments/criminology/hate/documents/fc-full-report>; Matthew Williams and Jasmin Tregidga, All Wales Hate Crime Project (Race Equality First and Cardiff University 2013)

$<$ http://orca.cf.ac.uk/60690/13/Time\%20for\%20Justice-All\%20Wales $\% 20$ Hate $\% 20$ Crime $\% 20$ Project.pdf>

279 [2008] EWHC 509 (Admin) [10].

280 [2008] EWHC 509 (Admin) [11].

281 [2011] 2 Cr App R (S.) 29.

282 [2011] 2 Cr App R (S.) 29 [10].
} 
not. It's prejudice, because black people cannot be racist against white people, but if we try and explain that to an officer outside, or to someone who doesn't understand the basics in relation to race and racism what that actually is, they won't understand that - not at all." (Interview Police Staff 03)

Such a perception also led one District Judge to claim that anti-British abuse is less likely to be prosecuted as hate crime:

"I think the bigger problem is a lack of consistency in prosecution; and certainly, l've seen cases involving different ethnic groups, so Scots, Irish or Welsh, and sometimes people because they're white, where clearly there's been racial hostility used towards them but no prosecution based on that hostility - just a simple offence used. So that can be a problem in practice." (Interview District Judge 08)

While there is some limited evidence to suggest that some courts are reluctant to convict minority against majority hate crimes, new research ${ }^{283}$ suggests that disproportionality high numbers of BAME perpetrators are being proceeded against as hate crime offenders. Indeed, one District Judge remarked:

"I see now the reverse more often than not ... So the person with the black skin always ends up in the dock, no matter what. So he might call somebody a 'white bitch'. And now they're being prosecuted for that. And whether it's again that sort of institutional discrimination against black people. ... I don't know ... Because I don't think ... Well a white person wouldn't be there necessarily for calling somebody a 'white bitch'. They should be!" (Interview District Judge 01)

Given that hate crime laws were originally enacted to protect and respond to violence against BAME people, and given that BAME people may suffer institutional racism and are disproportionately represented throughout the criminal justice process, ${ }^{284}$ it is concerning to find the possibility of disproportionately high rates of prosecution against BAME defendants.

\section{RECOMMENDATION}

We recommend that the CPS monitor the ethnic background of defendants proceeded against for all types of hate crime.

Further research on the occurrence of minority versus majority hate crimes would also help improve the knowledge base on the impacts that hate crime legislation may be having on different identity groups.

\footnotetext{
${ }^{283}$ Mark A Walters and Alex Krasodomski-Jones, Hate Crime Offending: Who, What, When and Where? University of Sussex and DEMOS (forthcoming).

${ }^{284}$ See, for example, Ministry of Justice, Statistics on Race and the Criminal Justice System 2014 (Ministry of Justice 2015) <https://www.gov.uk/government/collections/race-and-the-criminal-justice-system>; Ministry of Justice, Black, Asian and Minority Ethnic Disproportionality in the Criminal Justice System in England and Wales (Ministry of Justice 2016) <https://www.gov.uk/government/publications/black-asian-and-minority-ethnic-disproportionality-in-the-criminal-justice-systemin-england-and-wales>; Ministry of Justice, The Lammy Review (Ministry of Justice, 2017) <https://www.gov.uk/government/uploads/system/uploads/attachment_data/file/643001/lammy-review-final-report.pdf>
} 


\subsection{RELUCTANCE TO PROCEED AGAINST "SAME-RACE" HATE CRIMES}

Although the prosecution of minority against majority hate crimes caused some differences in opinion amongst interviewees, far more comments were made about the problems faced by the courts when dealing with intra-community hate crime, i.e., incidents where hostility is demonstrated against a person of the same (or similar) group identity as the defendant.

The case law on this topic is not without equivocation. In White, ${ }^{285}$ the defendant, W, who was of West Indian origin, called his victim an "African bitch". Pill LJ held that:

"While it may be unusual ... for a person to show hostility to another based on the other's membership of a racial group where the alleged offender comes from the same racial group, we see no basis for holding that such hostility cannot in law be shown. It may be more difficult in such cases to establish that the hostility is of racial, national or ethnic origin as the case may be. However a person may show hostility to his own kind whether racial, ethnic or national." 286

While the court makes it clear that hostility can be demonstrated intra-communally, it highlights the fact that establishing evidence of this may prove difficult. In the case of $P a l^{287}$ the defendant, a young Asian male, called the victim (who was described as of "Asian appearance") a "White man's arse licker" and a "brown Englishman" and later physically attacked him. The court held that the offence was not racially aggravated because the defendant's remarks were motivated by anger and referred not to the victim's racial group but to his relationship with white people. ${ }^{288} \mathrm{Pal}$ has since been said to be heavily dependent upon its facts, with the courts suggesting that such demonstrations of hostility would fall within s. $28(1)(a)$ of the CDA. ${ }^{289}$

During our interviews, it became clear that, in practice, there was a general attitude amongst many practitioners that "same-race" hate crime are not really hate crimes at all. One independent barrister lamented:

“... interestingly, a lot of my cases have been people being accused of hate crimes against their own group; which has always ended up as a bit of a nonsense. I had another case where somebody ... said, 'You look like Lewis Hamilton'. And he said 'You're a coconut ... And he basically was saying to him, 'You're not a real black person - I'm a real black person'." (Interview Independent Barrister 02)

Another defence barrister commented:

"He called her 'a monkey dancing to the organ grinder's tune'. Now by that, he meant, what is a black person like you working for a racist police force? Not telling her 'You're a

\footnotetext{
${ }^{285}$ [2001] EWCA Crim 216.

${ }^{286}$ [2001] EWCA Crim 216 [20].

287 [2000] Crim. L.R. 756.

${ }^{288}$ The court noting further that "it is quite unreal to suggest on the basis of the facts found that the Respondent is anti-white men"; the facts being that Pal had been with a group including white youths at the time of the incident which the court took as evidence that the defendant was not being racist.

${ }^{289}$ DPP v McFarlane [2002] EWHC 485 (Admin); Rogers [2007] UKHL 8.
} 
monkey'. And certainly not motivated by hostility to a racial group. He was incandescent with rage about it, which is why we had this appeal ... it didn't even get a custodial sentence. And we won the appeal. Although there is now authority to say I shouldn't have won that appeal." (Interview Independent Barrister 01)

Others noted that "same-race" hate crimes could cause confusion for the jury who may find it difficult to comprehend racial hostility as occurring between individuals with the same or similar backgrounds:

"I mean the one which sometimes causes problems for the jury, understandably, is the self-hating hate crime, you know? When someone black is accused of calling someone else 'black' - an epithet. And, you know, then it all gets very confusing for the jury about, well how can it be demonstrating hostility towards someone based on their racial grouping when that person is also ....? You know ... Which, quite rightly, they're right to get confused by that because, yes, the person is being insulting, but is it really what the legislation was intended to stop?" (Interview Independent Barrister 11)

Confusion amongst jurors was matched by the perception (especially amongst independent barristers) that magistrates are less likely to convict defendants of racially aggravated offences where the complainant and the defendant are from the same (or similar) ethnicity. One interviewee stated:

“... there's also going to be more of a disconnect with these offences between, you know, a predominantly white, older male bench, judges ... . and then a lot of clients, some of whom would say, 'I said black, he said black, you know? We're both black ... what is this about? You know? Why on earth is this something that matters?'” (Interview Independent Barrister 02)

It is not only same or similar racial backgrounds that can confuse the courts' approach to hate crime. Commenting in relation to anti-religious hate crime, one District Judge stated:

"I don't think we can call a Muslim harassment case, where the victims are other Muslims, we can't call that religious harassment, can we?" (Interview District Judge 02)

Finally, it is important to note that "same-race" (or same-religion) hate crimes can actually mask inter-group hostilities by conflating people's ethnicities and nationalities with the colour of their skin. Many hate crimes occur between different communities within the broad umbrella of a "racial group" (such as where a Pakistani Asian perpetrator targets an Indian Asian victim). Such cases can be perceived as non-hate related violence because they occur between individuals sharing a presumed identity characteristic. This presumption can mask the hostilities that exist between groups of individuals from different cultural and ethnic backgrounds. In some cases, interviewees noted that the courts had actively prevented them from examining witnesses on whether the complainant and defendant were from different ethnic backgrounds:

“... I tried to cross-examine the complainant to try and find out, you know, what the root of this alleged hostility was and why he felt that that it was racially aggravated, given that 
they were both Asian. I tried to find out, you know, where he was from in Asia, what nationality he'd regard himself as or what ethnic group he'd categorise himself as. And I was actually prevented from doing that by the magistrates who said I shouldn't be asking where he's from. But I thought it was very relevant where you've got two people from the same continent, and in order to kind of clarify why it was that he felt this was racist language used towards him when the defendant is Asian himself." (Interview Independent Barrister 09)

\section{RECOMMENDATION}

Our findings suggest that, while leading case law makes it clear that "same-race" hate crimes are to be treated like any other type of hostility, in practice, there is a perception that cases involving complainants and defendants that share a racial characteristic should not be pursued under the CDA or the CJA provisions. We recommend that further information about "same-race" hate crimes, and when (and whether) they should be prosecuted as RRAOs, should be included in CPS guidance. 


\section{Sentencing}

In Part A of this report, we set out the legislative framework of hate crime in England and Wales, including the relevant sentencing provisions. It will be recalled that RRAOs, prosecuted under the CDA, attract a higher maximum sentence than the basic version of the offences. For all other hate crimes, if the prosecution proves a demonstration of hostility or a hostile motive based on race, religion, disability, sexual orientation or transgender identity, the judge must enhance (uplift) the sentence in accordance with s. 145 (race and religion) or s. 146 (disability, sexual orientation and transgender identity) of the CJA (though the sentence cannot exceed what is prescribed for the basic offence). In this part of the report, we consider the purpose of enhanced penalties and look at how the legislative regime for sentencing hate crimes operates in practice, including: whether judges are passing "appropriate" sentences; whether rehabilitation and community programmes are appropriate for hate crimes; judges' approaches to determining sentence "uplifts" for hate crimes; general awareness and application of ss. 145 and 146; the use of Newton hearings; and the relationship between the CDA and CJA.

\subsection{THE PURPOSE OF ENHANCED PENALTIES}

There are a multitude of rationales that underpin the hate crime provisions. ${ }^{290}$ This report does not examine all of these in detail. Indeed, the theoretical arguments justifying hate crime legislation are now well-rehearsed within the extant literature ${ }^{291}$ However, we did explore the main reasoning provided by judges for enhancing sentences in hate crimes cases. To further understand the justifications for enhancing sentences for hate crimes, we asked CPS lawyers, independent barristers, judges, the police, and victim advocates whether they felt that the current legislative framework helped to ensure that defendants are "sentenced appropriately" 292 for their crimes. The section then examines: how non-punitive (community and rehabilitative) sanctions can be used more widely to form of part, or all, of a penalty "uplift"; the methods judges use to calculate their uplifts; problems associated with "double counting" of the hostility element at sentencing; whether there is a difference in approach to uplifting sentences for crimes motivated by, verses demonstrating, hostility; the use of victim personal statements (VSP) and community impact statements (CIS) to reveal

\footnotetext{
${ }^{290}$ See Jennifer Schweppe and Mark A Walters, 'Hate crimes: Legislating to enhance punishment' (Oxford Handbooks Online in Criminology and Criminal Justice 2015); John Stanton-Ife, Criminalising Conduct with Special Reference to Potential Offences of Stirring up Hatred against Disabled or Transgender Persons (Law Commission 2013).

${ }^{291}$ John Stanton-Ife, Criminalising Conduct with Special Reference to Potential Offences of Stirring up Hatred against Disabled or Transgender Persons (Law Commission 2013); David Brax, 'Hate Crime Concepts and their Moral Foundations: A Universal Framework?' in Jennifer Schweppe and Mark A Walters (eds) The Globalization of Hate: Internationalizing Hate Crime? (OUP 2016).

${ }^{292}$ Note we did not explain what was meant by "appropriate", as we wanted to see how interviewees interpreted what an appropriate sentence for hate crimes might be.
} 
the distinct harms of hate crimes; issues with a lack of awareness within parts of the CJS in relation to the CJA provisions; problems with the use of Newton hearings; and finally the complex relationship between the CJA and the CDA provisions.

\subsubsection{Justifications for penalty enhancements}

By far the two most common reasons provided by judges for enhancing sentences were based on retributive principles (i.e. commensurate and deserved punishment) and deterrent approaches (including examples of individual, general and educative deterrence).

Chief amongst the principled justifications for penalty enhancements for hate crime has been the assertion that hate crime is a more serious category of offence (compared with their basic counterparts), both in terms of the harms they cause and the level of culpability that is attached to offenders' mens rea. Researchers have long pointed out that hate crimes are likely to "hurt more" 293 and, therefore, should be classified as a graver category of offending that attract enhanced penalties. This retributive approach to punishing hate crime offenders is now well supported by empirical research that indicates that hate-motivated offences are more likely ${ }^{294}$ to cause heightened levels of harm, both in terms of physical and emotional trauma, to the victim, when compared to non-hate offences. ${ }^{295}$ Other studies have shown that hate crimes can also have damaging emotional, behavioural and spatial impacts on entire minority communities (indirect victimisation). ${ }^{296}$ The "ripple effect" of many hate crimes means that incidents not only affect direct victims, but can cause immense fear, anxiety, and anger in other community members, which researchers have shown can lead to many individuals changing the way they dress, how they look, and even what locales within their community they are prepared to visit. ${ }^{297}$

Legal scholars have also argued that hate crime offenders are more culpable for their crimes (compared with basic offences) because they are more morally blameworthy for their actions. Schweppe argues that the increased blameworthiness of hate crime offenders resides in the

\footnotetext{
${ }^{293}$ Paul Iganski, 'Hate crimes hurt more' (2001) 45(4) American Behavioral Scientist 626.

${ }^{294}$ Feinberg argues legislatures employing the harm principle must also consider the gravity of a possible harm and the probability of it occurring in determining specific prohibition. The graver the harm and the greater the possibility it occurring the greater the case is for criminalisation. Joel Feinberg, The Moral Limits of the Criminal Law Volume 1: Harm to Others (OUP 1987) $215-216$

${ }^{295}$ See e.g. Gregory M Herek, J Roy Gillis and Jeanine C Cogan, 'Psychological sequelae of hate-crime victimization among lesbian, gay, and bisexual adults' (1999) 67(6) Journal of Consulting and Clinical Psychology 945; Gregory M Herek, J Roy Gillis, Jeanine C Cogan and Eric K Glunt, 'Hate Crime Victimization Among Lesbian, Gay, and Bisexual Adults: Prevalence, Psychological Correlates, and Methodological Issues' (1997) 12(2) Journal of Interpersonal Violence 195; Jack McDevitt, Jennifer Balboni, Luis Garcia and Joann Gu, 'Consequences for victims: A comparison of bias- and non-bias-motivated assaults' (2001) 45(4) American Behavioral Scientist 697; Steven F Messner, Suzanne McHugh and Richard B Felson, 'Distinctive characteristics of assaults motivated by bias' (2004) 42(3) Criminology 585; Paul Iganski, Hate Crime and the City (Policy Press 2008); Wen Cheng, William Ickes and Jared B Kenworthy, 'The Phenomenon of Hate Crimes in the United States' (2013) 43(4) Journal of Applied Social Psychology 761. For example, recent data taken from the Crime Survey for England and Wales recorded that 34 percent of hate victims stated they were affected "very much" compared with just 14 percent of victims of crime overall (Home Office, Ministry of Justice and Office for National Statistics, 'An overview of hate crime in England and Wales' (2013) 46

$<$ https://www.gov.uk/government/statistics/an-overview-of-hate-crime-in-england-and-wales>).

${ }^{296}$ Jenny Paterson, Rupert Brown, Mark A Walters and Diego Carrasco, 'Feeling others' pain: Indirect effects of hate crime on two victimised communities' (forthcoming) showed that (community) indirect victimisation can be more severe for hate-motivated incidents compared with similar non-hate motivated incidents. See also Jenny Paterson, Rupert Brown and Mark A Walters, 'The indirect effects of anti-LGB\&T hate crimes: the moderating effects of identification and number of perpetrators' (forthcoming); Barbara Perry and Shahid Alvi, '"We are all vulnerable": The in terrorem effects of hate crimes' (2012) 18(1) International Review of Victimology 57.

${ }^{297}$ Jenny Paterson, Rupert Brown, Mark A Walters and Diego Carrasco, 'Feeling others' pain: Indirect effects of hate crime on two victimised communities' (forthcoming).
} 
added element of discrimination that the perpetrator purposefully evinces. ${ }^{298}$ Acts of hate and hostility undermine our democratic society and are likely to cause (or at least exacerbate) social and cultural divisions in society.

Both enhanced harm and elevated moral indignation mean that the law holds hate crime offenders to a higher degree of culpability for their actions than those who commit basic offences. Baroness Hale, in her leading speech in the House of Lords case of Rogers, explains why we have specific hate crime laws:

"The mischiefs attacked by the aggravated versions of these offences are racism and xenophobia. Their essence is the denial of equal respect and dignity to people who are seen as 'other'. This is more deeply hurtful, damaging and disrespectful to the victims than the simple versions of these offences. It is also more damaging to the community as a whole, by denying acceptance to members of certain groups not for their own sake but for the sake of something they can do nothing about. This is just as true if the group is defined exclusively as it is if it is defined inclusively." 299

A number of judges interviewed for this study provided similar evaluations of the need for enhanced penalties when sentencing hate crime offenders. One District Judge explained that these reasons were particularly salient in the current political climate:

"[W]hat I want to do is just send out a message, you know, that this offence is much more serious because of that hostility ... because it's just so corrosive ... I mean ... the fact that it undermines clearly our democratic values, it leads to feeling of victimisation to those to whom it's addressed; and there's a danger, particularly currently with Brexit and everything that's going on, particularly in relation to religious and racially aggravated offending, that that sort of behaviour is going to become more prevalent. So I'm trying to nip it in the bud really." (Interview District Judge 09)

We see here that the seriousness of hate crime offences is measured both by the cultural harms that hate crimes are likely to cause (infringement of democratic values) as well as the individual harms that are inflicted on the victim. Beyond this reasoning is the reference the judge makes to the aim of preventing further harm (especially in times of heightened racial and religious animus). This second aim of sentencing relates to deterrence theory. The theory posits that by increasing sentences for hate crime offenders, the state helps to eradicate such crimes by making it less "worthwhile" for the offender to repeat their actions (individual deterrence), while also deterring others from publicly expressing their hatred (general deterrence). ${ }^{300}$ However, the specific and general deterrent effects of hate crime legislation and enhanced penalties are not supported by empirical evidence. In fact, in some cases, it is possible that leaving court feeling stigmatised could result in rejection of the court's ethical position and lead to recidivism. ${ }^{301}$

\footnotetext{
298 Jennifer Schweppe, 'Defining Characteristics and Politicising Victims: A Legal Perspective' (2012) 10(1) Journal of Hate Studies 173.

299 [2007] UKHL 8 [12].

300 Based on ideas of "utility": see Jeremy Bentham, An Introduction to the Principles of Morals and Legislation (Pickering 1823).

${ }^{301}$ See Elizabeth Burney, 'Using the Law on Racially Aggravated Offences' [2003] Crim LR 28, 35.
} 
Nonetheless, some commentators have argued that the social condemnation provided by hate crime laws may help to form a source of what is known as "educative deterrence". ${ }^{302}$ By this they mean that the specific criminalisation of hate crimes serves a communicative role which sends a strong message to the public against demonstrations of identity-based hostilities. This message, in turn, reinforces positive social mores that denounce prejudice and that discourage future acts of hatred (see also 11.1.3). ${ }^{303}$ We found evidence of this approach to sentencing in a number of reported cases: for instance Rose LJ in the case of Saunders states:

"One of the most important lessons of this century, as it nears its end, is that racism must not be allowed to flourish. The message must be received and understood, in every corner of our society, in our streets and prisons, in the services, in the workplace, on public transport, in our hospitals, public houses and clubs, that racism is evil. It cannot coexist with fairness and justice. It is incompatible with democratic civilization. The courts must do all they can, in accordance with Parliament's recently expressed intention, to convey that message clearly, by the sentences which they pass in relation to racially aggravated offences. Those who indulge in racially aggravated violence must expect to be punished severely, in order to discourage the repetition of that behaviour, by them or others." 304

Regardless of whether, in practice, enhanced sentencing has (or can have) a deterrent effect, it was clear that most interviewees felt that hate crimes were deserving of more serious punishment. But does the legislative framework provide the necessary means through which hate crime offenders can receive an "appropriate" penalty?

\subsubsection{Looking beyond deterrent and retributive uplifts}

Does the fact that hate crime hurts more, mean that hate crime offenders should always be punished more severely than those who commit basic offences? The increased maximum sentences for aggravated offences under the CDA certainly signifies that this should be the case. However, simply adding more time onto an offender's term of imprisonment, or adding an additional sum of money onto a fine, is unlikely to fulfil the Government's aims of "preventing hate crime by dealing with the beliefs and attitudes that can lead to hate crime" and reducing the number of incidents that occur in our communities. ${ }^{305}$

A District Judge reflected on whether sending offenders to prison for longer really does any good in terms of helping offenders to challenge their negative beliefs and attitudes:

"It's got to be really bad, because often the short sentences that we've the power to impose in the Magistrates' Court are not going to do any good. He's just locked up in a

\footnotetext{
302 Jennifer Schweppe and Mark A Walters, 'Hate crimes: Legislating to enhance punishment' (Oxford Handbooks Online in Criminology and Criminal Justice 2015).

303 Jennifer Schweppe and Mark A Walters, 'Hate crimes: Legislating to enhance punishment' (Oxford Handbooks Online in Criminology and Criminal Justice 2015)

${ }^{304}$ [2000] 1 Cr App R 458, 461.

305 Home Office, Action Against Hate: The UK Government's plan for tackling hate crime (2016)

<https://www.gov.uk/government/uploads/system/uploads/attachment_data/file/543679/Action_Against_Hate_-

_UK_Government_s_Plan_to_Tackle_Hate_Crime_2016.pdf>
} 
prison which is like a people factory. I know that; I've been in one today ... And l've visited them before ... They don't do a lot of good. They haven't the resources or the man- or person-power to deliver meaningful programmes except for longer serving prisoners, so they're just contained. They're just warehoused, and then they're let back out subject to probation supervision." (Interview District Judge 06)

The Law Commission consultees stressed that reforming enhanced sentencing alone would not adequately deal with the causes or consequences of hate crime and that measures beyond sentencing uplifts were therefore a necessary part of addressing hate crime including rehabilitation, re-education and restorative justice. ${ }^{306}$ Although it is important for the aggravated offences to send a strong message censuring hate crimes, greater (or at least some) consideration must be given to the use of non-punitive sentences in order to tackle the underlying causes and harms of such crimes. ${ }^{307}$

\subsubsection{Focusing on community and rehabilitation sentences as going towards the uplift}

Section 142 of the CJA states that there are five purposes to sentencing that the courts "must have regard to". These are: (a) the punishment of offenders, (b) the reduction of crime (including its reduction by deterrence), (c) the reform and rehabilitation of offenders, (d) the protection of the public, and (e) the making of reparation by offenders to persons affected by their offences. These purposes mean that the courts can, and should, use their sentencing powers to attach other types of sanctions (programmes) to hate crime offenders' sentences that focus on both rehabilitation and restorative measures. There are a number of ways in which judges can do this. One District Judge and one police officer mentioned specific intervention programmes that can be used for hate crime offenders; these included the Thinking First/Thinking Skills Programme and the Promoting Human Dignity Programme (PHD): ${ }^{308}$

"[l]t's a ... nineteen days' programme that can be attached as a requirement under the Criminal Justice Act ... just like unpaid work, curfew, mental health condition, alcohol ... This is a 'Think First Programme' or 'Thinking Skills Programme', I think they call it now, but it was 'Think First' then. It's to try and instil in them some structured thinking, almost like a count to ten approach before you immediately fly off the handle impulsively and behave in this kind of fashion. Think, in your own mind, whether it's the right thing to do, try and understand right from wrong; and even if you can't do that, think about the consequences and what it's like if it happens to you. ... They get them to try and have more victim empathy, so they concentrate on how would you feel if it was your sister who used to be a brother, and is now a sister, and everybody in your community was treating her like you're treating her." (Interview District Judge 06)

\footnotetext{
${ }^{306}$ Law Commission, Hate Crime: Should the Current Offences be Extended? (Law Com No 348, 2014)

<https://www.gov.uk/government/uploads/system/uploads/attachment_data/file/316103/9781474104852_Print.pdf>

${ }^{307}$ Mark A Walters, Hate Crime and Restorative Justice: Exploring Causes, Repairing Harms (OUP 2014).

${ }^{308}$ See further information about these programmes in Mark A Walters and Rupert Brown with Susann Wiedlitzka, Preventing

Hate Crime: Emerging Practices and Recommendations for the Improved Management of Criminal Justice Interventions - Final Report (Sussex Crime Research Centre and the International Network for Hate Studies 2016)

<https://www.sussex.ac.uk/webteam/gateway/file.php?name=preventing-hate-crime-final-report.pdf\&site=539>
} 
"[T]hey're one of the only Probations I know in and around the country that have a hate crime programme for offenders which is called Promoting Human Dignity (PHD), so we're recommending to judges that they refer them to that." (Interview Police Staff 03)

This police officer also spoke about the need for the PHD programme to be developed and the need for increasing referrals to this programme, as they "should be tenfold" (Interview Police Staff 03).

Depending on the seriousness of the offence, ${ }^{309}$ a hate crime intervention programme could be used as a mandatory part of a sentence, and as a specific means of imposing a sentence "uplift". However, as it currently stands, there are only a small number of locations throughout England and Wales that provide community-based and rehabilitation interventions for hate crime - and those that do exist focus heavily on racially motivated offending. In their review of criminal justice interventions for hate crime, Walters et al found that:

"... our searches indicated that hate crime was not a priority for offender management agencies in many parts of England and Wales, with those areas where programmes did exist being limited to locations where hate crime was perceived to be a particular 'problem'." 310

Several interviewees noted the paucity of programmes available for them to refer offenders onto; for instance one District Judge commented:

"There are no specific rehabilitation programmes geared around hate crimes. ... When we make a community order now we can't stipulate what they do. We can only say you'll do rehabilitation activity requirements up to a number of days. And then the CRC or the Probation determine what goes into that. ... So if you make a suspended sentence order now, then you might not attach any requirements to it, just because that in itself would be sufficient punishment because, you know, they've recognised that they've done wrong." (Interview District Judge 01)

Other comments by judges indicated that rehabilitation requirements were rarely, if ever, used for hate crime offenders; one Crown Court judge noted:

"I think that it's an interesting debate whether, for example, in some cases of hate crime, whether the public interest may be best served by people going on a course so they can understand other people's views. ... I don't know whether the Probation Service... I'm not aware that they have any course on hate crime. ... It would be a pretty good idea actually. ... To change people's perceptions of other people." (Interview Crown Court Judge 02)

\footnotetext{
${ }^{309}$ One District Judge pointed out one of the problems with the ability to impose community penalties in low-level offences: "I do want to stress that point ... I don't want to seem that I'm over-punitive. It opens the door; it's the key in the lock to opening up community penalties ... because if it's fine only you can't impose community penalties because the offence is deemed not serious enough. And I think that is a serious defect" (Interview District Judge 06).

${ }^{310}$ Mark A Walters and Rupert Brown with Susann Wiedlitzka, Preventing Hate Crime: Emerging Practices and

Recommendations for the Improved Management of Criminal Justice Interventions - Final Report (Sussex Crime Research Centre and the International Network for Hate Studies 2016)

<https://www.sussex.ac.uk/webteam/gateway/file.php?name=preventing-hate-crime-final-report.pdf\&site=539>
} 
One of the perceived problems of using community or rehabilitation programmes for hate crime is that these will be seen as a "soft touch". However, penalty enhancements can, and must, (based on s. 142 of the CJA) be synthesised with other approaches to sentencing. Some studies have shown that alternative sanctions for hate crime can reduce recidivism, with one study showing that $45 \%$ of offenders who had attended an empathy-based programme ${ }^{311}$ that was attached to a community order reoffended after completion of the programme. This was compared with $75 \%$ of a control group who had been dealt with by the court for racially aggravated offences. ${ }^{312} \mathrm{~A}$ wider review of research into rehabilitation programmes for hate crime suggests that "cognitive-based therapies, involving either one-toone or group based work ... provide one small part of a very complex strategy for preventing hate crime". ${ }^{313}$ It is suggested that the CJS pursue a policy that ensures community and rehabilitation programmes form part of the criminal justice response to hate crime and are fully utilized as part of the sentencing framework. ${ }^{314}$

We believe that while hate crime legislation is necessary to send a message to perpetrators, victims, communities, and society that such hostility and prejudices are unacceptable, the potency of this message need not be tied (solely) to punitive outcomes for hate crime. The criminalisation and conviction of hate crime offenders can also be supported by community and rehabilitation programmes (as well as restorative justice practices, as outlined above) that aim to address the hostile attitudes that give rise to this type of offending. This is not to suggest that the enhanced penalties should be abolished, but rather it is to urge the courts to save the most severe of punitive penalties as a last resort.

\section{RECOMMENDATION}

When dealing with first and second time offenders, the court should consider community- or custody-based rehabilitation interventions (where available) as a means of "uplifting" sentence.

For example, where the basic version of the offence might ordinarily attract a six-month term of imprisonment, this could be uplifted by attaching a rehabilitation programme to this term of imprisonment (as against, for example, adding three months to the term as a percentage uplift for the aggravation).

The courts would be better supported in this approach to sentencing where probation services bring specific community and rehabilitation programmes to the attention of the court in areas where they are available.

\footnotetext{
${ }^{311}$ The Smile Hate Crime Awareness Programme.

${ }^{312}$ Paul Iganski, with Karen Ainsworth, Laura Geraghty, Spiridoula Lagou and Nafysa Patel, 'Understanding how "hate" hurts: a case study of working with perpetrators and potential perpetrators', in Neil Chakraborti and Jon Garland (eds) Responding to Hate Crime: The Case for Connecting Policy and Research (Policy Press 2015).

${ }^{313}$ Although more long term research is needed to show whether these interventions "work" for hate crime offenders: Mark A Walters and Rupert Brown with Susann Wiedlitzka, Preventing Hate Crime: Emerging Practices and Recommendations for the Improved Management of Criminal Justice Interventions - Final Report (Sussex Crime Research Centre and the International Network for Hate Studies 2016) 34 <https://www.sussex.ac.uk/webteam/gateway/file.php?name=preventing-hate-crime-finalreport.pdf\&site=539>

${ }^{314}$ Mark A Walters, 'Readdressing Hate Crime: Synthesizing Law, Punishment and Restorative Justice' in Thomas Brudholm and Birgitte Johansen (eds), Hate, Politics, Law (OUP, forthcoming).
} 


\subsection{ARE SENTENCES "APPROPRIATE”?}

We encountered mixed views on whether judges have sufficient sentencing powers and pass appropriate sentences in hate crime cases. When asked how satisfied victims usually are with the sentence that is handed down by the court, one interviewee who provides support for victims explained that "it's kind of split down the middle. You know, usually you get very happy outcomes and then other times not so happy" (Interview Victim Charity Practitioner 04). One victim support and policy professional was "hesitant to generalise because people have all sorts of different responses ..." (Interview Victim Charity Practitioner 05). However, they explained that TV and media coverage of serious incidents can sometimes raise expectations, leaving some victims disappointed "where a sentence dips far below these massive twenty-year sentences or whatever, these lifetime sentences" (Interview Victim Charity Practitioner 05). Similarly, a second interviewee from the victim support sector explained that "clients ... may have instinctive feelings about the sentence, but then once it's explained to them either by us or the CPS or the police, they kind of understand why certain sentences are the way that they are" (Interview Victim Charity Practitioner 06).

The perception amongst many of the practitioners that we interviewed, particularly judges and independent barristers, was that, overall, sentencing powers and sentences passed are appropriate:

"There's enough leeway in sentencing for you to do what you need to do. As long as there's one lacuna - as long as the charge is right. As long as the charge is right, you can sentence appropriately" (Interview District Judge 02)

"I think judges are sentencing appropriately, frankly." (Interview Crown Court Judge 08)

"[F]rom what I know, I wouldn't say that the sort of sentences are disproportionate or lenient or anything." (Interview Independent Barrister 16)

However, two independent barristers pointed to "tough" sentences that had been unsuccessfully appealed, and one Crown Court judge took the view that sentences for hate crimes may be too harsh:

"Since most people who are convicted of so-called 'hate crime' offences are not actually guilty of doing something because they genuinely are motivated by racial or religious hatred, I think the sentences are a bit on the stiff side." (Interview Crown Court Judge 03)

Conversely, a few CPS lawyers expressed disappointment at the amount of uplift which is sometimes applied:

"I've seen cases where the court have said, yes we agree this is a hate crime; we're going to uplift a conditional discharge from six months to nine months, which I think is insulting. The same with some financial penalties - l've seen courts suggest that they've uplifted $£ 50$ fines to $£ 75$. So there's cases where you feel they're paying lip service to the need to uplift the sentence." (Interview CPS 01) 
In terms of whether judges have sufficient powers to sentence appropriately, a small minority of judges expressed frustration at their limited sentencing powers in hate crime cases. Two District Judges thought that there should be a higher maximum sentence for the racially aggravated s. 5 public order offence, which has a maximum penalty of a fine not exceeding level 4 on the standard scale. Similarly, one Crown Court judge raised concerns about the limits of ss. 145 and 146 :

"I have pointed out that the problem with 145 and 146 is that you are limited to the maximum sentence for the offence itself; and if the maximum sentence for the offence itself is low, then there's not the scope to increase it because of the aggravating factor. So that is, I think, a severe limitation in the section in the Criminal Justice Act." (Interview Crown Court Judge 05)

Due to the vast range of sentences that can be given for hate crimes, it is not possible to ascertain a single perspective on "appropriate" sentencing for such offences. Generally, the sentencing framework was perceived to be flexible enough to provide judges with a range of sentences that hate crime offenders are felt to "deserve". Whether this is done consistently is a very different matter (explored further in the following sections).

While we are convinced of the need for strong hate crime laws which are applied equally across identity groups, we also believe that there is a need to start a new conversation about the use of harsher penalties as the sole (or main) means through which the criminal justice system seeks to address the causes and consequences of hate crime. ${ }^{315}$ In this regard, we have offered further thoughts on the use of rehabilitation and restorative justice measures, based on recent research and the comments made by a number of interviewees during this study (see sections 7.6 and 9.1). Next, we explore how judges determine the "appropriate" uplift in sentence for hate crime.

\subsection{ENHANCED PENALTIES: APPROACHES TO CALCULATING SENTENCE UPLIFTS}

How do judges determine the level of uplift for an aggravated offence? The Sentencing Advisory Panel previously laid out a two-stage approach to sentence racially aggravated offences which was adopted by the Court of Appeal in Kelly and Donnelly. ${ }^{316}$ The court should first decide on the appropriate sentence without the element of racial or religious aggravation, but including any other aggravating or mitigating features. The sentence should then be enhanced to take account of the racial or religious aggravation. ${ }^{317}$ When handing down the sentence, the judge should state publicly what the appropriate sentence would

\footnotetext{
${ }^{315}$ See Mark A Walters, Hate Crime and Restorative Justice: Exploring Causes, Repairing Harms (OUP 2014); Mark A Walters and Rupert Brown with Susann Wiedlitzka, Preventing Hate Crime: Emerging Practices and Recommendations for the Improved Management of Criminal Justice Interventions - Final Report (Sussex Crime Research Centre and the International Network for Hate Studies 2016) 14 <https://www.sussex.ac.uk/webteam/gateway/file.php?name=preventing-hate-crime-finalreport.pdf\&site $=539>$

${ }^{316}$ [2001] 2 Cr App R (S) 73 CA. The Court of Appeal in R v Higgins [2009] EWCA Crim 708 reaffirmed Kelly and Donnelly and noted that the two-stage approach was now adopted by the Sentencing Guidelines for assault cases.

${ }^{317}$ Subsequent case law has clarified that, where the aggravating feature of the offence is so inherent and integral to the offence that it is not possible sensibly to assess the overall criminality in such a discrete way (such as a public order offence where the entirety of the offending behaviour is a demonstration of racial hostility), the court must assess the seriousness of the conduct involved and its criminality as a whole (Fitzgerald [2003] EWCA Crim 287).
} 
have been without the racial or religious aggravation. This approach is now set out in sentencing guidance provided by the Sentencing Council, which applies to hostility based on all five protected characteristics (as explained at section 4.3 of this report). ${ }^{318}$ Crown Court cases with sentences that appear to be unduly lenient may be referred to the Court of Appeals for review, ${ }^{319}$ provided that the offence is triable on indictment or is on a list of eitherway offences (which all RRAOs are).

The interview data provided a more nuanced understanding of how judges determine sentence where the offence is aggravated by identity-based hostility. During discussions on whether enhanced sentences were "appropriate" for hate crime offenders, some judges referred to the amount of "uplift" they would give for a hostility aggravated offence. These discussions revealed a variation in approach to sentencing hate crimes, which could be categorised into three types of (potentially interlinking) methods. These can be summarised as follows:

1. The intuitive approach - no exact percentage or calculation is applied. Judges gauge the level of sentence, intuitively, based on the facts as presented as a whole, as well as their sentencing experience.

2. The sentencing category climber - sentencers do not apply a percentage uplift but instead simply climb to the next sentencing range using the category levels as set out in Sentencing Guidelines.

3. The percentage uplift - the judge follows the guidelines for the general seriousness of the offence and then applies a percentage uplift to the final penalty.

One Crown Court judge explained how approaches two and three are used (and often mixed):

"Well judges broadly fall into two large categories, particularly with the Sentencing Guidelines at the moment. There are those who - absolutely rightly - conduct a mathematical exercise. So they go up tab A, they come across to column 2, they have their figure; they reduce it for a guilty plea on whatever ... mitigation ... And then they increase it by fifty per cent normally - sometimes two thirds for a religiously or racially aggravated offence. I'm afraid I'm in the old school, where I know what the right sentence is. Without getting a calculator out! And so the answer is I would anticipate that the way I deal with it - rightly or wrongly - is that if it has a true racial or religiously aggravated feature, it will be immediate imprisonment, in cases that would otherwise be suspended. And I probably increase on average the sentence by about fifty per cent." (Interview Crown Court Judge 04)

Another judge explained how they would not calculate a percentage uplift, but instead would use the Sentencing Guidelines to move the offence to the next sentencing category:

\footnotetext{
${ }^{318}$ Sentencing Council, '1. Racial or religious aggravation - statutory provisions' (n.d.)

$<$ https://www.sentencingcouncil.org.uk/explanatory-material/item/hate-crime/1-racial-or-religious-aggravation-statutoryprovisions/>

${ }^{319}$ Criminal Justice Act 1988, ss. 35 and 36.
} 
"So it's based on that you wouldn't go, 'Oh I would add thirty per cent normally'... It's based on the guidelines ... it sticks you up onto the next level and then you have to start from the guideline again ... Think of [an] example ... the proper assessment is that it's lesser harm and lower culpability for a punch in the street ... without any injury and lasting consequence lead to a community service. When that is done in a racial situation, you'd be thinking custody ... whether l'd lock him up immediately or not, I don't know ... you'd have to look at the mitigating ... It might be a suspended sentence, which, you know ... could be a bit of a cop-out. But on the other hand, it's got serious consequences for him if he breaches it ... So you might be talking about six months' custody or something like that. Because he had a trial, I might not be minded to suspend it". (Interview Crown Court Judge 09)

Other judges explained that they simply added a percentage on the sentence to reflect the hostility-based aggravation:

"I make it clear what element is for the offence without racial aggravation and what is for the offence with ... So people will know they got fifty per cent more because it was racially aggravated." (Interview Crown Court Judge 04)

One District Judge also provided a recent example, noting that the defendant received "a $50 \%$ uplift" for his offence (Interview District Judge 08). However, another District Judge stated that the percentage increase could be half of this:

"[l]t's twenty- five, thirty per cent, something like that ... around a quarter to a third. But again, that's a matter of judgement, depending on the type of thing that's been said, you know." (Interview District Judge 02) 320

Conversely, one District Judge said they would sometimes go as far as to give a $100 \%$ uplift:

"I would say normally it's about fifty per cent, and it can go up to a hundred per cent ... And that's because I sort of take a very tough line ... I am a very tough sentencing judge." (Interview District Judge 09)

Those judges that followed a more intuitive approach to sentencing were unable to provide any direct percentages or calculations relating to the uplifts that they gave for aggravated offences. One Crown Court judge described this as the "I'm not a fool approach" to sentencing:

"[T]he phrase that I talk to other judges about and one which I found very helpful is the 'I'm not a fool' approach. So I'm not a fool. I can see what the guidelines are. I know exactly where the limits are. And neither am I a fool; but when I look at the facts in this case do I see facts that go well outside that because the racial aggravation is so serious? Equally there may be other cases where I say, you could say it's important to recognise the presence of the element which is the racial aggravation is tiny compared to the gravity of the underlying offence. I mean ... racial aggravation could arise, for example, in relation to

\footnotetext{
${ }^{320}$ One other District Judge stated, "it's about 30\%" (Interview District Judge 10).
} 
a completely separate type of offence like a burglary, where, together with everything else that's happened there could be some final element which gives some indication of a racial motivation. And in those circumstances, it's open to you to say, 'Well I'm not a fool. I can see how this relates to the substantive offence, and I therefore needn't be limited by the guidelines.' So actually, although it looks from the outside that we're quite hemmed in by guidelines, actually from this side they're extremely helpful, but they're not overly restrictive. And they're not necessarily a good predictor of what the outcome is going to be. I'd like to say that the facts of the case are always a better predictor of what the outcome is going to be in terms of sentence than actually where it fits in the guideline." (Interview Crown Court Judge 07)

The varied responses provided by interviewees reflect the fact that judges both diverge in their approaches to sentencing generally, and more specifically to the way in which they determine sanctions for hate crime. Although average uplifts can be gleaned from analysis of sentencing data (see Table 10), what our qualitative interviews revealed was that there can be vastly different approaches to uplifting sentences depending on the presiding judge (the same differences cut across both Magistrates' and Crown Courts). ${ }^{321}$ This will inevitably mean that some defendants will receive significantly more uplift in their sentence compared with others, despite the form of aggravation being consistent across cases (e.g. evidence of racial or religious hostility). Commentators have, in the past, referred to a "postcode lottery" in terms of sentencing disparity across locations. ${ }^{322}$ We found evidence here of a possible "presiding judge lottery", which could ultimately determine the amount of uplift a hostilitybased offence will attract.

The lack of consistency in sentencing was a prominent concern amongst interviewees:

"[l]t can be just down to judicial discretion ... And that varies so much from judge to judge how seriously they take these things ... it's crazy." (Interview Independent Barrister 14)

"[T]he current way of 'think of what it would have been without the racist element and then add a bit, or the discriminatory element and then add a bit', that's not clear. So it's not easy for that to be replicated across the jurisdiction. So I can do it in my way, but my mate, whoever it is, might come and sit in my seat the next day and he might do it in a slightly different way. And how would you then actually say that to the community.

Because the prosecution, as I say, they want you to say, 'And we've given you --- uplift' ... But how is that quantified? So it's an act of judicial discretion. So if there is a clear policy imperative for people in society to know where the boundaries of the behaviour are and what the consequences of crossing the boundaries are, that clarity is not there, other than it's going to be worse ... Which may be enough, I don't know. But at the moment it's an imprecise sentencing art as opposed to science." (Interview District Judge 03)

\footnotetext{
${ }^{321}$ Burney and Rose previously recorded sentence enhancements for racially aggravated offences of between $40-300$ per cent, indicating that there are vast disparities in the amount of uplift given in race hate crime cases. Elizabeth Burney and Gerry Rose, Racist Offences: How is the Law Working? (Home Office Research Study 244, 2002) 16.

${ }^{322}$ Peter Walker, "Young offenders face sentencing lottery, say critics", The Guardian (2010).

<https://www.theguardian.com/society/2010/feb/15/youth-courts-sentencing-postcode-lottery>
} 
While some flexibility is required in every case, both District Judges and CPS lawyers spoke of the need for further guidance on the amount of uplift to apply at sentencing, as a way to improve consistency and public confidence:

“[T] here aren't any sort of specific guidelines as to the amount of uplift that there should necessarily be; and that, I suppose, would provide some element of assistance, I think, to lay members and professional judiciary as well. That could be of use." (Interview District Judge 11)

"I think it would help to have some guidelines in respect of what that should be ... I don't believe there are any at this moment in time ... it's just an increase, whatever you feel might be appropriate ... But some guidance wouldn't go astray ... so that you do have some consistency in what courts are giving. And then it increases public confidence, doesn't it, if you know that this is the minimum you could expect to get if you report an offence. I think it does increase public confidence." (Interview CPS 12)

We provide further recommendations on improving sentencing consistency below.

\subsection{ENHANCED PENALTIES: DOUBLE COUNTING}

As well as being mindful of the potential for inconsistency, judges should also be aware of the prospect of "double counting". Within our case law review, we noted the possibility of the hostility element of RRAOs being "double counted" at sentencing. In Letchford, ${ }^{323}$ for example, the defendant was sentenced to 42 months' detention in a young offender institution for racially aggravated assault occasioning actual bodily harm, contrary to s. 29 of the CDA. The sentence was appealed on the grounds that it was manifestly excessive. The Court of Appeal found that, while the judge had been "right to express his and society's deep abhorrence for the racially aggravated assault", there had been an element of double counting. ${ }^{324}$ The factors which the judge took into account in placing the assault in Category 1 , in terms of seriousness of assault, also influenced his decision to punish the element of racial aggravation with an increase of two years' detention. Effectively, the racial aggravation resulted in the sentence being increased twice. The sentence of 42 months was quashed and replaced with one of three years' detention.

Double counting aggravating factors at sentencing is inconsistent with sentencing guidance. The Sentencing Guideline, Overarching Principles: Seriousness, states that, where an aggravating factor is already reflected in the penalty for the offence, it cannot be used as justification for increasing the sentence further, and, when applying aggravating factors, "care needs to be taken to avoid 'double-counting'." ${ }^{225}$ The guidance on sentencing hate crime states that sentencers should first determine the appropriate sentence, leaving aside the

\footnotetext{
${ }^{323}$ [2014] EWCA Crim 1474.

324 Letchford [2014] EWCA Crim 1474 [24].

${ }^{325}$ Sentencing Guidelines Council, Overarching Principles: Seriousness Guideline (2004) para 1.21

<https://www.sentencingcouncil.org.uk/wp-content/uploads/web_seriousness_guideline.pdf>
} 
element of aggravation, and then increase the sentence to take account of the aggravation. ${ }^{326}$

Our findings indicate that there is a real risk of "double counting" in hate crime cases. The risk arises because racial or religious hostility may influence the judge when determining the starting point for a RRAO and then be used to uplift the sentence, as in Letchford. Also, judges may be asked to apply s. 145 of the CJA to a RRAO which already has a sentence uplift:

"Section 145 and 146 don't tend to crop up that often, except in the context where the prosecution try to remind me of the need to enact sentence uplifts for offences which already had the maximum sentence uplifted by reason of ss. 28 to 32 of the Crime and Disorder Act ... there's an element of double counting that could become involved. The offences which are specifically racially or religiously aggravated already have a sentence uplift provided by Parliament, so announcing an additional uplift is, well, wrong in my view." (Interview District Judge 07)

Section 145 applies "where a court is considering the seriousness of an offence other than one under sections 29 to 32 of the Crime and Disorder Act 1998" (emphasis added). Given that the position is expressly set out in the legislation, it is of some concern that prosecutors may be requesting that $\mathrm{s}$. 145 be applied to sentences for RRAOs. The relationship between s. 145 and the RRAOs is discussed in more detail below in section 9.9.

It emerged from the interviews that "double counting" can occur not only in the context of the RRAOs, but also where a judge uplifts a sentence for a non-RRAO based on aggravating factors set out in Sentencing Guidelines and then applies ss. 145 or 146:

"What they don't want to do is what they call 'double count'. 'Are you asking me to double count?' I've heard that said. 'You're asking me to increase it because it's in the

Sentencing Guidelines as an aggravating feature, and you're asking me to add something as well because it's 145 or 146?' And I think the CPS guidance would say yes you do, but you know, it clearly does cause some - anecdotally - it does cause some issues at sentence." (Interview CPS 08)

CPS guidance suggests that a sentence should not be increased because the hostility element is an aggravating factor in a Sentencing Guideline and again pursuant to ss. 145 or 146. For example, the CPS guidance on prosecuting disability hate crime states that, in respect of assault, "under the Assault Guideline, the s146 statutory aggravating factor should be taken into consideration at step 1 (determining the offence category). There must be no subsequent element of double counting." ${ }^{327}$ There may be a particular risk of double counting for disability hate crime, where the victim's vulnerability is treated as an aggravating factor

\footnotetext{
${ }^{326}$ Sentencing Council, '3. Approach to sentencing ' (n.d.) <https://www.sentencingcouncil.org.uk/explanatorymaterial/item/hate-crime/3-approach-to-sentencing/>

${ }^{327}$ Crown Prosecution Service, 'Disability Hate Crime and other Crimes against Disabled People - Prosecution Guidance' (2017) <http://www.cps.gov.uk/legal/d_to_g/disability_hate_crime/> This guidance also appears in the CPS guidance on prosecuting racist and religious hate crime, and prosecuting homophobic, biphobic and transphobic hate crime.
} 
under Sentencing Guidelines, or as part of an offence, ${ }^{328}$ and s. 146 is applied to uplift the sentence. $^{329}$

In an effort to avoid "double counting", ss. 145 and 146 may become side-lined or viewed as redundant:

"So if you had particular serious injuries and racial aggravation or religious aggravation, disability or sexual orientation, that would take it into the top category. ... in effect, [Sentencing Guidelines embody] s. 145. So actually, whether you would then need to say 'I'm actually adding an uplift ...,' because you wouldn't add an uplift because you've actually jumped them into a higher category of sentence, so you can't double count it ...

So in one sense the guidelines almost ... they don't go against s. 145 , but they absorb it, it seems to me. ... for any offence where there's a definitive guideline, it renders the operation of s. 145 - not nulled - but it kind of incorporates the operation of s. 145 into the decision making process". (Interview Independent Barrister 07)

Consequently, the hate crime element of an offence might be applied to the sentence, but not announced in court in the way that is required by ss. 145 and 146 . This could undermine the "labelling" function of the legislation:

"[W]e have this issue that comes out a lot with disability cases where the court is saying, 'Well I recognise that the victim is vulnerable, so I'm going to increase the sentence because of the vulnerability and treat it seriously. I don't need to further say that it's a hate crime.' And I don't think all parts of the judiciary understand the importance to those communities of having that label put on it, and that recognition that it's been increased for the hostility." (Interview CPS 01)

Several independent barristers and CPS lawyers noted that the overlap between Sentencing Guidelines and ss. 145 and 146 can cause confusion. Accordingly, there may be a need for more, or clearer, guidance on "double counting", or "double uplifting", in hate crime cases, particularly for offences that include the hostility element as part of the offence, or are subject to a Sentencing Guideline which includes the hostility element. Judges need to know the stage at which they should take account of the hostility element and how to present it to the court.

\subsection{THE IMPORTANCE OF MENS REA IN SENTENCING: DIFFERENCES BETWEEN HATE CRIMES "MOTIVATED BY" VERSUS "DEMONSTRATING" HOSTILITY}

It is clear from the case law and our interviews that the penalty enhancements for hate crime are an important means through which the criminal justice system recognises the offender's increased culpability and the elevated harms caused by hate crime. However, there were some differences in opinion as to the way in which demonstrations of hostility should be

\footnotetext{
${ }^{328}$ See, for example, the sexual offences against persons with a mental disorder under the Sexual Offences Act 2003.

${ }^{329}$ The specific issues that arise in relation to disability hate crime, and the relationship between hostility and vulnerability, are considered further in section 10 .
} 
sentenced compared with cases where the offender is motivated by racial hostility (or other prejudices). There was a sense amongst most judges interviewed that offenders motivated by hostility should receive a harsher penalty, despite the fact that most had never come across a hate-motivated offence. However, reflecting the view of some judges that demonstrations of hostility are not truly hate crimes, several interviewees noted that these judges would only uplift the sentence where the offender was motivated by hostility. One Crown Court judge noted:

"I'm not sure that in all cases that the appropriate increase in sentence is applied. Particularly to crimes that are ... have a demonstration of hostility, as opposed to a motivation. I think all judges do grasp that any offence which is motivated by hostility is very serious. Whether they all grasp that demonstrating hostility is something which should, and indeed must, carry an increased sentence, I simply don't know ... but I suspect not." (Interview Crown Court Judge 05)

The interviewee explained further:

“... I can hear judges at times thinking 'Well, you know, he did say a few unpleasant things, but everyone does ...' And I say, 'Yeah, but that's dreadful. That makes it much more serious' ... 'Well does it really?' you hear people say ... 'Does it really make it that much more serious? He was thumping him - that's serious enough'." (Interview Crown Court Judge 05)

Such comments may go some way in helping to explain why only $33.8 \%$ of successfully completed hate crime cases attract a declared penalty uplift. ${ }^{330}$

Other judges stated that hate-motivated offences would simply carry higher penalties than those that "objectively" demonstrate hostility:

"The offence which was motivated by hatred of a religious group or ethnic minority or because of someone's sexuality would attract a bigger sentence than an offence which was simply aggravated in the heat of the moment by someone saying something spiteful and hurtful, which wasn't the essence of the argument in the first place." (Interview Crown Court Judge 05)

"I think if I've got cogent evidence that, for instance, somebody has assaulted somebody because they are black, because they'd planned to trap a black student in an alleyway and beat them up solely because they're black, that's very different than having an argument with a student about something, and them happening to be black and having a fight with them, and calling them a name in the fight. The two things are quite different to my view. And they have to be sentenced differently." (Interview District Judge 02)

These comments reflected similar feelings amongst some legal practitioners in the early 2000s, who felt that the "law came down rather hard on people who, in the course of "normal

\footnotetext{
${ }^{330}$ Crown Prosecution Service, 'Hate Crime Report 2014/2015 and 2015/16' (CPS 2016) 14 <http://www.cps.gov.uk/publications/docs/cps_hate_crime_report_2016.pdf>
} 
working class mayhem' as one person put it, uttered words which were part of their natural vocabulary. For them, the law was simply ahead of the times." 331 There was some evidence to suggest that, fifteen years on, the law may still be ahead of the times.

A number of judges explained that hate-motivation cases gave rise to a completely different approach to sentencing compared with demonstrations of hostility. The former category of crime was often considered as a more serious offence from the start of proceedings, whereas hostility demonstrated in the heat of the moment was a secondary, or "add-on", aspect of the crime which was considered as just one factor at sentencing. One interviewee explained:

"Within an offence which is motivated by hate you would start from a bigger point. So you wouldn't be saying 'I'm going this far and then increasing it', you'd be saying 'I'm going that far'. So the whole sentencing exercise would be different. You would be approaching it from the very beginning as being a very serious crime, rather than a crime which is being made more serious by the demonstration of racial aggravation. And an offence which was motivated by hate starts in a completely different category ... a completely different category. So your mindset in the way that you construct your sentence is very different." (Interview Crown Court Judge 05)

This quote indicates that the risk of "double counting" (explained above) may be greater in cases where there is evidence of motivation than where there is a demonstration of hostility, as motivation is more likely to affect the starting point for a sentence, before it is uplifted.

\subsubsection{Why is motivation more serious than demonstrating hostility?}

The main reason given for the harsher sentencing of hate-motivated offences was that a motivation of hostility signified an increased level of culpability, which was directly linked to the mens rea element of the offence. One District Judge explained:

"It seems to me that as a matter of principle something that involves a mental element is likely to be more serious than something that just required an objective expression of hostility." (Interview District Judge 05)

Another judge similarly explained that, while the harm may be the same between hatemotivated crimes and offences involving a demonstration of hostility, the level of blameworthiness was different between the two types of cases:

"And whereas the person who is motivated ab initio by antipathy towards a racial group, sexual orientation, whatever it happens to be ... you know ... 'I'm going to do a bit of queer bashing tonight', then that, I think, demonstrates a much greater culpability. I think that's the distinction: it's a greater culpability. The harm at the end of the day is probably similar, because the person on the receiving end, the victim, feels equally aggrieved. But when you're looking at the culpability of the offender, I think it's greater for the person who is motivated by it rather than the person who is just going to commit the underlying offence

\footnotetext{
${ }^{331}$ Elizabeth Burney and Gerry Rose, Racist Offences: How is the Law Working? (Home Office Research Study 244, 2002$) 20$.
} 
and anyway and adds on the racial or sexual orientation epithet." (Interview Crown Court Judge 08)

Three explanations emerged as to why judges felt that hate-motivations gave rise to greater levels of culpability. The first was that motivation was a reflection of the fact that hatred or hostility was the central cause of the offence, as against a peripheral factor that occurs during the commission of the crime. A District Judge explained their thinking in the following terms:

"I think motivation sort of implies the underlying hostility, that there's a whole offence is ... and ... you know, underneath it all is that racial hatred of some sort directed towards someone or a group of people. Whereas hostility can sometimes arise more spontaneously during the course of something, where someone will use a phrase, as in again the public order context, where they make reference whilst ... They've started an offence and they're in the process of committing it they then make reference to the fact that they've got a physical attribute or their racial group during the course of that incident, which is not ... doesn't have the underlying motivation. The offence wasn't committed for that purpose but it has taken on that added hostility based upon their racial grouping or presumed racial grouping." (Interview District Judge 11)

A second reason offered by some judges was that motivation was likely to indicate premeditation in the offending, which is in and of itself an aggravating factor in sentencing:

"Well, somebody who goes out specifically with a view to inflicting injury or offence at people because they are black or because they are whatever. And you can be satisfied that they've formed that intention or desire to commit the offence for that reason, has to be more premeditated, and therefore an aggravating factor, considerably aggravating, as opposed to somebody who goes out, gets drunk, and because they had this innate hostility, spit it all out. I think there is a difference." (Interview District Judge 04)

This explanation echoed two of the points listed in the Sentencing Council's guide on hate crime as heightening the level of aggravation, including whether the offence was planned or deliberately set up to be offensive. ${ }^{332}$

A third reason given for the enhanced culpability related to the level of threat that a hatemotivated offender poses to the victim and to society:

"I mean, if you've got somebody who holds those [far-right] views such that the attack is entirely based on that, that seems to me precisely what the legislation was intended for. Somebody who is drunk and does what drunk people do, which is that they reduce to the lowest possible common denominator when trying to offend the person in front of them, is unpleasant, and needs to be told that that's not how life is conducted, but are far less of a threat than somebody who holds the sort of views that somebody who is motivated to commit the offence does." (Interview Crown Court Judge 04)

\footnotetext{
${ }^{332}$ Sentencing Council, '3. Approach to sentencing' (n.d.) <https://www.sentencingcouncil.org.uk/explanatory-material/item/hatecrime/3-approach-to-sentencing/>
} 
Only three judges felt that there would not necessarily be a difference in their approach to sentencing motivated versus demonstrated hostility. One interviewee commented:

"No. I don't really see there's particularly a distinction ... I think in practice it's one of those sort of academic ... areas of academic interest, but in practice it will make little difference." (Interview District Judge 09)

Another interviewee explained that the sentence was likely to be the same, as the harm done in each type of case is likely to be similar:

“... really it doesn't make a great deal of difference to me in terms of sentencing, because if this sort of language is being used, whether someone is motivated to say it or if they've simply demonstrated, well the damage is done when the words are used in the context of the offence." (Interview District Judge 07)

Finally, one judge commented that much depends on the overall context of either type of case:

"... it's not simply a question of saying that the one is worse than the other ...

Conceptually you've got motivation as part of pre-planning. Motivation is far more likely to be something which is held prior to the person coming into the criminal event, and so that means that you're looking at ... that's already beginning to tick boxes to do with preparation, planning, singling out, victimising; and that's plainly an extremely serious aggravating factor, much higher culpability because of that. On the other hand, it could be that an offence which lacks racial motivation the underlying event is extremely serious. And then you've got additional hostility demonstrated at the time, which might go well beyond victimising the individual person who is the victim of the assault ... So it's kind of apples and pears isn't it as to exactly what the scenario is, as to what's kind of ... I mean, they're going to be different types of sentences, aren't they?" (Interview Crown Court Judge 07)

Notwithstanding the fact that some judges remained reluctant to accept certain demonstrations of hostility as aggravating offences, and that cases involving hostility motivation were very rare, most judges believed that, were they to sentence a hate crime motivated by hostility, they would treat it more seriously. The reasoning provided for this diverged slightly, ranging from those who believed that hate-motivation enhanced culpability because it was the main cause of the offence, to those who believed that motivation equated to premeditation, to those who viewed motivation as posing a greater threat to individuals and society. Others, however, focused on the harms that hostility is likely to cause, with these sentencers noting that the harm is likely to be the same whether demonstrated or motivated.

The different ways in which judges approach sentencing in cases involving demonstrations versus motivations of hostility may or may not reflect wider disparities in sentencing practices. However, what is clear from this research is that no single approach to determining sentence severity is taken by judges in respect of hate crime cases. 


\subsection{UNDERSTANDING HARM AT SENTENCING: THE IMPORTANCE OF VICTIM PERSONAL STATEMENTS}

As part of its guidance on hate crime, the Sentencing Council states that the court should consider the impacts on the victim and others, including whether the offence caused particular distress to the victim and/or the victim's family, and whether it caused fear and distress throughout a local community or more widely. ${ }^{333}$ As we have seen above, it is these often-elevated harms that make hate crimes a distinct type of offence worthy of a discrete sentencing regime. But to what extent do the courts examine these direct and indirect impacts of hate crime at sentencing?

During discussions on the legislation, three judges raised concerns about whether sufficient account is taken of "how being racially abused or abused because of a characteristic that you can't change ... affects a person" (Interview District Judge 01). One Crown Court judge was conscious of how age and education can influence sentencing practices:

"[T]o call someone 'black' or, you know, an unpleasant word for a Pakistani goes to core of who they are. And I think grasping that is something which, I think, only those judges like myself who've grown up trying their best to understand and apply issues of diversity, I think we're the ones that grasp it. You see I'm someone who was appointed through a system whereby you've had to demonstrate your understanding of diversity and diverse issues, and the understanding of that as an important issue in dispensing justice. But that's really only within the last ten years." (Interview Crown Court Judge 05)

One way in which the courts can become more attuned to the distinct harms of hate crime is for victims to provide Victim Personal Statements to the court. The College of Policing's Hate Crime Operational Guidance makes reference to Victim Personal Statements (VPS), which police officers should offer victims "in all cases of personal crime". ${ }^{334}$ The Guidance also notes that the timing of the VPS is important, as these may be necessary for bail hearings early on in the process or after the victim had time to process and asses the long-term impact of the hate crime at a later point in time. ${ }^{335}$ The Guidance further suggests that communication with the local CPS hate crime coordinator is beneficial, so that the coordinator can advise on when the timing of the VPS is most valuable to the prosecution. ${ }^{336}$

\footnotetext{
${ }^{333}$ Sentencing Council, '3. Approach to sentencing' (n.d.) <https://www.sentencingcouncil.org.uk/explanatory-material/item/hatecrime/3-approach-to-sentencing/>

${ }^{334}$ College of Policing, 'National Policing Hate Crime Strategy' (2005)

$<$ http://www.college.police.uk/What-we-do/Support/Equality/Documents/National-Policing-Hate-Crimestrategy.pdf\#search=hate $\% 20$ crime>

${ }^{335}$ College of Policing, 'National Policing Hate Crime Strategy' (2005)

<http://www.college.police.uk/What-we-do/Support/Equality/Documents/National-Policing-Hate-Crimestrategy.pdf\#search=hate $\% 20$ crime>

${ }^{336}$ College of Policing, 'National Policing Hate Crime Strategy' (2005)

$<$ http://www.college.police.uk/What-we-do/Support/Equality/Documents/National-Policing-Hate-Crime-

strategy.pdf\#search=hate $\% 20$ crime>
} 
The Crown Prosecution Service also explains that VPS can help identify the needs, support and protection a victim may need, in addition to being considered by the court when determining the sentence. ${ }^{337}$ One independent barrister explained:

"[Y]ou know sentencing is vastly more complicated than it was in 1998, and even $2003 \ldots$ And everything has to be taken into account. And so, to use an example, the victim impact statement is something which has developed highly since 2003, and certainly since 1998 ... And sentencers are now obliged ... the Crown are obliged to provide in most cases a victim impact statement ... so in a case such as this, where there has been a religious or racial aggravation, or any other type of aggravation happened to come out, either the evidence itself, the crime evidence, or in the victim impact: 'I felt I was targeted because for example whatever group, he is demonstrably racist or he's demonstrably homophobic' ... or whatever it is ... can all be reflected in that sentencing." (Interview Independent Barrister 03)

One Crown Court judge explained what the victim can address in a VPS, how it forms part of the sentencing process, and how judges take VPS into consideration:

"[Victim Personal Statements] are very important. There are obviously things that ... [they] are not allowed to go into. For example, you can't say 'I want you to lock the defendant up and throw away the key', and you can't say ... as a remarkable number of people do ... 'Oh I forgive him ... Please give him a community order' or something like that. But they are confined to the effect of the offence, but ... And they're dealt with in various ways, ... the person concerned can read the statement out in court, or they can have it read, which is a little more common - that is the prosecution lawyer can read it. But the usual way that they are dealt with is that you read them to yourself. What you say in open court is you've been handed the statements, you've read them to yourself and you will take them into account. And I frequently refer to them in sentencing remarks, and say what note l've taken of them and ... So they are important, yes, they would be good things to have." (Interview Crown Court Judge 06)

One CPS prosecutor gave an example of a VPS being used at sentencing:

"In addition to the evidence that had been given by the bus driver at the time of the attack, she also made a personal, a Victim Personal Statement, which was read out in court, which said amongst other things, 'I was shocked, hurt and to a point humiliated at some complete stranger shouting obscene racial slurs. I feared for my safety because all I had was a plastic drivers' screen between me'. So we obviously adduced the evidence from her witness statement of the racially aggravated offending, and then supplemented that by a Victim Personal Statement and then the sentence was increased by fifty percent." (Interview CPS 17)

In addition to VPS, the courts can also benefit from understanding the community impacts of hate crimes. These indirect harms are often assumed consequences of hate incidents. One

\footnotetext{
${ }^{337}$ Crown Prosecution Service, 'Victim Personal Statements' (2013)

<http://www.cps.gov.uk/legal/v_to_z/victim_personal_statements/index.html>
} 
District Judge explained that Community Impact Statements could ensure that the indirect harms of hate are more fully considered by the courts:

"Well whilst the victim of course can't tell us how we should sentence because that's not a matter for them, we're obliged to take into account the impact that an offence has had on a victim, or indeed the local community ... If there was a statement on behalf of the local congregation, for example, about how it made them feel as a collective about going to that synagogue, what would happen when they went there and so on and so forth, then that would be quite important to us. Because one of the dangers, I think, of hate crime is not that it gets minimised, but that sometimes - and I do hear this from some victims of hate crime, sadly - they do say that 'Well after umpteen years of racial abuse ... it's just like water off a duck's back ... And I'm used to it, and I ignore it and it's stupid.' And whilst I would never make the assumption, I hope, that that's what happens, it is quite important to know if there's been a particular impact on a particular person or particular community as a result of hate crime, then we should hear about it. So we can consider whether to reflect it in the sentence we pass." (Interview District Judge 07)

There was a sense amongst many interviewees that much more could be done to ensure that VPS and the impacts on communities reached sentencers. One District Judge commented:

"I think there's more the prosecution could do in terms of making sure there are Victim Personal Statements available for the victims of this kind of crime, so that we can hear directly either from the victim themselves if the defendant is convicted, but at least from a statement, about what this has meant to the victim. Because otherwise we're left making assumptions, and they may be perfectly valid assumptions about how the crime has impacted on the victim, but sometimes there may be things that have impacted greatly but which we just wouldn't know about, which would be important for us to know about. So I suppose that sort of wraps itself up into a sort of more training, more information request." (Interview District Judge 07)

A practitioner working for a charitable organisation feared that VPS were not being used and that some judges see them as unnecessary:

"Victim Impact Statements I think are very important, and again, too many times they're not allowed to be used. ... Because the courts don't see it as necessary. ... And sometimes defending counsel can object to them. And sometimes the courts say well there's no need because, you know, particularly if a person ... Again, you see, if a person has been found guilty or has pleaded guilty, the impact on the victim isn't always taken into account ... 'Oh well, they pleaded guilty, therefore this is the tariff which is available to us to give ... there's nine months.' Whereas, if the Impact Statement is read out ... and we've had this a couple of times, where the Impact Statement has then been allowed, the judge has then said 'Yes, given now what I know the impact is on the victim, I'm increasing that sentence to ...' So it's the fairness of the system and the fairness in the application of the disability hate crime justice which is appalling. They're not getting it." (Interview Victim Charity Practitioner 03) 
Another practitioner for a charitable organisation also indicated that victims of hate crime were not always given the opportunity to provide a VPS:

"[N]ot all people who report a hate crime have the opportunity to give one, and so it can be quite useful, therapeutic for that person and to help the court understand at sentencing stage kind of what the impact was ... it just isn't always clear." (Interview Victim Charity Practitioner 05)

\section{RECOMMENDATION}

All police services should make it a priority to offer all complainants of hate crime the opportunity to participate in the VPS scheme. Officers should explain how information about the direct impacts of hate crime can be an important part of the sentencing process. The police should also consistently liaise with the CPS regarding the timing of such statements, and increased efforts should be put into making VPS and CIS available to courts during sentencing.

\subsection{APPLYING SS. 145 \& 146 CJA 2003: LACK OF AWARENESS AND RELUCTANCE TO ENGAGE WITH THE PROVISIONS}

In its final report, the Law Commission highlights that many consultation respondents had concerns about the inconsistent application of the sentencing provisions under the CJA. ${ }^{338}$ One of the problems that has been identified in this report is the failure to identify and investigate hostility early enough in the criminal process, meaning that the prejudice element of many crimes is often an afterthought for the court's consideration (see sections 6.2 above and 11.1.2 below). One CPS lawyer remarked:

"[T]here is still a tendency to focus on the actual proving the offence has been committed rather than thinking about 146 at the same time ... [Magistrates] tend to think about it at the point of sentence without really grasping it from the onset. And I think again, that's because of the way the legislation's framed - it's an add-on almost, rather than something that is an integral part of the actual offence." (Interview CPS 08)

Of greater concern is that evidence of hostility can sometimes be lost altogether:

"[I]t may get forgotten. And I have seen cases where it has because we pick up on those and then we do go back to our lawyers and say, 'Well this is not good' ... because we have to be open and honest about the cases that we prosecute, and at some point may be disclosed to members of the public; and it's not good to have to feed that back. So we do speak to individuals personally and we will say, 'Well why have you forgotten to mention the uplift?' That's why it's difficult because it's not part of the original offence." (Interview CPS 12)

\footnotetext{
${ }^{338}$ Law Commission, Hate Crime: Should the Current Offences be Extended? (Law Com No 348, 2014) para 3.14 <https://www.gov.uk/government/uploads/system/uploads/attachment_data/file/316103/9781474104852_Print.pdf>
} 
Why is evidence of hostility lost in the course of the criminal process? During the interviews, two key themes emerged in response to this question. The first was that, despite ss. 145 and 146 having been in force since 2005, there remains widespread lack of awareness about the provisions amongst key professionals. This was especially the case amongst defence counsel and within sections of the judiciary:

"And when you say how does defence counsel deal with it, they're quite unaware of ss. 145 and 146 - as are some members of the judiciary. ... The Crime and Disorder Act, they're used to it - it's included, they deal with it as part of the offending. It often takes them by surprise, ss. 145 and 146 . And I think it probably takes the judiciary by surprise as well sometimes." (Interview CPS 03)

One of the reasons given for this lack of awareness is that, historically, there has been both a failure to publicise and, in turn, use the provisions. From our CPS interviews, this appeared to have changed over the past few years. CPS managers consistently told us that they had improved the way they prosecute offences in cases involving a ss. 145 or 146 uplift. This is also borne out in the CPS statistics which show that declared uplifts have increased from $11.8 \%$ in $2014 / 15$ to $33.8 \%$ in $2015 / 16 .{ }^{339}$ One CPS manager noted:

"I think the CPS has done a good deal recently to improve the way that it has prosecuted uplift cases under 146 and 145. And we saw a great increase in them, in [county X] for about, I think five per cent to about fifty-five per cent ... So there's been a great push with prosecutors." (Interview CPS 03)

Some prosecutors noted that the Magistrates' Courts had also become more aware of the provisions, based on the fact that they were regularly applied in these courts. This finding was reinforced by the District Judges that we interviewed, most of whom were well versed in the provisions, to the extent that some felt they had to remind prosecutors of their applicability:

“You get prosecutors that don't prepare properly. You get prosecutors that cases are switched between courts quite often. They don't necessarily look through their lists properly, so they'll rely on the summary, rather than going through the statements. Lack of resources maybe. Regular updating and training." (Interview District Judge 01)

Another District Judge stated:

"I don't think l've ever had to prompt anybody about something that appeared to be racially or religiously aggravated. I have had to prompt people [prosecutors] to address the issue of whether something is a disability hate crime or a homophobic hate crime because it's been overlooked." (Interview District Judge 05)

While, generally speaking, both CPS lawyers and District Judges had a good comprehension of the applicability of the CDA and the CJA provisions, the same did not always apply to

\footnotetext{
${ }^{339}$ Crown Prosecution Service, 'Hate Crime Report 2014/2015 and 2015/16' (CPS 2016) 14 <http://www.cps.gov.uk/publications/docs/cps_hate_crime_report_2016.pdf>
} 
Crown Court judges, who were often said to be unaware of the sentencing provisions. Several of the Crown Court judges we interviewed were not aware of ss. 145 or 146. All, however, were well versed in the Sentencing Guidelines provided by the Sentencing Council, and referenced these as guiding them when sentencing hostility-based offences. This often left a tension between whether the court's duty was to follow the Guideline or whether, in addition to this, they were required to apply ss. 145 and 146:

"So there are examples ... where the judge has said, 'But I can deal with this as an aggravating feature under the sentence guidance. Why am I actually being asked to do this [apply ss. 145 or 146]?' I mean the answer clearly is because the legislation requires it. But, there is a kind of tendency to sort of say, well for 145 and 146 do I really need this, because l've got the aggravating feature enshrined in the Sentencing Guidelines ... But nevertheless, there's a tendency for either some confusion on the part of magistrates and judges or a tendency to say, 'well it's already incorporated there ..."' (Interview CPS 08)

Such a situation also had consequences for double counting at sentencing (as explained above in section 9.4). In some cases, judges' strict adherence to referring only to the Sentencing Guidelines resulted in them refusing to apply the statutory uplift:

"[S]ome are slipping through the net where the bench either refuses to uplift or ... And we do get judges that refuse the uplift as well. But we have to make it absolutely clear ... the sentence must be altered if you find the hate crime element ... That, I think, is where there have been some problems ... where there's an uplift because of disability hate crime or sexual orientation or transgender identity." (Interview CPS 16)

The second theme that emerged in response to the question of why evidence of hostility is lost, or not accounted for, at sentencing was that, even where the courts were aware of the CJA provisions, many remained reluctant to apply them. As one interviewee stated, "trying to persuade them [judges] to go through the mechanics of 146 and declare it; and then to uplift it; and to identify the uplift. It can be quite difficult" (Interview CPS 03). Such statements demonstrated that there is still much more that can be done to increase awareness of the legislation amongst the judiciary in order to improve the consistent application of the provisions. Recommendations on improving sentencing practices are provided at the end of this section.

\subsection{NEWTON HEARINGS}

Where judges are alert to the need to consider hostility at sentencing, there are procedures that must be followed. A sentence should only be uplifted to reflect aggravation on the basis of race, religion, disability, sexual orientation or transgender identity if the hostility element, or aggravating factor, has been proven. If the defendant is convicted of a RRAO, then the aggravating factor will have been proven as part of the prosecution case. However, if the defendant is convicted of a non-RRAO and the aggravating factor was not dealt with at trial, or (more likely) the defendant pleaded guilty to a non-RRAO and disputes the aggravating factor, a Newton hearing should usually be held to determine whether ss. 145 or 146 
applies. ${ }^{340}$ This principle was established by the Court of Appeal in the case of O'Callaghan: ${ }^{341}$

"In our judgment, where the question of racial aggravation has not arisen at trial, then even when it is open to the sentencer to pass an increase on the ground of racial aggravation (as we are prepared to assume it was here) either a Newton hearing must be held or, at the very least, plain and adequate notice must be given by the sentencer that he is considering sentencing on an enhanced or aggravated basis. Fairness and principle both demand that such a course should be taken." 342

A Newton hearing is a procedure that is used to determine disputed factual issues which could have a substantial bearing on the sentence. ${ }^{343}$ One Crown Court judge that we interviewed gave the following helpful description:

"A Newton hearing is where there is no dispute about the defendant's guilt, but there is dispute about the basis upon which the guilt is founded. So the defendant might say 'I am guilty', or be found guilty, 'but this element of the evidence I don't accept'. And if that is the case, then before you can sentence on the basis that that element is proven, the judge would have to have a separate hearing in which evidence is called to that issue, and the judge would then have to determine whether he or she is satisfied that ... that aspect of the offence has been proven. ... If you're sure the prosecution is right, you sentence on that basis ... So you're sure that racist words were said. If you're not sure, then you must sentence on the defendant's version of the facts ... so there's no racial aggravation." (Interview Crown Court Judge 05)

During a Newton hearing, both the prosecution and the defence can call evidence and crossexamine witnesses, and the onus is on the prosecution to satisfy the judge to the criminal standard of proof that their version of events is correct. ${ }^{344}$

The Law Commission found concerns that the proper procedure for Newton hearings is not always followed in hate crime cases. There was also concern that the process of determining hostility at sentencing is sometimes less than thorough compared with the examination of allegations of hostility at trial. This could result in unfairness to victims if the aggravating factor is not taken into account, and unfairness to defendants if they are not afforded a sufficient opportunity to challenge the allegation of hostility. ${ }^{345}$ Defendants might also be deterred from contesting the allegation at a Newton hearing because, if the matter is

\footnotetext{
${ }^{340}$ The guidelines on the approach to sentencing hate crime state that '[a] court should not conclude that offending involved aggravation related to race, religion, disability, sexual orientation or transgender identity without first putting the offender on notice and allowing him or her to challenge the allegation.' Sentencing Council, '3. Approach to sentencing' (n.d.) <https://www.sentencingcouncil.org.uk/explanatory-material/item/hate-crime/3-approach-to-sentencing/> ${ }^{341}$ [2005] EWCA Crim 317.

342 O'Callaghan [2005] EWCA Crim 317 [18].

${ }^{343}$ See Newton (1983) 77 Cr App R 13.

${ }^{344}$ Underwood [2004] EWCA Crim 2256 [9].

${ }^{345}$ Law Commission, Hate Crime: Should the Current Offences be Extended? (Law Com No 348, 2014) para 3.14 <https://www.gov.uk/government/uploads/system/uploads/attachment_data/file/316103/9781474104852_Print.pdf>
} 
resolved against them, any "sentence discount" afforded for pleading guilty to the basic offence may be reduced. ${ }^{346}$

The recent case of Sheard ${ }^{347}$ brought the concerns about the conduct of Newton hearings to the fore. The defendant was sentenced to three years and six months imprisonment for the manslaughter of a gay 18-year-old who had Asperger's syndrome, epilepsy, a speech impairment and learning difficulties. The defendant had set the victim on fire during the victim's eighteenth birthday party. For the purpose of sentencing, the prosecution asserted that the defendant had targeted the victim because of his vulnerability and had directed homophobic abuse towards him. The defence asserted that the defendant and victim had been engaged in horseplay. A Newton hearing was held on the papers, meaning that no witnesses were called to give evidence, which the judge found surprising. Based on the papers, the judge was not convinced that the offence involved "cruel behaviour towards a vulnerable target". The sentence attracted criticism and was referred by the Attorney General to the Court of Appeal for being unduly lenient. The Court of Appeal declined to increase the sentence because of the impossibility of testing the prosecution's allegations with oral evidence and giving the defendant the opportunity to respond. The Court did, however, note that if the Attorney General's submissions had been supported by oral evidence adduced by the prosecution at the Newton hearing, it was likely that the sentence would have been quashed as unduly lenient. ${ }^{348}$ The decision demonstrates the importance of gathering and presenting sufficient evidence of hostility for sentencing. Following Sheard, the CPS revised its guidance on the conduct of Newton hearings, which now state that oral evidence should be called to help the judge to resolve issues of fact that are substantially disputed. ${ }^{349}$

Because of these previously highlighted concerns, a section of the interview guide was dedicated to exploring the use of Newton hearings for hate crime in more detail. Our findings suggest that Newton hearings are rarely held. Many of the Crown Court and District Judges we interviewed had not experienced a Newton hearing in a hate crime case:

“It doesn't happen often. I can't remember one.” (Interview District Judge 10)

"I can't say that l've ever had a Newton trial on ... They are not infrequent. But not so much around racially aggravated things. Usually more around, l'd say, assault cases." (Interview District Judge 08)

"I've never known it to happen, but it would be a normal Newton hearing dealt with in the normal way." (Interview Crown Court Judge 06)

Various reasons were cited for the lack of Newton hearings, including: the hostility element of an offence usually being dealt with at trial, particularly if it was related to race or religion; sparing victims from having to give evidence in court; and not wanting to deter guilty pleas. There was a perception amongst some District Judges that Newton hearings are

\footnotetext{
${ }^{346}$ Underwood [2004] EWCA Crim 2256 [11]; Sentencing Council, 'Reduction in Sentence for a Guilty Plea Definitive Guideline' (2017) <https://www.sentencingcouncil.org.uk/wp-content/uploads/Reduction-in-Sentence-for-Guilty-plea-DefinitiveGuide_FINAL_WEB.pdf>

${ }^{347}$ [2013] EWCA Crim 1161. See Una Morris, 'Lessons to Be Learned from Sheard v. R' (2013) 177(32) Criminal Law and Justice Weekly 540.

${ }^{348}$ Sheard [2013] EWCA Crim 1161 [50].

${ }^{349}$ Crown Prosecution Service, 'Legal Guidance on Newton hearings' (n.d.)

<http://www.cps.gov.uk/legal/l_to_o/newton_hearings/>
} 
unnecessary in the Magistrates' Court because the aggravated element would not make a substantial difference to the sentence. One District Judge noted that "in the summary jurisdiction the penalties that we impose are reasonably small anyway" (Interview District Judge 03).

Another explained that:

'[B]ecause the difference is not that substantial in the Magistrates' Court, we don't have a lot of Newton hearings. ... So if, say, it's simple common assault but sexual orientation, it's still only going to give you a maximum of six months' imprisonment ... You have to think of resources, you have to think of the fact that the person has to then come and give evidence where otherwise they wouldn't ... I'm not sure that the gain is worth the candle, you know, having somebody stand up there and say that just so that you put another, if it's twelve weeks you put another four weeks and he only serves half of it, how much difference does that make." (Interview District Judge 10)

However, one District Judge (Interview District Judge 05) and several CPS lawyers thought that the aggravated element should make a significant difference to the sentence in summary cases. One CPS lawyer explained that prosecutors sometimes need to remind magistrates to hold Newton hearings:

"[I]t's something that we have to look out for; particularly, I'm afraid, in the Magistrates' Court ... I mean they do do a smashing job, but ... we have to make it absolutely clear you must have a Newton hearing if the sentence is going to be altered, and the sentence must be altered if you find the hate crime element. So we can't just sort of let them say, 'Well, you know, we were going to give them a year anyway ... It's not going to make any difference.' Well, you know, sorry ... but it should be a year and two months in fact, if we prove the other element. That, I think, is where there have been some problems." (Interview CPS 16)

In contrast to the Magistrates' Court, several Crown Court judges felt that the aggravated element would ordinarily justify a Newton hearing:

"... the underlying background here is that there's a hate crime element to this ... then if the defendant doesn't accept it, the judge almost certainly, unless as I say, it's just a minor element, then we'll have a Newton hearing." (Interview Crown Court Judge 08)

"[T]here are very clear criteria for when they would be necessary. I mean, it's necessary where the difference between the prosecution and the defence is sufficiently great to make a difference to sentence. And it would be a rare case where you say that the racial aggravation would make no difference." (Interview Crown Court Judge 07)

For many judges in both courts, a substantial difference in sentence means a change in the type of sentence:

"The difference for me is, is it going from a fine to a community penalty. Or is it going from a community penalty to custody." (Interview District Judge 04) 
"The real difference is whether it would put it into prison rather than unpaid work or something like that." (Interview District Judge 10)

"[l]f I find the words or acts were performed it often makes the difference between prison and not prison. Because otherwise I wouldn't hold the Newton hearing. ... Although obviously length is important in truth. ... It's whether you're going inside often, rather than whether you're going inside for three months or six months." (Interview Crown Court Judge 04)

Judges also pointed to defendants as a key reason for the lack of Newton hearings, particularly where the defendant pleads guilty to the basic offence. In their experience, defendants would rather accept the aggravated element than risk losing credit for a guilty plea. A guilty plea attracts a sentence reduction of between one tenth and one third, depending on the stage at which the plea was entered. ${ }^{350}$ New sentencing guidelines, which came into effect in June 2017, state that:

"[W]here an offender's version of events is rejected at a Newton hearing ... the reduction which would have been available at the stage of proceedings the plea was indicated should normally be halved. Where witnesses are called during such a hearing, it may be appropriate further to decrease the reduction." 351

Three Crown Court judges and four District Judges confirmed that defendants would lose some, or even all, credit for a guilty plea if the hate crime element was proven:

"Of course it's no credit for a guilty plea really ... if the Newton hearing is there. It really undermines the guilty plea completely." (Interview District Judge 04)

"I wouldn't give credit for the guilty plea anymore. ... I would completely discount it because it will have forced the witness to come to court to give evidence ... There's been some new guidelines ... l'll just have to remind myself what that says, but generally that would be my approach, that you'd lose your credit". (Interview District Judge 09)

One Crown Court judge also noted that Newton hearings are not in the best interest of defendants, it being preferable to have the aggravated element put before a jury (as explained further in section 11.1.5):

“... Defence counsel are also aware that the argument that may impress a jury will not impress somebody like me who has been thirty-one years in the profession ... And so they tend not to risk losing the credit for plea by a Newton." (Interview Crown Court Judge 04)

\footnotetext{
${ }^{350}$ See Sentencing Council, 'Reduction in Sentence for a Guilty Plea Definitive Guideline' (2017)

$<$ https://www.sentencingcouncil.org.uk/wp-content/uploads/Reduction-in-Sentence-for-Guilty-plea-DefinitiveGuide_FINAL_WEB.pdf>

${ }^{351}$ Sentencing Council, 'Reduction in Sentence for a Guilty Plea Definitive Guideline' (2017)

$<$ https://www.sentencingcouncil.org.uk/wp-content/uploads/Reduction-in-Sentence-for-Guilty-plea-DefinitiveGuide_FINAL_WEB.pdf>
} 
However, a minority of interviewees, particularly CPS lawyers, did have experience of Newton hearings in hate crime cases, and one District Judge explained that, for some defendants, it is worth a "punt":

"[Y]ou know, we're talking about a difference of, you know, a hundred hours of unpaid work or an extra couple of months in custody. So I suppose they think it's worth a punt, they being the defendants ... It's worth a punt sometimes to see if they can get away with it." (Interview District Judge 04)

Although the judges we interviewed did not have much first-hand experience of Newton hearings in hate crime cases, we found widespread familiarity with the relevant rules and procedures for Newton hearings, as well as the significance of the outcome:

"My view though is that when it comes to racial aggravation it's a very important thing not to fudge. And so, if there is going to be no aggravation, that's going to be because there's been a Newton hearing and you have heard from the defendant, and you then say, 'I cannot be sure that there was racial aggravation in this case, and therefore you won't be sentenced on that basis.' Equally, a defendant needs to know that if they are going to be sentenced it's because you are sure, having heard evidence about it. And so, for me, it's one of those areas; domestic violence is another area as well, where the importance of sentencing on a truth basis is something which overrides the pragmatism of saying 'Well, in reality it's not going to make too much difference ... to the sentence one way or the other"'. (Interview Crown Court Judge 07)

"Because you are the tribunal of fact on that point. And if you're going to penalise somebody for particular conduct, then you have to be sure to the criminal standard that that aggravating feature does exist." (Interview Crown Court Judge 08)

The practitioners we interviewed did not raise any objection to the principle of Newton hearings, and one Crown Court judge spoke of the benefits of gaining more information about the case and the defendant, even if the issue of hostility is not proven (Interview Crown Court Judge 07). Overall, our findings indicate that the main issue in respect of Newton hearings is the perception that they are unnecessary in the majority of hate crime cases. This may be viewed as a problem in the light of our findings as to lack of awareness or application of ss. 145 and 146 of the CJA, as outlined in section 9.7. It is also concerning that the fear of losing a sentence reduction seems to prevent many defendants from exercising their rights to challenge allegations against them.

\subsection{THE RELATIONSHIP BETWEEN THE RRAOS AND THE CJA}

The maximum sentences for RRAOs can be up to 400 per cent higher than the basic offences (e.g. common assault versus aggravated assault) (see section 3.1.1). This means that, when sentencing for sexual orientation, disability or transgender hate crimes, the judge's sentencing range is much reduced compared with RRAOs. The disparity between ranges not only causes concern for principled sentencing, but it can also have practical implications, as demonstrated by the following Crown Court judge: 
"I used section 146 recently ... And I found that very frustrating, because the Crime and Disorder legislation creates greater penalties; but of course 145 and 146 don't. So because the homophobic case was simply charged as threatening behaviour, and it had come here because he was in breach of a Crown Court order by committing the offence ... that was the only reason it had got to this court. So because he pleaded guilty to threatening behaviour, which carries a maximum sentence of six months, then the Magistrates' realised, 'Oh by the way, he's subject to a Crown Court suspended sentence', and therefore they then committed it to this court for sentence. And that was the only way I was able to deal with it, because otherwise it wouldn't have been serious enough. The problem then is the maximum sentence is six months, so the ability to increase the sentence because of the homophobic aggravating factors was virtually nil. Because the offence itself was worth six months' minus credit for a guilty plea, but then I have to and that it's aggravated by the homophobic comments, and there's no way to go because there isn't sufficient powers within that offence. So I think that's a failing in ss. 145 and 146, that you need to be able to increase the penalties using those sections, as you can with the actual offences in the Crime and Disorder Act." (Interview Crown Court Judge 05)

We see here an example of a defendant being referred to the Crown Court for sentencing because the seriousness of the crime was increased by identity-based hostility, only for the judge to have little room to enhance the sentence due to the low range of sentencing available to them. However, with more serious offences at least, the available sentence ranges are usually sufficient to take account of identity-based hostility. ${ }^{352}$

As well as creating disparities in available sentences, having aggravated criminal offences in one piece of legislation and enhanced sentencing provisions in another has caused confusion as to how to sentence some racially or religiously aggravated offending. In theory, the RRAOs and the penalty enhancing sentencing provisions are "mutually exclusive". Section 145 of the CJA "applies where a court is considering the seriousness of an offence other than one under sections 29 to 32 of the Crime and Disorder Act 1998" (emphasis added). This means that $\mathrm{s} .145$ cannot be applied where the defendant was convicted of a RRAO under the CDA. It also means that the court should not apply s. 145 to a basic offence where a racially or religiously aggravated form of the offence was charged but resulted in an acquittal. ${ }^{353}$ However, the wording of s. 145 has created confusion as to whether the provision can be applied to an offence which could have been, but was not, charged as a RRAO (e.g. a common assault which was not charged as a racially aggravated common assault). ${ }^{354}$ The complex and unclear inter-relationship between the RRAOs and s. 145 was

\footnotetext{
${ }^{352}$ The Law Commission found that the sentences imposed for RRAOs tend to fall well below the maximum available for the basic offence. See Law Commission, Hate Crime: The Case for Extending the Existing Offences Appendix C - Impact Assessment (Consultation Paper No 213, 2013) para C.61.

${ }^{353}$ McGillivray [2005] EWCA Crim 604; Sentencing Council, Magistrates' Court Sentencing Guidelines 446

$<$ https://www.sentencingcouncil.org.uk/publications/item/magistrates-court-sentencing-guidelines/>

${ }^{354}$ Law Commission, Hate Crime: Should the Current Offences be Extended? (Law Com No 348, 2014) paras 2.65-2.71

<https://www.gov.uk/government/uploads/system/uploads/attachment_data/file/316103/9781474104852_Print.pdf>
} 
a cause of concern and dissatisfaction for some respondents to the Law Commission's consultation. ${ }^{355}$

Practitioner guidance suggests that s. 145 should not be applied to basic offences which could have been, but were not, charged as RRAOs. ${ }^{356}$ However, in O'Leary, a case that was decided after the publication of the Law Commission's report, the Court of Appeal held that s. 145 does not necessarily exclude the basic offences. ${ }^{357}$ In consequence of the court's decision and reasoning, where a RRAO could have been, but was not, charged, racial or religious aggravation can sometimes be dealt with at sentencing. The precise circumstances in which this can happen remain unclear. ${ }^{358}$ In O'Leary, it was relevant that: the indictment at no point included an aggravated form of the offence in question; ${ }^{359}$ the defence had an opportunity to challenge the issue of racial aggravation at a trial; ${ }^{360}$ the sentencing judge concluded to the criminal standard that the offence was racially aggravated; and the judge's finding was not inconsistent with a jury verdict. However, the Court of Appeal clarified that, "in the majority of cases where the evidence supports an aggravated form of [the offence], then it should be placed upon the indictment." 361

One CPS interviewee interpreted the decision in O'Leary to mean that a sentence uplift can now be requested where a RRAO could have been, but was not, charged:

"There's been a recent appeal judgment which is quite interesting, because we always understood the position was that, if you had charged the simple offence when there was a racially aggravated option available, that you couldn't then ask for that simple offence to be uplifted, using s. 145 of the Criminal Justice Act. But there's been a recent case that says yes you can - if the evidence is there, you can." (Interview CPS 01)

Conversely, one District Judge thought it was wrong both as a matter of law and principle to aggravate basic offences by the "back door":

"[l]f the Crown Prosecution Service can ... charge racial or religious aggravation, and for whatever reason choose not to ... then it would be wrong for a judiciary then to uplift because of their own interpretation of what [for example] "black bastards" meant. ... The case law says that you should not ... it's an unfair approach, almost a backdoor approach, to aggravating the offence, where the opportunity to charge the aggravated offence was not taken up, or alternatively they had been acquitted of it. So you do have to be alive to those issues." (Interview District Judge 06)

\footnotetext{
${ }^{355}$ Law Commission, Hate Crime: Should the Current Offences be Extended? (Law Com No 348, 2014) paras 3.42, 4.1684.172, 5.17 <https://www.gov.uk/government/uploads/system/uploads/attachment_data/file/316103/9781474104852_Print.pdf> ${ }^{356}$ Sentencing Council, 'Magistrates' Court Sentencing Guidelines' (n.d.) 446

$<$ https://www.sentencingcouncil.org.uk/publications/item/magistrates-court-sentencing-guidelines/>; Crown Prosecution Service, 'Racist and Religious Crime - Prosecution Guidance' (2017) <http://www.cps.gov.uk/legal/p_to_r/racist_and_religious_crime/> ${ }^{357}$ O'Leary [2015] EWCA Crim 1306.

${ }^{358}$ See Abenaa Owusu-Bempah and Mark Walters, 'Racially aggravated offences: When does section 145 of the Criminal Justice Act 2003 apply?' [2016] 2 Crim LR 116.

${ }^{359}$ See also McGillivray [2005] EWCA Crim 604; Kentsch [2005] EWCA Crim 2851

${ }^{360}$ See also O'Callaghan [2005] EWCA Crim 317.

${ }^{361}$ O'Leary [2015] EWCA Crim 1306 [18].
} 
From a defence perspective, it is better for the issue of aggravation to be heard by a jury, as is explained in section 11.1.5:

"The position tends to be that defence perfectly properly say, if you want to allege a religious or racial motivation for an offence, put it on the indictment. ... It's taking away something that the defence would say is a jury question. So you tend to see it more that way, and people tend to say, 'Well no, no ... you shouldn't increase for that ... He should have been charged with it ..." (Interview Crown Court Judge 04)

In practice, it seems that the issue is unlikely to arise often. Many judges and CPS interviewees were confident that if an offence can be charged under the CDA, it will be. Consequently, s. 145 is reserved for offending that is not covered by the CDA, and is "rarely used" (Interview CPS 03). However, four District Judges expressed a willingness to apply s. 145 where the RRAO could have been, but was not, charged. As two of them explained:

“... of course, there's nothing to prevent you from putting in an uplift if something's racially aggravated, even if it wasn't charged as such. Why not? You know, you take all the factors into account." (Interview District Judge 04)

"So that case where it's charged with ... a simple offence ... and then there's some racial element to it ... I have said it's racially aggravated to some extent and raised that. And the defence are very quick on you to say, 'Well it's not been charged as such'. And I think there's an expectation that it should be charged under the Crime and Disorder Act. But clearly it's still open to us." (Interview District Judge 01)

It is evident that the decision in O'Leary has done little, if anything, to clarify the relationship between s. 145 and the RRAOs, and may even have complicated the matter further. As noted by one CPS lawyer, the overlap between s. 145 and the RRAOs is "quite difficult for courts and prosecutors to grasp in many cases" (Interview CPS 20). The responses from interviewees indicate that this is another area where there is a need to simplify, or, at least, clarify the current law:

"I think it could be simplified, and I think that all of these various potential aggravations ... Why should they not all be under the same umbrella, different subsections or sections of a new Act. Or they could become section 32 a, b, c, d of the 1998 Act ... and get rid of section 146." (Interview District Judge 06)

The potential for law reform in relation to simplifying the legislative framework is discussed in Part C (section 11.5).

\subsection{CONCLUSIONS}

No single approach to sentencing hate crime could be identified during this study. Instead, the research revealed that there were three distinct, but sometimes overlapping, approaches to calculating the "uplift" for hostility at sentencing. These disparate approaches are likely to result in significant differences in the amount of uplift that is applied in hate crime cases. Furthermore, it was clear that uplifts were almost always applied punitively - meaning that additional time was added to a term of imprisonment or a higher fine was applied. The use of community-based and rehabilitation interventions were rarely used as part of an offender's 
sentence. An opportunity for judges to use their sentencing powers in order to challenge the underlying offending behaviour is therefore being missed.

Judges also differed in their approaches to sentencing crimes motivated by hostility compared with those where the hostility was demonstrated by the offender. While most judges felt that motivation indicated a higher degree of culpability, there were different reasons provided as to why this enhanced offender blameworthiness. For other judges, the harm that hate crimes are likely to cause was considered to be more important when determining sentence than the reason for committing the offence. In terms of better understanding the harms caused by hate crime, some interviewees noted that the use of both Victim Personal Statements and Community Impact Statements should be used more consistently to articulate to the court the extent to which hate crime harms individuals and minority communities. It is of some concern, therefore, that VSP and CIS are viewed by some judges as being "unnecessary".

A number of other issues arose during the interviews, including that some practitioners still remain unaware of the CJA provisions, that confusion remains as to the relationship between the CJA and the CDA, and that some judges remain reluctant to apply the CJA provisions altogether. Conversely, we also identified the potential for some judges to double count hostility when determining sentence; such as where racial or religious hostility influences the starting point when sentencing a RRAO and then is used again to uplift the sentence within the guideline category; or where judges are asked to apply s. 145 of the CJA to a RRAO which already has a sentence uplift; and finally where judges uplift a sentence based on aggravating factors set out in Sentencing Guidelines and then also apply ss. 145 or 146.

\section{RECOMMENDATION}

We recommend that the Sentencing Council provide a new Guideline for hate crime that sets out the following information for the courts:

1. The general approach that should be taken to determining the level of uplift, whether that be a percentage range or a policy of moving the offence to the next category range.

2. Clear and concise information on when and how to take account of the hostility element when it is covered by the CJA as well as a Sentencing Guideline or the offence charged. This should include a statement that sentencers must not enhance penalties twice, by uplifting using the CJA provisions and then Sentencing Guidelines, or vice versa.

3. The factors that should be taken into account when sentencing cases involving motivation and demonstrations of hostility.

4. The relationship between the CDA provisions and the CJA provisions, including when the latter should not be applied in court.

5. That due regard should be given to the availability of community and rehabilitation programmes as forming part of any uplift given.

6. That VPS and CIS should be read out in court before sentence is determined. 


\section{Prosecuting disability hate crime}

Problems with prosecuting and sentencing disability hate crimes were so prevalent across the cohort of interviewees that we have dedicated a separate section of this report to disability hate crime law. Many issues facing criminal justice responses to disability hate crime have previously been highlighted by a joint criminal justice inspection in $2013{ }^{362}$ The inspectorates found that, despite definitions and guidance from criminal justice agencies, "there was a lack of clarity and understanding as to what constitutes a disability hate crime and confusion between policy definitions and the statutory sentencing provision contained within section 146 of the Criminal Justice Act $2003 .{ }^{363}$ Furthermore, the report highlights the need for improved evidence collation for disability hate crime cases and for the CPS to present such evidence to the court at sentencing in a more consistent fashion. Two years later, in their follow up report, the inspectorates concluded that "there has been insufficient progress made against the recommendations. An opportunity to achieve improvements in the criminal justice system for all members of society has not yet been taken." ${ }^{364}$

It became clear throughout this study that most of the problems preventing the successful application of hate crime law for disability hate crime remain. That is not to deny that positive steps have been made by the CPS (and other agencies) in improving recording, monitoring and prosecution of disability hate crime (see Part A). However, the data (both statistical and qualitative) revealed a vast gap between the way that disability hate crimes are dealt with by the CJS compared with other strands of hate crime. Below, we explore a number of themes that emerged during this study. We start with the types of hate crime most commonly experienced by disabled victims.

\subsection{TYPES OF OFFENCE EXPERIENCED BY DISABLED VICTIMS}

As we highlight in section 5 , disability hate crimes do not always reflect the offending behaviour common to other types of identity-based hostility. Tables 4 and 5 in this report show that the most common types of hate crime across the protected characteristics included assaults and public order offences (causing harassment, alarm and distress). However, in terms of disability hate crime, there are two other categories of offences that are commonly perpetrated against victims. These are property offences (including theft, robbery, burglary and fraud) and sexual offences. Together, these categories of offences made up

\footnotetext{
${ }^{362}$ Criminal Justice Joint Inspection, Living in a Different World: Joint Review of Disability Hate Crime (CJJI 2013) <https://www.justiceinspectorates.gov.uk/cjji/wp-content/uploads/sites/2/2014/04/CJJI_DHC_Mar13_rpt.pdf>

${ }^{363}$ Criminal Justice Joint Inspection, Living in a Different World: Joint Review of Disability Hate Crime (CJJI 2013)

<https://www.justiceinspectorates.gov.uk/cjji/wp-content/uploads/sites/2/2014/04/CJJI_DHC_Mar13_rpt.pdf>

${ }^{364}$ Criminal Justice Joint Inspection, Living in a Different World: Joint Review of Disability Hate Crime (CJJI 2013) para 1.13

<https://www.justiceinspectorates.gov.uk/cjji/wp-content/uploads/sites/2/2014/04/CJJI_DHC_Mar13_rpt.pdf>
} 
$38 \%$ of all disability hate crimes proceeded against in court. One independent barrister emphasised how these particular types of offending epitomise the different nature and context in which disability hate crimes occur:

“... disability offences [are] more for financial-type offences - frauds, thefts, things like that. Racially aggravated offences ... tend to be more of the public order and assaults and things of that nature." (Interview CPS 15)

Because of the different nature of disability hate crime, and the different context in which offending occurs, police investigators may overlook or fail to gather evidence of identitybased hostility, as the circumstances diverge from what is considered an archetypical "hate crime":

"... the mistreatment of the infirm in a care home; the theft by the carer of money from somebody's bank account who they're looking after; the depletion of funds from a relative's bank account when they're suffering from dementia; the theft of somebody's wallet if they happen to be in a wheelchair and things of that nature, which we're used to dealing with, but perhaps haven't been as good historically at identifying it as hate crimes than some of the more obvious insulting behaviour that gets targeted towards people of different skin colour." (Interview CPS 04)

Recent training of all CPS lawyers on disability hate crime has helped to improve the prosecution of disability hate crime. The vast majority of CPS interviewees spoke of the usefulness of recent training programmes in this regard, which, it was asserted, had made many prosecutors reconsider when targeted abuse will amount to a demonstration or motivation of disability hostility:

"a training brief that was delivered in a classroom environment to every prosecutor with the aim of driving up awareness of disability hate crime, and getting lawyers to think about those cases which they might not at the moment think of as disability hate crimes, but which could be." (Interview CPS 04)

This has meant that investigators and prosecutors should move beyond the typical evidence of "verbal slurs" and/or written epithets because offenders "don't generally wear 'I hate people with disability' badges" (Interview Independent Barrister 07). Nonetheless, training amongst the CPS alone could not address the apparent reluctance that remains within other areas of the criminal justice system to understanding when a crime against a disabled person will provide evidence of "hostility". Both the police and judges came in for consistent criticism in this regard, none more so than in relation to confusion that the issue of perceived vulnerability gives rise to.

\subsection{THE ISSUE OF PERCEIVED "VULNERABILITY”}

Disability is not a characteristic covered by the CDA, and so, while the issue may arise at trial, it need not be proven until the sentencing hearing, pursuant to s. 146 of the CJA. Nevertheless, proving disability hostility was considered to be the most difficult of all types of hostility by prosecutors. Those cases which were the "easiest cases to win are where the 
defendant says something, demonstrates hostility at the time of committing the offence" (Interview CPS 03), such as where the defendant has shouted 'you crippled bastard', 'you retard', 'you mong', 'you spastic'” (Interview CPS 20).

More common, and by far more difficult to prove, are cases where no directly disablist remarks have been uttered during the commission of the offence. In these types of cases, prosecutors often rely on factors such as additional taunting of the victims, gratuitous violence attached to the incident, or highlighting the fact that there is a lack of evidence suggesting "why else carry out the conduct?" (Interview CPS 03). In most of these cases, the offences directed against disabled people are intrinsically connected with the perceived "vulnerability" of the victim. The issue of vulnerability is by no means new to discussions on this area of law and policy. Both academics and practitioners have highlighted how the perceived vulnerability of the victim is intrinsically connected to the prejudices which perpetrators demonstrate towards them. ${ }^{365}$

Many interviewees provided detailed examples of cases that they had been involved in where a complex relationship between perceived vulnerability and hostility had inhibited the successful prosecution of an offence as a disability hate crime:

"I think disability is the hardest strand to prosecute - and identifying disability hate crime as well - it's the overlap with vulnerability. And that is a real challenge, and I think it's caused a lot of debate, and I think that the flagging, identification process does not distinguish particularly between the actual vulnerability and the disability. Obviously you've got to be clear for s. 146. And there's been a lot of confusion about whether or not we could argue in court that if someone is targeting someone because of their vulnerability, and that vulnerability arises because of their disability, it's whether s. 146 would apply.

And I think across the board there's been lots of confusion about that. And the vulnerability - I mean I don't think it is that difficult - I think people are trying to read the legislation in a way that would suit them rather than actually ... I think that s. 146 cannot be read for us to conflate the two together without there being some distinct evidence." (Interview CPS 14)

“... the defendant approached and said 'Have you got any change?' You know, very friendly. And then they gave him some change. And then it was, 'Well could you come to the cash point and give me $£ 30$ please? I really need it, I can't get home, I'm hungry, I've got all sorts of problems.' And our victim did, and then the defendant kind of pushed it, you know? 'Can we go to the other bank and get £10?', knowing that the victim was vulnerable and couldn't stand up for himself how to complain, and maybe wouldn't piece it all together and realise that this wasn't normal behaviour... Those cases aren't always

\footnotetext{
${ }^{365}$ Katharine Quarmby, Getting Away with Murder: Disabled People's Experiences of Hate Crime in the UK (Scope 2008) <http://www.scope.org.uk/Scope/media/Images/Publication\%20Directory/Getting-away-with-murder.pdf>; Hannah MasonBish, 'Conceptual issues in the construction of disability hate crime' in Alan Roulstone and Hannah Mason-Bish (eds), Disability, Hate Crime and Violence (Routledge 2012); Equality and Human Rights Commission, Hidden in Plain Sight: Inquiry into Disability-related Harassment (EHRC 2011) <https://www.equalityhumanrights.com/en/publication-download/hidden-plain-sightinquiry-disability-related-harassment>; Criminal Justice Joint Inspection, Living in a Different World: Joint Review of Disability Hate Crime (CJJI 2013) <https://www.justiceinspectorates.gov.uk/cjji/wpcontent/uploads/sites/2/2014/04/CJJI_DHC_Mar13_rpt.pdf>
} 
obvious because there's no threat, there's not ... The word 'hostility' appears in hate crime in the legislation, but for this sort of offence - disability hate crime and 'hate' - it's hard to see the word 'hate' there. It's taking advantage of the situation." (Interview CPS 16)

In such cases, the motivation of the defendant becomes key to proving disability hostility and involves evidencing that there is "an attitude towards that person's disability ... probably they've been wound up by the way the person is because of their disability and that's why they slapped them." (Interview CPS 05). For a successful prosecution of a case flagged as a disability hate crime, and for the successful application of s. 146, the Crown must "look into the mind of the offender to prove beyond reasonable doubt what's going on in his head" (Interview CPS 05). Such a task is so fraught with complexity that, in most cases, prosecutors sought some additional element, beyond the victim's perceived vulnerability, to establish the presence of hostility. For instance, one CPS prosecutor remarked:

"In a vulnerability case, to argue s. 146 would apply, we would have to have some sort of clear evidence that it was more than just vulnerability. So for instance if you had an elderly person who was robbed, the robbery is complete, and then the defendant has the victim's purse, it's done, and then he kicks the walker, and then makes some sort of adverse comments on social media; then you could argue that that amounts to a s. 146 case and therefore should receive something on top. I mean that was actually a case study we used in our disability hate crime training, as one where we could argue s. 146." (Interview CPS 14)

While it was understood by most prosecutors that evidence beyond that which showed the defendant had "taken advantage" of the victim's disability would be needed to secure an uplift under s. 146, some (a minority of interviewees) argued that the fact that someone had been targeted by reason of their disability should be evidence enough of a demonstration/motivation of hostility. One CPS prosecutor argued:

"I would equate, even if it's taking advantage of, as well as a disability hate crime in terms of hostility, those two could be grouped together as an aggravating feature in either way." (Interview CPS 18)

However, this position was clearly not the view of most interviewees. In fact, this line of argument led some CPS interviewees to make the charge that certain practitioners and civil society groups were attempting to conflate vulnerability and hostility to suit their own purposes. One CPS prosecutor noted:

"I think across the board there's been lots of confusion about ... vulnerability - I mean I don't think it is that difficult - I think people are trying to read the legislation in a way that would suit them ... I think that s. 146 cannot be read for us to conflate the two together without there being some distinct evidence. There seems to have been a misunderstanding - and probably still is in the criminal justice agencies - about whether or not that argument is sustainable ... But it has to be different for sentencing because you've got the Sentencing Guidelines, which explicitly mentions vulnerability, but for sentencing purposes and outlining what uplift has been imposed because of the 
aggravating feature, I think it's got to be clear that the vulnerability is different from the disability. And I think that there is an argument for having legislation saying if you're targeting or demonstrating - particularly targeting vulnerable people - and those people are disabled, then there could be an argument to say that we need that in legislation. But my view is that we don't, because the Sentencing Guidelines do reflect vulnerability." (Interview CPS 14)

The problem with the conflation of vulnerability and hostility, it was argued by some interviewees, is that it can set up a false expectation amongst victims and communities that reporting a crime as motivated by disability will result in a sentencing uplift:

"I've certainly heard and seen material where [third sector groups] have been delivering training to community members and setting up false expectations because of a misunderstanding of the legislation, particularly in terms of the sentencing ... Let's give you an example. I've got a learning disability. I have assistance from a carer/home-help. I'm downstairs, the home-help's upstairs. The home-help steals something from the room. That's discovered by a family member two weeks later. That gets reported, the perception of the victim is that's been committed because l'm disabled - that's hostility against me so it's flagged as disability hate. At the time of the commission of the offence, there's been nothing said or done other than the offence itself. There's no other evidence in terms of the motivation, so whilst we'd flag it, it wouldn't attract an uplift. Now some of the third sectors are saying, 'If you report it, everything will attract an uplift', and that's the false expectation that's been set." (Interview CPS 07)

The divisions across interviewees in terms of whether targeting vulnerability is the same as demonstrating hostility is one that is not easily surmounted. Consequently, in terms of how disability related crimes are prosecuted, much depends on the prosecutor who takes charge of the case. As one interviewee noted, "it really depends on the lawyer who's looking at it, which, I think, strikes me as a problem. There's no real clear guidance" (Interview Independent Barrister 17). It was clear from the interviews that the approach taken to prosecuting disability hate crime diverged slightly across areas and between CPS lawyers who continue to take different approaches to what does and does not amount to disability "hostility". 366

While disagreements continue unabated, what was clear from almost all interviewees who discussed disability hate crime was that, even where prosecutors present carefully curated evidence of disability hostility, there remains considerable "pushback" from the courts as to the cogency of such evidence. Judges have generally stayed firm in their belief that selecting a victim because they are considered vulnerable (or an easy target) is insufficient to prove "hostility" for the purposes of hate crime legislation:

"They'd [the defendants] befriended [the victim] in kind of a kebab shop, offered to walk him home, and then when they get him to a subway they robbed him quite brutally - they sort of punched and kicked him to the ground and so on, and robbed him. That case,

\footnotetext{
${ }^{366}$ The need for further guidance was reiterated by other interviewees.
} 
though, was quite interesting because the CPS reviewing lawyer had said that this was clearly a disability hate crime and we want to ask for the sentencing uplift. When I looked at it, on the evidence, the two defendants hadn't said anything to him in terms of offensive language or anything like that to do with his disability. It was clear, and the judge accepted - and I think to some extent the defence barristers - had to accept as well, that he'd been targeted because he was very obviously vulnerable, so they thought he was very easy pickings. But it was trying to bridge that gap between him being targeted because he's vulnerable, and targeted because they were motivated by hostility to him based on his disability. [We] put forward the arguments that it was such gratuitous violence that they must have been motivated by more than just wanting his money, so were motivated by his disability. But in the end, the judge found that although it was clearly aggravated by the fact he was disabled and they'd picked on him because he was easy pickings, that it didn't fall into the hate crime bracket for the purpose of the uplift." (Interview Independent Barrister 17)

Failure to recognise disability hostility in cases where the victim has been specifically targeted because of their disability does not mean that convicted defendants do not receive any uplift in sentence. It was made clear throughout all interviews that, in such cases, the judge would almost certainly refer to the victim's "vulnerability" as an aggravating factor, as per sentencing guidelines. However, the commonly stated position that disabled victims are "vulnerable" victims by judges should not go without criticism. ${ }^{367}$ It is now well documented within academic research that the labelling of disabled people as "vulnerable" serves to perpetuate a false representation of disabled people as innately weak, and as somehow incapable of caring for themselves. Statements to this effect are in and of themselves a means of infantilising disabled individuals. Awareness of the marginalising effects of labelling victims as innately vulnerable had penetrated many CPS lawyers' approach to prosecuting hate crime - in many cases much to their frustration:

"[W]here we can't show that the offence was motivated by hostility towards the disability, which effectively is 'disablist', we have to go down the route of saying that the case involves an aggravating feature of targeting a vulnerable victim. Now that in itself is an aggravating feature in all sentencing exercises; but first of all, it wrongly characterises disabled people as vulnerable almost per se, and secondly, it doesn't label the perpetrator as being a person who has committed a hate crime - which is hugely important."

(Interview CPS 20)

It was clear that most judges were yet to share this understanding of disability, or how labelling victims as "vulnerable" can contribute to the marginalisation of many disabled people. The result is that most disability hate crimes do not attract the sentencing uplift which is prescribed under s. 146 of the CJA. In fact the most recent statistics published by the CPS show that just $11 \%$ of convictions for disability hate crime resulted in a declared "uplift". 368

\footnotetext{
${ }^{367}$ The CPS are alive to these criticisms and provide guidance on appropriate language that should be employed by prosecutors involved in such cases: Crown Prosecution Service, 'Disability Hate Crime and other Crimes against Disabled People Prosecution Guidance' (2017) <http://www.cps.gov.uk/legal/d_to_g/disability_hate_crime/>

${ }^{368}$ Crown Prosecution Service, 'Hate Crime Report 2014/2015 and 2015/16' (CPS 2016) 14

<http://www.cps.gov.uk/publications/docs/cps_hate_crime_report_2016.pdf>
} 
Such a situation calls into question the continued utility and workability of the legislative provisions - at least in their current form. Two CPS managers reflected:

"As far as disability hate crime is concerned and s. 146 ... we're very much trying to knock a square peg into a round hole trying to fit the facts into a form of language in the legislation that is not really designed to fit." (Interview CPS 20)

"This causes us huge problems, because cases that almost common sense would tell you, surely that's disability hate crime? When it actually comes to fitting the facts into s. 146, we frequently find it very difficult, if not impossible, to do so." (Interview CPS 20)

"I mean, with the successful homophobic cases in my area we're getting an eighty per cent uplift in the sentence of the cases which are successful where we're saying it's a homophobic hate crime. But in relation to disability hate crime we probably won't achieve anything better than twenty per cent. And that's because we're flagging a lot of cases as disability hate crimes, but it is very, very difficult to prove what is actually going on in the secret place in a defendant's head ... courts, I think, don't like branding people in that way. I mean, virtually all of the cases that I've mentioned as examples of disability hate crime ended up with findings against us, that we hadn't proved the application of s. 146. I mean there are positive examples as well, obviously, but the majority of them are not successful." (Interview CPS 05)

\subsection{CONCLUSIONS}

This study shows that more must be done to address what has become a complex and vexing problem for the successful application of hate crime legislation and policy. Despite various scholarly works, justice inquiries and training programmes, the question of whether crimes targeted against disabled people should be understood in terms of vulnerability or hostility continues to inhibit the enforcement of laws that are aimed at protecting disabled people from hate crime. The central issue appears to be the meaning of "hostility" and how a literal interpretation of this word has failed to include targeted abuse towards someone's disability. As one interviewee stated, "you've got this word hostility, but hostility really translates down to ... would they really have tried this offence if it wasn't for the fact that the victim has learning difficulties (for example)?" (Interview CPS 16). Perhaps, then, a different concept or wording should be used to encapsulate this type of identity-based offending. In this regard, and using further theorisation of different models of hate crime laws below, we offer an option for law reform that we believe will help to transform the operationalisation of hate crime legislation for disability hate crime (see 11.6). 
HATE CRIME AND THE LEGAL PROCESS - FINAL REPORT

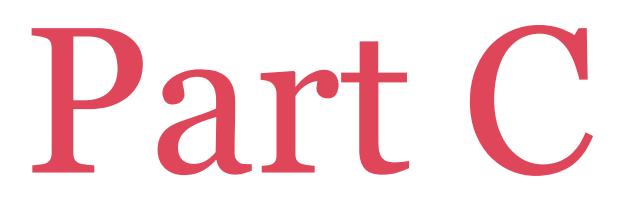

\section{The case for law reform}




\section{Part C: The case for law reform}

As part of our wider study into prosecution and sentencing practices, we asked interviewees whether they felt that the current framework of legislation should be reformed in any way. ${ }^{369} \mathrm{It}$ should be clear to readers by now that parts of the law are not operating in a way that makes the greatest or most effective use of the provisions for all types of hate crime. As part of its final report, the Law Commission recommended that any future review should consider the possibility of repeal as well as extension of the law. We would like to emphasise that any changes to the law must be evidence-based. This study aims to provide evidence on which law reform can be based. As one District Judge commented:

" $[\mathrm{H}]$ opefully in the not too distant future, criminal justice legislation [will be] rewrite[n] based upon research, based upon best practice, what we've learned over those years, [creating] new provisions, which ... incorporate all aspects of aggravation relating to race, religion, disability, sexual orientation and transgender ... we've got all these years of experience - fourteen years of the 2003 Act. And we've got nearly twenty years of the 1998 Act, we ought to be able to take the best of both ... Redraft it, modernise it, and set it out with clear definitions." (Interview District Judge 06)

In this final section, we examine in detail several options for law reform. These options are based on our analyses of extensive case law, statistics, and interview data, as well as theoretical models of hate crime law.

\footnotetext{
${ }^{369}$ Note that we did not directly ask judges whether the law should be reformed as part of the ethical clearance for the study obtained by the Judiciary Office. However, the issue of law reform was often brought up by judges themselves during interviews.
} 


\section{Should the CDA and CJA be repealed or amended?}

There was little appetite for the wholesale repeal of hate crime laws, either the CDA or the CJA provisions, amongst those interviewees who were questioned about law reform. It was clear from the majority of interviewees that hate crime laws were now considered a necessary part of the State's toolkit in responding to hate-based offending. In particular, the CDA provisions were considered to be the cornerstone of the legal framework that were reasonably well understood by most legal practitioners, including judges. This was reiterated both by CPS prosecutors and judges:

"... the bit of legislation that will most commonly be in front of the court is the Crime and Disorder Act, of those the most common offences, and those offences that are specifically deemed to be racially aggravated ..." (Interview District Judge 05)

"It's invariably the Crime and Disorder Act. I cannot think of a Criminal Justice Act case." (Interview Crown Court Judge 08)

"... without doubt that's the Crime and Disorder section 28 , the race hate crime that is without a doubt the most numerous. In terms of the ones which we actually prosecute." (Interview CPS 13)

There was, however, a substantial number of professionals who believed that the law could be improved through legislative reform measures. The most pressing issue was that the CDA be amended to include all five strands of recognised hate crime.

\subsection{EQUALISING THE LAW UNDER THE CDA}

Interviewees were asked a number of questions regarding the operationalisation of the current framework of hate crime legislation. However, they were not specifically asked whether the law should be equalised, so as to avoid the inference from interviewers that this was a preferred deposition. Just over half of interviewees who discussed law reform with us favoured amending the law to include disability, sexual orientation and transgender identity in the CDA provisions, alongside race and religion. A number of reasons were advanced for this position, as detailed below.

\subsubsection{Hierarchies of hate}

The Law Commission's final report on hate crime recommended that, in the absence of a full review of the legislation, the three characteristics under s. 146 of the CJA be transposed into 
the CDA, to ensure that all five groups are protected equally by the criminal law. A key issue raised in the Commission's report was that the current framework is considered to be discriminatory, as it prescribes different sentencing maxima for different protected characteristics - despite the fact that all five strands of hate crime are well evidenced social problems. This has led to what some commentators have referred to as a "hierarchy of hate". ${ }^{370}$ Interviewees in this study also highlighted this as problem:

"[S]o what you've got with s. 146 is potentially a little bit of a fudge. Because they haven't given them [sexual orientation, disability and transgender] complete equality because the maximum penalty stays at six months, say, for a common assault - it doesn't go up to two years. So I think I find it difficult that if it's race or religion, it goes up to two years; if it's homophobic, transphobic or disability it sticks at six months for, say, a common assault, cause that is only a kind of equality - it's not complete parity." (Interview CPS 03)

“... you've got a hierarchy - two aggravating type offences that can be specifically charged, and then three others which are like bolt-ons as an aggravating factor. It is like a second-class citizen to the primary charge, and I think that should be changed." (Interview District Judge 06)

The difference in approach across strands creates the potential for a drastic impact on case outcomes, as explained by one CPS lawyer:

"[l]magine [a] situation with two [victims] ... one of them is black and the other one is transgender. Two rocks are thrown, one hits the black boy on the forehead - he gets a cut; and the other hits the transgender girl on the forehead and she gets a cut - the ridiculous situation is the same behaviour with the same hostility produces a two-year maximum sentence for one of the victims and a six-month maximum sentence in relation to the offence against the other victim." (Interview CPS 05)

The disparity in law has prompted claims by some consultees to the Law Commission that all five of the monitored strands should be treated equally under the law, as per the obligations set out under s. 149 of the Equality Act 2010. ${ }^{371}$ The Commission responded to these claims by asserting that the Equality Act does not require public authorities to achieve the goals of eliminating discrimination but rather they must have due regard to the need to achieve them. In their final report, the Commission concludes:

"To assist them in complying with their public sector equality duty, public authorities such as police forces need legislation in this area to be clear. The present system does not help in that regard, in that it treats some protected characteristics differently despite (1) all of them being protected for purposes of hostility-based offending (by the enhanced

\footnotetext{
${ }^{370}$ Law Commission, Hate Crime: Should the Current Offences be Extended? (Law Com No 348, 2014) 84

<https://www.gov.uk/government/uploads/system/uploads/attachment_data/file/316103/9781474104852_Print.pdf>

${ }^{371}$ Law Commission, Hate Crime: Should the Current Offences be Extended? (Law Com No 348, 2014) 84

<https://www.gov.uk/government/uploads/system/uploads/attachment_data/file/316103/9781474104852_Print.pdf>
} 
sentencing system) and (2) there being no obvious justification for the different legislative treatment." 372

Indeed, the variation in the level of legislative protection given to the five "protected characteristics" is problematic for the consistent and effective application of the Government's hate crime action plan. Moreover, failure to ensure that hate crime laws apply equally to all protected characteristics may send the message that some types of hate are more serious than others, or that certain groups of people are more deserving of protection under the law than others. This cannot be what Parliament has intended for the five protected victim groups.

\subsubsection{Taking all hate crime "seriously"}

Another reason why interviewees favoured amendment to include all characteristics in the CDA related to the practicalities of prosecuting criminal offences and the questions that prosecutors must ask when preparing a case:

"[O]ur primary role is to gather evidence and present evidence and obtain a conviction. And what we're talking about is evidence to support the charge. So if you've got a racially aggravated charge, you have to ask yourself as a police officer and as a prosecutor, 'Do I have enough evidence to prove the assault or the abusive behaviour or whatever it is, and the racial hostility?' Now if you're dealing with a sexual orientation hate crime or a disability hate crime, you don't need to ask the same question, you know, in strictly legal terms; all you need to do is prove that an assault has happened, and then - almost as an afterthought - when it comes to the point of sentence, you start thinking about can you ask the court for an uplift on the basis of the aggravating factor ... Whereas if you were doing points to prove for something that was flagged as a disability hate crime, it wouldn't actually feature in one of the strict points to prove for the charge that was being considered." (Interview CPS 01)

Such statements were common across interviews, emphasising that evidence of hostility is only central to those cases where it makes up part of the substantive offence. In reality, and as we have seen above, this meant that evidence of hostility in non-race and non-religious hate crimes did not always make its way into trials and, in some cases, into sentencing hearings. In practice, this left "the other strands far behind" (Interview CPS 06) in terms of sentencing outcomes.

Many prosecutors stressed the importance of including all five identity characteristics within the CDA, as this would enable both the police and the CPS to make sure the "hate" element of the offence was integral to the case presented in court. One interviewee commented:

"[G]et the prosecution to stake its colours [to] the mast right at the beginning to say, not only do we say this is common assault, but we say you demonstrated hostility based on sexuality at the same time - give us that offence!" (Interview CPS 03)

\footnotetext{
${ }^{372}$ Law Commission, Hate Crime: Should the Current Offences be Extended? (Law Com No 348, 2014) 94 <https://www.gov.uk/government/uploads/system/uploads/attachment_data/file/316103/9781474104852_Print.pdf>
} 
It was believed that this approach would also make prosecuting hate crime much easier:

"[I]t's far easier for prosecutors just to prosecute the offence because it's simply a discrete offence in its own right." (Interview CPS 20)

Others noted that "the court has accepted that it's a separate offence [referring to racially and religiously aggravated offences] and they have to be treated differently" (Interview CPS 11). Equalising the law under the CDA would, therefore, ensure that all characteristics are treated the same in law and, in turn, sentenced under one sentencing regime; thereby reducing the potential disparity in sentencing that currently exists between different types of hate crime.

The disparity in approach to addressing hate crime strands is reflected in the statistics (presented above, in section 5.5) that show disproportionately high rates of recorded hate crime and prosecutions for racially and religiously aggravated offences compared with sexual orientation, disability or transgender hate crimes. In particular, there are disproportionately low levels of disability and anti-LGBT hate crimes recorded by the police, compared with the CSEW estimated numbers that occur in society. Of the police recorded hate crimes in $2015 / 16,49,419$ were hate crimes based on race; 7,194 were based on sexual orientation; 4,400 were based on religion; 3,629 were disability hate crimes; and 858 were transgender identity hate crimes. This can be compared to CSEW data which estimate that there are 104,000 of hate crimes based on race each year; 67,000 disability hate crimes; 31,000 religion-based hate crimes; and 27,000 sexual orientation-based hate crimes. If these estimates are accurate, it means that just $5 \%$ of disability hate crimes are recorded by the police. This can be compared to race-based hate crimes where almost $48 \%$ of the estimated number of incidents that occur are officially recorded by the police..$^{373}$

\footnotetext{
${ }^{373}$ Note that $58 \%$ of respondents from the CSEW stated that they reported an incident of race-based hate crime to the police (see section 5.1 and 5.5). This means that out of an estimate of 104,000 race-hate crimes, 60,000 purportedly came to the attention of the police, and out of this number just over 49,000 incidents were then officially recorded.
} 
Table 11 Numbers of police recorded hate crime by strand compared with numbers estimated by $\mathrm{CSEW}^{374}$

\begin{tabular}{|c|c|c|c|}
\hline Strand of hate crime & $\begin{array}{l}\text { CSEW estimated hate } \\
\text { crimes }\end{array}$ & $\begin{array}{l}\text { CSEW estimated hate } \\
\text { crimes reported to } \\
\text { the police }\end{array}$ & $\begin{array}{l}\text { Police recorded hate } \\
\text { crimes }\end{array}$ \\
\hline Race & 104,000 & 60,320 & 49,419 \\
\hline Religion & 31,000 & 13,330 & 4,400 \\
\hline Sexual orientation & 27,000 & *no estimates available & 7,194 \\
\hline Disability & 67,000 & 34,840 & 3,629 \\
\hline Transgender identity & $\begin{array}{c}\text { *no estimates } \\
\text { available }\end{array}$ & $\begin{array}{c}\text { *no estimates } \\
\text { available }\end{array}$ & 858 \\
\hline
\end{tabular}

Why are certain hate crimes disproportionately under/over-recorded? There are two likely reasons for this. The first reason is that the police are failing to correctly identify certain types of reported hate incidents. In section 5, we highlight CSEW data that suggest that $57 \%$ of hate crimes that come to the attention of the police are recorded as such. Significantly, the types of hate crime not originally codified in the criminal law correlate with the types of hate crimes that the police are least likely to record as "hate crimes". Several interviewees suggested that the fact that sexual orientation, disability and transgender offences are not proscribed in law as "aggravated offences" meant that they were less likely to be investigated as "hate crimes", and evidence of hostility and prejudice was, therefore, less likely to be presented to the CPS and pursued in court. We have seen also in section 8 how some practitioners disagree over what conduct does and does not amount to evidence of prejudice or hostility against disabled people, meaning that even when evidence of hostility is presented in court it is not always accepted as proof of hostility motivation.

The second reason why certain types of hate crime are not recorded and prosecuted is that certain groups may be less likely to report incidents to the police. For instance, many victims of disability hate crime may not know that they have been the victim of a hate crime, or they may not have access to a telephone or the internet to report; this is especially the case where a carer or relative is the perpetrator of hate. ${ }^{375}$ Some LGBT victims may not wish to report incidents for fear of being outed. ${ }^{376}$ These factors (amongst others) mean that many

\footnotetext{
${ }^{374}$ Note that total numbers for both police recorded data and CSEW data amount to more than the total of incidents. This is because some incidents will be motivated by more than one identity characteristic. Police statistics refer to the year $2015 / 16$, CSEW numbers are averaged estimated from March 2014 - March 2016.

${ }^{375}$ Criminal Justice Joint Inspection, Living in a Different World: Joint Review of Disability Hate Crime (CJJI 2013) <https://www.justiceinspectorates.gov.uk/cjji/wp-content/uploads/sites/2/2014/04/CJJI_DHC_Mar13_rpt.pdf>

${ }^{376}$ Neil Chakraborti and Stevie-Jade Hardy LGB\&T Hate Crime Reporting: Identifying Barriers and Solutions (EHRC 2015)

$<$ https://www.equalityhumanrights.com/sites/default/files/research-lgbt-hate-crime-reporting-identifying-barriers-andsolutions.pdf>
} 
hate crimes go unchallenged by the justice system altogether. However, while it is true that many victims of anti-LGBT and disability hate crime will not report incidents to the police, the percentage of unreported incidents may not be significantly lower than for race-case hate crime. For example, the CSEW data suggest that $52 \%$ of disability hate crimes came to the attention of the police, compared with $58 \%$ of victims of race hate crime. We see here that the estimated percentage of respondents that stated their hate crime incident came to the attention of the police is slightly lower for disability hate crime compared with race-based hate crime. Yet it is nowhere near as significant as the gap between the percentage of disability hate crimes, as estimated by the CSEW that are recorded by the police as hate crimes (just $5 \%$ ), compared with the percentage of estimated race hate crimes that are recorded as such (48\%) (see sections 5.1 and 5.5 ).

One CPS lawyer believed that inclusion of the other strands could have the effect of changing the way certain groups perceive their own victimisation, which could, in turn, enhance reporting of hate crimes:

“... so many people from the community don't realise that some of the abuses they're suffering on a night or daily basis could constitute an offence, whereas if the word got out that there are specific offences for when you're abused in relation to your disability, then I think that would be a big boost to community confidence and also an aid to reporting, when people do realise that that is a criminal offence, and yes it will be taken seriously." (Interview CPS 21)

There is the potential, then, for inclusion to ensure that all strands of hate crime are taken seriously by the CJS, while simultaneously encouraging greater reporting amongst each of the five victim groups.

\subsubsection{The importance of symbolic denunciation}

Adding to the principled and practical arguments outlined above, are a number of symbolic reasons for the inclusion of all protected characteristics under the criminal law. Most prominent is the assertion that the inclusion of all five characteristics under the CDA would provide an important symbolic statement regarding the moral reprehensibility of identitybased hostilities. It is argued that the criminal law, more than any other strand of law, plays a fundamental role in furnishing the boundaries of (un)acceptable conduct. Walters argues that, in relation to hate crime law, the criminalisation of certain identity-based hostilities:

"provides an essential means through which certain positive norms are supported (acceptance of 'difference') and various negative social conducts are condemned (public expressions of prejudice). In so doing, a public declaration that the criminal law has been breached (as distinct from the serving of punishment) communicates to the public about 'what is required of them as citizens'. Expressive iterations of the criminal law can provide for longer-term messages about the social acceptance of identity-based prejudices." 377

\footnotetext{
${ }^{377}$ Mark A Walters, 'Readdressing Hate Crime: Synthesizing Law, Punishment and Restorative Justice' in Thomas Brudholm and Birgitte Johansen (eds), Hate, Politics, Law (OUP, forthcoming).
} 
One independent barrister similarly summarised the symbolic importance of including all characteristics in the CDA:

"They need to be charged as separate offences because it sends a message out to society that these type of crimes won't be tolerated. And also puts them on the radar, because crimes, hate crimes against people, you know, transgender people and people based on their sexual orientation, because they don't have their own, you know, separate section, and hate crime legislation - because it's not its own separate offence as such, they're kind of more under the radar. And I think, if they were lifted so that they had their own separate offence, then they'd probably be taken much more seriously; and it would shift offenders' attitude." (Interview Independent Barrister 09)

It is this shift in attitude against certain types of hate crime which some believe is supported by hate crime law. ${ }^{378}$ Correlated with the enactment of the aggravated offences is the significant reduction in the number of racist hate crimes, as estimated by the British Crime Survey (and CSEW). The total number of estimated racially motivated crimes in 1995 was 390,000 , this reduced by $28 \%$ to 280,000 in $1999^{379}$ (the year after the CDA was enacted). Since then, estimated numbers of race hate crimes have continued to fall from 206,000 (2002-2004), to 179,000 (2004-2005), ${ }^{380}$ to 154,000 incidents (2011-2013), ${ }^{381}$ to 106,000 $(2012-2014),{ }^{382}$ and further reducing to 104,000 (2014-2016) ${ }^{383}$ These figures show that since 1995 the estimated number of racist hate crimes have fallen by $73 \%$. It is unclear whether UK hate crime laws are (partly) the cause for this reduction, ${ }^{384}$ as there is only correlational evidence of a decrease in hate crime. ${ }^{385}$ However, this correlation is not unique to the UK. Recent research by Brian Levy and Denise Levy found that there is a clear

\footnotetext{
${ }^{378}$ Mark A Walters, 'Readdressing Hate Crime: Synthesizing Law, Punishment and Restorative Justice' in Thomas Brudholm and Birgitte Johansen (eds), Hate, Politics, Law (OUP, forthcoming).

${ }^{379}$ Anna Clancy, Mike Hough, Rebbecca Aust and Chris Kershaw, Crime, Policing and Justice: The Experience of Ethnic Minorities, Findings from the 2000 British Crime Survey (Home Office Research Study 223, 2001).

${ }^{380}$ Krista Jansson, Black and Minority Ethnic Groups' Experiences and Perceptions of Crime, Racially Motivated Crime and the Police: Findings from the 2004/05 British Crime Survey (Home Office Online Report 25/06, 2006).

<http://webarchive.nationalarchives.gov.uk/20110218141400/http://rds.homeoffice.gov.uk/rds/pdfs06/rdsolr2506.pdf>

${ }^{381}$ Home Office, Ministry of Justice and Office for National Statistics, 'An overview of hate crime in England and Wales' (2013) <https://www.gov.uk/government/statistics/an-overview-of-hate-crime-in-england-and-wales>

${ }^{382}$ Hannah Corcoran, Deborah Lader and Kevin Smith, Hate Crime, England and Wales, 2014/15 (Statistical Bulletin 05/15, Home Office 2015)

<https://www.gov.uk/government/statistics/hate-crime-england-and-wales-2014-to-2015>

${ }^{383}$ Office for National Statistics, "Number of incidents of hate crime, by strand of hate crime and percentage of those incidents reported to the police, Crime Survey for England and Wales, years ending March 2014 to March 2016, combined (12-month averages)'

<https://www.ons.gov.uk/peoplepopulationandcommunity/crimeandjustice/adhocs/007533numberofincidentsofhatecrimebystran dofhatecrimeandpercentageofthoseincidentsreportedtothepolicecrimesurveyforenglandandwalesyearsendingmarch2014tomarch 2016 combined12monthaverages>

${ }^{384}$ The large decrease in estimated racist hate crimes is not evidence that the introduction of the aggravated offences caused this reduction, only that the decreases in incidents is correlated with the time period the legislation has been operational. There is also little room for complacency. There have been significant rises in reported hate crimes since the EU referendum and the latest CSEW data taking in this period are yet to be released. See further discussion, Hannah Corcoran and Kevin Smith, Hate Crime, England and Wales, 2015/16 (Statistical Bulletin 11/16, Home Office 2016)

<https://www.gov.uk/government/uploads/system/uploads/attachment_data/file/559319/hate-crime-1516-hosb1116.pdf>

${ }^{385}$ What is particularly interesting is while crime survey data have shown racist crimes significantly decreasing since the enactment of the legislation, social attitude research has shown that prejudiced attitudes towards people of other races has slightly increased over the past 15-20 years or so. NatCen Social Research, 30 years of British Social Attitudes self-reported racial prejudice data (n.d) <https://diversityuk.org/wp-content/uploads/2014/06/selfreported-racial-prejudice-datafinal.pdf> This indicates that while prejudiced attitudes have not necessarily improved, people's criminal conduct based on these attitudes has reduced.
} 
correlation between the implementation of hate crime laws in US states and pro-equality policies and decreases in hate crime. ${ }^{386}$

Some advocates of this approach to criminalisation argue that not only does the law play an important role in supporting positive social mores which may help to reduce overall levels of racism and other prejudices, ${ }^{387}$ but it also helps to ensure that targeted communities feel protected by the state. ${ }^{388}$ One police officer noted:

"I think they [the trans community] still feel there's a disparity in terms of legislation; but the trans community, the gender identity community, they - and this is based on anecdotal feedback - you know, l'm meeting with a number of representatives from communities. But they're still feel unheard, not listened to." (Interview Police Staff 01)

A victim-advocate stated:

"I think it's a good idea for separate legislation in terms of homophobia is because it's taken seriously then, and it's understood to be taken seriously. It seems that the uplift aspect of the criminal justice system in terms of homophobic cases is not working, and the add-on to the existing offences is actually devaluing it." (Interview Victim Charity Practitioner 06)

Although the Law Commission rightly cautions against relying solely on the potential communicative effects of the offences to justify their existence, ${ }^{389}$ the potential for symbolic denunciation should not be underestimated. As we have seen above, specific criminalisation may not only send a message of denunciation, but it can also play an important role in making sure that targeted communities feel protected. ${ }^{390}$

\subsubsection{The benefits of consistent "flagging"}

There were practical reasons for the inclusion of the other strands in the CDA that went beyond the trial and sentencing stage of the criminal process. Many interviewees spoke of the importance of "flagging" hate-based offences within the criminal justice system so that statutory agencies are aware of the type of crime that an offender had been convicted of. Accurate flagging can have three important functions. The first is that it helps to identify repeat offenders when dealing with future incidents of hate. Without specific labelling of an offence on the Police National Database (PNC), potentially probative evidence can be missed in court, meaning that sentencing of similar offences in the future could be impacted:

\footnotetext{
${ }^{386}$ Brian L Levy and Denise L Levy, 'When Love Meets Hate: The Relationship between State Policies on Gay and Lesbian Rights and Hate Crime Incidence' (2016) 61 Social Science Research 142. The authors acknowledge that "a definitive determination of causality would require rigorous control". They try to overcome this by using a number of controls and using time lags to show that after a certain period of time post-enactment of law/policy there is then a reduction in hate crime/ or increase in reporting.

${ }^{387}$ Antony Duff, Punishment, Communication and Community (OUP 2001).

${ }^{388}$ Alon Harel and Gideon Parchomovsky, 'On Hate and Equality' (1999) 109 Yale LJ 507.

${ }^{389}$ Law Commission, Hate Crime: Should the Current Offences be Extended? (Law Com No 348, 2014) 98

<https://www.gov.uk/government/uploads/system/uploads/attachment_data/file/316103/9781474104852_Print.pdf>

${ }^{390}$ Note that some theorists question whether the criminal law can affect positive social change, and many believe that the criminal law should be used only as a last resort. See generally, Douglas Husak, 'Criminal Law as a Last Resort' (2004) 24(2) OJLS 207 and Jeremy Horder, Ashworth's Principles of Criminal Law (8th edn, OUP 2016) 73-77.
} 
"At the moment you wouldn't ... necessarily see an uplift on sentence recorded on somebody's PNC record, so when they come before the court for further offences you wouldn't necessarily know that the burglary, the theft, the assault that's on their record was an offence that was dealt with by the court that received an aggravated or an increased and uplifted sentence. If they had committed an offence under the Crime and Disorder Act, then very clearly it's on the record that that's what it is. So from a practical point of view, things like that make a difference to how they're dealt with in the future. If they commit further offences then it's clear that they've got a previous history of it". (Interview CPS 15)

"[I]t's very helpful for the Crown when we have things like bail applications where we want to apply for a criminal behaviour order, it's helpful to pick up a record of previous convictions and know exactly what kind of an offender you're dealing with." (Interview CPS 12)

"If you succeed in convicting somebody of that offence, it's very clear on their criminal record that they've been convicted of a racially aggravated offence or a religiously aggravated offence; whereas with the other strands it's almost like a sort of bolt-on to another prosecution." (Interview CPS 15)

Second, criminal justice agencies that are tasked with addressing offending behaviour postsentence are also likely to be assisted where offences are labelled to reflect the hateelement of an offence. As one interviewee explained, "[i]t also would appear on the previous conviction so if Probation were dealing with an offender, they could tailor what they were doing better" (Interview CPS 11).

Failure to include ss. 145 and 146 crimes on the PNC as aggravated offences means that the CPS and other agencies must do additional work to ensure that the hostility element of the offence is recognised by the Probation Service or by Community Rehabilitation Companies:
"And we try to kind of educate the Probation Service as what to look at ... you know, look behind the charge itself ... into ... was it motivated in any way. Because there's a disconnect there as well with the information they get. Whereas if they can see it's disability related on the charge or on the memo of conviction, then they would be clearer about it as well. It just seems we're all doing a lot of work around trying to show that these crimes are motivated by hostility towards disability, homophobia and transphobia; which we don't have to do in the race hate kind because the charge tells us it is and the conviction tells us it is, and it's obvious therefore that it is." (Interview CPS 08)

Third, accurate labelling of hostility-based offences also ensures that victims and targeted communities see that justice has been done and that the crimes committed against them have been treated as "hate crimes". After all, a victim may report a hate crime to the police where it is recorded as such, the CPS then accept the hostility element and proceed against the defendant as a "hate crime" offender, and the court may uplift the sentence stating in open court why the uplift has been applied. This process produces an expectation that the 
offender will thereafter be treated as a "hate crime offender". Yet, post-sentence, most nonCDA offences will not be flagged on the PNC as "hate crimes". The resulting disparity amongst strands of hate crimes sends an unintended message to communities that the offenders of certain types of hate are somehow less culpable for their crimes, and are, therefore, less deserving of the label that is attached to racially and religiously aggravated offences.

\subsubsection{Defendants' rights will be better protected under the CDA}

For defendants who are accused of hostility-based offending, it might be thought preferable for the hostility element to be determined by a judge at sentencing, rather than be prosecuted under the CDA. This is because, if a defendant is convicted under the CDA, they face a higher maximum sentence than they would for a basic offence. Also, the aggravated element of the offence shows on their criminal record. We have explained that defendants can be reluctant to plead guilty to the RRAOs precisely because they fear being labelled a "racist" (see section 7.2.2). However, during our discussions with judges and lawyers, it became apparent that the interests of the defendant may be better served by the CDA than the CJA. We identified three key reasons for this proposition.

First, and perhaps most significantly, there was a perception amongst a number of Crown Court judges, CPS lawyers and independent barristers that the CDA provides a safeguard for defendants:

"[the CDA offences] gives defendants a safeguard if they happen to be charged with those offences, that they can only be dealt with more severely if a court, a jury or otherwise is satisfied to the criminal standard following a trial that it tried." (Interview Crown Court Judge 01)

"the defence position is protected at the moment, because that extra aggravation needs to be proven to the criminal standard by a prosecution in front of a jury. And so it remains an ingredient of the offence which needs to be proven, and therefore it attracts the same protection that defendants have in all jury trials ... and I happen to think we have an excellent system of justice in terms of in its balance towards the defence - quite rightly, given that they face a charge which is brought by the state, which has tremendous resources in order to investigate and try and prove that." (Interview Independent Barrister 13)

One way in which the CDA safeguards defendants is by ensuring transparency. Where a defendant is charged with a RRAO, it is clear from the outset that racial or religious aggravation will be an issue at the trial, and the defence can prepare to challenge the evidence of hostility:

"But I just think that the defendant's position would be better protected if hostility were proved as part of the offence, as an ingredient of the - as it is with the Crime and Disorder Act. Because then it's very clear what the prosecution are saying, what the court has to be sure of; and all of the protections and other things that operate to protect the defendant are in place - and obviously so." (Interview CPS 03) 
The CDA also safeguards defendants by enabling jury trials, unless the charge is a racially aggravated s. 5 public order offence which can only be tried in the Magistrates' Court. The prosecution bears the burden of proving the hostility element of a hate crime beyond reasonable doubt, regardless of whether it is dealt with at trial as part of a RRAO, or by a judge at a Newton hearing. However, a number of interviewees suggested that juries are more open to defence evidence and scrutinise the hostility element more thoroughly than judges or magistrates:

"[S]ome defendants have the protection of the verdict of a jury before they can be sentenced more severely. Other ones just are because the judge says I'm satisfied of this and that, and judges are usually somewhat easy to satisfy of the existence of aggravated features than juries maybe." (Interview Crown Court Judge 01)

"I'm afraid most judges, if they're sentencing someone, tend to go with ... 'We found everything, the prosecution witnesses on the whole true, so aggravate it.' And there's no appeal against that. You can try and appeal it in the Court of Appeal and they'll say, 'Well the judge is the one who heard the case, used his discretion. We weren't there, we're not going to interfere with that.' So at least having it separate, as a separately charged offence, you know exactly what the jury did or didn't find. Which I think is probably the right way to deal with it." (Interview Independent Barrister 04)

The second reason why the CDA may best serve the interests of the defendant is tactical. We have noted throughout this report that juries are perceived to be reluctant to convict defendants of RRAOs, and in sections 8.2 and 8.4, we explained how defence barristers can use this to their advantage to secure acquittals.

The third reason is that, regardless of the prospect of acquittal, it is the role of a jury, and not a judge, to decide questions of fact:

"[T]here's something a little distasteful in the context of our criminal code, in the way in which our system of justice is evolved, by leaving such important matters of fact to a judge when a judge invites the jury into court and tells them, 'We try this case together. We have different roles. You are the judges of fact.' It's somewhat out of line if the judge is then in a position to decide whether or not something as important as the motivation for the crime, in particular with the likely uplift in sentence which may accrue from that. And it is left to the judiciary. And I think a number of judges may feel uncomfortable in respect of that; notwithstanding that, for instance, in cases of murder [judges] may need to make those decisions themselves." (Interview Independent Barrister 13)

One Crown Court judge explained that they would prefer not to step into the fact-finding arena:

"As a judge, l'd rather have, you know, any question of ... any question of fact really, l'd want to be able to defer to the jury, and l'd want there to be - in an aggravated offence an opportunity for a defendant to be able to run the case that they want in front of a jury, rather than have a lesser jury trial with me doing a Newton." (Interview Crown Court Judge 07) 
When considering the respective roles of judge as tribunal of law and jury as tribunal of fact, we cannot overlook the fact that, in practice, juries hear only a small minority of cases. The vast majority are decided by Magistrates. Also, judges often make findings of fact, particularly at the sentencing stage when applying Sentencing Guidelines and determining the presence of aggravating and mitigating factors. In its report, the Law Commission used the example of drug importation or dealing offences, where the judge's finding of fact as to the level of role played by the defendant will have a significant impact on the custodial term served, even though this is not an element of the offence. ${ }^{391}$

The Commission took the view that "fairness to defendants facing a possible sentence uplift under section 146 CJA can be ensured by adequately informing them of the hostility allegations in advance of sentencing and giving them a full opportunity to contest the allegations with evidence". ${ }^{392}$ However, even if notice is given to the defence and Newton hearings are properly conducted, there remains at least the perception that judges and magistrates are too ready to accept the prosecution's version of events at sentencing.

Moreover, the right to elect a jury trial may be seen as an important check in hate crime cases. For example, one could assert that the issue of hostility is so significant, and so connected to societal norms and values, that it should be determined by lay people who are representative of the community, even if that risks a perverse verdict:

"[J]uries can do what they like. ... they can bring in perverse verdicts as long as they want to. That's one of the joys of the system. We've no control over them. And certainly, you know, if you've got an East End case ... being dealt with by an East End jury, who see this sort of thing going on in their market every bloody day ... Nobody pays the slightest bit of attention to it ... And they don't want to convict people. Which is wrong in the law. But nonetheless right. I would acquit too. ... Juries are a lot more sensible than our legislators at times, I think ..." (Interview Independent Barrister 01)

Finally, where the finding of hostility comes from a jury, rather than a judge, it may also be more readily accepted by both the defendant and wider community:

"[The CDA is] definitely better for the defence ... I always flip between the two, but it is better, because you'd rather a jury decide than a court. Because it's fair and it gives it a legitimacy ... that in any conviction you want to have." (Interview Independent Barrister 04)

"But I think many judges ... do not wish to be tribunes of fact, they are tribunes of law ... Such that a defendant can't say, 'Well the judge had it in for me ... he didn't like me ....' No, no, no ... it was the jury ... the jury don't know who you are ... you know. This is the first time they've seen you. They've convicted you, not the judge. And the judge simply prompts the sentence." (Interview Independent Barrister 13)

\footnotetext{
${ }^{391}$ Law Commission, Hate Crime: Should the Current Offences be Extended? (Law Com No 348, 2014) para 4.154 <https://www.gov.uk/government/uploads/system/uploads/attachment_data/file/316103/9781474104852_Print.pdf> ${ }^{392}$ Law Commission, Hate Crime: Should the Current Offences be Extended? (Law Com No 348, 2014) para 4.153 <https://www.gov.uk/government/uploads/system/uploads/attachment_data/file/316103/9781474104852_Print.pdf>
} 
It seems then that the interests of the defendant may be better protected under the CDA than the CJA. What is beneficial to the defence may not appear favourable for the prosecution. As we note in the next section, some interviewees expressed concern that prosecution under the CDA leads to defendants being acquitted. However, practitioners must not underestimate the importance of procedural fairness, or that the proper concern of the prosecution is accurate outcomes. The criminal law is a very powerful tool which the state uses to control and regulate behaviour, and criminal convictions come with far-reaching consequences, including potential loss of liberty. It is, therefore, paramount that there is sufficient evidence to support a conviction.

\subsection{ABOLITION OF THE RRAOS?}

The Law Commission report notes that 54 out of the 116 consultees who responded to a question regarding the sentencing regime felt that the CJA provisions, if properly applied, could be adequate to deal with hate crimes. ${ }^{393}$ In 2002, Burney and Rose found that about half of judges consulted would prefer racial hostility to remain at sentencing. ${ }^{394}$ Within this study, 12 CPS lawyers, three Crown Court judges ${ }^{395}$, three District Judges and three independent barristers stated that the CDA should be extended to include the other three characteristics (four CPS lawyers, one barrister and most other judges did not express a preference, though most were generally supportive of the current framework of legislation ${ }^{396}$ ). Four CPS lawyers, three Crown Court Judges and 13 barristers stated (or inferred) that the law should not be extended.

Several defence barristers felt that the law was cumbersome and that the offences were actually leading to offenders being acquitted of both aggravated and basic offences. For these interviewees, it was felt that either the RRAOs should be abolished, with judges left to make up their own minds regarding hostility aggravation, or that the CDA should not be extended further. In regard to repealing the legislation one interviewee remarked:

"I would repeal the statute. Simple, easy. Back to where we used to be ... Let the judges make up their own minds." (Interview Independent Barrister 01)

Another independent barrister argued that adding new characteristics was not going to help address the problem of hate crime and would just complicate the criminal process further:

“... to have separate offences for disability or sexuality isn't necessarily going to solve a problem. Society is not going to make it go away, and it doesn't make proving the case any easier - in fact it may make it harder; because if - taking an Actual Bodily Harm case as an example - if all you need to prove is that there was unlawful violence that caused actual bodily harm, why would you need the added hurdle of proving that it was motivated by a hatred of disability or that there were words, so the defendant said the word 'cripple' before he hit someone in a wheelchair, why would you need to give the prosecution that

\footnotetext{
${ }^{393}$ Law Commission, Hate Crime: Should the Current Offences be Extended? (Law Com No 348, 2014) 79 <https://www.gov.uk/government/uploads/system/uploads/attachment_data/file/316103/9781474104852_Print.pdf>

${ }^{394}$ Elizabeth Burney and Gerry Rose, Racist Offences: How is the Law Working? (Home Office Research Study 244,2002$) 95$.

${ }^{395}$ Note that judges were not asked set questions about law reform.

${ }^{396}$ This was in line with the Judiciary Office's request that we not ask judges their opinions on law reform.
} 
problem? Because, if the jury aren't sure about the word that was used, then they don't convict; whereas if you prove the Actual Bodily Harm charge, it's better for the judge ... whether it's said or not." (Interview Independent Barrister 15)

One independent barrister noted that any extension would simply allow for more loopholes and provide further means for the defence to exploit weaknesses in the law:

"You can't patch it up. You can't make it better. And as long as it exists, l'll exploit it to its full ... And if guilty people then get off offences they have committed because they've been charged with offences they haven't committed, that's Parliament's fault - not mine." (Interview Independent Barrister 01)

The concerns expressed in this section, and which are also explored in sections 7 and 8 , highlight again the need for clearer guidance on hate crime legislation and that further simplification of the provisions may be required. We explain below why abolition of the CDA is not the answer to these problems, and we offer further options for law reform aimed at improving the application of the law.

\subsubsection{Clogging up the Crown Court with "Iow-level" hate crimes}

Beyond the concerns that the legal framework had become too complex to operate successfully were those who viewed the legislation as administratively inexpedient. Such a concern was prominent amongst three Crown Court judges, as highlighted above in section 7.3 and 7.4. These judges felt that too many "low-level" offences (such as racially or religiously aggravated s. 4, 4A and 5 public order offences) were being sent to the Crown Court, when ordinarily the basic version of the offence would be tried in the Magistrates' Court. One judge remarked:

"... most of this racially aggravated harassment and breach of the Public Order Act should only be dealt with summarily - that is to say by the Magistrates', not by the Crown Court ..." (Interview Crown Court Judge 03)

Interviewees noted that in many cases, defendants accepted that they had committed the basic offence but were loath to accept responsibility for the racial or religious element of the aggravated offence. This often meant that crimes which could have been dealt with expediently in the Magistrates' Court would be listed for trial in the Crown Court in order to determine whether a single word had been uttered during the commission of the offence. One independent barrister remarked:

"And I have certainly been aware of situations where you have a full Crown Court trial, not over whether or not there was a fight, not over whether or not there was an assault which is entirely accepted. Not only whether or not there was abuse, but whether or not simply one word was used as part of that abuse. And at times when I see that, there's part of me that wonders whether or not it would just be simply wiser not to have it as a separate offence, but to treat it as an aggravating feature." (Interview Independent Barrister 10) 
RRAOs are likely to have additional administrative costs, as more cases go to trial. One interviewee detailed the extensive costs of proceedings against aggravated offences in the Crown Court:

“... we're frequently reminded, the figure that's bandied about is that I think it's $£ 10,000$ a day is the cost of the trial in the Crown Court." (Interview CPS 20)

In order to save time and costs, some Crown Court judges felt that the CDA offences should be replaced with the sentencing provisions only. One judge explained:

"You've got more flexibility [with the CJA]. And flexibility in the system is to be welcomed. So in other words it could reduce the number of cases that come to the Crown Court, cutting cost, cutting time delays, giving the magistrates more cases to deal with. And equally, when you get a case which has resulted in a plea of guilty in the Crown Court, the only question then is whether it's going to be racially aggravated, it's much cheaper and quicker for that to be determined by a judge rather than empanelling a jury and going through a whole trial on the issue. Much more efficient." (Interview Crown Court Judge 08)

Others argued that the sentencing provisions were preferred, but with extended sentencing ranges so that uplifts in sentence could still reach a larger range, "have higher maximums with clear sentencing guidelines." (Interview Independent Barrister 16)

\subsection{CONCLUSIONS}

Notwithstanding the numerous practical and theoretical justifications for maintaining (or abolishing) the CDA offences, it is clear from much of the evidence gathered that judges are far from being "very schooled" on sentencing hate crime. Without specific offences, many cases would continue to fall into a "justice gap". The abolition of the CDA offences may well bring cost efficiencies, ensuring that fewer cases reach trial and more cases are dealt with in the Magistrates' Courts. Nonetheless, given the operational realities of hate crime legislation, there are strong arguments in favour of amending the CDA to include the three other strands of hate crime. The substantive offences would help to ensure that law enforcement agencies and the CPS take hate crimes seriously and that evidence of hostility becomes central to cases that proceed to prosecution. The criminal offences under the CDA also serve a symbolic function, with the potential to send messages of social denunciation for hostilitybased conduct, as well as ensuring that victimised communities feel protected from such abuse. Additionally, substantive offences ensure that defendants have an opportunity to challenge the allegation of hostility, and that the evidence against them can be thoroughly scrutinised. Finally, substantive offences are more likely to appear on an offender's record, providing important information to service providers working with offenders, post-sentence.

In a recent study on preventing hate crime, Walters et al recommend that "only where there is a compelling and legitimate reason for treating characteristics differently should this be the 
case in law." 397 This study has found that, on balance, the arguments in favour of extending the CDA outweigh those put forward by the judges and barristers that preferred the sentencing provisions. This is not to deny that there are real procedural difficulties that must be surmounted, nor can we overlook the significant resource constraints that currently exist within the criminal justice system. However, cutting costs cannot come at the expense of pursuing the most effective methods of addressing, or responding to, the targeted victimisation of minority groups, or ensuring that defendants are sufficiently safeguarded. Many procedural problems can be addressed through changes to practice and further guidance, as recommended in Part B. ${ }^{398}$

\section{Reform Option 1: Extension of the CDA to include sexual orientation, disability and transgender identity}

We recommend, as a minimum or alternative to our other reform options (below), that Parliament amend s. 28 of the CDA to include sexual orientation, disability and transgender identity.

\subsection{WHAT CATEGORIES OF OFFENCE SHOULD BE INCLUDED UNDER THE CDA?}

If Parliament follows reform option 1 and simply adds the other three characteristics to the CDA, there is still likely to be a significant proportion of hate crimes cases that will fall outside the ambit of the statute. In Part A of this report, we presented data that showed that certain identity groups are more likely than others to experience crimes that are not covered under ss. 29-32 of the CDA. In particular, disability hate crimes often involve property or sexual offences, both of which are not included under the CDA. Together, these categories of offences made up $38 \%$ of all disability hate crimes proceeded against in court during 2015/16.

One CPS lawyer explained the problem of inclusion without reconsidering the categories of offence that fall under the Act:

"I think there needs to be some equalisation of the law. So the one obvious solution to that would be to amend the Crime and Disorder Act or to introduce some new provisions for disability and sexual orientation and transgender hostility that would match what already exists for racial and religious hostility. There are some problems with that approach because simply dropping those categories into the existing legislation wouldn't work, particularly with disability hate crime, where the profile of the offending is slightly different. So whereas, I think, with race hate, what we commonly encounter offences such as

\footnotetext{
${ }^{397}$ Mark A Walters, Rupert Brown and Susann Wiedlitzka, Preventing Hate Crime: Emerging Practices and Recommendations for the Improved Management of Criminal Justice Intervention (Sussex Crime Research Centre and the International Network for Hate Studies 2016) 14 <http://sro.sussex.ac.uk/64925/>

${ }^{398}$ Note that we do not offer any specific legislative reform options for ss. 145 or 146 (other than possible introduction of a "by reason" test that is set out in section 11.6) for two reasons. The first is that our preferred recommendation is set out in section 11.5, which recommends abolishing ss. 145 and 146 and replacing these provisions with a single act that would prescribe aggravated offences in the criminal law. The second is that the Law Commission has already set out options for improving the application of the CJA provisions. The recommendations that we set out in this report in relation to prosecution and sentencing practices support these options.
} 
violence, threats and abuse, some of that happens with disability hate crime as well. But the other category of offending against disabled people is those offences that you could categorise as exploitation. So there's more ... Sexual offences, property offences and so on, that if you simply drop disability into the existing racial and religious framework would be missed out." (Interview CPS 01)

For this reason, the equalisation of protected characteristics under the CDA must go further than simply transposing the three protected characteristics into the legislation. Further consideration must be given to the types of offence that should fall within the remit of the Act. The basis for this analysis should start with the statistics collated by the police and the CPS (see section 5). Further evidence from victimisation studies (including the CSEW) will also help to uncover the most common types of hate crimes experienced by different identity groups. In terms of racial, religious and sexual orientation hate crimes, the most common forms of crime are likely to already be covered by the CDA. Police statistics suggest that the majority of hate crimes for these groups involve public order offences (threats of violence/ causing harassment, alarm and distress), physical assaults and criminal damage (see section 5). Analysis of CSEW data concurs with the police statistics, showing that the vast majority of hate crimes for these groups occur across these types of offence. ${ }^{399}$ However, as we have seen above, disability hate crimes can differ significantly. Though the majority of crimes still fall within the ambit of public order offences or physical assaults, other common types of disablist hate crimes include sexual offences and property offences (including theft and fraud).

Some interviewees asserted that the exclusion of certain categories of offence from the CDA can lead to perverse outcomes, with RRAOs attracting higher sentences than more serious non-RRAOs. The example of affray was mentioned in numerous interviews. One CPS lawyer explained:

"Take for example racially aggravated common assault, [the CDA] increases it from six months' tops to two years, making it an either way offence. Similarly a s. 4 Public Order Act offence, six months to two years. But affray, well that's just three years anyway isn't it? So yeah, an affray can be rather more serious than a s. 4. It's difficult to actually have a thematic approach to sentencing. It's all rather, I think clumsy is the word best used." (Interview CPS 13)

The inclusion of racially aggravated common assault under the CDA provides the court with a maximum term of imprisonment of two years. However, the more serious basic offence of affray, even if aggravated by hostility, can only attract a maximum of three years because it is not included in the CDA.

\footnotetext{
${ }^{399}$ Home Office, Ministry of Justice and Office for National Statistics, 'An overview of hate crime in England and Wales: bulletin tables' (2013) Table 1

<https://www.gov.uk/government/statistics/an-overview-of-hate-crime-in-england-and-wales>
} 
Interviewees highlighted a number of other examples of offences which are commonly aggravated, but not included in the CDA. The two most common were violent disorder and $\mathrm{s}$. $18 \mathrm{GBH}$ (wounding or causing grievous bodily harm with intent). ${ }^{400}$ In relation to s. 18 , several interviewees were perplexed as to why this offence could not be aggravated under the CDA while the less serious s. 20 offence (wounding or inflicting grievous bodily harm) could be. One District Judge commented:

“you can have a racial s. 20 wounding, yeah, but you can't have a racial s. 18 wounding. So you can racially stab somebody and be held to account for it, but you can't racially intend to stab somebody, right? And I know why people say this ... That's because the maximum sentence for a s. 18 is life imprisonment, so you can't increase the sentence. But I think that, if you had such an offence, you could still have a maximum sentence of life imprisonment, you just would change the guideline, couldn't you?" (Interview District Judge 02)

Several other interviewees took similar issue with the approach taken to sentencing aggravated murders:

“... in the schedule that deals with sentencing in mandatory life sentences ... So, as I say does Kelly and Donnelly apply to that? Should the court not just say it's in a high category but the sentence would have been the minimum term would have been this but for this aggravating feature? And the Kelly and Donnelly approach doesn't seem to apply but then we've got a different approach to different types of offences. And I think it would be helpful if it was consistent across the board and that the judge does announce it." (Interview CPS 13)

The main reason why s. $18 \mathrm{GBH}$ and murder (and other homicide offences) were not included in the CDA was that the offences already attract a maximum sentence of life imprisonment. As the CDA prescribes for enhanced maximum sentences, there was seemingly little reason to include these offences, especially as the sentencing range could still be affected by hostility aggravation under the CJA provisions and Sentencing Guidelines. However, as we have seen above, there are persuasive reasons why such basic offences should be prescribed in the criminal law, including both symbolic and practical. ${ }^{401}$ One way to avoid the problem of hitting the sentencing maximum ceiling is to retain the basic offence maximum for all hate crime offences, but with an explicit statement in the CDA that the aggravation must be considered during sentencing.

\footnotetext{
${ }^{400}$ Burney and Rose also found support for s. $18 \mathrm{GBH}$ and s. 3 POA affray to be added to the list of offences covered by the CDA. Elizabeth Burney and Gerry Rose, Racist Offences: How is the Law Working? (Home Office Research Study 244, 2002) 15.

${ }^{401} \mathrm{~A}$ critique of the offences chosen for inclusion under the CDA can also be found in Richard D Taylor, 'The role of aggravated offences in combating hate crime, 15 years after the CDA 1998 - time for a change?' (2014) 13(1) Contemporary Issues in Law $76,78$.
} 
Others mentioned that the nature of hate crime had changed dramatically over the past five to ten years, with many incidents now taking place online. Although these types of crime (and hate speech offences) fell outside the scope of this study, many interviewees felt that statutory agencies had yet to get to grips with successfully addressing such incidents. ${ }^{402}$

\section{Reform Option 2: Extension of offence categories under the CDA}

Any future law reform must take careful consideration of the offences that should be included within the legal framework. Based on the statistics and interviewee data, the following offences should be considered for inclusion:

- Affray

- Violent disorder

- All sexual offences

- Theft and handling stolen goods

- Robbery

- Burglary

- Fraud and forgery

- S. 18 Grievous bodily harm

- Homicide offences

The expansion of categories to include the most common types of hate crime is likely to bloat the CDA to the point where it would be more practical to include all categories of offence under the Act. As we suggest in option 3 below, one way of dealing with this complex problem is to enact new legislation that establishes a new general provision that prescribes for aggravated offences which apply to all categories of crime, much in the same way as the CJA currently does. ${ }^{403}$

\subsection{A NEW HATE CRIME ACT?}

The current framework of hate crime legislation, while providing important powers to the court to recognise identity-based hostilities, leaves much to be desired in terms of its consistent application. Much of the problem lies in the fragmented nature of the provisions and the crossover between criminal offences and sentencing provisions. One CPS interviewee summarised the problem with the current structure of the law:

“For a practitioner, once they've got their head round it, it's not difficult. But if you're not properly trained, if you don't practise regularly, or if you're a member of the public, it will soon become a bit foggy. And it's not easy to follow." (Interview CPS 13)

A District Judge was even more emphatic about the issues facing the current framework:

\footnotetext{
${ }^{402}$ The CPS' new statement on hate crime which commits the CPS to "[t]reat online complaints as seriously as offline complaints and encourage all to be reported to the police" may go some way to improving responses to internet hate crime. Crown Prosecution Service, Public Statement on Prosecuting Racist and Religious Hate Crime (CPS 2017 ) 5 $<$ http://www.cps.gov.uk/publications/docs/racist-religious-hate-crime-statement-2017.pdf>

${ }^{403} \mathrm{Or}$, as we will go on to recommend, the commission of an offence by reason of the victim's (presumed) group identity).
} 
"if you've got trained criminal lawyers who are a little bit confused by it - and they are sometimes - then how do you expect the public, whether they be victims, witnesses, relatives of victims and witnesses, victim support advisers and, of course, defendants, to understand it? And I don't think there's any justification for it anymore. It should be clearer." (Interview District Judge 06)

Notwithstanding the principled and symbolic problems of maintaining a dual system of aggravated offences to deal with certain types of offending and sentencing provisions for all other hate crime (e.g. a hierarchy of hate), there are also multiple practical problems caused by the fragmented structure of hate crime laws, which have been examined throughout this report. These include a lack of awareness of the CJA provisions amongst legal professionals compared with the CDA sections (section 9.7); a complex and confusing relationship between ss. 145 and 146 and ss. 29 to 32 of the CDA (section 9.9); the potential for double counting the hostility element at sentencing (section 9.4); and persistent judicial resistance to applying the CJA provisions (section 9.9).

A third option for law reform that was advocated by several interviewees aimed at simplifying the current framework was the creation of a new Hate Crime Act. A single Act could contain all the relevant provisions for hate crime under one code that aggravates any offence where there is sufficient evidence of hostility:

"the second option then, I suppose, is to have some sort of generic codification of hate crime. So, you know, whatever criminal offence that you're prosecuting, that there's the ability to identify that as a hate crime." (Interview CPS 01)

"I do sometimes wonder if maybe the shorthand way of doing it would be to abolish the scheme as it presently exists, and just have one perhaps hate crime act, in which you could say that if these characteristics are proved, the maximum sentence increases to this, and it has to be as part of the offending: just have it in one hate crime act ... Rather than several different sources, a sort of equality there, a sentencing provision there, actually you've got to prove it as part of the offence there. I think my preferred view is if Parliament wants to criminalise certain kinds of hostility, it should be included in the body of the offence, as it is in the Crime and Disorder Act." (Interview CPS 03)

Such an Act would enable juries and magistrates to "make up their mind about [hostility aggravation] during the trial." (Interview CPS 03). This would have the potential for reducing confusion and helping to ensure that all hostility aggravated offences are taken seriously by the police, CPS and the judiciary.

One issue that would arise were all crimes to have an aggravated version in the criminal law is that new sentencing maxima would need to be set for every criminal offence on the statute books. One way to avoid what would be administratively unfeasible is to prescribe the sentencing maxima for the aggravated offences as the same that is already prescribed for the basic offence. The legislation would, however, contain an additional provision that the sentence must be aggravated and the amount of uplift must declared in court (similar to the approach taken to the current ss. 145 \& 146 CJA provisions). 
There are five reasons why new aggravated offences could work without being accompanied by higher sentencing ranges.

1. Statistics show that the courts rarely sentence aggravated offences above the sentencing maxima that is set for the basic offence. Average sentences for aggravated offences go nowhere near the maximum for even the basic offence, indicating that the higher range is simply not needed in practice (see Table 10).

2. Judges should put more focus on community, restorative, and rehabilitation-based interventions as part of their "uplifts", and avoid unduly long prison sentences that fail to adequately challenge the root causes of hate and hostility.

3. Such an approach to re-criminalisation would avoid the problem of determining which offence categories should fall under the CDA, and further avoid the confusion between when the CDA and/or the CJA provisions should apply in court, as the CJA provisions would no longer be needed. 404

4. There are myriad justifications for specific aggravated offences beyond that of enhancing penalties, including practical reasons (ensuring hate crimes are taken seriously by the CJS and that offences are flagged properly post-conviction) and symbolic (including expressed denunciation and messages of support to targeted communities).

5. It would be administratively impractical to prescribe new sentence maxima for all aggravated criminal offences.

\section{Reform Option 3: Including all aggravated offences under one Act}

New legislation should be enacted that consolidates hate crime laws into a single Act. We recommend the enactment of a new Hate Crime Act, based on the relevant provisions currently contained in the Crime and Disorder Act 1998, but extending to all five protected characteristics and all categories of crime. (The Hate Crime Act could also be used to consolidate other relevant offences, namely the stirring up offences in the Public Order Act 1986).

The legislation should mirror the wording as set out in ss. 145 and 146 CJA in so far as the courts "must" take into consideration hostility (or by reason of the selection of the victim, explained directly below) and state in open court how the sentence has been affected by the aggravation.

If this option is pursued, the CJA provisions would no longer be needed and should be abolished.

\footnotetext{
${ }^{404}$ If there remains an exhaustive list of types of offences which can be prosecuted as aggravated offences under the CDA, it will remain necessary to include all other offences under the sentencing legislation. The improved operationalisation of these provisions must be sustained via the recommendation already put forward by the Law Commission, including that all hate crime outcomes be monitored via the PNC, and that the CPS (or the courts) record whether an offence is aggravated by identity based hostility, and that an uplift has been imposed.
} 


\subsection{AMENDMENT OF S. 28(1)(B): INTRODUCING A "BY REASON" TEST}

In section 10, it became clear that the prosecution of certain types of hate crime under the current framework is simply unworkable. One CPS lawyer succinctly summarised the situation as follows:

"the wording for race has been applied for the prosecution of religious hate crime, transphobic, homophobic; it doesn't work, in my opinion, and the opinion of a lot of professionals for disability hate crime. And the reason for that is this: it's that disability hate crime is different." (Interview CPS 20)

However, it is not only disability hate crime that s. 28(1)(b) is failing. The motivation part of the legal test under s. 28(1)(b) has also proved highly difficult to evidence in court for all types of hate crime, making this part of the Act almost impotent in addressing aggravated offences, as one independent barrister and one Crown Court judge noted:

“... the Crime and Disorder Act section (b), 'the offence is motivated ...'। have never seen that charged ... I must admit, in my entire career l've not come across a case where s. 28.1 (b) was used." (Interview Independent Barrister 13)

"I've never had ... seen an indictment in [county $\mathrm{X}$ ] or [county $\mathrm{Y}$ ] which alleges someone whose crime was motivated by the relevant kind of hatred." (Interview Crown Court Judge 06)

As we saw in Part B of this report, the main issue with s. 28(1)(b) is that proving motive beyond reasonable doubt requires evidence that proves why a defendant has carried out an act. It requires the CPS to prove, not only what the defendant intended to do, but to evidence his reasoning for doing it. Such an undertaking is often so difficult to prove in court that it rarely forms part of a prosecutor's case.

What, then, can be done to improve the general application of the legislation? Generally, there are two discrete models of hate crime legislation that are used globally. ${ }^{405}$ The most commonly used model in Europe is known as the "hatred motivation model" (also commonly referred to as the "racial animus model"). Under this approach to legislating against hate, legislatures design provisions which specifically prescribe for the offender's hatred or prejudice within the definition of the offence and/or the aggravation at sentence. The definition of identity-based hostility within the English and Welsh legislation reflects this model. For example, under both subsections of s. 28 of the CDA, the offender must either demonstrate or be (partly) motivated by identity-based hostility. In other words, there must be evidence of some form of hatred, prejudice, bias, or identity-related animus (i.e. hostility) for the offence to be made out.

A second model of hate crime legislation that has proliferated mostly within the US is the "group selection" model. Under these types of law, the offender must have "selected" their victim from a particular protected group. Specific evidence of verbalised prejudice, bias, or

\footnotetext{
${ }^{405}$ Frederick M Lawrence, Punishing Hate: Bias Crimes Under American Law (Harvard University Press 2006)
} 
hostility is not required. Instead, it is considered that, by virtue of specifically targeting a victim because of the victim's identity characteristics, the offender has evinced prejudice or bias towards that individual.

How are "group selection" laws worded to reflect this? In some US states, the words "intentionally selects" and "because of" have been used, such as in Virginia where § 18.2-57 of the Criminal Code states:

"A. Any person who commits a simple assault or assault and battery is guilty of a Class 1 misdemeanor, and if the person intentionally selects the person against whom a simple assault is committed because of his race, religious conviction, color or national origin, the penalty upon conviction shall include a term of confinement of at least six months, 30 days of which shall be a mandatory minimum term of confinement."

Other states have used the phrase "by reason of" within their statues. For example, the Criminal Code in Illinois reads as follows:

"Sec. 12-7.1. Hate crime.

(a) A person commits hate crime when, by reason of the actual or perceived race, color, creed, religion, ancestry, gender, sexual orientation, physical or mental disability, or national origin of another individual or group of individuals, regardless of the existence of any other motivating factor or factors, he commits assault, battery, aggravated assault, misdemeanor theft, criminal trespass to residence, misdemeanor criminal damage to property, criminal trespass to vehicle, criminal trespass to real property, mob action, disorderly conduct, harassment by telephone, or harassment through electronic communications..." ${ }^{406}$

A penalty enhancement is applied where the offender has committed a basic offence by reason of one of the specified group identity characteristics. ${ }^{407}$ Such provisions can be both broader and narrower than laws which incorporate a hatred model. Group selection models are broader because they may capture cases where no outward manifestation of prejudice or bias is demonstrated by the offender. In other words, the provisions may include incidents where no hatred or hostility is verbally expressed during the commission of the offence. However, they are also narrower than the current "demonstration of hostility" provisions because the prosecution needs to prove the reason underlying the offender's behaviour, in this case, that the offence was committed because of the victim's identity. The current English and Welsh provisions do not require any such evidence regarding reason; though s. $28(1)(b)$ does require evidence of motive if this subsection is pursued.

\footnotetext{
${ }^{406}$ Bold added for emphasis. Note that other European countries such as France, Bulgaria and use a version of the discriminatory selection model in legislating against hate crime, see OSCE Hate Crime and Practical Guide $<$ https://www.osce.org/odihr/36426?download=true>

${ }^{407}$ Goodall notes that not all group selection models are applied in practice the way that they are prescribed in law, with some judgments inferring that additional hatred or animus might be required. Kay Goodall, 'Conceptualising 'racism' in criminal law' (2013) 33(2) LS 214, 224-226.
} 
One of the concerns with the discriminatory model of legislation is that it may capture offences that are not caused by conscious feelings of hatred or hostility against someone's characteristic. ${ }^{408}$ Walters provides the example of the offender who selects "a Jewish victim based on a mistaken belief that Jewish people carry more cash with them." ${ }^{409}$ The offender may feel no "conscious" prejudice towards Jewish people but simply think that it is more likely that they will obtain a higher financial return by targeting them. In such a situation, can we accurately describe the offender's actions as hate-based? The answer to this question lies in a comprehension of, firstly, the mechanics of the way the provisions are applied and, secondly, an understanding of the original purpose of hate crime legislation.

In relation to the mechanics of the legislation, in order for group selection cases to adequately reflect the culpability of the targeted selection, the victim's identity characteristic should amount to a sine qua non of the offence. The relevant question to ask is: "but for" the victim's protected characteristic, would the offence have been committed? Where the answer is in the affirmative then the aggravated version of the offence is made out. Returning to the question of whether targeted victimisation should be considered as "hate crime", regardless of whether there is a demonstration of hostility, we need to first understand why intentional targeting of certain victims should be specifically protected in law. The reasoning for this is as follows. The intentional targeting of an individual by reason of their protected characteristic is, in and of itself, evidence of bias and discrimination. ${ }^{410}$

This is not to suggest that any intentional selection of an individual because of their identity should be categorised as a hate crime. The key to understanding the reasons for protecting certain groups from targeted victimisation in this way is to understand why certain groups are protected under hate crime law in the first place. More detailed discussion of this is found in Appendix A, but for the purposes of understanding the use of "group selection" models of hate crime, we simply note here that certain identity characteristics have been identified by the legislature as requiring special protection in the criminal law (sentencing provisions). Certain characteristics are protected in recognition that members of identity groups have been historically victimised and oppressed (see further Appendix A). Disproportionate levels of targeted victimisation against these groups is likely to cause heightened levels of individual and community harm, and, as such, the law is needed to protect these groups from, or respond to, targeted abuse (see section 9.1.1).

The intentional targeting of members from protected groups "because of" their identity is to purposefully subjugate those individuals because of who they are. Such actions feed directly into the negative stereotyping of certain groups and builds upon the social oppression that they have experienced historically. Wang argues that:

\footnotetext{
${ }^{408}$ Frederick M Lawrence, Punishing Hate: Bias Crimes Under American Law (Harvard University Press 2006).

${ }^{409}$ Mark A Walters, 'Conceptualizing "hostility" for hate crime law: minding "the minutiae" when interpreting section 28(1)(a) of the Crime and Disorder Act 1998' (2014) 34(1) OJLS 47.

${ }^{410}$ See Lu-in Wang, 'Recognizing opportunistic bias crimes' (2000) 80 Boston University Law Review 1399.
} 
"These malevolent stereotypes often include beliefs that successful minority groups gained at the expense of others because they achieved their success illegitimately, through scrupulous business practices or special government "handouts". ${ }^{411}$

Viewed in this context, the original example of the selection of the Jewish victim who is perceived to carry more cash is likely to reflect the biased stereotypes attached to Jewish people. ${ }^{412}$ Danner argues that in this type of case, the "decision to select a member of a protected group as his victim makes the perpetrator more blameworthy: he knowingly or recklessly joins other wrongdoers in a demonstration of bias and discrimination that ultimately harms our society". ${ }^{413}$

We see abundant evidence of victims being targeted because of discriminatory beliefs in our exploration of disability hate crime cases above. There will be many other examples of hate crimes where victims are targeted because they are perceived to be both vulnerable and "different". ${ }^{414}$ The transgender woman who is sexually assaulted and beaten because the offender knows she can do nothing to protect herself, or the young Muslim girl whose head scarf is torn from her head because she is seen as an easy target are but two examples of "hate crimes" committed by reason of the victim's identity. In many of these types of cases, there is no clear-cut outward (i.e. verbal) manifestation of hostility, neither will there always be sufficient proof to show that the defendant was "motivated" by hostility. Yet, these cases, and many more like them, illustrate how often certain groups of people are brutalised, sometimes tortured, and often abused not for anything they have said or done, but simply because of who they are. Their perceived vulnerability cannot be disentangled from the judgements that offenders make about the worthiness of their victim's value as human beings. ${ }^{415}$ Victims are "selected" because their "difference" means that they are deemed to be somehow less, and their worth as equal members of society is therefore diminished. We see evidence of this throughout the cases of so-called "mate crime", where offenders purposefully manipulate their victims, treating them as playthings to be used and later abused. These types of incidents cannot be explained away by saying that the victim was simply vulnerable to abuse. Their perceived vulnerability is based on a prejudice that the offender holds towards the victim. Hence, evidence that shows that an offender purposively

\footnotetext{
${ }^{411}$ Lu-in Wang, 'Recognizing opportunistic bias crimes' (2000) 80 Boston University Law Review $1399,1431$.

${ }^{412}$ Karen Franklin, 'Unassuming Motivations: Contextualizing the Narratives of Antigay Assailants' in Gregory M Herek (ed.), Stigma and Sexual Orientation: Understanding Prejudice Against Lesbian, Gay Men, and Bisexuals (Sage 1998), also gives the example of the stereotype that gay men are "ideal targets" because they are privileged members of the economic upper class, who have more money, nicer cars, posh apartments with nice "stuff in 'em'”: cited in Lu-in Wang, 'Recognizing opportunistic bias crimes' (2000) 80 Boston University Law Review 1399, 1431.

413 AM Danner, 'Bias crimes and crimes against humanity: culpability in context' (2002) 6 Buffalo Crim LR 389, 406. Also cited in James Chalmers and Fiona Leverick, A Comparative Analysis of Hate Crime Legislation: A Report to the Hate Crime Legislation Review (University of Glasgow 2017) 43.

${ }_{414}$ Neil Chakraborti and Jon Garland, 'Reconceptualising hate crime victimization through the lens of vulnerability and "difference"' (2012) 16(4) Theoretical Criminology 499; Mark A Walters, 'Why the Rochdale Gang should have been sentenced as "hate crime" offenders' (2013) 2 Crim LR 131.

${ }^{415}$ Katharine Quarmby, Getting Away with Murder: Disabled People's Experiences of Hate Crime in the UK (Scope 2008) <http://www.scope.org.uk/Scope/media/Images/Publication\%20Directory/Getting-away-with-murder.pdf>; Hannah MasonBish, 'Conceptual issues in the construction of disability hate crime' in Alan Roulstone and Hannah Mason-Bish (eds), Disability, Hate Crime and Violence (Routledge 2012); Equality and Human Rights Commission, Hidden in Plain Sight: Inquiry into Disability-related Harassment (EHRC 2011) < https://www.equalityhumanrights.com/en/publication-download/hidden-plain-sightinquiry-disability-related-harassment>; Criminal Justice Joint Inspection, Living in a Different World: Joint Review of Disability Hate Crime (CJJI 2013) <https://www.justiceinspectorates.gov.uk/cjji/wpcontent/uploads/sites/2/2014/04/CJJI_DHC_Mar13_rpt.pdf>
} 
selects a perceivably vulnerable victim by reason of their protected characteristics is evidence of identity-based prejudice.

Despite a myriad of criminal justice inquiries, CPS guidance, research reports, and the lobbying efforts by disability groups, it is clear that judges and many enforcement agencies refuse to comprehend discriminatory selection of disabled victims as evidence of hostility. It is likely that this is due to the word "hostility" itself. Scholarly discussions that aim to illustrate how targeting perceived vulnerability can also amount to a form of identity-based hostility, are unlikely to be applied in practice. Parliament should question whether 12 lay jurors can be expected to grasp the complexities of the relationship between the concepts of "hostility" and "perceived vulnerability", when legal practitioners remain divided on the issue (section 10.2). Without any specific legislative guidance, the literal (dictionary) meaning of hostility, as applied by jurors, will not fit well with cases that involve some form of pre-existing relationship with the victim; cases that are likely to involve some form of grooming; faux friendships; a carer's role; or those just opportunistically "taking advantage" of someone.

It is for these practical reasons that a new sub-section using a "by reason" test will likely provide greater flexibility in addressing all types of hate crime. We found support for this type of legal reform amongst several interviewees. For instance, one stated:

"My main bugbear about hate crime is the inadequacy of s. 146 to deal with disability hate crime, and what would make it easier for prosecutors and what I would love to see in the legislation - new legislation ... is for disability hate crime to be targeting of a disabled person, for the legislation to say that and make it clear." (Interview CPS 20)

The introduction of a new "by reason" test would not be without its drawbacks. It would mark a significant shift in the model used to legislate against hate crime - one which diverges slightly from the agreed CJS definition of hate crime. Changes to the law will likely require further amendments to police definitions of hate crime. This will require time and effort on the part of all criminal justice agencies. Any new definition would also need to be added to all policy documents, prosecution guidance and Sentencing Guidelines.

We do not consider that this would extend the scope of hate crime law. Rather, it would lead to more appropriate uses of the law. Thus, where a defendant may have been convicted of a basic offence against a disabled victim and had their sentence increased because of the victim's perceived "vulnerability", under our proposal, the offence could more accurately be labelled and disposed of as a hate crime (and, as explained above and below, we are not proposing "harsher" sentencing practices). Moreover, the majority of hate crime cases would continue to fall within under s. 28(1)(a), due to its broad scope. This first part of the current test remains an important tool when tackling most hate crimes that come before the courts (with the proviso of additional guidance for this part of the test, see section 8).

We acknowledge that this change would require a change to the current definition of hate crime. However, we do not believe that this would involve a major policy shift in the general approach the Government has taken to addressing such offences. Rather, the change in wording to s. 28(1)(b) will enable prosecutors to more effectively tackle complex cases that 
involve identity-based hostility, but which do not include typical incidents of verbalised prejudice. Unless new ways of defining certain types of hate crime are pursued in law (and policy), we believe that the current system will continue to fail many victims of hate crime.

\section{Reform Option 4: Amendment of section 28(1)(b) to replace motivation with a "by reason" test}

We propose that the successful prosecution of all types of hate crime will be improved by amending s. 28(1)(b) (or equivalent in a new Hate Crime Act) so that the provision reads as follows:

(1) An offence is racially or religiously aggravated [or aggravated in relation to disability, sexual orientation or transgender identity] for the purposes of sections 29 to 32 if

(a) at the time of committing the offence, or immediately before or after doing so, the offender demonstrates towards the victim of the offence hostility based on the victim's membership (or presumed membership) of a racial or religious group, or based on the victim's sexual orientation (or presumed sexual orientation), disability (or presumed disability), or transgender identity (or presumed transgender identity); or

(b) the offence is committed by reason of the victim's membership (or presumed membership) of a racial or religious group, or by reason of the victim's sexual orientation (or presumed sexual orientation), disability (or presumed disability), or transgender identity (or presumed transgender identity).

\subsection{CONCLUSIONS}

The arguments outlined in this final part of the report in favour of extending the law to include all five protected characteristics are evidence-based, and have taken into account the current law, policy, guidance, statistics and practice. Legislation aimed at preventing hate and hostility must not give rise to divisions and inequalities between the groups it aims to protect. This is not simply a point of principle, but one of symbolic importance, and of significant practical relevance. However, a number of new issues arise where extension of the CDA relates to group characteristics only; including the need for further consideration of what offence categories should be incorporated into the legislation in order that the law encompasses most types of hate crime. We have provided a list of offences that the data suggest are prevalent enough to warrant inclusion. Yet even with these inclusions, there would remain a dual system of law that specifically proscribes some criminal offences, while others fall within sentencing legislation. The fragmented framework of legislation adds to its complexity and ultimately leads to a two-tiered approach to dealing with hate crime. As such, our preferred option for reform is to create a new Hate Crime Act that would consolidate the current framework of offences and sentencing provisions. This approach would avoid many of the complexities that the relationship between the CDA and the CJA provisions give rise to, and would provide much-needed simplicity to the comprehension of the law. We propose that the new law should proscribe any offence in the criminal law as aggravated by one of the five protected characteristics. The Act would not specifically prescribe separate enhanced 
penalties for every "aggravated" offence, but instead state that the judge "must" treat the offence as aggravated (mirroring the current CJA provisions). The same maximum sentence would apply for the aggravated offences as is set for the basic version of the offence.

Beyond these changes, we have proposed that a new "by reason" test to proving aggravation be implemented within either the CDA (and CJA) or the new Hate Crime Act, if enacted. This test would replace the current motivation of hostility test set out under s. 28(1)(b) of the CDA (as replicated under the CJA provisions). The key reason for this proposed change is based on a significant practical issue. The motivation test is rarely, if ever, used and where it is applied (most frequently in disability hate crime cases) it is often unsuccessful. The main issue with proving motive of hostility is that many "hate crime" cases involve the selection of a victim based on both the victim's perceived vulnerability, which is intrinsically linked to that individual's presumed "difference". As we have argued above, the targeting of individuals who are "different" (based on a protected characteristic), which is based on the perception that these individuals' difference makes them innately weak or an "easy target", is a form of prejudice and hostility in and of itself. Yet despite numerous guidance documents, training programmes, criminal justice reports and academic studies explaining that this is the case, legal practitioners and jurors continue to reject such cases as providing sufficient evidence of "hostility". It is, as one practitioner pointed out, like fitting "a square peg into a round hole" (Interview CPS 20). We are not confident that further guidance or training on this matter will be sufficient to challenge the huge justice gap that exists for hate crime - that which especially affects victims of disability hate crime. Legal amendments to the model of hate crime are therefore required if the CJS is to finally get to grips with effectively addressing all forms of hate crime.

We recognise that our reform options represent some major changes to the structure of current hate crime legislation. However, what we are advocating is not a (significant) extension of criminal law or an extension of sentencing powers, but rather a consolidation of existing legislation and minor amendments to wording that will enhance the effective application of the law. This will require amendments to both policy and guidance documentation. We believe that these changes will significantly improve the CJS' capacity to tackle hostility and hate-based offending. 


\section{Appendix A}

\section{DISCUSSION PAPER: WHAT OTHER CHARACTERISTICS SHOULD BE INCLUDED UNDER HATE CRIME LAWS?}

It has been outside the scope of this report to examine the types of characteristics that should be considered for inclusion under hate crime law. The question of which characteristics should be included under the framework of hate crime legislation is an important one, and one that the Law Commission suggested as part of a full-scale review of aggravated offences. ${ }^{416}$ We are unable to provide any definitive answer to this question here. However, in this addendum discussion paper we offer some initial thoughts on the criteria that might be used when determining what characteristics should fall within hate crime legislation. The discussion is based on both qualitative data obtained during this study and secondary analysis of theoretical literature.

\section{Choosing characteristics to be protected under the criminal law}

The process of determining whether other group characteristics should be incorporated within the CDA (or new Hate Crime Act, as we propose) must start with a careful consideration of the purpose of criminal law. The reason for this is that the criminal law is one of the gravest forms of social control. ${ }^{417}$ Its application can result in significant restrictions to the liberties of those who are convicted of breaching its rules. In general, most legal theorists agree that the creation of specific criminal offences can only be justified where the conduct in question can be shown to be wrongful and that it is necessary to employ the criminal law to condemn and prevent such conduct. ${ }^{418}$ In determining whether a particular kind of conduct is wrongful, a number of questions can be asked, prominent amongst these is whether the conduct in question creates a particular type of harm (or risk of harm ${ }^{419}$ ), which must be restricted in order to prevent such harms from occurring in society. ${ }^{420}$ John Stuart Mill famously argued that the state should only intervene to restrict autonomy when it is necessary to prevent harm to others. ${ }^{421}$ Distinguishing between those harms that are

\footnotetext{
${ }^{416}$ Law Commission, Hate Crime: Should the Current Offences be Extended? (Law Com No 348, 2014) para 1.61 <https://www.gov.uk/government/uploads/system/uploads/attachment_data/file/316103/9781474104852_Print.pdf>

${ }^{417}$ Husak asserts that "A criminal statute cannot be necessary to accomplish a purpose if other means could so more easily", Douglas Husak, 'The Criminal Law as Last Resort' (2004) 24(2) OJLS, 207, 212.

${ }^{418}$ For a review of the theories on criminal law and criminalisation, see Sally Kyd, Tracey Elliot and Mark Walters, Clarkson and Keating: Criminal Law ( ${ }^{\text {th }}$ edn, Sweet and Maxwell 2017) ch 1.

${ }^{419}$ See Joel Feinberg, The Moral Limits of the Criminal Law Volume 1: Harm to Others (OUP 1987).

${ }^{420}$ Known as the liberal school or "harm principle".

421 John Stuart Mill, On Liberty (2nd edn, John W. Parker \& Son 1860). Feinberg adds causing "serious offence" to this approach to criminalisation: Joel Feinberg, The Moral Limits of the Criminal Law Volume 2: Offense to Others (OUP 1988). This harmbased approach can be compared to legal moralism which focuses more on the morality of conduct as determining its wrongfulness: see e.g. Patrick Devlin, Morals and the Criminal Law (OUP 1965).
} 
necessary to regulate under the criminal law and those which fall outside the purview of the criminal law has not always been straightforward. ${ }^{422}$

The inclusion of new characteristics within the CDA would in effect create new criminal offences, each of which must be justified under criminal law theory. Inclusion is complicated further by the fact that hate crimes are already criminalised. For example, an assault is already a codified offence that can attract severe punishments. If this type of harm is already criminalised how, then, can re-criminalisation be justified? Key to answering this questions is the argument that re-labelling certain basic offences into "hate crime" offences is based on evidence that suggests that certain hate-based offending causes distinct types of harms, which are likely to "hurt more". Without evidence to show that hate crimes cause different types of individual, community and societal harm, it is difficult to justify the creation of new aggravated offences for conduct that is already criminalised. We have referred throughout this report to the large body of research that shows that hate crimes risk causing greater emotional and physical traumas to victims, ${ }^{423}$ as well as indirect harms to community members who share the same (or similar) identity characteristics. ${ }^{424}$ We have also noted that hate crimes are an attack on fundamental principles that underpin our liberal society, such as our commitments to equality, dignity and respect. McGlynn and Rackley argue that legislatures have a duty to take such attacks of principle into consideration by moving beyond direct cause and effect to what they label as "cultural harm". ${ }^{425}$ Hate crime laws must, in part, be about challenging the social norms which support environments of identity-based hostility.

In determining what characteristics should be included under the hate crime provisions, ${ }^{426}$ Parliament must begin by examining whether certain social groups are experiencing targeted victimisation that causes the types of distinct harms that are outlined above. ${ }^{427}$ One of the most cogent ways to provide this type of evidence has been through the uncovering of histories of abuse and persecution that certain identity groups have endured. Some of the

\footnotetext{
${ }^{422}$ See e.g. John Kaplan, 'The Role of the Law in Drug Control' (1971) 6 Duke Law Journal 1065, who distinguishes between primary harms (involving direct harms to others) and secondary harms (involving indirect harms to others).

${ }^{223}$ See e.g. Home Office, Ministry of Justice and Office for National Statistics, 'An overview of hate crime in England and Wales' (2013) <https://www.gov.uk/government/statistics/an-overview-of-hate-crime-in-england-and-wales>. Feinberg argues that the greater the possibility of harm "the less probable its occurrence need be to justify prohibition of the conduct that threatens to produce it": Joel Feinberg, The Moral Limits of the Criminal Law Volume 1: Harm to Others (OUP 1987) 215-216.

${ }^{424}$ Jenny Paterson, Rupert Brown, Mark A Walters and Diego Carrasco, 'Feeling others' pain: Indirect effects of hate crime on two victimised communities' (forthcoming) showed that (community) indirect victimisation can be more severe for hate-motivated incidents compared with similar non-hate motivated incidents. See also Barbara Perry and Shahid Alvi, "We are all vulnerable": The in terrorem effects of hate crimes' (2012) 18(1) International Review of Victimology 57,and see section 9.1.1 above.

${ }^{425}$ Clare McGlynn and Erika Rackley, 'Criminalising Extreme Pornography: A Lost Opportunity' [2009] 4 Crim LR 245, 256.

${ }^{426}$ For a recent review of the literature on what victim groups should be protected under hate crime law, see Chara Bakalis, 'The victims of hate crime and the principles of the criminal law' (2017) LS, doi: 10.1111/lest.12171 14. See also Gail Mason, 'Victim Attributes in Hate Crime Law: Difference and the Politics of Justice' 54(2) British Journal of Criminology 161; Mohamad AlHakim, 'Making a home for the homeless in hate crime legislation' (2015) 30(10) Journal of Interpersonal Violence 1755; Jennifer Schweppe, 'Defining Characteristics and Politicising Victims: A Legal Perspective' (2012) 10(1) Journal of Hate Studies 173.

${ }^{427}$ Chalmers and Leverick similarly argue that in order to restrict the law to those groups most deserving of the specific protection of hate crime law, the list of characteristics should focus on groups that are unjustifiably marginalised or stigmatised, or possess forms of difference that have a justifiable claim to respect. James Chalmers and Fiona Leverick, $A$ Comparative Analysis of Hate Crime Legislation: A Report to the Hate Crime Legislation Review (University of Glasgow 2017) 65-66. In making such determinations, much can be gained from exploring the concepts of vulnerability, "difference", equality and "disadvantage". See Neil Chakraborti and Jon Garland, 'Reconceptualizing hate crime victimization through the lens of vulnerability and "difference"' (2012) 16(4) Theoretical Criminology 499; Gail Mason, 'Victim Attributes in Hate Crime Law: Difference and the Politics of Justice' 54(2) British Journal of Criminology 161; Mohamad Al-Hakim, 'Making a home for the homeless in hate crime legislation' (2015) 30(10) Journal of Interpersonal Violence 1755.
} 
most salient examples of such histories have been: anti-black abuse, including racial segregation, discrimination and violence going back to slavery and beyond; antisemitic persecution, including the genocide of Jews during WWII; widespread Islamophobia and the rise in Islamophobic attacks post-9/11; the criminalisation of homosexuality and torturous treatment of gay and bisexual people; the acknowledgement of pervasive targeted victimisation of disabled people; and, more recently, the social isolation, stigma and abuse experienced by transgender individuals.

There need not be a long or deep history of hate and hostility against a group of individuals, but it will be important that there is evidence to show that certain groups are being subjected to sustained and pervasive forms of targeted victimisation. Evidence of prolific types of targeted abuse may well mean that certain new characteristics are added immediately to the criminal law (after a review is conducted by the legislature), or it may mean groups are added in a piecemeal way over longer periods of time as and when certain types of targeted violence develop into serious social problems that serves to justify additional criminal proscription.

We re-emphasise that any new characteristic that is added to hate crime law should reflect specific harms and wrongs that have been evidenced as requiring criminalisation. An implicit feature of the criminal law is that it must not be forward-looking in preventing harms that we think might occur sometime in the future. That is to say, the criminal law should not be used to proscribe conduct that we predict will become problematic - thereby preventing it before it becomes harmful. To do so would add an element of guesswork into the criminal law, meaning conduct would be regulated and individual liberties restricted without cogent evidence of individual injury or societal harm.

In determining what characteristics should have special protection under hate crime law, we propose that the legislature should consider whether there is sufficient evidence of "hate" (i.e. prejudice, bias, identity-based hostility):

1. That affects an identifiable group of individuals, which

2. Risks enhancing the levels of harms experienced by those individuals and others like them; and

3. That undermines societal commitments to the principles of equality, dignity and respect of others, and

4. That requires re-criminalisation as a necessary means of aiding the prevention of the conduct.

\section{Including other characteristics under the Sentencing Guidelines}

Though we have argued above that not all characteristics can be protected under the criminal law (unless evidenced as requiring legislative protection), one way to ensure that other forms of identity-based prejudice are recognised during the criminal process is to ensure that they can still feature at sentencing. In relation to the sentencing guidelines, the same controls and general rules of parsimony we find in criminal law theory become less 
salient. Sentencing guidelines do not carry the same symbolic weight as the criminal (or sentencing) laws; neither do the provisions set out in law sentencing maxima. Instead, sentencing guidelines help the courts to ascertain a number of mitigating and aggravating factors in any given case that should be reflected in the sentence of the court.

Along with the five characteristics included under ss. 145 and 146 of the CJA, the current Sentencing Guidelines also allow the courts to consider as an aggravating factor whether the offender demonstrated or was motivated by hostility based on the victim's age, sex, (presumed) gender identity or the "deliberate targeting of a vulnerable victim". ${ }^{428}$ This means that currently eight characteristics are covered by sentencing provisions/guidelines, plus any victim who is targeted for being vulnerable. This list helps to ensure that the other types of "hate crime" currently monitored by police forces across England and Wales can be treated as crimes aggravated by "hostility" at sentencing, without falling within the ambit of the criminal law offences as proscribed by the CDA.

Sentencing guidelines have the clearest scope to ensure that other identity-based hostilities (beyond the five protected characteristics) are recognised during the sentencing stage of the criminal process. However, even with the eight characteristics currently covered, other group identities, such as subcultural groups ${ }^{429}$ and homelessness ${ }^{430}$ (amongst others), remain absent from any official provisions or guidelines. This means that other groups are likely to remain beyond the consideration of the court at sentencing. One way to avoid such a predicament is to provide the courts with a non-exhaustive list of characteristics that can aggravate an offence. ${ }^{431}$ While there may be insufficient evidence showing that these hostilities are prolific and distinct enough to justify re-criminalisation (or inclusion under sentencing legislation), the courts should still have discretion to consider whether certain hostilities have any significant impacts in individual cases.

We doubt that the inclusion of such hostilities as aggravating factors from time to time by the courts at sentencing will serve to undermine the value or the potency of hate crime legislation more generally; rather they will serve as an important function in ensuring that certain groupbased prejudice are not excluded from sentencing decisions. ${ }^{432}$

\footnotetext{
${ }^{428}$ See e.g. Sentencing Guideline Assault 4.

${ }^{429}$ See Jon Garland and Paul Hodkinson, "“F*king Freak! What the hell do you think you look like?" Experiences of Targeted Victimisation Among Goths and Developing Notions of Hate Crime' (2014) 54(4) British Journal of Criminology 613.

${ }^{430}$ See Mohamad Al-Hakim, 'Making a home for the homeless in hate crime legislation' (2015) 30(10) Journal of Interpersonal Violence 1755

${ }^{431}$ As suggested by Jennifer Schweppe, 'Defining Characteristics and Politicising Victims: A Legal Perspective' (2012) 10(1) Journal of Hate Studies 173. Several jurisdictions have taken this inclusive approach to the characteristics that are included as part of sentencing provisions for hate crime. For example, in Canada section 718.2(a)(i) of the Criminal Code provides that: "... evidence that the offence was motivated by bias, prejudice or hate based on race, national or ethnic origin, language, colour, religion, sex, age, mental or physical disability, sexual orientation, or any other similar factor [should be taken into account in sentencing]."

${ }^{432}$ Schweppe argues that this approach would reduce the role of identity politics and reduce hierarchies of hate: Jennifer Schweppe, 'Defining Characteristics and Politicising Victims: A Legal Perspective' (2012) 10(1) Journal of Hate Studies 173. However, an over-inclusive approach can lead to some controversy, with the NSW courts including paedophiles within their interpretation of the legislation: see Gail Mason, 'The symbolic purpose of hate crime law: Ideal victims and emotion' (2014) 18(1) Theoretical Criminology 75, who argues that this is a step too far; in contrast see Yasmin Scott, 'Violence Against Paedophiles: A Problem for Hate Crime Law?' Crim LR (forthcoming), who argues that paedophilia as a mental disorder should be protected as a type of mental disability under the hate crime provisions.
} 
The Sentencing Guidelines should consider including under "Other aggravating factors":

1. The offender demonstrated hostility based on any group identity characteristic of the victim (or presumed group identity characteristic); or

2. The offence is committed by reason of the victim's membership (or presumed membership) of a social identity group.

Such an amendment to the guidelines does not extend the powers of the courts to sentence hate crime. Neither does it give additional discretion to the courts to decide what a "hate crime" is. Indeed, individual judges are already free to consider the targeting of individuals and any heightened impacts that this causes as a form of aggravation when considering the harm element of an offence. However, the codification of "any group identity characteristics" within the guidelines will help to ensure that judges are more alert to the possibility of hostility being demonstrated towards other group identities and that this may in some cases increase the seriousness of an offence. This may, in turn, help to uncover patterns of hate-based violence that are disproportionally affecting certain groups in society. 
UNIVERSITY OF SUSSEX

SCHOOL OF LAW, POLITICS AND SOCIOLOGY

FREEMAN BUILDING

BRIGHTON

BN1 9QE

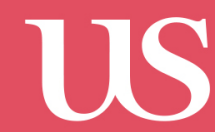

UNIVERSITY

OF SUSSEX 